\title{
Design of a Technology Demonstration \\ Closed Brayton Cycle Engine \\ for Small Electrical Power Generation Application
}

\begin{abstract}
by
Michal P. Siorek

B. Eng (Aerospace)

Carleton University

Ottawa, Canada
\end{abstract}

A thesis submitted to the Faculty of Graduate Studies and Research in partial fulfillment of the requirements for the degree of

Master of Applied Science

Ottawa-Carleton Institute of Mechanical and Aeronautical Engineering
Carleton University
Ottawa, Canada

August 2004

(C) Copyright

2004, M. P. Siorek 


$\begin{array}{ll}\begin{array}{l}\text { Library and } \\ \text { Archives Canada }\end{array} & \begin{array}{l}\text { Bibliothèque et } \\ \text { Archives Canada }\end{array} \\ \begin{array}{l}\text { Published Heritage } \\ \text { Branch }\end{array} & \begin{array}{l}\text { Direction du } \\ \text { Patrimoine de l'édition }\end{array} \\ \begin{array}{l}\text { 395 Wellington Street } \\ \text { Ottawa ON K1A ON4 }\end{array} & \begin{array}{l}\text { 395, rue Wellington } \\ \text { Ottawa ON K1A ON4 } \\ \text { Canada }\end{array}\end{array}$

Your file Votre référence

ISBN: 0-494-00753-2

Our file Notre référence

ISBN: 0-494-00753-2

NOTICE:

The author has granted a nonexclusive license allowing Library and Archives Canada to reproduce, publish, archive, preserve, conserve, communicate to the public by telecommunication or on the Internet, loan, distribute and sell theses worldwide, for commercial or noncommercial purposes, in microform, paper, electronic and/or any other formats.

The author retains copyright ownership and moral rights in this thesis. Neither the thesis nor substantial extracts from it may be printed or otherwise reproduced without the author's permission.
AVIS:

L'auteur a accordé une licence non exclusive permettant à la Bibliothèque et Archives Canada de reproduire, publier, archiver, sauvegarder, conserver, transmettre au public par télécommunication ou par l'Internet, prêter, distribuer et vendre des thèses partout dans le monde, à des fins commerciales ou autres, sur support microforme, papier, électronique et/ou autres formats.

L'auteur conserve la propriété du droit d'auteur et des droits moraux qui protège cette thèse. $\mathrm{Ni}$ la thèse ni des extraits substantiels de celle-ci ne doivent être imprimés ou autrement reproduits sans son autorisation.
In compliance with the Canadian

Privacy Act some supporting forms may have been removed from this thesis.

While these forms may be included in the document page count, their removal does not represent any loss of content from the thesis.
Conformément à la loi canadienne sur la protection de la vie privée, quelques formulaires secondaires ont été enlevés de cette thèse.

Bien que ces formulaires aient inclus dans la pagination, il n'y aura aucun contenu manquant.

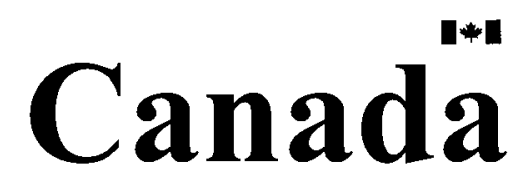




\begin{abstract}
A requirement to dispose of waste oils in remote communities, in an environmentally friendly and cost effective manner, has initiated interest in developing an engine for small electrical power generation that is capable of utilizing waste oils. Through an assessment of numerous engine technologies, it has been determined that the closed Brayton cycle (CBC) engine is most suitable and potentially most cost effective technology for this market requirement. As a result, a program to design and develop a technology demonstration CBC engine has been initiated. The program objective is to initiate the design of an operational, low cost unit that does not necessarily operate at high cycle efficiencies.
\end{abstract}

The CBC engine design is initiated by performing detailed thermodynamic cycle calculations, for which the theory is presented. Cycle arrangement and working fluid is selected based on cycle calculations and CBC engine requirements. Gas operating conditions and component performance specifications are selected by performing a parametric analysis on the effect on cycle performance. It has been decided to utilize air as a working fluid since it is cost-effective to replenish in remote areas. The recuperated free-turbine arrangement has been selected since it offers the highest performance at lowest cost, and offers a simple means of mechanical attachment of the alternator. Cycle efficiency is predicted to be 15.1 percent at the design-point turbine inlet temperature of $1025 \mathrm{~K}$ and compressor pressure ratio of 2.98. The compressor inlet temperature and pressure has been selected as $298 \mathrm{~K}$ and $119 \mathrm{kPa}$ respectively.

Low CBC engine cost is achieved by utilizing off-the-shelf components, which includes application of readily available turbochargers for turbomachinery. The gas generator and the free-turbine turbocharger have been selected. The performance map for each turbocharger has been obtained in order to perform off-design cycle calculations. The design-point compressor, High-Pressure turbine, and Low-Pressure turbine isentropic efficiency is predicted as 77 percent, 70 percent, and 78 percent respectively. 
The thermal hydraulic sizing of the tube-fin heat exchanger and the shell and tube heat exchanger for the application as a hot-side heat exchanger HSHE has been performed. Detailed thermal hydraulic theory is presented. Selection of heat exchanger type is performed by a weighted quantitative analysis. The shell and tube heat exchanger has been selected for application as a HSHE.

The preliminary design dictates that it is possible to develop a low-cost CBC engine by utilizing off-the-shelf components such as turbochargers. The highest costing component will be the Hot Side Heat Exchanger due to the requirement to utilize hightemperature materials. HSHE sizing does not dictate prohibitive costs that would prevent competitiveness of the $\mathrm{CBC}$ engine. However, due to the modest efficiency of the technology demonstration unit (predicted at 15 percent), CBC engine application will be limited to areas with high energy cost and the requirement for waste fuel disposal. 


\section{Acknowledgements}

First and foremost, I would like to express my sincere gratitude to my thesis supervisor, Professor J.E.D. Gauthier, for his efforts in ensuring my acceptance to and graduation from the Masters program. Professor Gauthier has continually provided guidance and assistance in technical and personal matters throughout my undergraduate and graduate studies, for which I forever will be thankful. I would also like to thank my thesis co-supervisor Professor Junjie $\mathrm{Gu}$, for his guidance in heat exchanger design.

I would like to thank my industrial supervisor, Mr. Gary D. Webster, for providing the opportunity to gain valuable experience through my residency at Advanced Engine Technology Ltd. I would also like to express my gratitude for Mr. Webster's cash and in-kind contributions, as well as his time and efforts spent seeking funding and providing technical guidance.

I would also like to express my sincere gratitude to Ms. Carole Champion whose efforts where critical in attaining funding from Materials Manufacturing Ontario (MMO). I would also like to thank MMO for providing the generous financial contribution in the form of the Industrial Practice Masters Scholarship. This funding enabled me to continue my education and gain valuable technical experience at Advanced Engine Technology Ltd. (AET).

I would also like to thank the staff of AET, for their technical assistance, their manufacturing expertise, and their friendship, which helped make the residency at AET a positive experience. I especially like to thank Denny Raymond for his efforts in fabricating several components.

Finally, I would like to thank my family for their love, support, and continual financial assistance, and Jes for her continuous love, encouragement, and support. 
Abstract___ ii

Acknowledgements ___ iv

Table of Contents _ $v$

List of Figures __ xvi

List of Tables ___ Xxi

Nomenclature _

CHAPTER 1 — 1

Introduction __ 1

1.1 Background _ 1

1.2 Project Objective 6

1.3 Thesis Objective__ 7

CHAPTER 2 — 8

Overview of Distributed Power Generation Technologies and Market_ 8

$2.1 \quad$ Power Generation Industry Restructuring ___ 8

2.2 Distributed Generation__ 9

2.2.1 Introduction

2.2.2 Distributed Generation Application Areas___ 11

2.2.3 Distributed Generation Capacity ___ 12

2.2.4 Distributed Generation Technology Overview __ 14

2.2.4.1 Internal Combustion Engines __ 14

2.2.4.2 External Combustion Engines___ 18

2.2.4.3 Renewable Energy Technologies ___ 20

2.2.5 Renewable Energy Power Generation Market___ 21

2.2.6 Distributed Generation Technology Gap __ 22 
CHAPTER 3

CBC Engine Literature Survey

3.1 Introduction —24

3.2 Historical Industrial Application Areas of the CBC Engine __ 25

3.2.1 Overview of Previously Erected CBC Gas Turbine Cogeneration Plants 25

3.2.2 System Description 27

3.2.3 Conclusions Gained from Operation of the CBC Cogeneration Plants_33

3.3 Historical Nuclear Application Areas of the CBC Engine 35

3.3.1 Nuclear Application Overview 35

3.3.2 CBC Helium Turbine Plant at Oberhausen 36

3.4 Historical Space Application Areas of the CBC Engine 39

3.5 Niche Market Application Areas of the CBC Engine 41

3.6 Indirectly-Fired Open Gas Turbine 42

3.7 Biomass-Fired Open-Cycle Gas Turbines 47

3.8 Literature Survey Conclusions 48

\section{CHAPTER 4} 49

CBC Engine Potential Niche Market and Preliminary Market Application Area 49

4.1 Preliminary Market Application Area 49

4.1.1 Introduction 49

4.1.2 Potential Benefits Offered by the CBC Engine 50

4.1.3 CBC Engine Sales Forecast __ 52

4.1.4 Potential Energy Savings _ 54

4.1.5 Carbon Dioxide Emissions Savings__ 59

4.2 Cost Benefit Considerations _ 61

4.3 CBC Potential for Biomass Fuel Utilization _ 62

4.4 CBC Market Study Conclusions __ 63 
CHAPTER 5

$5.1 \quad$ Introduction 65

5.2 Simplifying Assumptions 66

5.3 Gas Properties 67

5.3.1 Gas Constant 67

5.3.2 Specific Heat at Constant Pressure 67

5.3.3 Specific Heat Ratio 68

5.3.4 Enthalpy 69

5.3.5 Other Gas Properties 69

5.4 Component Efficiencies and Performance___ 69

5.4.1 Compressor 70

5.4.2 Turbine 71

5.4.3 Heat Exchanger 73

5.4.4 Indirectly-Fired Combustor 73

5.4.5 Cold-Side Heat Exchanger 74

5.5 Overall Cycle Performance 75

5.5.1 Work Output 75

5.5.2 Cycle Performance 76

5.6 Cycle Configuration Alternatives 76

5.7 Summary 78

vii 
CHAPTER 6

6.1 Introduction 79

6.2 Closed-Cycle Working Fluid Design Choice 81

6.2.1 Effect of Working Fluid on CBC Performance 81

6.2.2 Effect of Working Fluid on CBC Component Performance 87

6.2.3 Material Compatibility 94

6.2.4 CBC Working Fluid Design Choice 94

6.3 CBC Performance Calculations 99

6.3.1 CBC Configuration 99

6.3.2 CBC Performance versus Open-Gas Turbine Performance 103

6.4 Effect of Turbine Inlet Temperature on Cycle Performance 105

6.5 Effect of Compressor Inlet Temperature and Pressure on Cycle Performance 108

6.6 Effect of Component Performance on the CBC Engine 110

6.6.1 Heat Exchangers 110

6.6.2 Turbomachinery 113

6.7 Conclusions 115

viii 
CHAPTER 7

Turbomachinery Sizing and Evaluation of Design and Off-Design

Performance

7.1 Introduction 118

7.2 Turbomachinery Performance Overview ________ 119

7.3 Turbocharger Sizing___ 122

7.3.1 Initial Sizing 122

7.3.2 Design-Point Modification for Turbomachinery Operational Point Matching 125

7.4 Steady-State Performance Prediction 129

7.5 Off-Design CBC Performance Prediction 133

7.6 Off-Design Performance of a Hypothetical OBC Engine 137

7.7 Conclusions 139

CHAPTER 8 141

Heat Exchanger Thermal-Hydraulic Theory

8.1 General Introduction 141

8.2 Heat Exchanger Classifications Considered for CBC Application 142

8.2.1 Plate-Fin Heat Exchanger 142

8.2.2 Tube-Fin Heat Exchanger 143

8.2.3 Shell and Tube Heat Exchanger 144

8.3 General Fluid Flow and Heat Transfer Relations 147

8.4 Heat Exchanger Thermal-Hydraulic Design Theory 149 
8.5 Input Data - Required Geometrical Parameters 153

8.5.1 Shell Configurations 153

8.5.1.1 Shell and Tube Heat Exchanger 153

8.5.1.2 Tube-Fin Heat Exchanger 157

8.5.2 Tube Geometry 157

8.5.2.1 Tube Outer Diameter 157

8.5.2.2 Tube Thickness 158

8.5.2.3 Tube Length 158

8.5.2.4 Number of Tubes 158

8.5.3 Fin Geometry 158

8.5.4 Tube Arrangement 159

8.5.4.1 Tube Layout 159

a) Shell and Tube Heat Exchanger 159

b) Tube-Fin Heat Exchanger 160

8.5.4.2 Tube Pitch 161

8.5.5 Baffle Geometry 162

8.5.5.1 Baffle Type Selection _ 162

8.5.5.2 Baffle Cut 165

8.5.5.3 Baffle Spacing__ 166

8.5.5.4 Baffle Thickness __ 166

8.5.6 Number of Sealing Strips _ـ 167 
8.6 Tubular Heat Exchanger Convective Heat Transfer and Pressure Drop Relations for Shell-Side Flow 168

8.6.1 Geometrical Relations 168

8.6.1.1 Bare-Tube Bank 169

a) Inline Arrangement 169

b) Staggered Arrangement 170

8.6.1.2 Circular Finned-Tube Bank 172

a) Inline Arrangement 173

8.6.2 Heat Transfer and Pressure Loss Correlations for Shell-Side Flow 174

8.6.2.1 Cross Flow across Bare Tubes 174

8.6.2.2 Cross Flow across Circular Finned Tubes 175

8.7 Shell and Tube Convective Heat Transfer and Pressure Drop Relations for Shell-Side Flow 178

8.7.1 Shell and Tube Heat Exchanger Sizing - Introduction to the Bell-

Delaware Method 178

8.7.2 Shell-Side Flow Mechanism 178

8.7.3 Shell-Side Heat Transfer Overall Relation 181

8.7.4 Geometrical Relations 184

8.7.4.1 Tube Bundle Geometry 184

8.7.4.2 Baffle Spacing 186

8.7.4.3 Baffle Geometry 187

8.7.4.4 Number of Effective Tube Rows in Crossflow and in Baffle Window 187

8.7.5 Flow and Leakage Areas 189

8.7.5.1 Shell-Side Crossflow Area 189

8.7.5.2 Baffle Window Flow Area 189

8.7.5.3 Hydraulic Diameter 190

8.7.5.4 Tube Bundle-to-Shell Bypass Area 190

8.7.5.5 Shell-to-Baffle Leakage Area 191

8.7.5.6 Tube-to-Baffle Hole Leakage Area 191 $\mathrm{xi}$ 
8.7.6 Shell-Side Crossflow Velocity and Reynolds Number ___ 192

8.7.7 Heat-Transfer and Pressure Drop Correction Factor Correlations _ 192

8.7.7.1 Correction Factor for Baffle Cut and Spacing, $J_{c} \_192$

8.7.7.2 Correction Factor for Baffle Leakage Effects, $J_{l} \_193$

8.7.7.3 Correction Factor for Bundle Bypass Effects, $J_{b} \longrightarrow 193$

8.7.7.4 Correction Factor for Unequal Baffle Spacing at Inlet and Outlet, $J_{s}$ 195

8.7.7.5 Correction Factor for Adverse Temperature Gradient in Laminar Flow, $J_{r}$ 196

8.7.8 Overall Heat Transfer Coefficient Correlation 196

8.7.9 Correlations for Total Shell-Side Pressure Drop 197

8.7.10 Accuracy of the Bell-Delaware Method 200

8.8 Heat Transfer and Pressure Loss Correlations for Tube-Side Flow 200

8.9 Conductive Heat Transfer Relations for Tubular and Shell and Tube Heat Exchangers 203

8.10 Fouling Resistance 205

8.11 Conclusion 207

xii 
CHAPTER 9

9.1 Introduction 209

9.2 Heat Input Split 210

9.3 Tube-Fin Heat Exchanger Sizing for HSHE Application 211

9.3.1 Initial Specifications 211

9.3.2 Parametric Analysis of Tube Geometry and Tube Arrangement on Heat Exchanger Size

9.3.2.1 Selection of Tube Diameter and Type 212

9.3.2.2 Selection of Heat Exchanger Dimensions and Fin Height 215

9.3.2.3 Selection of Fin Pitch 217

9.3.2.4 Selection of Tube Pitch 219

9.3.3 Tube-Fin Heat Exchanger Geometry Considered for Application as a HSHE 221

9.4 Shell and Tube Heat Exchanger Sizing for HSHE Application 224

9.4.1 Initial Specifications 224

9.4.2 Parametric Analysis of Tube Geometry and Tube Arrangement on Heat Exchanger Size 225

9.4.2.1 Selection of Tube Diameter and Length 225

9.4.2.2 Selection of Tube Layout 228

9.4.2.3 Selection of Tube Pitch Size 231

9.4.2.4 Selection of Baffle Cut Size 233

9.4.2.5 Selection of Baffle Spacing 235

9.4.2.6 Selection of Number of Sealing Strips 238

9.4.3 Shell and Tube Heat Exchanger Geometry Considered for Application as a HSHE 240

xiii 
9.5 Comparative Analysis of the Tube-Fin Heat Exchanger and Shell-Tube Exchanger

9.5.1 Heat-Transfer Surface Area Requirement 243

9.5.2 Number of Tubes Required 243

9.5.3 Tube Length 244

9.5.4 Proneness to Flow Induced Vibration (FIV) - Difficulty of Tube Support Implementation

9.5.5 Transition Section Consideration 245

9.5.6 Ability to Withstand Pressure - Relative Shell Size and Thickness Requirement 245

9.5.7 Fouling Consideration/Ease of Cleaning 246

9.5.8 Heat Exchanger Fabrication Consideration 247

9.5.9 Ease of Integrating a Burner 248

9.5.10 Pressure Drop 248

9.5.11 Heat Exchanger Selection 249

9.6 Conclusion 250

CHAPTER 10 251 Conclusions and Future Work

10.1 Conclusions 251

10.2 Future Work 257

xiv 


\section{References}

\section{Appendix A}

Detailed Calculations of Potential Energy Savings and Carbon Dioxide Emissions Savings

Appendix B

Properties of Gasses

Appendix C

Turbocharger Performance Maps

Appendix D

Heat Transfer Correlations

Appendix E

Gas Stream Fouling Factors 


\section{List of Figures}

\section{CHAPTER 1}

Figure 1.1: Closed Brayton Cycle Component Configuration Diagram.............................2

\section{CHAPTER 2}

Figure 2.1: Distribution of Existing Microturbine CHP Installations.............................13

Figure 2.2: Simple-Cycle Gas Turbine Capital Cost and Efficiency Trend with Size .....17

Figure 2.3: Capital Cost Comparison as a Function of Size of Simple-Cycle Industrial Gas Turbines and Reciprocating Engines ..................................................... 17

\section{CHAPTER 3}

Figure 3.1: Cycle Diagram of the CBC Cogeneration Plants Erected in Germany ..........28

Figure 3.2: CBC Plant Efficiency at Off-Design Operating Conditions .........................32

Figure 3.3: Section View of the Coal-Fired Air Heater ................................................34

Figure 3.4: Indirectly-Fired Power System..............................................................44

\section{CHAPTER 5}

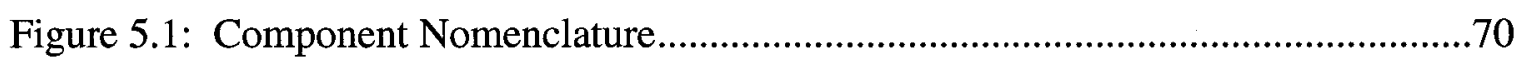

Figure 5.2: Power Turbine Arrangement and Nomenclature.........................................77

xvi 


\section{CHAPTER 6}

Figure 6.1: Effect of Working Fluid Type on CBC Efficiency for an Ideal Case where Pressure Losses are Neglected

Figure 6.2: Effect of Working Fluid Type on CBC Efficiency for a Realistic Case where Pressure Losses are accounted .84

Figure 6.3: Effect of Working Fluid on CBC Specific Power Output .86

Figure 6.4: Cycle Efficiency as a Function of CBC Configuration and Compressor

Pressure Ratio .102

Figure 6.5: Specific Power Output as a Function of CBC Configuration and Compressor Pressure Ratio 102

Figure 6.6: Performance Comparison between Open and Closed Brayton Cycles in

Free-Turbine Arrangement 104

Figure 6.7: Performance Comparison between Open and Closed Brayton Cycles in

Free-Turbine Arrangement

Figure 6.8: Shaft Efficiency versus Specific Power Output for a Range of Turbine Inlet Temperatures and Compressor Pressure Ratios

Figure 6.9: Specific Fuel Consumption versus Specific Power Output for a Range of

Turbine Inlet Temperatures and Compressor Pressure Ratios.

Figure 6.10: Effect of Compressor Inlet Pressure on Efficiency and Specific Power

Output

Figure 6.11: Effect of Compressor Inlet Temperature on Efficiency and Specific

Power Output

Figure 6.12: Effect of Recuperator and Hot-Side Heat Exchanger Effectiveness on

CBC Shaft Efficiency

Figure 6.13: Effect of Recuperator and Hot-Side Heat Exchanger Pressure Loss on

CBC Shaft Efficiency

Figure 6.14: Relation between Available Heating Power and CSHX Effectiveness.......112

Figure 6.15: Shaft Efficiency as a Function of H.P. and L.P. Turbine Isentropic Efficiencies

Figure 6.16: Shaft Efficiency as a Function of Compressor Isentropic Efficiency .114 xvii 


\section{CHAPTER 7}

Figure 7.1: H.P. Turbine Corrected Mass Flow Rate as a Function of Compressor

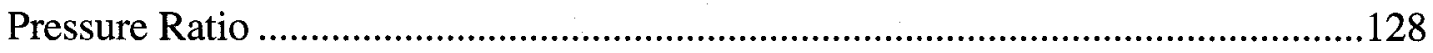

Figure 7.2: Shaft Efficiency as a Function of Compressor Pressure Ratio........................128

Figure 7.3: Shaft Efficiency and Power Output as a Function of Compressor Inlet Pressure

Figure 7.4: CBC Efficiency and Shaft Power Output as Controlled by the

Compressor Inlet Pressure from Full to Half Load. 136

Figure 7.5: CBC Efficiency and Shaft Power Output as Controlled by Turbine Inlet

Temperature from Half Load to No Load.............................................................136

Figure 7.6: Fuel Flow Requirement at Off-Design Conditions .....................................137

Figure 7.7: Part-Load Efficiency as a Function of Power for the CBC and the OBC....139

\section{CHAPTER 8}

Figure 8.1: Heat Exchanger Configurations: (a) Plate-Fin, (b) Fin-Tube, and (c) Shell

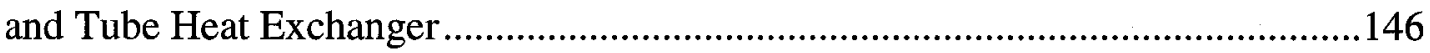

Figure 8.2: TEMA Front Head, Rear Head, and Shell Geometry Designations..............156

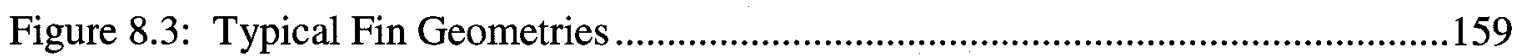

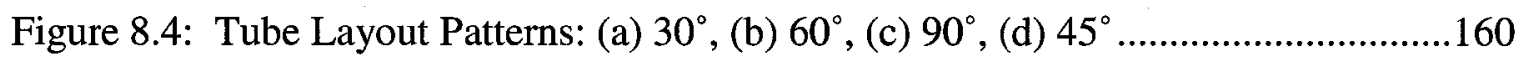

Figure 8.5: Tube Pitch for Tube Layout Patterns: (a) $30^{\circ}$, (b) $60^{\circ}$, (c) $90^{\circ}$, (d) $45^{\circ} \ldots \ldots . . .161$

Figure 8.6: Geometry of Plate Baffles .......................................................................164

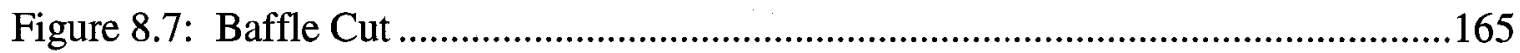

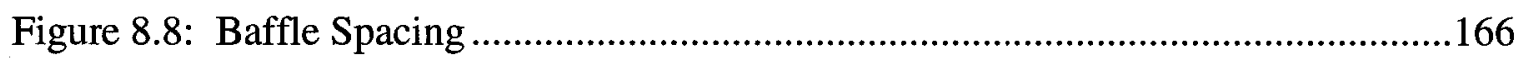

Figure 8.9: Sealing Strip Orientation .............................................................................167

Figure 8.10: Inline Tube Bank Geometry ...........................................................................171

Figure 8.11: Staggered Tube Bank Geometry …………………………………….....171

Figure 8.12: Staggered Unit Cell Arrangement and Associated Nomenclature ..............172

xviii 
Figure 8.13: Bypass and Leakage Flow Paths: a) Single Pass Baffle, b) Two-Pass Baffle. 180

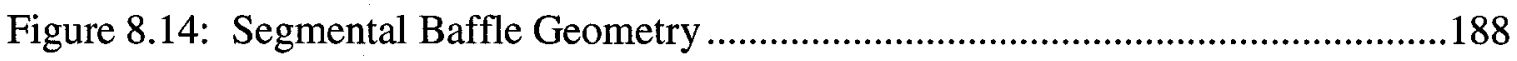

Figure 8.15: Regions for Shell-Side Pressure Drop Calculations. 199

\section{CHAPTER 9}

Figure 9.1: Heat-Transfer Rate Requirement for Each Heat Exchanger as a Function of Recuperator Effectiveness .......................................................................210

Figure 9.2: Tube Count as a Function of Tube Type and Tube Diameter .....................213

Figure 9.3: Surface Area as a Function of Fin Type and Tube Diameter......................213

Figure 9.4: Effect of Fin Height on (a) Tube Count, (b) Surface Area of Tubing...........216

Figure 9.6: Effect of Tube Pitch on Heat Exchanger Pressure Loss..............................220

Figure 9.7: Outer Geometry of the Tube-Fin Heat Exchanger ...................................222

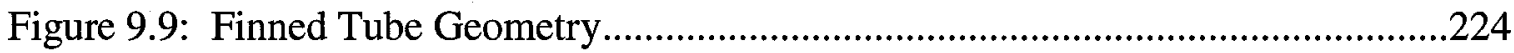

Figure 9.10: Heat-Transfer Surface Area as a Function of Tube Length for Various

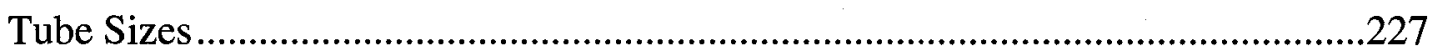

Figure 9.11: Tube Count as a Function of Tube Length and Tube Size .......................227

Figure 9.12: Shell-Side Pressure Drop Function of Tube Length and Tube Size...........228

Figure 9.13: Heat-Transfer Surface Area as a Function of Tube Length for Various

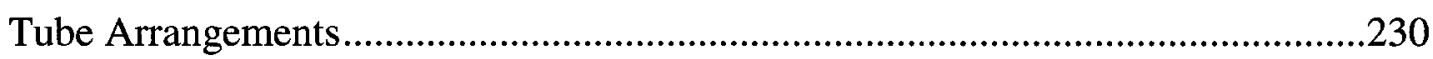

Figure 9.14: Shell-Side Pressure Drop Function of Tube Length and Tube Size..........230

Figure 9.15: Heat-Transfer Surface Area as a Function of Tube Length for Tube

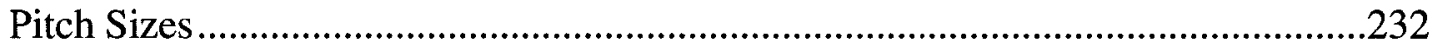

Figure 9.16: Tube Count as a Function of Tube Length for Various Tube Pitch Sizes..232

Figure 9.17: Shell-Side Pressure Drop Function of Tube Length for Various Tube

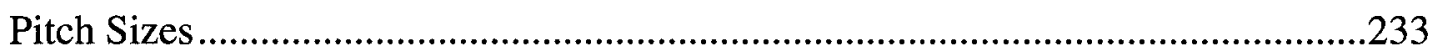

Figure 9.18: Surface Area as a Function of Baffle Cut............................................234

Figure 9.19: Pressure Ratio as a Function of Baffle Cut ..........................................234

xix 
Figure 9.20: Surface Area and Tube Count Requirement as a Function of Central

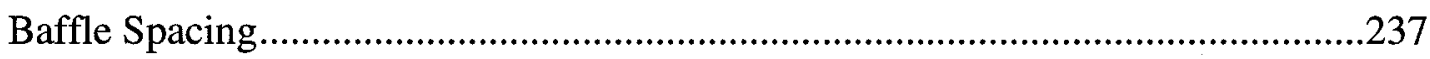

Figure 9.21: Predicted Pressure Drop as a Function of Central Baffle Spacing............237

Figure 9.22: Surface Area and Tube Count Requirement as a Function of Number of

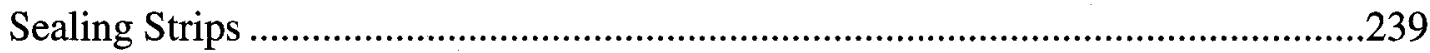

Figure 9.23: Predicted Pressure Drop as a Function of Number of Sealing Strips........239

Figure 9.22: External Geometry of the Shell and Tube Heat Exchanger ......................241

Figure 9.25: Tube Layout in the Shell and Tube Heat Exchanger...............................242

\section{APPENDIX B}

Figure B.1: Specific Heat of Helium-Argon and Helium Xenon Mixtures

Figure B.2: Thermal Conductivity of Helium-Argon and Helium Xenon Mixtures

Figure B.3: Viscosity of Helium-Argon and Helium-Xenon Mixtures

Figure B.4: Prandtl Number of Helium-Argon and Helium-Xenon Mixtures

\section{APPENDIX C}

Figure C.1: Compressor Performance Map with Selected CBC Design and Off-Design Points

Figure C.2: High Pressure Turbine Performance Map with Selected CBC Design and Off-Design Points

Figure C.3: Low Pressure Turbine Performance Map with Selected CBC Design and Off-Design Points

Figure C.4: Compressor Performance Map Depicting Design and Off-Design Points of the Hypothetical OBC Engine

Figure C.5: High Pressure Turbine Performance Map with Depicted Selected Design and Off-Design Points of the Hypothetical OBC Engine

Figure C.6: Low Pressure Turbine Performance Map with Depicted Selected Design and Off-Design Points of the Hypothetical OBC Engine

$\mathrm{XX}$ 


\section{List of Tables}

\section{CHAPTER 2}

Table 2.1: Downtime Costs of Service Industries ...................................................... 10

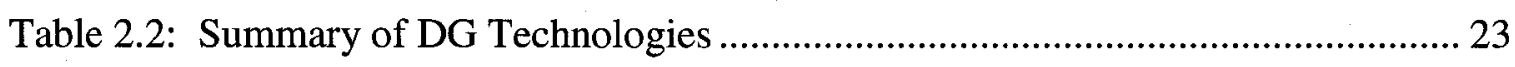

\section{CHAPTER 3}

Table 3.1: Working Air Operating Conditions of the Coburg and Obheiz $1 \mathrm{CBC}$

Cogeneration Plants ........................................................................ 28

Table 3.2 Main Operating Conditions and Measured Efficiencies of the Five CBC

Cogeneration Plants in Germany ....................................................... 30

Table 3.3: Turbomachinery Arrangement Details ....................................................... 32

Table 3.4: Helium Operating Conditions in the Oberhausen 2 CBC Cogeneration

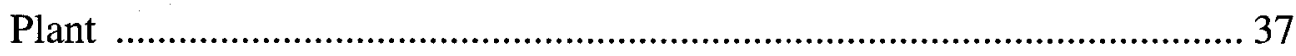

\section{CHAPTER 4}

Table 4.1 Ten-Year Sales Projection of CBC Engines .................................................. 53

Table 4.2 Ten Year Energy Savings Estimate offered by the CBC engine .....................58

Table 4.3 Ten-Year $\mathrm{CO}_{2}$ Emission Reduction Estimate ............................................. 60

$\mathrm{xxi}$ 


\section{CHAPTER 6}

Table 6.1: Efficiency Variation when Accounting for Pressure Losses ............................ 86

Table 6.2: Relative Heat Exchanger Surface Area Comparison with Working Fluid

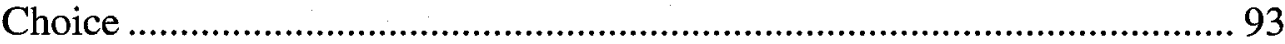

Table 6.3: Heat Exchanger Surface Area Comparison of Gas Mixtures and Air............ 98

CHAPTER 7

Table 7.1: Predicted Steady-State Working Gas Conditions

\section{CHAPTER 8}

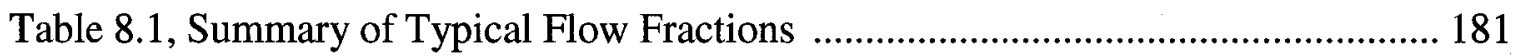

Table 8.2: Standard Shell Inner Diameter-to-Baffle Outer Diameter Clearance............. 185

\section{CHAPTER 9}

Table 9.1: Heat Exchanger Size as a Function of Fin Height ........................................ 216

Table 9.2: Effect of Tube Pitch on Heat Exchanger Size ............................................... 220

Table 9.3: Rating of Critical Heat Exchanger Design, Fabrication, and Performance Features.

xxii 


\section{APPENDIX B}

Table B.1: Properties of Selected Gasses

Table B.2: Coefficients for Variation of Specific Heat and Enthalpy for Air

Table B.3: Coefficients for Variation of Specific Heat and Enthalpy for Carbon Dioxide

Table B.4: Coefficients for Variation of Specific Heat and Enthalpy for Nitrogen Gas

\section{APPENDIX D}

Table D.1: Heat Transfer Correlations for Bare Tubes in Staggered and Inline Arrangement for Tube Banks of 10 Rows or More Tube Rows

Table D.2: Ratio of Heat Transfer Coefficient, $h_{0}$, for Tube Banks of less than 10 Rows of Tubes to Tube Banks of More than 10 Rows of Tubes for Bare Tubes in Staggered and Inline Arrangement

Table D.3: Correlation Coefficients for the Coulburn Factor, ji Used to Calculate the Ideal Heat Transfer Coefficient

Table D.4: Correlation Coefficients for the Friction Factor, fs Used to Calculate the Ideal Crossflow Pressure Drop

\section{APPENDIX E}

Table E.1: Gas Stream Fouling Factors

xxiii 


\section{Nomenclature}

\section{Abbreviations}

APU

CBC

$\mathrm{CDN}$

CDP

CFC

CHP

CIT

CPR

CSHE

DG

DOE

EC

FIV

GNTW

HHT

HHV

HIPPS

HITAF

HOEP

HRSG

HSHE

HTGR

HTGR-GT

H.P.

IC

IGCC
Auxiliary Power Unit

Closed Brayton Cycle

Canadian Dollar

Compressor Delivery Pressure

Chlorofluorocarbon

Combined Heat and Power

Compressor Inlet Temperature

Compressor Pressure Ratio

Cold-Side Heat Exchanger

Distributed Generation

Department of Energy (US)

External Combustion (Engine)

Flow Induced Vibration

Great Northwest Territories

High-Temperature Helium Turbine

Higher Heating Value

High Performance Power System

High Temperature Advanced Furnace

Hourly Ontario Energy Price

Heat Recovery Steam Generator

Hot-Side Heat Exchanger

High-Temperature Gas-Cooled Reactor

High-Temperature Gas-Cooled Reactor Gas Turbine

High Pressure

Internal Combustion (Engine)

Integrated Gasification Combined Cycle

xxiv 
IMO

LMTD

LNG

L.P.

MW

OBC

ORC

PV

RPM

SD GTD

SFC

TAT

TEMA

TIT

UPS

USD

USN

UTRC
Independent Market Operator

Log Mean Temperature Difference

Liquefied Natural Gas

Low Pressure

Megawatts

Open Brayton Cycle

Organic Rankine Cycle

Photovoltaic

Revolutions per Minute

Solar Dynamic Ground Test Demonstration

Specific Fuel Consumption

Thermally Activated Technologies

Tubular Exchanger Manufacturers Association

Turbine Inlet Temperature

Uninterrupted Power Supply

United States Dollar

United States Navy

United Technologies Research Center

XXV 


\section{Symbols}

\section{Chapter 5-7: $\quad$ Performance Calculations}

\begin{tabular}{|c|c|}
\hline $\mathrm{a}$ & Constant \\
\hline $\mathrm{C}$ & Constant \\
\hline $\mathrm{CH}$ & Constant \\
\hline $\mathrm{Cp}$ & Specific Heat at Constant Pressure \\
\hline $\mathrm{Cv}$ & Specific Heat at Constant Volume \\
\hline $\mathrm{D}$ & Diameter \\
\hline h & Static Enthalpy \\
\hline $\mathbf{h}_{0}$ & Stagnation Enthalpy \\
\hline$h^{\prime}{ }_{0}$ & Ideal Stagnation Enthalpy \\
\hline $\mathrm{L}$ & Tube Length \\
\hline $\mathbf{M}$ & Molecular Weight \\
\hline $\mathrm{m}$ & Mass Flow Rate \\
\hline $\mathrm{m}^{*}$ & Flow Parameter \\
\hline $\mathbf{N}$ & Rotational Speed \\
\hline $\mathbf{N}^{*}$ & Speed Parameter \\
\hline $\mathbf{P}$ & Static Pressure \\
\hline $\mathrm{P}_{0}$ & Stagnation Pressure \\
\hline$\Delta \mathrm{P}$ & Pressure Drop \\
\hline PR & Pressure Ratio \\
\hline Q & Heat Transfer Rate \\
\hline$q$ & Heat Transfer \\
\hline $\mathbf{R}$ & Gas Constant for Specific Gas \\
\hline $\mathrm{R}_{0}$ & Universal Gas Constant \\
\hline $\mathrm{T}$ & Static Temperature \\
\hline $\mathrm{T}_{0}$ & Stagnation Temperature \\
\hline $\mathrm{U}$ & Wheel Speed \\
\hline
\end{tabular}

xxvi 
W

W'

W

Chapter 6:

$\mathrm{D}_{\mathrm{e}}$

f

G

$\mathrm{g}_{\mathrm{c}}$

$\mathrm{h}$

$\mathrm{k}$

$\mathrm{Nu}$

$\operatorname{Pr}$

$\mathrm{R}_{\mathrm{i}}$

$\mathrm{R}_{\mathrm{fi}}$

$\mathrm{R}_{\text {fo }}$

$\mathrm{R}_{\mathrm{o}}$

$\mathrm{R}_{\mathrm{w}}$

$\mathrm{Re}$

$\Delta \mathrm{T}_{\mathrm{m}}$

$\mathrm{U}_{0}$

UA

$\mathrm{V}$
Actual Isentropic Work

Ideal Isentropic Work

Specific Work Output
Equivalent Diameter

Friction Factor

Mass Velocity

Acceleration due to Gravity

Heat Transfer Coefficient

Thermal Conductivity

Nusselt Number

Prandtl Number

Tube-Side Resistance due to Convection

Tube-Side Fouling Resistance

Shell-Side Fouling Resistance

Shell-Side Resistance due to Convection

Tube Wall Resistance

Reynolds Number

Mean Temperature Difference

Overall Heat-Transfer Coefficient

Thermal Conductance

Velocity

xxvii 


$\begin{array}{ll}\text { Greek Symbols: } & \text { Chapters 5-7 } \\ \gamma & \text { Specific Heat Ratio } \\ \Delta & \text { Difference } \\ \varepsilon & \text { Effectiveness } \\ \eta & \text { Efficiency } \\ \eta_{0} & \text { Overall Surface Effectiveness } \\ \mu & \text { Viscosity } \\ \rho & \text { Density } \\ \psi & \text { Work Coefficient }\end{array}$

\section{Subscripts:}

\section{Chapters 5-7}

a

avail

c

CSHX

D

e

f

gen

$\mathrm{H}$

H.P.

L.P.

M

m

R

R_CS

R_HS
Air

Available

Compressor

Cold Side Heat Exchanger

Ducting

Electrical

Fuel

Generator

Heater

High Pressure

Low Pressure

Monatomic

Mechanical

Recuperator

Recuperator - Cold Side

Recuperator - Hot Side

xxviii 


$\begin{array}{ll}\text { req } & \text { Required } \\ \mathrm{sh} & \text { Shaft } \\ \mathrm{t} & \text { Turbine } \\ \text { TOT } & \text { Total }\end{array}$

\section{Symbols:}

\section{Chapter 8: $\quad$ Heat Exchanger Thermal-Hydraulic Theory}

$\begin{array}{ll}A & \text { Total Heat-Transfer Surface Area } \\ A_{i} & \text { Tube-Side Surface Area } \\ A_{f} & \text { Fin Surface Area } \\ A_{F F} & \text { Free-Flow Area } \\ A_{F r} & \text { Frontal Area } \\ A_{o} & \text { Shell-Side Surface Area } \\ A_{p} & \text { Primary Surface Area } \\ a_{1-4} & \text { Coulburn Factor Correlation Coefficients } \\ b_{1-4} & \text { Friction Factor Correlation Coefficients } \\ C & \text { Constant } \\ C_{b h} & \text { Baffle Constant for Heat Transfer } \\ C_{b p} & \text { Baffle Constant for Pressure Drop } \\ C_{l} & \text { Tube Layout Constant } \\ C p & \text { Specific Heat at Constant Pressure } \\ d_{i} & \text { Tube Inner Diameter } \\ d_{f} & \text { Fin Diameter } \\ d_{0} & \text { Tube Outer Diameter } \\ d_{r} & \text { Fin Root Diameter } \\ D_{c t l} & \text { Tube Bundle Diameter } \\ D_{h} & \text { Hydraulic Diameter } \\ & \\ & \end{array}$




\begin{tabular}{|c|c|}
\hline$D_{i}$ & Inner Shell Diameter \\
\hline$D_{\text {otl }}$ & Tube Bundle Outer Diameter \\
\hline$D_{w}$ & Equivalent Diameter of a Segmental Baffle Window \\
\hline $\mathrm{F}$ & Correction Factor \\
\hline $\mathrm{F}_{\mathrm{c}}$ & Fraction of Tubes in Pure Crossflow \\
\hline $\mathrm{F}_{\mathrm{sbp}}$ & $\begin{array}{l}\text { Fraction of Bypass Leakage Flow Area to Shell-Side } \\
\text { Crossflow Area }\end{array}$ \\
\hline $\mathrm{F}_{\mathrm{w}}$ & Fraction of Tubes in Baffle Window \\
\hline $\mathrm{f}^{\prime}$ & Friction Factor \\
\hline$f_{s}$ & Shell-Side Friction Factor \\
\hline G & Mass Velocity \\
\hline $\mathrm{G}_{\mathrm{s}}$ & Shell-Side Mass Velocity \\
\hline $\mathrm{G}_{\mathrm{w}}$ & Window Mass Velocity \\
\hline $\mathrm{g}_{\mathrm{c}}$ & Gravitational Constant \\
\hline Gr & Grashof Number \\
\hline $\mathrm{Gr}^{*}$ & Corrected Grashof Number for Free Convection \\
\hline $\mathrm{h}$ & Heat Transfer Coefficient \\
\hline$h_{i}$ & Film Coefficient on the Tube Side \\
\hline$h_{\text {ideal }}$ & Film Coefficient for Pure Crossflow in an Ideal Tube Bank \\
\hline $\mathrm{h}_{\mathrm{o}}$ & Film Coefficient on the Shell Side \\
\hline $\mathrm{J}_{\mathrm{b}}$ & Heat-Transfer Correction Factor due to Tube Bypass Flow \\
\hline $\mathrm{J}_{\mathrm{c}}$ & $\begin{array}{l}\text { Heat- Transfer Correction Factor for Flow Deviation from Pure } \\
\text { Crossflow due to Baffles }\end{array}$ \\
\hline $\mathbf{J}_{1}$ & $\begin{array}{l}\text { Heat-Transfer Correction Factor for Leakage Flow around the } \\
\text { Baffle }\end{array}$ \\
\hline $\mathbf{J}_{\mathbf{r}}$ & $\begin{array}{l}\text { Heat-Transfer Correction Factor for Adverse Temperature } \\
\text { Gradient in Deeply Laminar Flow }\end{array}$ \\
\hline $\mathrm{J}_{\mathrm{s}}$ & $\begin{array}{l}\text { Heat-Transfer Correction Factor for Variable Baffle Spacing in } \\
\text { Inlet and Outlet }\end{array}$ \\
\hline $\mathrm{j}_{1}$ & Coulburn Correction Factor \\
\hline
\end{tabular}


k

$\mathrm{k}_{\mathrm{f}}$

$\mathrm{k}_{\mathrm{W}}$

$\mathrm{L}_{1}$

$\mathrm{L}_{2}$

$\mathrm{L}_{3}$

$\mathrm{L}_{\mathrm{bb}}$

$\mathrm{L}_{\mathrm{bc}}$

$\mathrm{L}_{\mathrm{bi}}$

$\mathrm{L}_{\mathrm{bo}}$

$\mathrm{Li}^{*}$

$\mathrm{L}_{\mathrm{o}}$ *

$\mathrm{L}_{\mathrm{pl}}$

$\mathrm{L}_{\mathrm{sb}}$

$\mathrm{L}_{\mathrm{tb}}$

$\mathrm{L}_{\mathrm{ti}}$

$\mathrm{L}_{\text {to }}$

$\mathrm{L}_{\mathrm{tp}}$

$\mathrm{L}_{\text {tp,eff }}$

$\mathrm{L}_{\mathrm{ts}}$

1*

$1_{c}$

$l_{f}$

$\mathrm{m}$

m*

$\mathrm{N}_{\mathrm{b}}$

$\mathrm{N}_{\mathrm{c}}$

$\mathrm{N}_{\mathrm{f}}$

$\mathrm{N}_{\mathrm{ss}}$

$\mathrm{N}_{\mathrm{t}}$
Thermal Conductivity

Fin Thermal Conductivity

Tube-Wall Thermal Conductivity

Tube Length

Shell Length in Shell-Flow Direction

Shell Length in No-Flow Direction

Tube Bundle to Shell Clearance

Central Baffle Spacing

Inlet Baffle Spacing

Outlet Baffle Spacing

Relative Inlet Baffle Spacing

Relative Outlet Baffle Spacing

Tube Lane Bypass Width

Baffle to Shell Clearance

Tube to Baffle Diametrical Clearance

Distance between Tube Sheets

Overall Shell Length

Tube Pitch

Effective Tube Pitch

Tube Sheet Thickness

Fin Effectiveness Geometrical Correction Factor

Length of Baffle Cut

Fin Height

Mass Flow Rate

Fin Effectiveness Heat Transfer Correction Factor

Number of Baffles

Total Number of Tube Rows that Cross the Heat Exchanger

Fin Pitch

Number of Sealing Strips

Number of Tubes

xxxi 


$\begin{array}{ll}\mathrm{N}_{\mathrm{t}}{ }^{\prime} & \text { Number of Tubes in One Row } \\ \mathrm{N}_{\mathrm{t}}{ }^{\prime} & \text { Number of Transverse Tube Rows } \\ \mathrm{N}_{\mathrm{tcc}} & \text { Number of Tube Rows Positioned between Baffle Cuts } \\ \mathrm{N}_{\mathrm{tcw}} & \text { Number of Tube Rows Positioned in Baffle Window } \\ \mathrm{N}_{\mathrm{tw}} & \text { Number of Tubes in One Window } \\ \mathrm{Nu} & \text { Nusselt Number } \\ \mathrm{n} & \text { Exponent } \\ \Delta \mathrm{P} & \text { Pressure Drop } \\ \mathrm{P}_{\mathrm{l}} & \text { Tube Pitch in Longitudinal Direction } \\ \mathrm{P}_{\mathrm{t}} & \text { Tube Pitch in Transverse Direction } \\ \mathrm{Pr} & \text { Prandtl Number } \\ \Delta \mathrm{p}_{\mathrm{b}, \mathrm{i}} & \text { Pressure Drop across an Ideal Tube Bank in Crossflow } \\ \Delta \mathrm{p}_{\mathrm{c}} & \text { Pressure Drop in Crossflow Section } \\ \Delta \mathrm{p}_{\mathrm{e}} & \text { Pressure Drop in Entrance and Exit Sections } \\ \Delta \mathrm{p}_{\mathrm{s}} & \text { Shell-Side Pressure Drop } \\ \Delta \mathrm{p}_{\mathrm{w}} & \text { Pressure Drop in One Window Section } \\ \Delta \mathrm{p}_{\mathrm{w}, \mathrm{TOT}} & \text { Pressure Drop in All Window Sections } \\ \mathrm{Q} & \text { Heat Transfer Rate } \\ \mathrm{q} & \text { Actual Heat Transfer } \\ \mathrm{q}_{\mathrm{i}} & \text { Ideal Heat Transfer } \\ \mathrm{R} & \text { Heat Capacity Ratio } \\ \mathrm{R}_{\mathrm{b}} & \text { Pressure Loss Correction Factor due to Tube Bypass Flow } \\ \mathrm{R}_{\mathrm{l}} & \text { Pressure Loss Correction Factor due to Baffle Leakage } \\ \mathrm{R}_{\mathrm{s}} & \text { Pressure Loss Correction Factor for Variable Baffle Spacing in the } \\ \mathrm{Re}_{\mathrm{di}} & \text { Tnlet and Outlet of the Heat Exchanger } \\ \mathrm{Re}_{\mathrm{do}} & \text { Shell-Side Reynolds Number based on Tube Outer Diameter } \\ \mathrm{Re}_{\mathrm{f}} & \\ \mathrm{R}_{\mathrm{fi}} & \text { Tube-Side Fouling Resistance } \\ & \\ & \end{array}$




$\begin{array}{ll}\mathrm{R}_{\mathrm{w}} & \text { Tube Wall Resistance } \\ \mathrm{r}^{*} & \text { Fin Tip-to-Root Radius Ratio } \\ \mathrm{r}_{\mathrm{e}} & \text { Fin Tip Radius } \\ \mathrm{r}_{\mathrm{lm}} & \text { Correlation Parameter for Baffle Leakage Effects - Total Baffle } \\ & \text { Leakage Area to Crossflow Area } \\ \mathrm{r}_{\mathrm{o}} & \text { Fin Root Radius } \\ \mathrm{r}_{\mathrm{s}} & \text { Correlation Parameter for Baffle Leakage Effects - Shell-to-Baffle } \\ & \text { to Total Baffle Leakage Area } \\ \mathrm{r}_{\mathrm{ss}} & \text { Number of Sealing Strips per Tube Rows in the Window } \\ \mathrm{S}_{\mathrm{b}} & \text { Bypass Area between Tube Bundle and Shell } \\ \mathrm{S}_{\mathrm{m}} & \text { Shell-Side Crossflow Area } \\ \mathrm{S}_{\mathrm{sb}} & \text { Shell-to-Baffle Leakage Area } \\ \mathrm{S}_{\mathrm{tb}} & \text { Tube to Baffle Leakage Area } \\ \mathrm{S}_{\mathrm{w}} & \text { Net Crossflow Area in one Baffle Window } \\ \mathrm{S}_{\mathrm{wg}} & \text { Total Flow Area in all Windows } \\ \mathrm{S}_{\mathrm{wt}} & \text { Segmental Baffle Window Area Occupied by Tubes } \\ \mathrm{s} & \text { Unfinned Tube Length } \\ \mathrm{t} & \text { Tube Thickness } \\ \mathrm{t}_{\mathrm{f}} & \text { Fin Thickness } \\ \mathrm{T} & \text { Static Temperature } \\ \mathrm{T}_{0} & \text { Stagnation Temperature } \\ \Delta \mathrm{T}_{\mathrm{m}} & \text { Mean Temperature Difference } \\ \Delta \mathrm{T}_{l m} & \text { True Mean Temperature Difference } \\ \delta \mathrm{T} / \delta \mathrm{r} & \text { Temperature Gradient } \\ \mathrm{U} & \text { Velocity } \\ \mathrm{U}_{\mathrm{s}} & \text { Ovell-Side Crossflow Velocity } \\ \mathrm{U}_{\mathrm{i}} & \text { Overall Outer-Tube Heat-Transfer Coefficient } \\ \mathrm{U}_{\mathrm{o}} & \text { Thermal Conductance } \\ \mathrm{UA} & \text { Half the Distance between Transverse Bare Tubes } \\ & \end{array}$




$\begin{array}{ll}\mathrm{x}^{\prime} & \text { Half the Distance between Transverse Finned Tubes } \\ \mathrm{x}_{1} & \text { Exponent } \\ \mathrm{y} & \text { Distance between Longitudinal Bare Tubes } \\ \mathrm{y}^{\prime} & \text { Distance between Longitudinal Finned Tubes } \\ \mathrm{z} & \text { Minimal Distance between Bare Tubes } \\ \text { z' } & \text { Minimal Distance between Finned Tubes }\end{array}$

Subscripts: $\quad$ Chapter 8

$\begin{array}{ll}\mathrm{c}, 1 & \text { Cold-Side Inlet } \\ \mathrm{c}, 2 & \text { Cold-Side Outlet } \\ \mathrm{d}_{\mathrm{i}} & \text { Tube Side } \\ \mathrm{h}, 1 & \text { Hot-Side Inlet } \\ \mathrm{h}, 2 & \text { Hot-Side Outlet } \\ \mathrm{s} & \text { Free-Stream Shell Conditions } \\ \mathrm{s}, 1 & \text { Shell Inlet } \\ \mathrm{s}, 2 & \text { Shell Outlet } \\ \mathrm{t} & \text { Free-Stream Tube Conditions } \\ \mathrm{t}, 1 & \text { Tube Inlet } \\ \mathrm{t}, 2 & \text { Tube Outlet } \\ \mathrm{w} & \text { Wall Condition }\end{array}$

xxxiv 


$\begin{array}{ll}\text { Greek: } & \text { Chapter 8 } \\ \alpha & \text { Thermal Diffusivity } \\ \beta & \text { Volume Coefficient of Expansion } \\ \eta_{\mathrm{f}} & \text { Fin Temperature Effectiveness } \\ \eta_{\mathrm{o}} & \text { Overall Surface Effectiveness } \\ \theta_{\mathrm{ctl}} & \text { Upper Centriangle Baffle Cut } \\ \theta_{\mathrm{ds}} & \text { Centriangle Baffle Cut } \\ \theta_{\mathrm{tp}} & \text { Tube Layout } \\ \mu & \text { Viscosity } \\ \rho & \text { Density } \\ \nu & \text { Kinematic Viscosity } \\ \varphi_{\mathrm{s}}{ }^{\mathrm{n}} & \text { Viscosity Correction Factor }\end{array}$

$\operatorname{XXXV}$ 


\section{CHAPTER 1}

\section{Introduction}

\subsection{Background}

Uncertainty in availability and cost of electricity, and the need for high quality electricity, has resulted in an increased distributed generation market. The increased market share is predominantly a result of small and large businesses seeking a means of protecting themselves against high energy prices and large financial losses due to the possibility of future blackouts and brownouts. Numerous distributed generation systems of varying size and application areas are market-ready and easily available. The majority of sizeable generators are fossil fuel fired. A market survey reflected that there is no cost-effective, distributed generation technology that utilizes renewable energy (discussed in Section 2.2.4-2.2.6), which may adequately supply electrical needs of a small business situated in an urban community. The closed Brayton cycle (CBC) engine has a strong potential of meeting this requirement. 
The $\mathrm{CBC}$ is a regenerative gas turbine that recycles the working gas in a closed loop. This working gas circulates around a closed loop between a heat source and a heat sink. Utilization of the same working gas imposes a requirement for the application of an indirectly-fired combustor in order to prevent entrainment of contaminated flue gasses. Additional heat is supplied to the high-pressure gas by diverting it through a heat exchanger (recuperator). Waste heat from the low-pressure working gas, at the turbine outlet, is transferred to the high-pressure gas exiting the compressor. The transfer of recuperated heat energy results in lower heat requirement that is provided by the external source to the working gas. Further cooling of the working gas (to the original state), is accomplished by the heat sink (cooler). Figure 1.1 illustrates the cycle diagram of a recuperated CBC. Working gas enters the compressor, a, is preheated by the recuperator, $\mathrm{b}$, and enters the indirectly-fired combustor, $\mathrm{c}$. The high-temperature, high-pressure gas is expanded through the turbine, $d$, and is cooled by the recuperator and the cooler, e, to the original state. An alternator, $f$, transfers the rotational mechanical energy to electricity.

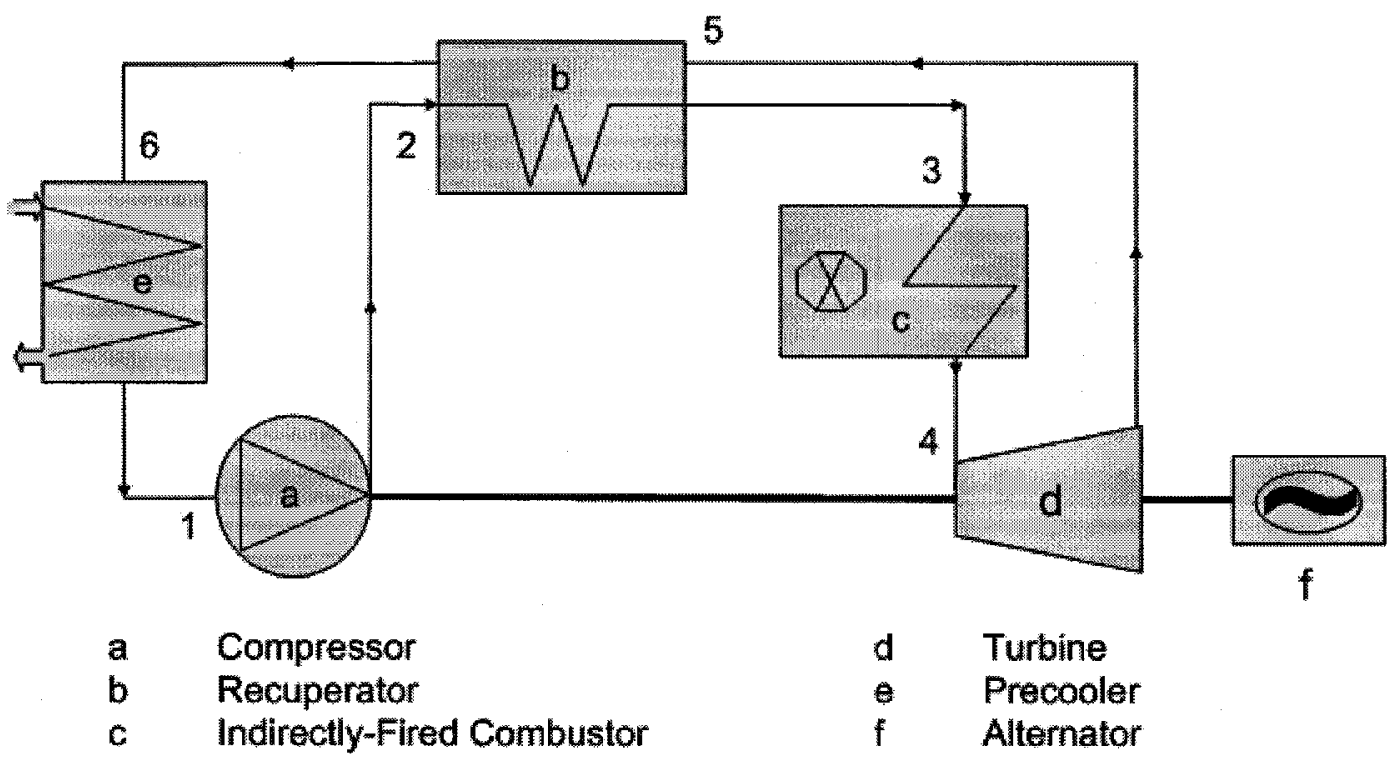

Figure 1.1: Closed Brayton Cycle Component Configuration Diagram [1.1] 
Several advantages are inherent to CBC gas turbines that are not realized in other open and closed cycle engines. These advantages include [1.2] $]^{1}$ :

1) Compatible with a wide range of heat sources including fossil fuels (such as gas, oil, and coal), solar, nuclear, and biomass. Fuel flexibility may be attained by choice of burner without design modification to other components. Concurrent utilization of several fuels is possible through integration of applicable burner designs.

2) Large quantity of high-temperature waste heat is present in the bottoming heat exchanger with the $\mathrm{CBC}$ engine. Waste heat may be directly and effectively captured and utilized for combined heat and power (CHP) production. The $\mathrm{CBC}$ engine has the potential to provide the total energy needs required by a building, including air conditioning through absorption cooling. Waste heat could also be utilized for a bottoming cycle, such as an organic Rankine cycle, which has the potential for highefficiency power generation. Through combined power and heating, the $\mathrm{CBC}$ has the potential to achieve net overall efficiencies exceeding 80 percent [1.3].

3) Capability of operating at constant efficiency over a broad power range. The control strategy of varying the cycle pressure level fixes the temperature levels and corrected mass flow rate with the end effect of operating the turbomachinery near the design operating point. In this manner, near constant cycle efficiencies can be obtained at a wide range of load [1.4].

\footnotetext{
${ }^{1}$ References are provided at the end of the thesis.
} 
4) Capability of generating variable heat quantity independently of power quantity. Through a flexible control strategy, which includes varying the cycle pressure and temperature levels and installing a recuperator bypass valve, independent control of the heat and power output may be attained. In this manner, the $\mathrm{CBC}$ engine is adaptable to variable space heating and cooling loads and energy loads.

5) Possibility of utilizing different working gasses (such as air, helium, nitrogen, oxygen, carbon dioxide, argon, neon, or gas mixtures). Utilization of a non-oxidizing, inert gas has the potential to extend component operation life as well as decrease system size as a result of the high heat-transfer coefficients. Moreover, the working gas is not environmentally harmful, hazardous, or highly flammable, facilitating non-hazardous maintenance.

6) Elevated pressure throughout the cycle results in compactness of the system and a high power density ratio. Although elevated, these working pressures are significantly lower than high pressures of an Organic Rankine Cycle or a steam plant.

7) Working gas is not contaminated with combustion by-products and flue gasses, resulting in extended-life operation in corrosion and fouling free atmosphere. Efficiency losses due to flue gas particulate deposits are averted.

8) Low thermal fatigue is incurred due to operation at constant temperature over a wide load range. 
9) Low noise signature is incurred as a result of absence of an inlet and an exhaust. Also, the limited quantity of moving components and simplicity of insulating a closed system results in a relatively low noise signature.

(10) Low vibration signature is incurred as a result of absence of reciprocating components.

(11) Simplicity resulting from the limited quantity of moving parts and auxiliary systems is a prime reason for potential engine life exceeding 120,000 hours [1.4].

The large number of potential benefits offered by a CBC engine has motivated numerous efforts to develop a CBC for combined heat and power applications. The ability to utilize indigenous coal at high efficiencies was the prime driver to develop the CBC plant in Europe. Several large-scale CBC engines have been erected in the $1950 \mathrm{~s}$ and 1960s. These plants operated with excellent reliability and availability and achieved an extensive service life of over 120,000 hours [1.2]. Despite these capabilities, the high capital cost of the high-temperature heat exchanger materials resulted in uncompetitive initial plant capital costs. Moreover, market availability of oil and later natural gas at a cost-effective price was responsible for a shift in the type of fuel utilized for power generation. Oil and natural gas fired CBC cogeneration plants were not economic (as compared to steam plants) and lost favour [1.4].

Concern of future shortages of fossil fuels has led to increased efforts in finding a cost-effective solution for utilization of renewable resources. Fuel flexibility of the indirectly-fired combustor corroborate that the $\mathrm{CBC}$ engine is a viable prime mover for distributed power generation fired by renewable and low-quality fuels. The distributed generation market is suitable for application of a $\mathrm{CBC}$ engine considering the significant increase in demand, especially for small businesses. This market application area is 
especially advantageous considering the inherently lower developmental costs of smaller sized engines.

\subsection{Project Objective}

The development of a CBC engine is comprised of short-term and long-term objectives:

Initially, the development of a technology demonstrator engine is essential in providing a means to attract future private funding. This funding will be necessary to further develop a cost effective and efficient CBC engine that can utilize waste oils and biomass as an alternative fuel for electric power generation. A research, design, and development program has been established to fabricate and test a technology demonstration $\mathrm{CBC}$ engine in order to validate the potential cost effectiveness for distributed power generation and verify the inherent system benefits. The main objective is to design, develop, fabricate, and test a 15 -to- $20 \mathrm{~kW}$ technology demonstration unit. Emphasis is placed on fabricating an operational unit in a limited time span with low capital cost expenditure. Less emphasis is imposed on the cycle efficiency due to the inherent cost increase.

The design and operating experience attained from the technology demonstration CBC engine would contribute to the future development of a reasonably efficient 25 kilowatt prototype engine. This product would be marketable to remote Northern communities for waste oil utilization. Sales from the waste-oil fired CBC engine would contribute in reducing the capital costs of the biomass engine since materials would be purchased in bulk and a fabrication assembly line would be established. 
Further development and larger production rates would reduce capital costs to a point where biomass-fired CBC engine would be competitive in terms of price and performance levels. The biomass-fired CBC engine would be introduced to the southern market.

\subsection{Thesis Objective}

This thesis encompasses 2 years of the initial 3-year program to develop a technology demonstration $\mathrm{CBC}$ engine. The objective of the initial 2 years was to mechanically design and develop a low-cost 15-to-20 kW CBC engine and commence fabrication. The thesis describes in detail the mechanical design of $\mathrm{CBC}$ components. 


\section{CHAPTER 2}

\section{Overview of Distributed Power Generation Technologies and Market}

\subsection{Power Generation Industry Restructuring}

The past decade has experienced unprecedented change in the North American power generation industry. In 1998, California was the first state to implement deregulation in North America, which was followed by over 25 other states [2.1]. In Canada, Alberta deregulated power generation as of January 2001, followed by Ontario in May 2002. Due to uncertainties in the power generation industry associated with the prospect of deregulation, power generation companies have been reluctant to invest in new, costly plants. For example, between 1996 and 2001, California added only 672 MW of capacity, while the load increased by $5500 \mathrm{MW}$ [2.1]. A similar scenario is occurring in Ontario, where energy companies such as TransAlta, Sithe Energies, and others have no interest in building new plants [2.2]. Moreover, peak-power reserve capacity may decline in a deregulated market, considering that power generation companies would be reluctant to invest in power generation capacity with limited operating time. The payback periods of these installations may be too lengthy to attract 
investors. Therefore, the prospect of rolling brownouts and blackouts, which occurred in California in the spring of 2001, may continue in the future, especially on hot summer days.

Deregulation has also imparted volatility in the cost of electricity. The majority of jurisdictions have implemented a comparable system to Ontario, where the Independent Electricity Market Operator (IMO) regulates the supply of electricity. The IMO also establishes the Hourly Ontario Energy Price (HOEP) based on supply and demand. Therefore, the customer is billed hourly fluctuating rates. During high demand periods, the price of electricity can escalate drastically. This can be especially true during peak demand periods, as seen in the first week of July 2002. The large demand, partly due to large air conditioning loads, was responsible for escalating the price of electricity to $\$ 0.47$ (CDN) per kilowatt hour as compared to the government-regulated price of 4.3 cents per kilowatt hour [2.3].

Moreover, questions have been raised on the reliability of the electrical grid. The eastern seaboard blackout of August 14, 2003 was a significant indication of the vulnerability the economy is susceptible to with lack of energy. The power outage was responsible for an estimated 1 billion dollars (USD) in losses in New York City alone [2.4], and Ontario's economy lost an estimated 550 million dollars (CDN) [2.5]. The major losses were due to loss of productivity and loss of perishable products.

\subsection{Distributed Generation}

\subsubsection{Introduction}

In response to the evolving power generation market, businesses are seeking a means of protecting themselves against high energy prices and large financial losses due to the possibility of future blackouts and brownouts that may occur as a result deficient 
energy supplies and low grid reliability. A common means of ensuring continuous power generation is by providing an on-site power-generating source. Emergency backup power generators have been common in hospitals to ensure functionality of vital life support systems. Other common emergency backup power installations include airports, utilities, and industries, where maintaining uninterrupted power is critical for protection of personnel and property [2.6]. Many businesses have taken a similar approach in protecting against loss of revenues as a result of grid power failures. As depicted in Table 2.1, potential hourly losses due to power failures in the service industry are significant. Therefore, numerous businesses have found it cost effective to invest in onsite, backup power generation.

Table 2.1: Downtime Costs of Service Industries [2.7]

\begin{tabular}{|c|c|}
\hline Industry & $\begin{array}{c}\text { Average Hourly } \\
\text { Downtime Costs } \\
\text { USD }\end{array}$ \\
\hline Cellular Communications & $\$ 41,000$ \\
\hline Telephone Ticket Sales & $\$ 72,000$ \\
\hline Airline Reservations & $\$ 90,000$ \\
\hline Credit Card Operations & $\$ 2,580,000$ \\
\hline Brokerage Operations & $\$ 6,480,000$ \\
\hline
\end{tabular}

Distributed power generation, as defined by the United States Energy Commission, refers to electric generation connected to the distribution level of the transmission and distribution grid, usually located at or near the intended place of use. These distributed generator systems may replace or supplement electrical service from the grid [2.8]. These systems range in size from less than a kilowatt to tens of megawatts, depending on load requirement. With a considerable size variation, the market application areas vary. 


\subsubsection{Distributed Generation Application Areas}

As previously introduced, distributed power systems are required for standby and emergency power systems for buildings that create public health and safety hazards or for buildings where absence of a backup generator would hamper rescue or fire-fighting operations. These systems typically start and operate independently of the grid to provide backup power. Several systems are offered with start times of ten seconds or less, in a range of climate conditions, to provide uninterrupted power supply (UPS) [2.6].

Escalating and fluctuating electricity prices (that have been a result of deregulation of the power generation industry) have resulted in potential cost effectiveness of distributed power generation for peak/load shaving or base-load power generation. Peaking/load shaving applications refer to the utilization of distributed generation (DG) during high demand periods, when energy prices are high. These systems are typically used for less than 1500 hours, and require low capital costs. In contrast, base-load generators often operate for over 6,000 hours and necessitate low operating costs and adherence to low emissions standards [2.9].

The high economic value of DG may be accredited to increasing demand of high quality, reliable power sources that have increasingly sensitive electric loads. Certain sensitive electric loads may only be met by high quality electricity produced by DG [2.8]. Moreover, the possibility of electricity sale at high market rates (to the IMO) during peak periods may be a strong market driver for installation of a DG system.

The close proximity of distributed power generation enables the utilization of waste heat for co-generation. Co-generation, or combined heat and power (CHP), may be used in conjunction with thermally activated technologies (TAT) which can provide electricity and space heating, air conditioning, and/or water heating, eliminating reliance from the grid. These systems provide high overall efficiencies, up to 85 percent, resulting in substantial energy savings. For this reason, CHP has traditionally been the 
most cost-effective DG option [2.8]. Applications of CHP typically have steady thermal loads such as office buildings, hotels, and healthcare centres.

Several niche market areas are pertinent to DG. Remote communities located distant from natural gas pipelines or electrical grids are common users of DG. DG for remote communities is a cost-effective option, considering that the cost of extending the grid can range from $\$ 1$ million per mile to $\$ 4$ million per mile (USD) [2.10]. Other potential niche market applications include the utilization of renewable fuel sources such as flare gas, biogas, coal-bed methane, and others for generation of electricity. Recently, gas flaring has become a serious environmental issue due to allegations of health concerns caused by high emissions. Worldwide, some 115 billion cubic meters of gas are flared or vented into the atmosphere every year [2.11]. Utilizing DG has the potential to burn flare gas in a controlled environment, effectively reducing emissions. Moreover, gas-drilling locations have become increasingly remote, further raising demand for an onsite power generation source.

\subsubsection{Distributed Generation Capacity}

Although DG has become more common, it has not significantly penetrated the power generation market. Currently, there is more than $60,000 \mathrm{MW}$ of distributed power installed in North America [2.12]. California is the largest DG electricity producer consisting of $2000 \mathrm{MW}$ in continuous DG and an additional $3000 \mathrm{MW}$ in backup DG [2.8]. With a total generation capacity of 55,000 MW in California [2.1], DG market share is only 9 percent, with CHP being the most common DG form. Existing CHP is concentrated primarily in five states: California, New York, New Jersey, Connecticut, and Massachusetts. The commonality between the states is the large population, high economic activity, as well as high-energy costs [2.11]. Typical CHP installation sites and their market share may be seen by the microturbine market distribution in Figure 2.1. The CHP installation distribution is based on surveyed existing microturbine capacity of $190 \mathrm{MW}$ located in 970 sites, each generating under $1 \mathrm{MW}$ [2.13]. 


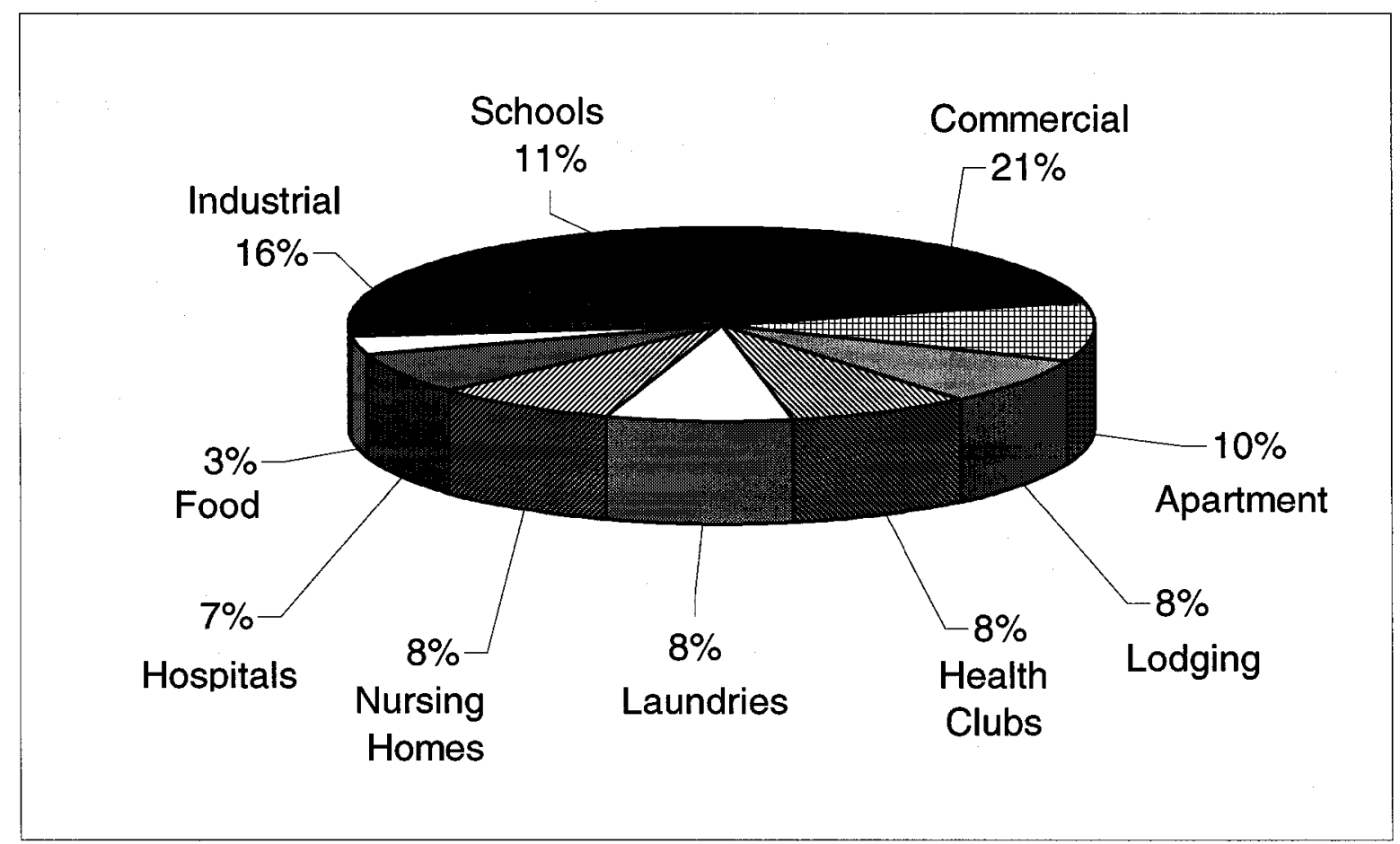

Figure 2.1: Distribution of Existing Microturbine CHP Installations [2.13]

Sales of backup power generators have steadily grown 7 percent annually; base-load and peaking sales have grown by 11 percent and 17 percent respectively [2.12]. In California, $300 \mathrm{MW}$ to $400 \mathrm{MW}$ in small-scale capacity have been added annually, and this trend is expected to continue [2.8]. The California Energy Commission Strategic Plan for DG forecasts the adoption of DG for the year 2020 to be as high as 20 percent of the Californian electricity growth [2.8]. Several reasons have attributed to the market growth. First, energy costs have considerably escalated and utilities have become less reliable due to outdated electric power infrastructure and inability of utilities to keep pace with soaring demand. Restructuring the power generation industry has led to competitive markets and reduced incentives for investment in new power generation facilities. Moreover, more stringent emissions regulations, lengthy regulation accreditation, and political involvement has led to the reluctance among utilities to invest in costly central power plants with lengthy payback periods. To accommodate the increasing demand, the only viable means of supplying additional capacity has been DG. Since DG has become 
increasingly more efficient, more reliable, and less costly, several utilities have installed and will continue to install additional DG capacity $[2.1,2.13]$.

Several other benefits are inherent to DG. Generation of electricity at or near the end user's location limits the transmission losses, which constitutes 5 percent to 8 percent of total energy transferred in medium and long distance transmission lines [2.14]. The reduction in transmission losses offered by DG technologies translates to substantial energy savings as well as infrastructure savings offered by the reduction of high-voltage power lines. Moreover, studies have shown that distributed generation may have a beneficial environmental impact. This is a result of spatial distribution of power generation as well as the utilization of cleaner burning natural gas fuel. Moreover, higher overall efficiencies are offered by DG-CHP technologies that replace supplementing burning of natural gas or oil for thermal loads [2.15].

\subsubsection{Distributed Generation Technology Overview}

Market-ready DG technologies may be segregated into three categories: internal combustion (IC) engines, external combustion (EC) engines, and renewable energy technologies. Each technology is offered for a range of sizes and applications.

\subsubsection{Internal Combustion Engines}

IC engines for distributed power applications have traditionally been the preferred technology for DG. Reciprocating engines or gas turbines, commonly referred as gensets, are offered in sizes from less than five kilowatts to over several megawatts. These units traditionally serve as backup power generators for residential, commercial, and industrial applications and are either stationed for use as uninterrupted power supply (UPS) systems or are packaged to facilitate ease of transportation for emergency backup power or peak shaving needs. In addition, IC generators are commonly used for baseload and CHP applications [2.8]. 
Reciprocating engines are offered in sizes from less than five kilowatts to over seven megawatts. Above eight megawatts, reciprocating engines lose favour due to large size and high capital costs [2.9]. A wide variety of fuels can be utilized in reciprocating engines, most commonly diesel and natural gas. Generator sets that utilize propane, landfill gas, and digester gas are also available. Typical engine efficiencies range from 25 percent to 47 percent, depending on engine and fuel type [2.16]. Rated efficiency does not greatly vary with load. In addition, quick startup times and high reliability are offered by reciprocating engines, as well as potential for long operating life of up to 20 to 30 years for large engines [2.8].

Reciprocating engines are the most commonly used technology for distributed generation. This is the lowest capital cost DG technology due to the low manufacturing costs of large engine quantities, as well as maturity of the technology. The capital cost per kilowatt, which typically increases with engine size due to increased manufacturing costs and lower production numbers, ranges between $\$ 300$ per $\mathrm{kW}$ to $\$ 900$ per $\mathrm{kW}$ (capital cost per $\mathrm{kW}$ in subsequent sections is quoted in USD) depending on size, fuel type, and engine configuration. However, total installed costs can be 50 percent to 100 percent higher than the engine due to additional costs imparted by balance of plant, equipment fees, engineering fees, and associated owner costs [2.17].

The primary disadvantage of reciprocating engines is that they produce high exhaust emissions. This is especially true for diesel engines, which emit high Carbon Dioxide $\left(\mathrm{CO}_{2}\right)$ and high Nitrogen Oxide $\left(\mathrm{NO}_{\mathrm{x}}\right)$ emissions. Reciprocating engines are noisy and exhibit vibration levels that are difficult to dampen. Moreover, a frequent maintenance schedule is required for reciprocating engines, mainly due to fluid replacement [2.16].

Conventional combustion turbine generators, or gas turbines, are offered between $500 \mathrm{~kW}$ to $25 \mathrm{MW}$ for DG, and up to $190 \mathrm{MW}$ for central power plant generation [2.8]. 
Gas turbines are competitive with other power generation options, with a capital cost range between $\$ 300$ per $\mathrm{kW}$ to $\$ 1000$ per $\mathrm{kW}$. As depicted in Figure 2.2 , the capital cost increases with decreasing power output, resulting in excessive and therefore uncompetitive costs below $500 \mathrm{~kW}$ [2.18]. Moreover, operating costs increase with decreasing power output due to a negative effect in the cycle efficiency. Gas turbines are typically more costly with respect to reciprocating engines in the small size range (below 4 megawatts), but the penalty is less with larger size [2.8]. In the upper size range (above 4 megawatts), gas turbines are typically competitive with respect to reciprocating engines (see Figure 2.3) [2.18]. Modern, simple-cycle gas turbine efficiencies range from 20 percent to 45 percent at full load, but part-load performance is poor. Heat recovery of large quantities of high-temperature exhaust gases is possible. Typical installed cost of a mid-sized gas turbine with heat recovery ranges from $\$ 1000$ per $\mathrm{kW}$ to $\$ 1200$ per $\mathrm{kW}$ [2.8].

Due to high specific power output, gas turbines are typically used in large industrial DG applications. Other applications include remote locations such as oil rigs, where space availability is at a premium [2.19]. Smaller generators have been offered, although these units were derived from Auxiliary Power Units (APUs) and were typically used for backup power as a result of the low cycle efficiency $[2.6,2.9]$. Low cycle efficiencies of small gas turbine engines have been addressed with the advent of microturbines.

Small simple-cycle, regenerative gas turbines, known as microturbines, have been developed to overcome cycle-efficiency limitations and high capital costs of small conventional gas turbines. Microturbines are small combustion engines with a power generation range of $25 \mathrm{~kW}$ to $500 \mathrm{~kW}$, and with fuel energy to electricity conversion efficiencies in the range of 20 percent to 30 percent. The modest efficiencies are attained with the use of a recuperator; non-recuperated microturbines attain efficiencies around 15 percent [2.8]. The most common microturbine application area is CHP since large 


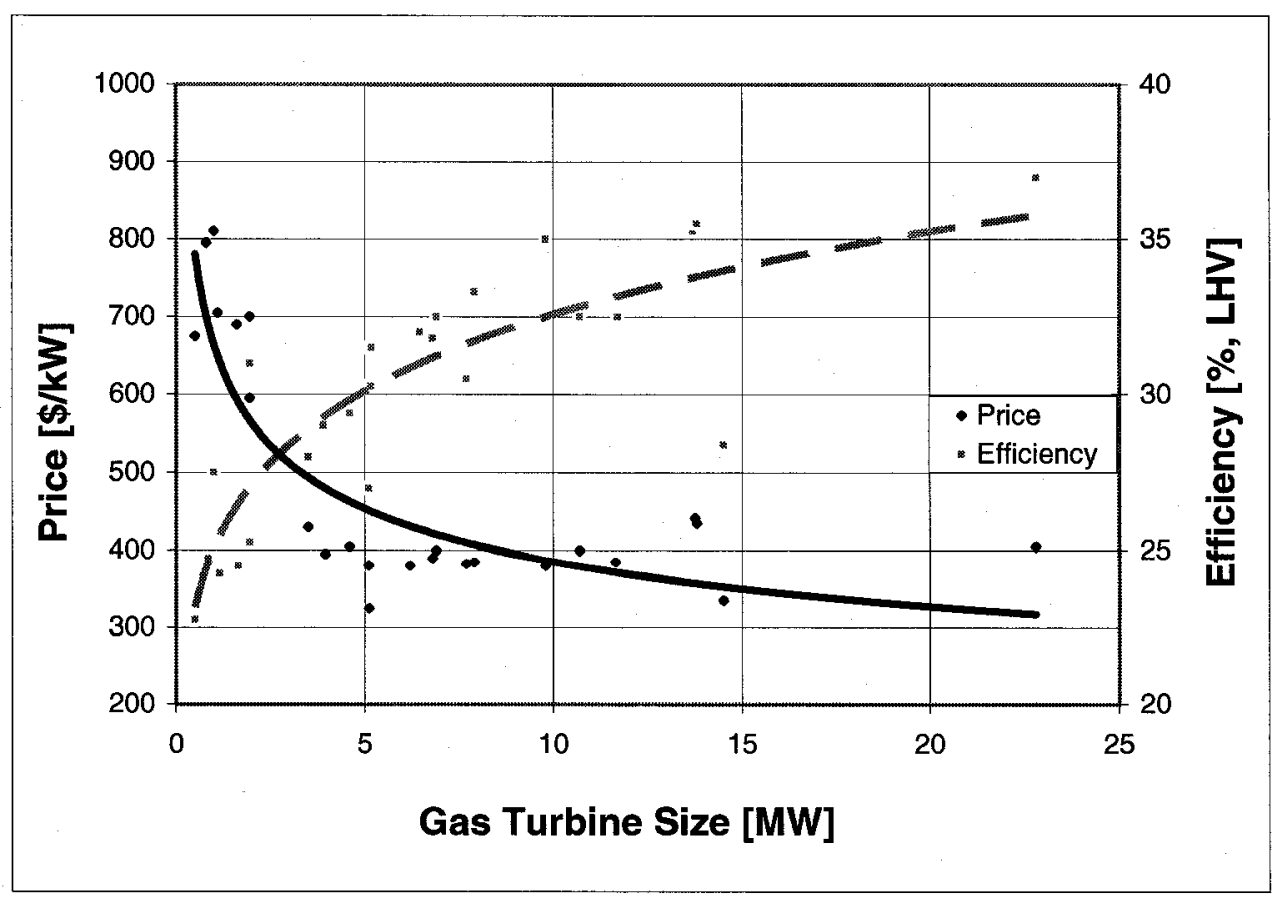

Figure 2.2: Simple-Cycle Gas Turbine Capital Cost and Efficiency Trend with Size [2.18]

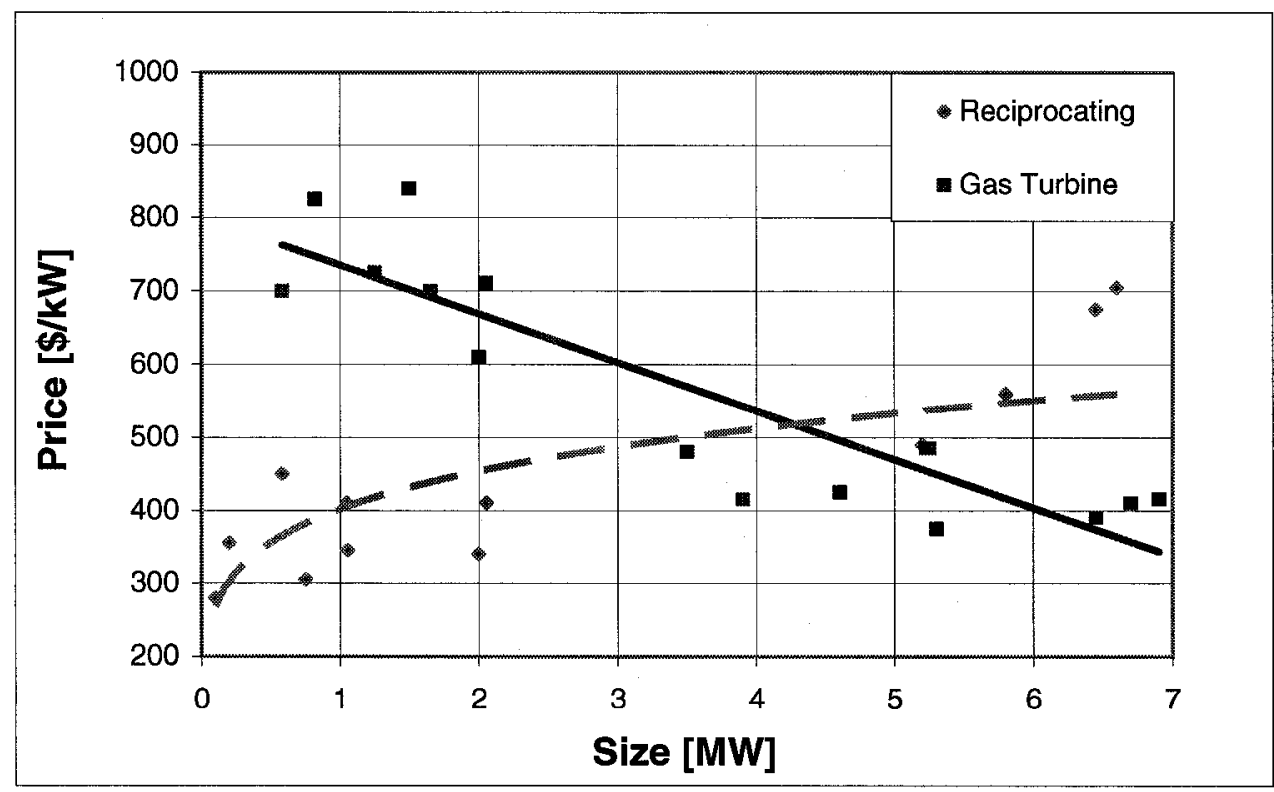

Figure 2.3: Capital Cost Comparison as a Function of Size of Simple-Cycle Industrial Gas Turbines and Reciprocating Engines [2.18] 
quantity of high temperature exhaust gases that may be utilized. Overall efficiencies as high as 85 percent can be achieved with implementation of CHP. Other microturbine application areas include base power and flare gas disposal. Microturbines are not typically applied to backup power and peak shaving application areas due to higher capital costs. Capital costs range is from $\$ 700$ per $\mathrm{kW}$ to $\$ 1100$ per $\mathrm{kW}$, which includes all hardware, software, and support. Heat recovery units incur an additional cost ranging from $\$ 75$ per $\mathrm{kW}$ to $\$ 350$ per $\mathrm{kW}$. The microturbine capital cost is higher than the cost of a reciprocating engine; however, microturbines can be placed in areas where size, weight, noise, and vibration levels are constrained. Moreover, microturbine emission levels are considerably lower than reciprocating engine emissions [2.8].

\subsubsection{External Combustion Engines}

The closed-cycle reciprocating engine, or Stirling engine, exhibits quiet operation and has the potential for high cycle efficiencies. High efficiencies may be attributed to high thermal conductivity of the inert working fluid, typically helium or hydrogen, sealed in a closed, low-noise system. Commercial Stirling engines are available in sizes ranging from $1 / 2 \mathrm{~kW}$ to $25 \mathrm{~kW}$. A variety of heat sources may be utilized, including solar power, which offers the potential for an emission-free energy source [2.17].

Capital costs of Stirling engines range from $\$ 2,000$ to $\$ 50,000$ per $\mathrm{kW}$, which limits the competitiveness with other DG technologies. Current application areas are specialized, which results in limited manufactured quantities that translate into high capital cost. This is especially true for space applications, where limited production results in the capital cost of $\$ 50,000$ per $\mathrm{kW}$. Ground-based power generation applications are typically priced near the lower portion of the price range as a result of greater number of units produced. The high capital cost may also be attributed to the complex mechanical design of Stirling engines that involves many moving components. Moreover, durability problems with shaft seals, piston rings, and bearings have inhibited widespread commercialization [2.17]. 
The most commonly used externally fired combustion power generation technology is the Rankine cycle, or steam power plant. The steam power plant is a low capital cost technology at the large-scale central power generation level. At the smallscale power generation level (few kilowatts to several megawatts), the Rankine cycle is uncompetitive due to the relatively high capital cost of the high-pressure boiler. Competitiveness may only be achieved by limiting the pressure level and thus reducing the high capital cost of the boiler. This is only possible with the utilization of an organic working fluid. Ammonia, Benzene, Chlorofluorocarbon (CFC), Freon, and Iso-Pentane are examples of organic substances with low latent heat and high density that are suitable for application in an Organic Rankine Cycle (ORC) [2.20]. The suitability of low operating pressures by organic fluids is a result of the low critical pressure of the working fluids [2.21]. The low operating pressure results in a simple system structure that is low cost. Application of readily available technologies is also responsible for the low system capital cost [2.20].

Most organic working fluids are prone to chemical decomposition and deterioration at high temperatures and pressures. The ORC system has a temperature operation limitation below the typical organic fluid stability threshold of $250^{\circ} \mathrm{C}$ to $350^{\circ} \mathrm{C}$. Due to the low turbine inlet temperature, as well as pressure, the theoretical thermal efficiency of the ORC is limited to a 30 percent maximum, although measured cycle efficiencies are typically lower (about 20\%) [2.21]. The low thermal efficiency of the ORC system limits the competitiveness of the technology. Moreover, limited waste heat extraction restricts the technology from CHP applications. (The waste heat extracted from the ORC condenser is low-temperature, which has limited use). As a result, the ORC has the potential to be utilized as a bottoming cycle in power plants that discard abundant quantity of low-grade waste heat. Despite the low capital cost, the low thermal efficiency and limited quantity of waste heat for CHP applications has restricted the interest in the application of the ORC system to DG. 
Another external combustion technology is the indirectly-fired closed-cycle gas turbine, also known as the closed Brayton cycle (CBC) engine. The CBC engine has been developed to overcome the large size and poor thermal efficiency limitations of conventional or open-cycle gas turbine engines. Initial CBC engine systems were considerably smaller and more efficient than open-cycle gas turbines of comparable power output. A number of closed-cycle gas turbines have been developed for space, naval, and nuclear applications. In Europe, several large-scale (several megawatts) power generation plants have been implemented to take advantage of flexibility of different combustion configurations for a variety of fuels $[2.19,2.22]$. These CBC generating plants had higher capital cost than other, more conventional systems. As a result, $\mathrm{CBC}$ plants were not competitive and lost favour. To this day, $\mathrm{CBC}$ technology has not been mass-produced or adapted to DG.

\subsubsection{Renewable Energy Technologies}

By converting solar energy directly to electricity, photovoltaic (PV) cells, or solar cells, are utilized to generate emission-free energy. Other advantages offered by PV technology include no fuel costs, limited maintenance costs, quiet operation, as well as long operation life. Until recently, high cost of materials used in solar cells have relegated the technology to powering satellites, high-tech backwoods cabins, and remotely located communication towers. Recent improvements in electrical conversion efficiency, as well as the reduction in materials and manufacturing costs have reduced PV unit cell costs. With current efficiency levels up to 18 percent [2.14], PV cells may generate the majority of residential energy needs at a cost range of $\$ 4.5$ to $\$ 7.00$ per watt (after rebates). However, with a rooftop-installation capital cost varying from $\$ 6,000$ to $\$ 10,000$, solar power is currently three to four times the cost of conventional fossil-fuel fired technology. Future reductions in capital costs must continue for widespread use of PV cells in DG applications including residential areas and small businesses that are not energy demanding [2.17]. Capital cost reductions are likely through efficiency 
improvements to decrease PV panel size, and reduction in manufacturing costs imparted by mass production.

Another renewable, emission-free energy source is the wind turbine. Wind turbines are capable of producing a wide range of power, varying from several kilowatts to five megawatts. Installed individually, wind turbines are suited for distributed power generation or may be grouped by a utility for large-scale power generation. DG applications may include farms and ranches, where space requirements are not a concern, as well as tall building rooftops, where tower installation is not necessary. Implementation in urban or small-lot suburban homes is unlikely due to large space requirements. Moreover, the 100 -foot tower required for small-scale turbines may infringe on local zoning restrictions.

Power generation from wind farms is currently the most cost-effective renewable energy option. Implementation of large-scale wind turbines, with a power output in the several megawatts range, has decreased the cost of wind power to levels almost competitive with conventional central power plants. Large-scale wind farms can be installed at a cost of $\$ 1000$ per $\mathrm{kW}$, which translates to a power generation cost in the range from 3 cents to 6 cents per kilowatt-hour. Further competitiveness is achieved with additional tax incentives offered by federal governments $[2.8,2.17]$. These tax incentives have prompted the increase of large-scale wind turbine capacity throughout Europe and North America. Small-scale wind turbines (in the range of several kilowatts to $500 \mathrm{~kW}$ ) suffer from high capital costs (about $\$ 2500$ per $\mathrm{kW}$ ), which may prevent widespread installation for DG applications.

\subsubsection{Renewable Energy Power Generation Market}

Renewable energy technologies have had recent success partly as a result of the Kyoto Protocol. The European Union has decreed that by 2011, 22 percent of electricity and 12 percent of energy should come from renewable sources [2.14]. As a result, PV 
and wind energy has undertaken a capacity growth rate greater than conventional energy technologies. PV cell worldwide annual growth rate has been 21 percent between 1995 and 2001, with majority installations in Japan, Germany, and the United States.

Similarly, worldwide annual growth rate of wind power between 1995 and 2001 has been 32 percent, with a six-fold increase in worldwide capacity [2.14]. With advancement of renewable energy technology, as well as larger production output, cost of renewable energy should continue to decrease. With lower renewable energy generating costs, renewable technology capacity growth is expected to continue to meet objectives set out by the Kyoto protocol.

\subsubsection{Distributed Generation Technology Gap}

DG and renewable energy power generation technology has recently exhibited significant market growth. Numerous technologies are offered for DG (as discussed in Section 2.2.4, and summarized in Table 2.2), however, there is no efficient and costeffective DG technology that utilizes renewable energy, which may adequately supply electrical and thermal demand of a small business situated in an urban community. Application of a DG technology that utilizes renewable energy may benefit from both the growing DG energy market and the growing renewable energy market. The closed Brayton cycle engine is potentially suitable for both emerging and growing markets. 
Table 2.2: Summary of DG Technologies

\begin{tabular}{|c|c|c|c|c|c|c|c|c|c|}
\hline Technology & Recip. & $\begin{array}{c}\text { Gas } \\
\text { Turbine }\end{array}$ & $\begin{array}{l}\text { Micro- } \\
\text { turbine }\end{array}$ & Stirling & $\begin{array}{c}\text { Rankine } \\
\text { Cycle }\end{array}$ & ORC & $\mathrm{CBC}$ & $\begin{array}{c}\text { Wind } \\
\text { Turbines }\end{array}$ & PV \\
\hline $\begin{array}{c}\text { Feasible } \\
\text { D.G. Size } \\
\text { Range }\end{array}$ & $\begin{array}{l}2 \mathrm{~kW}- \\
8 \mathrm{MW}\end{array}$ & $\begin{array}{c}500 \mathrm{~kW}- \\
25 \mathrm{MW}\end{array}$ & $\begin{array}{l}25 \mathrm{~kW}- \\
500 \mathrm{~kW}\end{array}$ & $\begin{array}{c}1 / 2 \mathrm{~kW}- \\
25 \mathrm{~kW}\end{array}$ & $\begin{array}{l}\text { Excessive } \\
\text { for D.G. }\end{array}$ & $\begin{array}{c}\text { Few kW - } \\
1.5 \mathrm{MW}\end{array}$ & $\begin{array}{l}2 \mathrm{~kW}- \\
50 \mathrm{MW}\end{array}$ & $\begin{array}{l}5 \mathrm{~kW}- \\
5 \mathrm{MW}\end{array}$ & $\begin{array}{l}<1 \mathrm{~kW}- \\
100 \mathrm{~kW}\end{array}$ \\
\hline Efficiency & $25-47 \%$ & $20-45 \%$ & $20-30 \%$ & $12-20 \%$ & $\geq 50 \%$ & $10-30 \%$ & $25-45 \%$ & $20-40 \%$ & $5-18 \%$ \\
\hline $\begin{array}{c}\text { Capital Cost } \\
\text { [USD/kW] } \\
\text { (No CHP) }\end{array}$ & $\begin{array}{c}\$ 300- \\
\$ 900\end{array}$ & $\begin{array}{l}\$ 300- \\
\$ 1000\end{array}$ & $\begin{array}{l}\$ 700- \\
\$ 1100\end{array}$ & $\begin{array}{l}\$ 2000- \\
\$ 50,000\end{array}$ & $\begin{array}{l}\text { Excessive } \\
\text { for D.G. }\end{array}$ & Low & TBD & $\begin{array}{l}\$ 1000- \\
\$ 2500\end{array}$ & $\begin{array}{c}\$ 6000- \\
10,000 \\
\text {-Rebates }\end{array}$ \\
\hline $\begin{array}{l}\text { Fuel } \\
\text { Type }\end{array}$ & $\begin{array}{c}\text { Gasoline, } \\
\text { Diesel, } \\
\text { NG, } \\
\text { Propane, } \\
\text { Landfill } \\
\text { Gas, } \\
\text { Digester } \\
\text { Gas }\end{array}$ & $\begin{array}{c}\text { Primarily: } \\
\text { NG, } \\
\text { Jet A1 }\end{array}$ & $\begin{array}{c}\text { NG, } \\
\text { Propane, } \\
\text { Landfill } \\
\text { Gas }\end{array}$ & $\begin{array}{l}\text { Primarily } \\
\text { NG } \\
\text { Other: } \\
\text { Biomass } \\
\text { and Solar }\end{array}$ & $\begin{array}{l}\text { Coal, } \\
\text { Fuel Oil, } \\
\text { NG }\end{array}$ & $\begin{array}{c}\text { Coal, } \\
\text { Fuel Oil, } \\
\text { Biomass, } \\
\text { Solar, } \\
\text { Waste } \\
\text { Heat }\end{array}$ & $\begin{array}{c}\text { Diesel, } \\
\text { NG, } \\
\text { Propane, } \\
\text { Coal } \\
\text { Biomass, } \\
\text { Landfill } \\
\text { Gas, } \\
\text { Digester } \\
\text { Gas, Solar }\end{array}$ & Wind & Solar \\
\hline $\begin{array}{c}\text { Adaptable to } \\
\text { CHP }\end{array}$ & Yes & Yes & Yes & Yes & Yes & Limited & Yes & No & No \\
\hline
\end{tabular}




\section{CHAPTER 3}

\section{CBC Engine Literature Survey}

\subsection{Introduction}

The ingenious idea of the closed Brayton cycle (CBC) gas turbine engine was first published by J. Ackeret and C. Keller in 1939 [3.1] and later developed mainly by the Escher Wyss Company, Zürich, Switzerland into a useful power plant [3.2]. The cycle characteristics of external heating, freedom of choice of cycle pressure level, cycle operating temperature and type of working gas, as well as the potential for combined power and heat production enabled the $\mathrm{CBC}$ engine to overcome the large size and poor thermal efficiency limitations of the conventional or the open-cycle gas turbine. Inherent advantages of $\mathrm{CBC}$ engine configuration include ability to utilize a wide variety of fuels, possibility of district heating, and plant longitivity. These inherent advantages have vindicated efforts to validate the $\mathrm{CBC}$ engine concept with pilot demonstration and limited commercial plants. Due to the wide range of applicability, numerous organizations have been involved in research and development of the CBC engine with varied success. This research and development has been extensively published in 
literature, and is presented based on power generation application area: industrial, nuclear, space, and niche application areas.

\subsection{Historical Industrial Application Areas of the CBC Engine}

\subsubsection{Overview of Previously Erected CBC Gas Turbine Cogeneration Plants}

Throughout the 1950s and 1960s, attention was devoted to utilization of low-cost and indigenously abundant coal as choice of fuel for power generation in Eastern Europe. Although coal-fired steam turbine plants were predominantly used in the power generation industry, attention was focused on utilizing plants with greater heating power. The CBC gas turbine was suited for medium output range in cogeneration of heat and power due to the availability of large quantity of easily recoverable heat from high temperature exhaust gasses. More than $11 \mathrm{CBC}$ plants have been erected in Europe and Japan [3.1]. Detailed account of the design and operating experience of five plants that have been build in West Germany by GHH Sterkrade $A^{1}{ }^{1}$ under a license agreement from Escher Wyss ${ }^{2}$ have been described by Bammert [3.1-3.7].

The pioneer CBC plant was built at the Escher Wyss works in Zurich, Switzerland in 1939. This oil-fired plant generated $2000 \mathrm{~kW}$ and achieved an electrical efficiency of over 32 percent with a turbine inlet temperature of $700^{\circ} \mathrm{C}$ [3.8]. This was an outstanding accomplishment considering that at the time, this $\mathrm{CBC}$ plant achieved record-high plant efficiency. In comparison, a $4000 \mathrm{~kW}$ open-gas turbine developed in the same year by a local competitor Brown, Boveri, and Cie. (BBC, now ABB), could achieve an electrical efficiency of only 17 percent at a turbine inlet temperature of $550^{\circ} \mathrm{C}$ [3.9]. The CBC plant provided power to the Escher Wyss works during the Second World War and

\footnotetext{
1. GHH M.A.N. Maschinenfabrik Augsburg-Nürnberg AG, Machiery, Plant and Systems Division, Oberhausen-Sterkrade, Germany

2. EW Escher Wyss AG, Ravensburg, Germany
} 
operated successfully over 6000 hours. Moreover, the plant proved viability of the closed-cycle concept and provided an initial technological base [3.8].

Due to the Second World War and the post-war economic situation, installation of the first commercial CBC plant required more than 15 years. The first commercial CBC gas turbine in the world was commissioned in 1956 at the Escher Wyss AG works located at the Ravensburg ("Raheiz"), Germany. The 2.0 MW electrical power output was used to supply electricity to furnaces and forging works in the factory as well as the bureau and fabrication buildings. Heat generated by the $\mathrm{CBC}$ engine, at an average heating power to electrical power ratio of $0.98^{\mathrm{MW}(\mathrm{h})} / \mathrm{MW}(\mathrm{e})$, provided two-thirds the demand of the factory and office buildings. The Raheiz plant was designed to operate on pulverized coal and heavy or light oil, depending on the relative fuel costs. The plant was operational for about 120,000 hours, with a high availability rate of 87 percent $[3.1,3.2]$.

The ability to control and generate large amounts of heating power without restrictions to electric power generation was an attractive advantage sought by municipalities with a large heating grid. Along with operation on pulverized coal, this attraction led to the installation of $\mathrm{CBC}$ gas turbine plants by the municipal public works of Coburg ("Coheiz") and Oberhausen ("Obheiz 1"). The Coburg plant was capable of generating 6.6 MW of electric power and between 8 and $16 \mathrm{MW}$ of heating power. The plant was initially commissioned in 1959 , but reconstruction was necessary due to low power output delivery, which was completed in 1962. The Oberhausen plant was rated at an electrical power output of $13.75 \mathrm{MW}$ and a heating power output of 18.5 to $28 \mathrm{MW}$, and was commissioned by the city in 1960 . This plant originally operated on coal-fired heat source, but later was retrofitted to gas as fuel supply situation changed in Germany. The heating to electrical power generation rated over the total operation period was 1.5 for the Coburg plant and 1.7 for the Oberhausen plant. The long-term experience with these plants was fully satisfactory, with the Oberhausen plant exceeding 120,000 hours of 
operation, and the Coburg plant exceeding 160,000 hours of operation with an availability rate of 83 percent and 73 percent respectively $[3.2,3.3,3.4]$.

The CBC gas turbine has also been erected for a colliery at Haus Aden with a primary role of supplying compressed air for ventilation. The compressor power requirement was $3 \mathrm{MW}$ of the rated power output of $6.37 \mathrm{MW}$, and the remaining power covered a portion of the colliery electrical load. The plant was designed to generate heating power of $7.6 \mathrm{MW}$, of which 70 percent was used for hot water supply to the mine, and 30 percent was used for heating a neighbourhood. The plant utilized mine gas and coal in a fluctuating ratio between 0 and 100 percent depending on mine gas availability. Since commissioning of the plant in 1963, the plant was in operation for about 120,000 hours, with an availability rate of over 91 percent $[3.2,3.5]$.

Another industrial CBC gas turbine was erected in 1967 by a steel mill in Gelsenkirchen ("Geheiz"). The largest of the closed-cycle air turbine cogeneration plants supplied the steel mill with electrical power of $17.25 \mathrm{MW}$ and heating power of 20 to 29 MW. This plant utilized blast furnace gas (as a first choice) with light fuel added depending on availability. The Geheiz plant achieved operating time of about 120,000 hours with relatively few malfunctions [3.2].

\subsubsection{System Description}

The $\mathrm{CBC}$ cogeneration plants erected in Germany had identical arrangement and number of components and may all be represented by the cycle diagram shown in Figure 3.1. The working fluid, air, was pre-compressed in the low-pressure (L.P.) compressor (a) and cooled in the intercooler (b) before being raised to maximum operating pressure in the high-pressure (H.P.) compressor (c). The air was then preheated in the recuperator (d), which transferred available heat from the high-temperature, low-pressure air available from the turbine outlet. Subsequently, the air was heated to maximum cycle temperature 


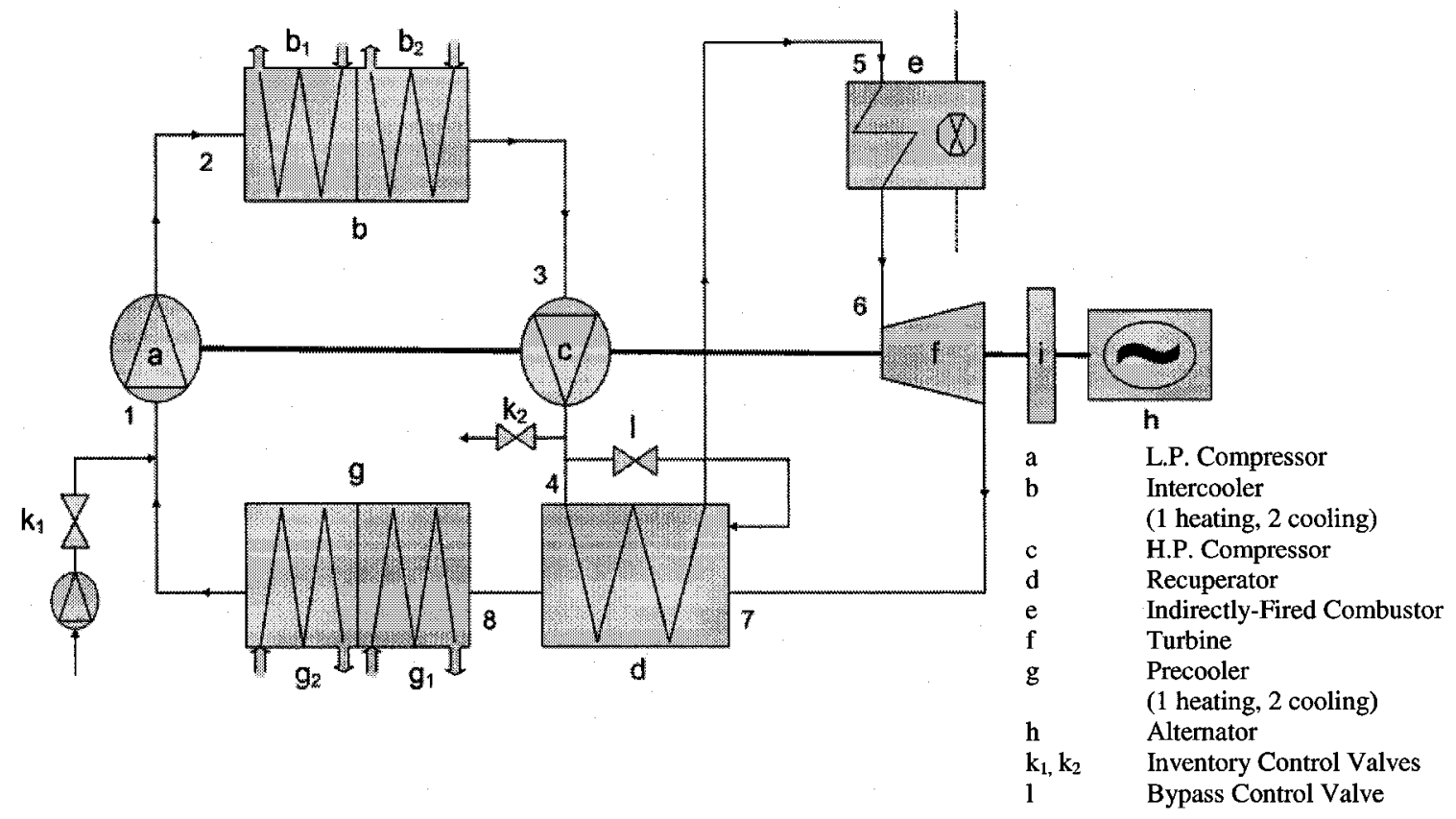

Figure 3.1: Cycle Diagram of the CBC Cogeneration Plants Erected in Germany [3.1]

Table 3.1: Working Air Operating Conditions of the Coburg and Obheiz 1 CBC Cogeneration Plants [3.3, 3.5]

\begin{tabular}{|c|c|c|c|c|c|}
\hline & & \multicolumn{4}{|c|}{ Working Air Operating Conditions } \\
\hline $\begin{array}{c}\text { Reference } \\
\text { Point }\end{array}$ & Component Inlet & \multicolumn{2}{|c|}{ Coburg Plant } & \multicolumn{2}{c|}{ Obheiz 1 Plant } \\
\hline & & $\begin{array}{c}\text { Temp } \\
\left({ }^{\circ} \mathrm{C}\right)\end{array}$ & $\begin{array}{c}\text { Pressure } \\
(\text { bar })\end{array}$ & $\begin{array}{c}\text { Temp } \\
\left({ }^{\circ} \mathrm{C}\right)\end{array}$ & $\begin{array}{c}\text { Pressure } \\
(\text { bar })\end{array}$ \\
\hline 1 & L.P. Compressor & 20 & 7.88 & 30 & 8.58 \\
\hline 2 & Intercooler & 76 & 13.08 & 124.5 & 19.75 \\
\hline 3 & H.P. Compressor & 20 & 12.91 & 30 & 19.52 \\
\hline 4 & Recuperator H.P. & 125 & 31.72 & 99.5 & 36.59 \\
\hline 5 & Air Heater & 425 & 31.28 & 419 & 36.07 \\
\hline 6 & Turbine & 680 & 29.66 & 710 & 34.34 \\
\hline 7 & Recuperator L.P. & 445 & 8.47 & 447 & 8.95 \\
\hline 8 & Precooler & 146 & 8.09 & 129.5 & 8.73 \\
\hline
\end{tabular}


in the indirectly-fired combustor (e), before being expanded in the turbine (f). Finally, the air was restored to the original condition by transferring heat in the recuperator (d) and the precooler (g). The intercooler (b) and the precooler (g) was divided into two parts, $b_{1}$ and $g_{1}$, which transferred heat to the hot water of the heating network, and the cooling parts, $\mathrm{b}_{2}$ and $\mathrm{g}_{2}$, which transferred heat to the atmosphere. The turbomachinery was coupled to a single shaft, which was connected to the alternator (h) through a gearbox (i). Inventory pressure control was achieved through utilizing two valves. A supply valve, $\mathrm{k}_{1}$, was used to feed air from storage bottles into the piping upstream of the L.P. compressor thus increasing power output. A blow-off valve, $\mathrm{k}_{2}$, was used to reduce the air quantity of the system, thus reducing the load. Moreover, a bypass valve, 1 , was used to for short-term power reduction to maintain heating power at low electric power requirements [3.1-3.3, 3.5].

The reference points in Figure 3.1 and Table 3.1 denote entry points to the respective cycle component. The working air conditions at the reference points for the Coburg and Obheiz plants are exemplified in Table 3.1, and the main operating conditions of all plants are depicted in Table 3.2. The plants have been operating at elevated pressures in order to utilize higher specific work, thus reducing system size. Compressor inlet pressures ranged from 7 to 10 bars, with an inlet temperature typically at $20^{\circ} \mathrm{C}$. The total compression ratio of the $\mathrm{CBC}$ plants was in the range of 3.36 to 4.15 , with an average value of 3.70. Operating turbine inlet temperatures (TIT) ranged between $680^{\circ} \mathrm{C}$ in the early designs to $710^{\circ} \mathrm{C}$ in the later plant designs, with corresponding turbine inlet pressures ranging from 27 to 39 bar. The TIT was modest in order to ensure longitivity of the turbomachinery components [3.3].

The electrical power output was raised with every plant installation from an initial 2.3 MW to $17.25 \mathrm{MW}$ in the final plant. This was accomplished through increasing cycle operating pressures and mass flow rates, and to a lesser extent, increasing the TIT. The modest increase of TIT (from $660^{\circ} \mathrm{C}$ to $711^{\circ} \mathrm{C}$ ) by an average of $5^{\circ} \mathrm{C}$ per year (which is 
Table 3.2 Main Operating Conditions and Measured Efficiencies of the Five CBC

Cogeneration Plants in Germany [3.2, 3.5]

\begin{tabular}{|c|c|c|c|c|c|c|}
\hline \multicolumn{2}{|c|}{$\begin{array}{c}\text { Plant } \\
\text { (Year of Commission) }\end{array}$} & $\begin{array}{c}\text { Raheiz } \\
\mathbf{( 1 9 5 6 )}\end{array}$ & $\begin{array}{c}\text { Coheiz } \\
\mathbf{( 1 9 6 1 )}\end{array}$ & $\begin{array}{c}\text { Adheiz } \\
\mathbf{( 1 9 6 3 )}\end{array}$ & $\begin{array}{c}\text { Obheiz_1 } \\
(\mathbf{1 9 6 0 )}\end{array}$ & $\begin{array}{c}\text { Geheiz } \\
\mathbf{( 1 9 6 7 )}\end{array}$ \\
\hline Peak Electric Power & $\mathrm{MW}$ & 2.3 & 6.6 & 6.37 & 13.75 & 17.25 \\
\hline Heating Power & $\mathrm{MW}$ & $2.4-4.1$ & $8-16$ & 7.6 & $18.5-28$ & $20-29$ \\
\hline Electrical Efficiency & $\%$ & 25.8 & 28.0 & 29.0 & 29.5 & 31.0 \\
\hline Mass Flow Rate & $\mathrm{kg} / \mathrm{s}$ & 26.2 & 74.1 & 71.9 & 129.3 & 153.0 \\
\hline Specific Mass Flow Rate & $\mathrm{kg} / \mathrm{s}$ & 11.5 & 11.2 & 11.3 & 9.4 & 8.9 \\
\hline MWe & & 7.2 & 7.9 & 8.15 & 9.48 & 10.4 \\
\hline L.P. Comp. Inlet Pressure & $\mathrm{bar}$ & 7.20 & 30 & 20 & 20 \\
\hline Turbine Inlet Pressure & $\mathrm{bar}$ & 30.5 & 29.7 & 30.4 & 34.3 & 37.8 \\
\hline Turbine Inlet Temp. & ${ }^{\circ} \mathrm{C}$ & 660 & 680 & 681 & 710 & 711 \\
\hline $\begin{array}{c}\text { Turbine Isentropic } \\
\text { Efficiency }\end{array}$ & $\%$ & 87.5 & 89.5 & 90.0 & 90.0 & 89.7 \\
\hline $\begin{array}{c}\text { H.P. Compressor } \\
\text { Isentropic Eff'cy }\end{array}$ & $\%$ & 81.5 & 82.0 & 82.5 & 83.5 & 86.2 \\
\hline $\begin{array}{c}\text { L.P. Compressor } \\
\text { Isentropic Eff'cy }\end{array}$ & $\%$ & 82.0 & 82.0 & 83.0 & 85.0 & 86.0 \\
\hline
\end{tabular}

typical for stationary gas turbines) was a result of development of heat-resistant austenitic pipe materials for the fossil-fired radiation heaters [3.4]. Power plant conversion efficiencies had also been increased as a result of continuous aerodynamic development of turbomachinery blading. This development led to isentropic turbine efficiencies exceeding 90 percent and isentropic compressor efficiencies exceeding 86 percent. Moreover, improvements in the aerodynamic design of diffusers and heat exchangers led 
to lower pressure drops throughout the system and higher heat transfer efficiencies, respectively. These continuous developments led to and improvement in electrical efficiencies with each subsequent plant, with the final plant exceeding a thermal efficiency of 30 percent at design conditions $[3.2,3.5]$. The main operating conditions and measured efficiencies of the five air turbine CBC plants erected in Germany are summarized in Table 3.2.

In addition to high thermal efficiencies, the CBC cogeneration plants operated at excellent part-load efficiencies. The efficiency of electrical power generation as a function of load for the $17 \mathrm{MW}$ Geheiz plant is plotted in Figure 3.2. A relatively flat efficiency curve from full power to half power has been measured. A significant drop in electrical efficiency is not apparent until quarter power. The high part-load overall efficiency can be attributed to the ability to control cycle pressures and hence mass flow rates through inventory control of the working air. As a result, temperatures in the cycle can remain nearly constant at part-load operation $[3.1,3.5]$.

Although the overall arrangement and number of components was identical for all plant designs, several component-specific changes were made throughout continuous development of the CBC cogeneration plants. These conversions were made to enable higher system pressures, higher mass flow rates, and improved component efficiencies. Changes in the turbomachinery were significant to accommodate the five-fold increase in mass flow rate. Throughout cycle development, the increase in mass flow rate dictated a change from radial compressors, as the Raheiz plant was equipped with, to a combination of axial and radial, as the Coheiz plant was equipped with, to a full axial design for the last erected plants. The turbine design was axial for all plants [3.2]. Details of turbomachinery arrangement are tabulated in Table 3.3.

Heat from combustion gasses was transferred to the clean working air indirectly through the air heater. The construction principle of a radiation and convection portion 


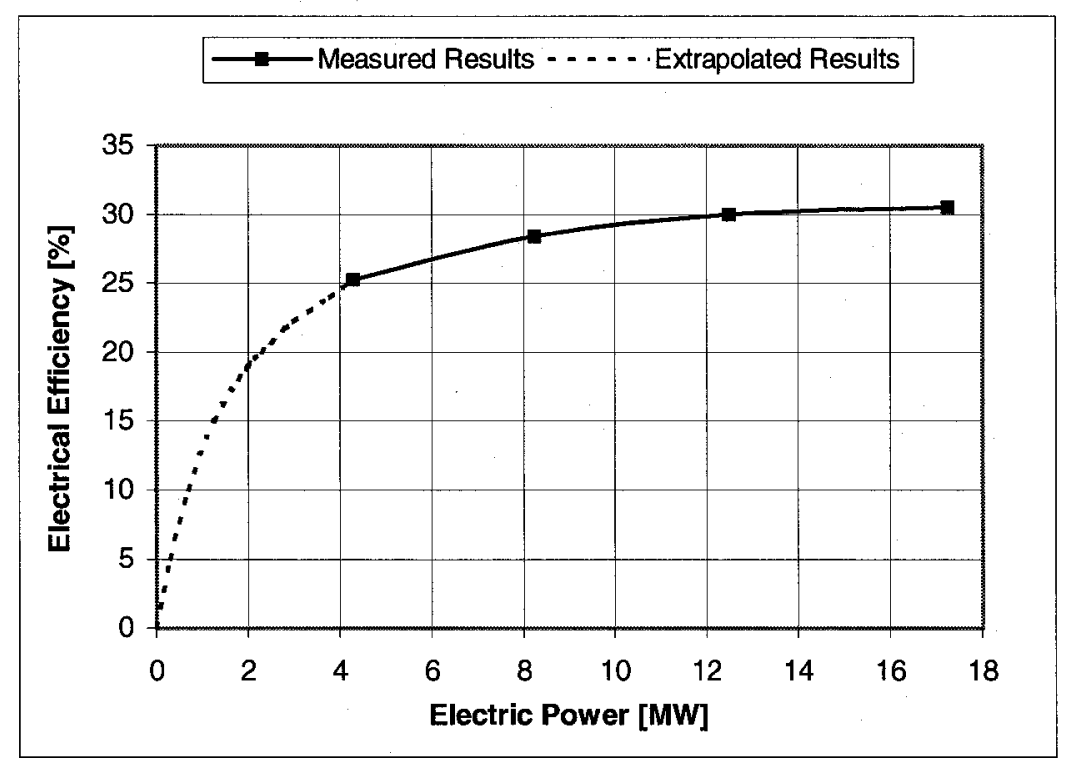

Figure 3.2: CBC Plant Efficiency at Off-Design Operating Conditions [3.1]

Table 3.3: Turbomachinery Arrangement Details [3.2]

\begin{tabular}{|l|c|c|c|c|c|}
\hline Plant & Raheiz & Coheiz & Adheiz & Obheiz_1 & Geheiz \\
\hline Compressor Type & Radial & A/R* & Axial & Axial & Axial \\
\hline $\begin{array}{l}\text { Compressor Stages } \\
\text { (L.P./H.P.) }\end{array}$ & $3 / 3$ & $6 / 7+1$ & $9 / 10$ & $9 / 6$ & $7 / 8$ \\
\hline Turbine Type & Axial & Axial & Axial & Axial & Axial \\
\hline Turbine Stages & 5 & 5 & 6 & 5 & 6 \\
\hline Speed of Turbo Set [RPM] & 12,750 & 8220 & 6640 & 8220 & 6650 \\
\hline Alternator Speed [RPM] & 3000 & 3000 & 3000 & 1500 & 3000 \\
\hline
\end{tabular}

*The Coheiz Plant was equipped with an axial L.P. and H.P. compressors followed by a radial H.P. compressor end stage. 
with roof-fired combustion chamber was used in all plants (see Figure 3.3). The downfired combustion chamber (a) consists of the radiation portion, and the upward pass (b) consists of the convection portion. The passes are connected at the bottom by a gas reversal duct (c). Burners (e) are positioned downward from the roof of the combustion chamber. The combustion chamber is circular in the initial CBC plant designs and converted to octagonal for ease of manufacturing in later designs. The furnace is completely lined with tubes (f), which constitute the radiant section. The convective part consists of coiled tubes $(\mathrm{g})$ in cross counter-current flow direction to the flue gasses [3.2, 3.3, and 3.7].

The heat exchangers have been designed to transfer approximately the same amount of heat as the indirectly-fired combustor. The Reheiz, Coburg and Adheiz plants employed a corrugated strip-fin tube heat exchanger. The heat exchangers of this type are of relatively short length but have a large diameter. Larger plants required heat exchangers with small plain tubes since difficulty in transportation that would be incurred in large-diameter strip-fin tube heat exchangers [3.3].

The coolers consist of a heating part and a cooling part. The heating part transfers heat from the working air to the hot water, and the cooling part transfers heat to the atmosphere. The heat exchanging surfaces consist of standard tubes with internally smooth and externally finned surfaces. Heating water flows in a counter-current arrangement with respect to the working air. Water flows inside the tubes and air on the outer tube periphery [3.3].

\subsubsection{Conclusions Gained from Operation of the CBC Cogeneration Plants}

Although the CBC power plants achieved excellent operating results in terms of efficiency, maintenance, and service life, they were not successful in the longer term. The plants were operated at a time when fuel oil and later natural gas had become market available and cost effective. Technological advances in steam-operated power stations 
led to construction of plants with ever-increasing capacities, which led to high

efficiencies through improved utilization of primary heat. The CBC engines exhibited an upper limit on the cycle efficiencies imposed by material ability to resist high temperatures in the indirectly-fired combustor (air heater). Moreover, the benefit of high cycle pressures that permitted smaller size of the turbo set, recuperator, and coolers of the CBC systems were overshadowed by considerable expenditure of austenitic metals used in the radiation heating surfaces of the air heater. The high capital cost of the air heater resulted in uncompetitive initial capital costs, and the $\mathrm{CBC}$ air turbine cogeneration plants lost favour.

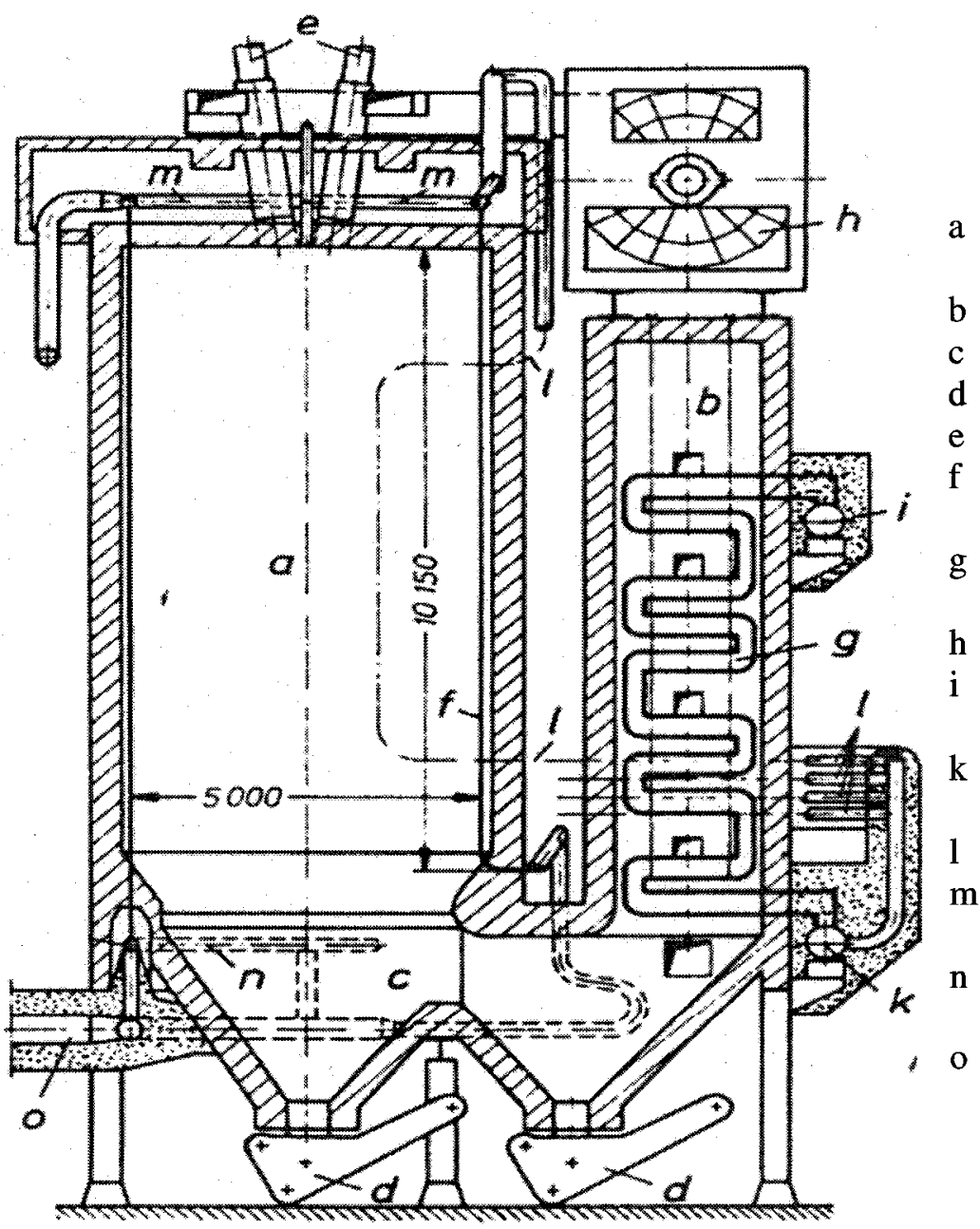

Combustion Chamber Convective Part Gas Reversal Pass Wet-Ash Extractor Burners Radiation Part Tubes Convection Part Tubes Air Preheater Inlet Header (Convection Part) Outlet Header (Convection Part) Connecting Pipes Inlet Header (Radiation Part) Outlet Header (Radiation Part) Double Shell Hot Air Pipe

Dimensions in $\mathrm{mm}$

Figure 3.3: Section View of the Coal-Fired Air Heater [3.3] 


\subsection{Historical Nuclear Application Areas of the CBC Engine}

\subsubsection{Nuclear Application Overview}

Adaptation of the $\mathrm{CBC}$ gas turbine to a high-temperature gas cooled reactor (HTGR) has been extensively studied due to several potential merits. Direct power conversion from single-cycle system offers improvements in plant simplification, size, capital cost, electric power conversion efficiency, and waste heat rejection as compared to two-cycle, steam power system [3.10, 3.11, 3.12]. High cycle efficiencies are possible with a nuclear $\mathrm{CBC}$ turbine due to direct expansion of the high-temperature reactor core coolant, which is typically helium. The high-temperature graphite reactor core of a HTGR does not impose metallurgical limitations (inherent in metallic fossil-fired heat exchangers) that restrict the turbine inlet temperature [3.12]. Additional advantage in flexibility in plant location is inherent with the possibility of dry cooling. Where cooling water is available, a bottoming cycle cogeneration option may be implemented for additional power and efficiency [3.13].

Conceptual development program of an HTGR-GT (high-temperature gas cooled reactor-gas turbine) plant has been initiated in the 1970s and continued into the 1980s, with the objective of developing the technology to a commercial readiness for utility service introduction in the late 1990s. The conceptual plant size in the range of $800 \mathrm{MW}$ to $1200 \mathrm{MW}$ has been extensively studied by General Atomic in the United States [3.123.14] and a similar program has been established by European High Temperature Helium Turbine (HHT) Project. Through validation of a technology base through a fossil-fired CBC helium gas turbine, simplification of the certification process would be possible. For technology validation purposes including design considerations of helium plants (as thoroughly described in literature $[3.14,3.15])$, a helium CBC turbine demonstration plant was developed [3.4, 3.12]. 


\subsubsection{CBC Helium Turbine Plant at Oberhausen}

The first cogeneration power plant employing a helium turbine has been built by Energiversorgung Oberhausen, AG (EVO) from 1972 to 1974. This cogeneration plant provided $50 \mathrm{MW}$ of electrical power and $53.5 \mathrm{MW}$ of heating power to Oberhausen, Germany. The main objective of plant installation has been to gain experience and technical information for future large nuclear helium CBC plants through long-time plant operation. For this reason, low system pressure and turbine inlet temperature was selected to yield a high volumetric flow rate of comparable magnitude to large-scale nuclear power plants. The net effect resulted in dimensions of major plant components, including turbomachinery, heat exchanger, and ducting, corresponding to a large-scale nuclear gas turbine (around $300 \mathrm{MWe}$ ). As a result, the centrifugal stresses in the turbomachinery correspond to those of a $300 \mathrm{MWe}$ plant. The increased plant size is also beneficial in terms of obtaining long-term experience in plant dynamic behaviour corresponding to a large-scale gas turbine $[3.11,3.16]$.

The major difference in the plant layout of the Oberhausen 2 helium plant and previous air turbine $\mathrm{CBC}$ plant is that a two-shaft arrangement was implemented in the Oberhausen 2 plant. Whereas in the previous air turbine plants the turbine was connected to the H.P. and L.P. compressor through one shaft, in the Oberhausen 2 plant an L.P. turbine was implemented on a separate shaft that was connected to the L.P. and H.P. compressors and H.P. turbine through a gear system. As a result, the compressors and the H.P. turbine rotational design speeds were chosen as 5000 RPM, and the L.P. turbine design rotational speed was chosen as 3000 RPM. Additional mechanical design aspects have been implemented in the Oberhausen 2 plant for helium containment comparable to requirement specifications of a nuclear power plant. To prevent any contaminated helium leakage from the remote possibility of disk brakeage, the turbomachinery was housed in heavy-duty spherical casings: one for the L.P. compressor, common one for the H.P. compressor and the H.P. turbine, and one for the L.P. turbine. Application of internal insulation was avoided to prevent potential particle contamination in the reactor, 
which could be deposited in various locations throughout the cycle. The design alternative of cooling the inside and outside casing by the H.P. compressor outlet gas was chosen. In addition, a system of three labyrinth seals was developed to contain the helium between the circuit helium and each of the bearings [3.16].

As previously discussed, the turbine inlet temperature and pressure was limited (in comparison to previously designed air turbines and conceptually designed nuclear power turbines) to increase the volumetric flow rate. A secondary motive for imposing this constraint was due to design considerations of the oil-fired helium heater. The limitation in turbine inlet pressure, to $27 \mathrm{bar}$, minimized the wall thickness of the tubes, thus reducing the overall cost. A low turbine inlet temperature of $750^{\circ} \mathrm{C}$ ensured higher creep strength required for extended plant design life. These design specifications had a governing factor in cycle operational parameters that are depicted in Table 3.4. The

Table 3.4: Helium Operating Conditions in the Oberhausen 2 CBC Cogeneration Plant [3.16]

\begin{tabular}{|c|c|c|c|}
\hline No. & Component Inlet & $\begin{array}{c}\text { Temperature } \\
{\left[{ }^{\circ} \mathrm{C}\right]}\end{array}$ & $\begin{array}{c}\text { Pressure } \\
{[\mathrm{bar}]}\end{array}$ \\
\hline 1 & L.P. Compressor & 25 & 10.5 \\
\hline 2 & Intercooler & 83 & 15.5 \\
\hline 3 & H.P. Compressor & 25 & 15.4 \\
\hline 4 & Heat Exchanger-H.P. Side & 125 & 28.7 \\
\hline 5 & Heater & 417 & 28.2 \\
\hline 6 & H.P. Turbine & 750 & 27.0 \\
\hline 7 & L.P. Turbine & 580 & 16.5 \\
\hline 8 & Heat Exchanger-L.P. Side & 460 & 10.8 \\
\hline 9 & Pre-cooler & 169 & 10.6 \\
\hline
\end{tabular}


resulting net thermal to electrical efficiency of 31.3 percent was demonstrated. To achieve an electrical power output of $50 \mathrm{MWe}$, a mass flow rate of $84.4 \mathrm{~kg} / \mathrm{s}$ was chosen.

The implementation of low-molecular weight gas necessitated the application of additional stages in the turbomachinery, as compared to utilizing air as a working gas. A 10-stage L.P. compressor and a 15-stage H.P. compressor were used to pressurize the helium from 10.5 bar to 28.7 bar. Expansion was accomplished by utilizing a 7 -stage H.P. turbine and an 11-stage L.P. turbine. The design of the hot side heat exchanger was similar to the design adapted for the air turbines. The external size of the heat exchanger was 22.5 meters in length and 4.5 meters in diameter, and the heat exchanger was composed of about 17,500 tubes of $12 \mathrm{~mm}$ outer diameter. The design of the intercooler and the pre-cooler were also similar to the air turbine design. For each, finned tubes with $20 \mathrm{~mm}$ inner diameter and $2550 \mathrm{~mm}$ length were used. The control strategy adapted for the helium plant had also been similar to the air turbine plants [3.16].

The fossil-fuel-fired helium heater design principle was to separate the combustion process from the process of heat transfer in order to prevent associated uncertainties with flame radiation. Heat transfer was separated into convective and gas radiation parts. The combustion chamber was refractory-lined, cylindrical shape of a 17.5-meter length and 12.5-meter height. Coke-oven gas was used as a fuel, with 5 percent excess air, which resulted in a heater efficiency of 92.2 percent. Tube outer diameters ranged between $31.8 \mathrm{~mm}$ and $63.5 \mathrm{~mm}$. The selected tube material was Incoloy 807, as this material was successfully employed in the Oberhausen air turbine plant. Further details on the helium heater may be found in Reference [3.16].

To date, no HTGR-GT commercial power plants have been erected, although a nuclear heat source has successfully been combined with a CBC gas turbine. A series of five mobile, nuclear $\mathrm{CBC}$ gas turbine power plants were developed for the United States Army by Aerojet-General Nucleonics throughout 1959 and 1960 [3.16]. Majority of 
information regarding this program was made available for the ML-1 plant, the first mobile nuclear CBC plant [3.17, 3.18]. The plant was designed to meet the United States Army mobility, logistics, and power quality requirements, with a power generation capability range of 300 to $500 \mathrm{~kW}$ at a wide ambient temperature range [3.18]. Mobility was achieved through compact and low weight design that readily enables transportation of the power plant in four packages: reactor, power conversion system, control system, and auxiliary systems. The plant was designed for a life requirement of 50,000 hours, with an overhaul and refuelling intervals of 10,000 hours. Oxygenated nitrogen was used as the working gas ( 0.5 percent $\mathrm{O}_{2}$ and 99.5 percent $\mathrm{N}_{2}$ by volume). Oxygen was introduced to prevent nitriding of the nuclear reactor fuel elements. Initial test trials of 3500 hours were successfully completed and documented in Reference [3.18]. Proven viability of utilizing the $\mathrm{CBC}$ power conversion unit with a nuclear power source was established. Successful development of the nuclear CBC power conversion unit conceived potential for utilizing this technology in naval and space applications.

\subsection{Historical Space Application Areas of the CBC Engine}

High power conversion efficiencies and high power-to-weight ratio offered by the $\mathrm{CBC}$ engine has driven interest in adapting the system for space power applications. Inherent flexibility of the $\mathrm{CBC}$ to a particular application and power level enables suitability of the system to various missions. The $\mathrm{CBC}$ engine may be designed for minimum mass, minimum radiator area, or maximum efficiency, or tailored to a combination of the above requirements. Therefore, the $\mathrm{CBC}$ engine has been considered for a wide variety of missions including earth orbit, deep space, and lunar missions [3.19].

Wide mission applicability may also be attributed to additional flexibility offered by the possibility of adapting a range of heat sources. Radioisotope, solar, and nuclear 
heat sources have been considered for application. Heat source selection is dependant on the power requirement. Isotope is applicable to the $0.5 \mathrm{~kW}$ to $15 \mathrm{~kW}$ power range, where the upper limit is imposed by high cost of fuel. Consequently, the main design driver for isotope systems is high efficiency. Solar dynamic heat sources are applicable in the $2 \mathrm{~kW}$ to $100 \mathrm{~kW}$ range. Below $2 \mathrm{~kW}$, the solar infrastructure size is excessive, and above 100 $\mathrm{kW}$, the infrastructure weight is excessive. The main design driver for solar systems is the energy storage system for eclipse periods. The upper power limit of $100 \mathrm{~kW}$ is also partly a result of the high weight of energy storage systems. Nuclear reactor heat source is competitive above $15 \mathrm{~kW}$. Below this size, the weight of the reactor is prohibitive, partly due to reactor shielding requirement [3.19].

Numerous study and development programs have been initiated to demonstrate technology readiness of the CBC system. Throughout the 1960s, NASA-Lewis Research Center has developed a radioisotope $\mathrm{CBC}$ power generation unit. The program objective was to achieve a power conversion efficiency exceeding 25 percent for a power output range of $2 \mathrm{~kW}$ to $10 \mathrm{~kW}$ with an operation life exceeding 5 years $(44,000$ hours). Extensive tests of key components have been successfully conducted and reported [3.203.25]. Recently, solar energy has become less costly. A solar power CBC space power system has been selected for NASA Space Station Freedom [3.26]. Moreover, a $2 \mathrm{~kW}$ Solar Dynamic Ground Test Demonstration (SD GTD) unit (a solar powered CBC) had lately been designed and operated in a simulated space environment [3.27]. Recent increases in power demand for launch vehicles have dignified utilization of nuclear power. A nuclear-fuelled CBC has been selected for European space program's ARIANE 5 launch vehicle [3.28, 3.29]. Interplanetary and deep space missions will require isotope or nuclear fuel sources, and studies are conducted in these areas [3.26, 3.30]. In conclusion, the studies based on development and testing that have undergone in the past 30 years have concluded that the CBC space power generation systems is a viable and safe prime mover for space power generation for a wide variety of manned and unmanned missions. 


\subsection{Niche Market Application Areas of the CBC Engine}

Application of the CBC engine for several other niche market applications areas have been considered. The CBC engine has been considered for naval applications for both the merchant fleet and United States Navy (USN). Studies concluded that the application of a CBC engine for a large transport ship has the potential to significantly decrease engine room space requirement as compared to an open-cycle gas turbine or steam power plant [3.31]. For this reason and other inherent advantages described in Chapter 1, the USN was interested in the CBC engine. A $29.8 \mathrm{~kW}$ (40 horsepower) laboratory engine has been designed, fabricated, and tested for the USN [3.32]. The design and operating experience has been used to perform an up-rating study for power levels pertinent to naval applications. Despite the significant research effort, no known naval vessels have been equipped with the $\mathrm{CBC}$ engine. However, interest has been renewed in application of a CBC engine to an autonomous underwater vehicle [3.33]. Increasing market demands for a vehicle that can operate independently for elongated periods has been placed by offshore oil and gas industry, surveying teams, and biological research [3.34]. The CBC engine is suitable for this application since it can operate air independently, with high power density, high reliability, and is a simple system [3.33]. These advantages may promote a future niche market role for the $\mathrm{CBC}$ engine.

Other applications considered for CBC plants included liquefied natural gas (LNG) vaporization [3.35] and seawater conversion to drinking water [3.36]. Independent utilization of waste heat from high efficiency power generation has the potential for economical operation for these applications [3.35, 3.36]. Another application area has combined refrigeration cycle with a $\mathrm{CBC}$ for production of liquefied gasses. Commonly referred to as a La Fleur cycle, this cryogenic process was used in the United States for liquefying nitrogen [3.8]. 


\subsection{Indirectly-Fired Open Gas Turbine}

Recently, the US Department of Energy (DOE) has recognized a market requirement for future coal-fired plants with high cycle efficiency, low environmental impact, and low capital cost. As coal is projected to remain the dominant fuel source for electric power generation, DOE has deemed that it is important to foster the development of next generation technologies that utilize this fuel. A marketable improvement in the cycle efficiency is only possible with the application of a Brayton cycle rather than a Rankine cycle. Therefore, DOE has initiated a research effort to develop a High Performance Power System (HIPPS) that utilizes an indirectly-fired, open-cycle gas turbine [3.37]. The DOE program objective is to [3.38]:

- Increase the cycle thermal efficiency of coal-fired plants to 47 percent based on the higher heating value (HHV). This is significantly higher than 35 percent for typical pulverized coal plants and 44 percent for advanced pulverized coal plants.

- Reduce emissions of sulphur oxide and nitrogen oxide pollutants to less than a tenth of current US new-plant standards, which is an environmental standard that meets or exceeds the strictest world standards for coal-fired power plants.

- Reduce greenhouse gas emissions, specifically carbon dioxide, by as much as 30 percent in the first commercial power plants and, as the technology matures, by more than 35 percent overall.

- Produce electricity at costs at least 10 percent below those of today's plants.

- Re-power existing coal-fired plants, producing significant gain in operating efficiency. 
HIPPS is a combined cycle plant that utilizes advanced aero-derivative or heavyframe gas turbine and commercially available steam turbine technologies, as well as commercially available subsystems. In this manner, the objectives are to be met with low capital cost that is competitive with current gas turbine combined cycle plants. Only the heating system requires additional design and development. The gas turbine heating system will combine a coal-fired high temperature advanced furnace (HITAF) and a topping natural gas burner. The natural gas burner will be based on current gas turbine combustors. The HITAF has been under development by the United Technologies Research Center (UTRC) [3.37, 3.39].

The HITAF is an indirectly-fired combustor that offers separation of the combustion products from the working gas, avoiding the expense of hot gas cleanup and corrosion of the turbine blades by coal ash. Metallurgical considerations limit the HITAF outlet temperature to $925^{\circ} \mathrm{C}\left(1700^{\circ} \mathrm{F}\right)$, which is 65 percent of the temperature rise required by the gas turbine. Future metallurgical improvements will enable the HITAF to achieve a 95 percent temperature rise. The topping combustor utilizes premium fuel (natural gas or no. 2 heating fuel) to increase the temperature up to $1370^{\circ} \mathrm{C}\left(2500^{\circ} \mathrm{F}\right)$, which is 35 percent of the total temperature rise. The topping combustor design allows for operation of the gas turbine on only natural gas, increasing the plant operating flexibility [3.39]. Waste heat is extracted from the turbine exhaust by the Heat Recovery Steam Generator (HRSG) that supplies steam to the bottoming Rankine cycle. Partial or entire turbine exhaust may flow to the HRSG. In the partial flow case, the remaining flow is directed to preheat the HITAF exhaust. Figure 3.4 shows a schematic diagram of the HIPPS plant [3.39]. The HIPPS plant has been under development since 1992. Pilot-scale testing of the HITAF has been successfully completed in a slagging furnace for over 2000 hours. Operational experience of the pilot-scale HIPPS plant is described in Reference [3.40]. Program objective had been to develop a prototype 300 MWe plant by 2005 [3.39]. 


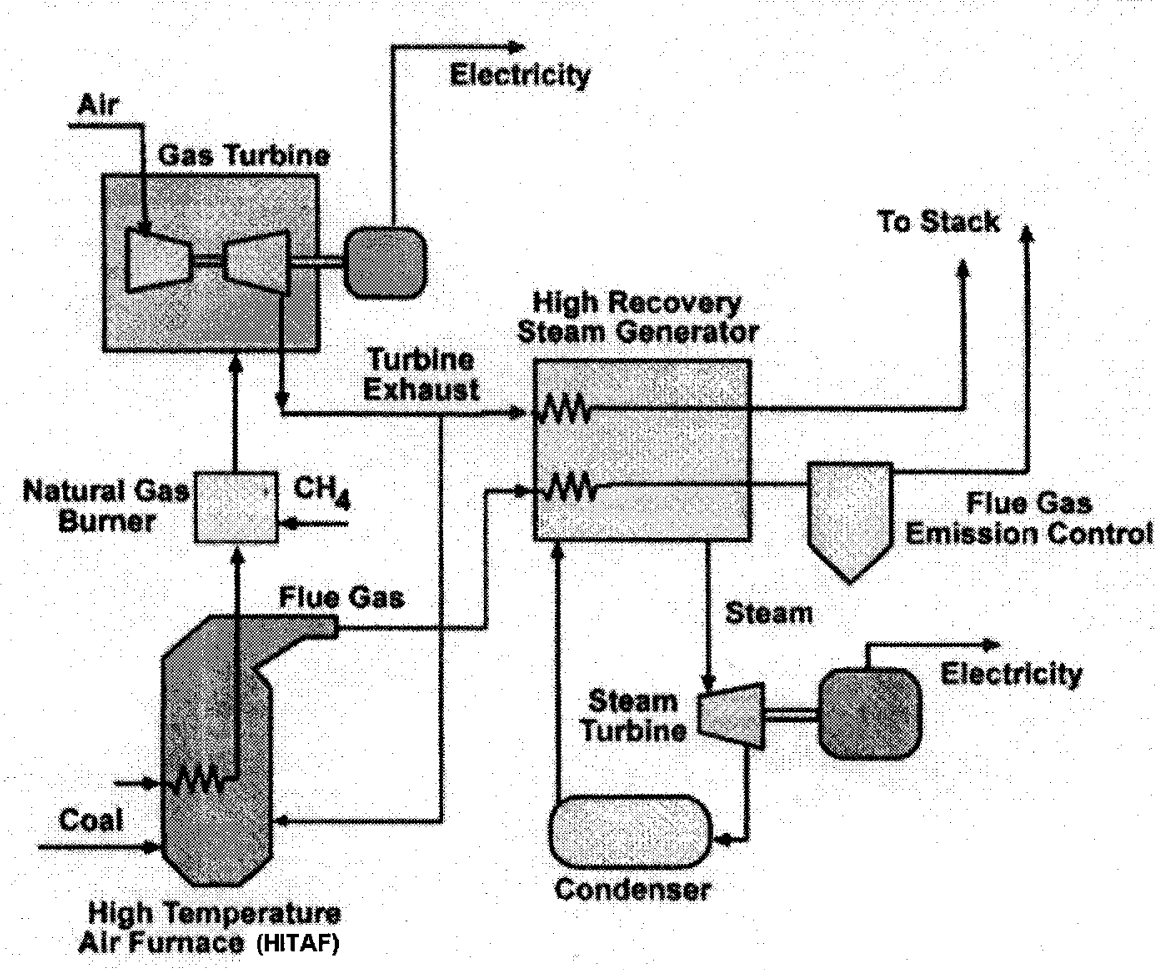

Figure 3.4: Indirectly-Fired Power System [3.39]

As of 1999, the HIPPS program has been reconfigured to a large-scale program with the objective to develop a multi-fuelled power plant with unprecedented emission and efficiency target. The DOE sponsored Vision 21 program aims to develop a power plant by the year 2015 that will produce no greenhouse-gas emissions and generate electric power at efficiency levels of 60 percent (based on HHV) on coal and 70 percent (based on HHV) on natural gas. Greenhouse-gas emission target will be met by introducing carbon sequestration. The plant design will accommodate a wide-range of fuels including coal, natural gas, biomass, and petroleum coke, depending on cost and availability. The plant will also supply a wide-range of products including electric power, process-heating power, liquid fuels, chemicals, or hydrogen. The Vision 21 program objective is to develop a power plant that generates electricity at market prices, has marketable improvements in efficiency, and low environmental impact [3.41]. 
The programs initiated by DOE confirm that an indirectly-fired heat exchanger can operate at high temperatures required for efficient operation of a gas turbine engine. Moreover, these efforts indicate that an indirectly-fired heat exchanger may be integrated with a Brayton cycle to utilize coal and other low-grade fuels and renewable resources such as biomass [3.39]. The open Brayton cycle does not benefit from higher cycle pressures that reduce heat exchanger size, and therefore, heat exchanger cost. However, in this case, utilizing existing open-cycle gas turbine and steam turbine reduces the development and capital costs to a level that would not be competitive with development of a closed-cycle turbine, since no commercially available components are available for a CBC plant [3.41].

Another approach for utilizing coal in an open-cycle gas turbine is through integration of a coal gasification process with a combined cycle, commonly known as an Integrated Gasification Combined Cycle (IGCC) plant. Gasification of coal is achieved by combining steam or an oxidant (oxygen or air) with granular coal in a pressure vessel to form a 'dirty' gas along with a slag or ash by-product. The dirty gas is purified in cyclone separators to remove particulates that are susceptible to corroding the turbine blades. Purified gas is delivered and fired directly in the combustor. This gas has low calorific value, about $5000 \mathrm{~kJ} / \mathrm{m}^{3}$, as compared to natural gas, which has a calorific value of about $39,000 \mathrm{~kJ} / \mathrm{m}^{3}$. However, the low calorific value does not impose an efficiency penalty. Although the IGCC plant capital cost is high, coal can be utilized more efficiently in an IGCC than a Rankine cycle [3.42].

Two IGCC demonstration plants have been erected: one in Cool Water, California and the other in Buggenum, Holland. The Cool Water plant had successfully operated for 27,000 hours between 1984 and 1989. Following the test period, the plant continued to provide electricity and operating experience. This plant has the generating capacity of 118 megawatts, of which 80 megawatts is generated from a standard General Electric gas turbine and the remaining 38 megawatts is generated by the heat-recovery steam turbine. 
The plant successfully demonstrated that a commercial gas turbine plant can operate viably for extensive periods on coal gas. In addition, the plant demonstrated that low emissions are possible with an IGCC plant due to the purification process of the coal gas. Moreover, the plant achieved higher performance levels than the conventional steam turbine. The program proved that with an optimized IGCC plant, it is possible to achieve efficiencies of 40 to 42 percent as compared to traditional coal-fired steam plant efficiencies of 36 to 38 percent [3.42].

The other IGCC demonstration plant had been erected in Buggenum in Holland in 1993 to demonstrate the technology at a larger scale. With a power output of 250 megawatts, the Buggenum plant was able to achieve a cycle efficiency of 43 percent. This plant further validated that an open-cycle gas turbine may be operated on coal gas with relatively low emissions [3.42].

The recent development and installation of a limited number of coal-fired combined cycle demonstration plants is primarily due to uncertainty in future price of natural gas and heating fuel. These programs have demonstrated that a large-scale (over 100 megawatts) open gas turbine may be operated efficiently on coal. Moreover, these demonstration programs substantiated that gas turbine operation on coal may be accomplished with low emissions. The relative cost and availability of coal and premium fuels will govern the type of fuel utilized in future power plants. In the case natural gas or distillate fuel prices become excessive, large-scale coal-fired combined cycles could be widely implemented. 


\subsection{Biomass-Fired Open-Cycle Gas Turbines}

Within the previous decade, an increased number of development programs of biomass fuelled open-cycle gas turbine engines have been initiated. The majority of these programs are concentrated in Northern Europe, which is a result of the European Union mandate for increased power generation from renewable resources. These programs are based on the technology developed for coal utilization as a result of the potential for high cycle efficiencies. Therefore, these open-cycle gas turbines typically employ an indirectly-fired heat exchanger or an IGCC. The indirectly-fired heat exchanger burns biomass in a separate gas stream, whereas the IGCC extracts the hydrocarbons from the fossil-fuel feedstock to generate a relatively clean, low heating value gas. Several current programs have successfully adapted these technologies to relatively large biomass-fuelled plants (few megawatts).

Although operation of biomass fuel in an IGCC plant has been successfully accomplished in a larger sized plant (few megawatts) [3.43], application of this technology to DG sized gas turbines is unlikely due to the large size requirement and high capital cost of the biomass-gasifier. Application of an indirectly-fired heat exchanger (HITAF) to an open-cycle gas turbine is comparable to a CBC engine. However, in a large-scale gas turbine the pressure level is considerably higher than in a small-scale recuperated gas turbine. Low-pressure levels in a small-scale gas turbine would result in uneconomic size of the indirectly-fired heat exchanger. Due to the relatively high capital cost, it is unlikely that a biomass-fired open-cycle gas turbine would be economic in a DG power range. 


\subsection{Literature Survey Conclusions}

The CBC engine has been successfully employed in numerous application areas utilizing a variety of heat sources. Long-term operation utilizing coal, coke-oven gas, and oil has been demonstrated in medium-scale combined heat and power plants. Operation with nuclear and solar power has been demonstrated in land and space environments. Moreover, the $\mathrm{CBC}$ engine has been considered for underwater and naval applications, and prototype models have demonstrated efficient operation.

The reviewed literature indicates that the $\mathrm{CBC}$ engine is flexible in application areas and power generation levels. This is not the case for open-cycle gas turbines, which are economic for large-scale power generation levels. Previous development programs have proven that the $\mathrm{CBC}$ engine may be successfully developed for power levels ranging from few kilowatts to 50 megawatts. Successful long-term operation of medium-sized power plants indicates that the CBC engine may be fuelled by a relatively low-quality fuel source. Recent development of an indirectly-fired gas turbine also indicates that a Brayton cycle may be fuelled by a relatively low-quality fuel source. In conclusion, the $\mathrm{CBC}$ engine has proven to be a viable prime mover for power generation. The system is especially suitable to niche market applications due to higher initial cost imparted by the high temperature heat exchanger. Niche market areas that utilize lowquality, low-cost fuel sources are especially suitable for application of the $\mathrm{CBC}$ engine technology. 


\section{CHAPTER 4}

\section{CBC Engine Potential Niche Market and Preliminary Market} Application Area

\subsection{Preliminary Market Application Area}

\subsubsection{Introduction}

The CBC engine has a strong market potential for utilizing waste oils and biomass fuels for remote on-site power generation and space heating/cooling and may provide a potential economic gain not available with current technology. There are 300 remote communities in Canada with a total population exceeding 200,000, which are not connected to an electrical grid or a piped natural gas network [4.1]. Many of these communities utilize diesel engines for electrical power generation, which operate on isolated grids. These communities are highly dependant on imported fuel, with a price strongly linked to transportation costs. As an example, a community located near Yellowknife (Wha Ti), which has a population of about 485 people requires 887,000 litres of diesel fuel annually. With a price of about one dollar per litre, the total price to 
the community for heat and power, including transportation costs, is in excess of $\$ 1$ million annually [4.2]. Moreover, diesel generators produce large quantities of waste oils, which are costly to dispose. Many of these communities have access to good renewable energy resources (including cooking and waste oils and biomass in southern areas), which has the potential for a sustainable, more cost-effective option for isolated power generation and space heating [4.1]. The CBC engine is a strong candidate for application in remote communities due to the ability to use biomass and waste oils for power generation and space heating applications.

\subsubsection{Potential Benefits Offered by the CBC Engine}

Canada's Northern Communities may benefit the most from the development of the $\mathrm{CBC}$ engine technology since the disposal of waste oils and other waste hydrocarbons (that are not contaminated with hazardous compounds) requires costly shipping to southern disposal sites. This is especially the case for Northern remote communities that are only accessible by air. Diluting waste oil with diesel fuel to ensure low emissions should provide an effective means of utilizing the potential energy in this highly ecologically sensitive climate. Once established, the technology may be subsequently adapted to biomass fuels, which also has a market potential in the Northern Communities, as well as southerly areas such as remote logging communities and waste disposal facilities. Other benefits of utilizing a CBC engine in Northern Communities include:

- The CBC engine concept has the potential to provide outstanding reliability with very low maintenance costs. Transporting heavier diesel engines and their component parts to the North results in higher costs than would be the case for a CBC engine. The costs of maintaining the large diesel engines in the North is also very high as maintenance personnel are often flown in from the South. The long travel time and frequent delays due to winter weather conditions significantly add to the maintenance expenses. 
- There is a higher seasonal requirement for waste heat in the North than there is in the South. The high cost of fuels in the North and colder temperatures for longer period make the utilization of waste heat even more attractive than in southern Canada. The cleaner combustion process of the CBC engine makes it easier, less costly, and less bulky to utilize engine waste heat. Other applications may allow waste heat to provide energy to an absorption refrigeration unit during warmer months, offering the possibility to utilize waste heat for a higher percentage of time during the year.

- The compact size of CBC engines implies that smaller facilities can be utilized. Smaller facilities utilize less heat in the winter and lower cooling in the summer. Initial building capital costs and building maintenance cost would generally be lower for smaller buildings. Additionally, the large diesel engines require costly, special low-frequency vibration isolation. The CBC engine, unlike the diesel, requires only minimal high-frequency vibration isolation. In many communities, the low-frequency vibrations from the diesel engines are very difficult to damp out due to the ease of transmission through the permafrost. The higher frequency vibrations for the $\mathrm{CBC}$ engines can be damped out cost-effectively relative to the large diesel application. Therefore, the $\mathrm{CBC}$ engine may be installed within a building envelope whereas the diesel engine has to be installed at a distant location from the community.

- Presently, large diesel engines used for electric power generation in Canada's North use a fuel that is essentially an aviation gas turbine fuel. This fuel is considerably more expensive than would be necessary for $\mathrm{CBC}$ engines. The only other fuel available in most Northern communities is gasoline. In the short term, a mixture of diesel fuel with waste oils with the required pour and cloud point characteristics could be used in CBC engines at a lower cost. 
In summary, there are a number of sound reasons for considering $\mathrm{CBC}$ engines for northern electric power generation. The potential market area could displace a significant quantity of fuel, consumed by the North, with an associated reduction in $\mathrm{CO}_{2}$ production and the exhaust emissions of unburned hydrocarbons, oxides of nitrogen, and carbon monoxide. It is proposed that a $\mathrm{CBC}$ engine be developed for northern electric power generation. Canada's Northern Communities that have larger buildings, such as community centres, hotels, and numerous row-house developments are especially a viable market potential due to a large space-heating requirement. There are 36 remote communities just in Nunavut and Nunavik, most of which are only accessible by air or barge [4.1]. Numerous other northern remote communities exist in the North West Territories and Yukon, however, the possibility of expanding the electrical grid or expanding the Mackenzie Delta Natural Gas Pipeline may lead to competition from utility companies or the microturbine industry. However, these communities do not have a means for disposal of waste oils. By providing a means of waste oil disposal, the CBC engine should also be competitive in these regions. Due to sufficient population, and accessibility by air or barge transportation that will ensure prompt delivery and service, it is estimated that thirty Northern communities can benefit from the CBC waste oil unit.

\subsubsection{CBC Engine Sales Forecast}

The overall goal of initiating the CBC waste oil unit is to lower the cost of CBC engine technology and increase the overall efficiency to a competitive level with microturbine engines, which should ensure competitiveness of a biomass $\mathrm{CBC}$ unit. With expected sales of thirty $25 \mathrm{~kW}$ units over a six year period, it is expected that the cost of electricity generation will be lowered from an estimated $\$ 2000$ per kilowatt to $\$ 2500$ per kilowatt for the first three prototype units to $\$ 800$ per kilowatt for the last eight units. Since the fuel prices are highly dependant on the mode of transportation, the first group of prototype units would be marketed for remote communities that are accessible only by air. The fuel prices in these regions are at least twice the amount paid in communities accessible by barge, and up to ten times the fuel prices in southerly areas [4.1]. 
Therefore, the potential fuel cost savings of the first units should outweigh the higher capital cost.

During the final phase of implementing the CBC waste oil unit, it is expected that CBC engine technology would be competitive with microturbines. At this point, the proposed $R \& D$ program to develop a biomass CBC unit would be completed, and the CBC biomass unit would be market ready. At this time, it is expected that biomass CBC units would be introduced to southerly areas. The ten-year sales projection of the waste oil and biomass CBC engines is depicted in Table 4.1, with estimated total sales of 42

Table 4.1 Ten-Year Sales Projection of CBC Engines

\begin{tabular}{|c|c|c|c|c|c|}
\hline Year & $\begin{array}{c}\text { Waste Oil } \\
\text { Units } \\
\text { Implemented }\end{array}$ & $\begin{array}{c}\text { Biomass } \\
\text { Units } \\
\text { Implemented }\end{array}$ & $\begin{array}{c}\text { Cost } \\
(\$ / k W h r)\end{array}$ & $\begin{array}{c}\text { Yearly Sales } \\
\text { (\$) }\end{array}$ & $\begin{array}{c}\text { Running } \\
\text { Total Sales } \\
\text { (\$) }\end{array}$ \\
\hline 2004 & 0 & 0 & - & 0 & 0 \\
\hline 2005 & 0 & 0 & - & 0 & 0 \\
\hline 2006 & 0 & 0 & - & 0 & 0 \\
\hline 2007 & 1 & 0 & 2,500 & 62,500 & 62,500 \\
\hline 2008 & 2 & 0 & 2,000 & 100,000 & 162,500 \\
\hline 2009 & 2 & 0 & 1,500 & 75,000 & 237,500 \\
\hline 2010 & 3 & 0 & 1000 & 75,000 & 312,500 \\
\hline 2011 & 6 & 0 & 900 & 135,000 & 447,500 \\
\hline 2012 & 8 & 2 & 850 & 212,500 & 660,000 \\
\hline 2013 & 8 & 10 & 800 & 360,000 & $1,020,000$ \\
\hline $\begin{array}{l}\text { Total Ten } \\
\text { Year Sales } \\
\text { Projection }\end{array}$ & 30 & 12 & & $1,020,000$ & $\$ 1,020,000$ \\
\hline
\end{tabular}


units and a total revenue of $\$ 1,020,000$ over the same six-year period. Revenues from these units will have to be reinvested in order to facilitate quicker, more cost-effective production of efficient biomass fuel utilization CBC units.

It should be noted that the technology demonstration CBC engine will generate 20 $\mathrm{kW}$ of electricity. This power output has been selected since lower initial funding is required for development of the generator and therefore, the development of the technology demonstration engine that will be used to attract private investment. However, the market-ready CBC engine is planned to generate $25 \mathrm{~kW}$, and the sales projection is based on this power output.

\subsubsection{Potential Energy Savings}

The utilization of waste oils for the purpose of power generation and space heating has the potential to conserve a significant amount of energy. The CBC engine can utilize waste oils by combining them with diesel fuel. A conservative estimate of combining 20 percent waste oil with diesel fuel for the continuous $\mathrm{CBC}$ engine operation throughout the year has the potential to save $790 \mathrm{GJ}$ of energy per engine per year. This estimate has been derived by calculating the energy required to continuously operate a production model CBC engine capable of producing $25 \mathrm{~kW}$ at a thermal to electrical conversion efficiency of 25 percent, and assuming 20 percent of the fuel is from waste oil. It is estimated that most of Canada's Northern Communities do not produce these large amounts of waste oil. In this case, the CBC engine may substantiate the role of consuming all non-hazardous waste oil.

The primary source of waste oil in northern communities is from diesel engine power generation stations and transportation vehicles. An average-sized northern community may generate $3 \mathrm{MW}$ of electricity, utilizing a large diesel engine. These large diesel engines require approximately 300 gallons of lubricating oil, which requires change every 1500 hours. A conservative estimate of the yearly production of waste 
lubricating oil per power generating engine is $5970 \mathrm{~kg}$. It should be noted that larger communities, such as Iqualuit, have four diesel engines: one for continuous power generation, one for peak loading, and two for standby. Smaller communities require smaller generators, and inevitably generate less oil. For an order of magnitude, conservative potential energy savings estimate, it is approximated that $5970 \mathrm{~kg}$ of waste oil is generated by power generation stations in each of the twenty communities with regular air service in Nunavut, Nunavik, and Northern Labrador. The CBC engine may therefore potentially consume $250 \mathrm{GJ}$ of waste oil per year from the power generation sector (typical lubrication oil has a calorific value of $42 \mathrm{MJ} / \mathrm{kg}$ ). This corresponds to 220 GJ of electrical and heating energy savings per community per year due to utilization of waste oil in CBC engine instead of incineration of the waste fuel.

Significant quantity of waste oil may be extracted from vehicles. The Motor Vehicle Division of the Department of Community Government and Transportation has been contacted to determine the amount of registered vehicles in Nunavut. From the registered vehicle count, the amount of waste oil generated has been estimated. It is expected that each vehicle requires four oil changes per year, and it has been assumed that motorcycles and ATVs require $2 \mathrm{~L}$ of oil, cars require $4.5 \mathrm{~L}$ of oil, and trucks require $8 \mathrm{~L}$ of oil per oil change. It is expected that a portion of oil is burned off, and ATVs and motorcycles generate $1.5 \mathrm{~L}$ of waste oil, cars generate $4 \mathrm{~L}$ of waste oil, and trucks generate $7 \mathrm{~L}$ of waste oil per oil change. The amount of waste oil generated by vehicles operating in Nunavut has been estimated to be $77,520 \mathrm{~kg}$. Since it is expected that the CBC engine will be implemented into larger communities, an estimate on the amount of waste oil generated by these communities has been performed on a per capita basis. There are 11 communities in Nunavut with a population over 900 people. The numerous communities with a smaller population are not accounted since it is unlikely that a CBC engine will be purchased by these communities. It has been estimated that each of the 11 communities generates $5067 \mathrm{~kg}$ of waste oil per community per year (please see the detailed potential energy savings calculations attached in Appendix A). It has been estimated that the CBC 
engine may potentially consume an additional $190 \mathrm{GJ}$ per community per year of waste oil generated by vehicles in Nunavut.

It is expected that communities in Nunavik and Northern Labrador would have a similar vehicle count, and therefore similar potential energy savings per community are expected. There are five communities with sufficient population in Nunavik, and four in Northern Labrador. Therefore, twenty CBC engines may be initially implemented in this region. Northwest Territories (GNWT) and Yukon are other potential regions for initial $\mathrm{CBC}$ engine implementation. There are at least 7 communities with a population exceeding 900 in GNWT and at least three in Yukon. These regions, however, are expected to have a greater number of vehicles owing to greater quantity and quality of roads. For this reason, the amount of waste oil generated by vehicles in GNWT and Yukon is calculated separately. The quantity of vehicles registered in GNWT has been obtained, and the amount of waste oil generated by these vehicles has been calculated (please see the detailed potential energy savings calculations attached in Appendix A). It has been estimated that $429,000 \mathrm{~kg}$ of waste oil is generated by vehicles in GNWT. This corresponds to an estimated $47,200 \mathrm{~kg}$ of waste oil generated per community per year in GNWT, which translates to 1980 GJ waste oil energy savings per community per year.

Moreover, the communities in GNWT and Yukon are larger in terms of population, resulting in larger power requirement per community. As a result, it is expected that these communities will generate a larger amount of waste oil from the power generation sector as compared to communities in Nunavut, Nunavik, and Northern Labrador. The general assumptions of the median engine size, quantity of waste oil generated by the engine, and the replacement interval have been used as in the communities in Nunavut. However, the quantity of waste oil generated by the communities in GNWT and Yukon from the power generation sector has been corrected for population (please see the detailed potential energy savings calculations attached in 
Appendix A). The amount of energy saving from power generation in GNWT and Yukon has been estimated at $330 \mathrm{GJ}$ per community per year.

The total energy savings of the waste oil CBC engine from power generation and transportation is $410 \mathrm{GJ}$ per community per year for the first 20 units implemented (into Nunavut, Nunavik, and Northern Labrador), and 2090 GJ for the later 10 units implemented (into GNWT and Yukon). It should be noted that several sources of waste oil have not been included in the above estimate. Waste oil generated by aircraft, inboard boats, and mining operations has not been considered due to difficulties in assessment. Also, additional sources of waste oil that are not categorized in the transportation sector, such as cooking oil, have not been included. In addition, energy savings would be imparted from a lower fuel demand for power generation as a result of utilizing waste oil obtained from vehicles. Therefore, the above estimate should be considered conservative.

Utilization of a biomass CBC engine has a greater potential of energy savings. The use of a renewable energy source for a reasonably efficient $25 \mathrm{~kW} \mathrm{CBC}$ engine has a potential of displacing $790 \mathrm{GJ}$ per engine per year of diesel of electrical power generated from a renewable fuel. The implementation of waste heat recovery for space heating/cooling has the potential to displace another $1000 \mathrm{GJ}$ per engine per year of heating fuel. The net energy savings offered by a biomass CBC engine is $1790 \mathrm{GJ}$ per engine per year. The above values have been calculated by estimating the amount of energy necessary to utilize a $25 \mathrm{~kW}$ diesel engine, with a typical efficiency of 40 percent and a conservative efficiency of waste heat extraction of 85 percent, accounted for continuous use over a year. 
As compounded in Table 4.2, the CBC technology may offer a cumulative 79,250 GJ of energy savings over the ten-year implementation period. This large potential energy savings is partly due to the possibility of a CBC engine operating for 100,000 hours (11 years).

Table 4.2 Ten Year Energy Savings Estimate offered by the CBC engine

\begin{tabular}{|c|c|c|c|c|c|c|c|}
\hline Year & $\begin{array}{c}\text { Waste Oil } \\
\text { Units } \\
\text { Implemented }\end{array}$ & $\begin{array}{c}\text { Biomass } \\
\text { Units } \\
\text { Implemented }\end{array}$ & $\begin{array}{c}\text { Total } \\
\text { Waste } \\
\text { Oil } \\
\text { Units }\end{array}$ & $\begin{array}{c}\text { Total } \\
\text { Biomass } \\
\text { Units }\end{array}$ & $\begin{array}{c}\text { Waste Oil } \\
\text { Unit } \\
\text { Energy } \\
\text { Savings } \\
\text { (GJ/year) }\end{array}$ & $\begin{array}{c}\text { Biomass } \\
\text { Units } \\
\text { Energy } \\
\text { Savings } \\
\text { (GJ/year }\end{array}$ & $\begin{array}{c}\text { Total } \\
\text { Energy } \\
\text { Savings } \\
\text { (GJ) }\end{array}$ \\
\hline 2004 & 0 & 0 & 0 & 0 & 0 & 0 & 0 \\
\hline 2005 & 0 & 0 & 0 & 0 & 0 & 0 & 0 \\
\hline 2006 & 0 & 0 & 0 & 0 & 0 & 0 & 0 \\
\hline 2007 & 1 & 0 & 1 & 0 & 410 & 0 & 410 \\
\hline 2008 & 2 & 0 & 3 & 0 & 1230 & 0 & 1640 \\
\hline 2009 & 2 & 0 & 5 & 0 & 2050 & 0 & 3690 \\
\hline 2010 & 3 & 0 & 8 & 0 & 3280 & 0 & 6970 \\
\hline 2011 & 6 & 0 & 14 & 0 & 5740 & 0 & 12,710 \\
\hline 2012 & 8 & 2 & 22 & 2 & 12,380 & 3580 & 28,670 \\
\hline 2013 & 8 & 10 & 30 & 12 & 29,100 & 21,480 & 79,250 \\
\hline
\end{tabular}




\subsubsection{Carbon Dioxide Emissions Savings}

Since shipping costs are prohibitive, the waste oil generated by northern communities is typically stored in barrels or incinerated. Storage of oil may cause leakage, which is harmful to the highly ecologically-sensitive northern environment and may be avoided by the utilization of a CBC engine with co-generation. Space heating with waste oil may reduce $\mathrm{CO}_{2}$ emissions by an estimated 21 tonnes per engine per year for units implemented in Nunavut, Nunavik, and Northern Labrador (initial 20 units), and 104 tonnes for units sold to GNWT and Yukon (later 10 units). This estimate is derived from the predicted energy savings offered by utilizing waste oil (described in Appendix A) and by considering that waste oil is typically incinerated. Moreover, electricity generation should reduce the load on large diesel engines, and therefore, reduce $\mathrm{CO}_{2}$ emissions by 104 tonnes per year, as estimated by utilizing the conversion factor of 0.43 $\mathrm{kg}$ of $\mathrm{CO}_{2} / \mathrm{kWhr}$ [4.3]. The total potential reduction of emissions by one waste oil CBC engine may be as much as 125 tonnes of $\mathrm{CO}_{2}$ per year for the initial 20 units and 213 tonnes for the later 10 units (please see detailed emissions savings calculations attached in Appendix A).

A $25 \mathrm{~kW}$ biomass $\mathrm{CBC}$ engine has the potential to reduce 104 tonnes of $\mathrm{CO}_{2}$ per engine per year for electricity generation (same as waste oil $\mathrm{CBC}$ unit). An additional emissions reduction of 82 tonnes of $\mathrm{CO}_{2}$ per engine per year may be accounted since biomass would be used for space heating, consequently displacing the $1000 \mathrm{GJ}$ of energy utilized for space heating. Therefore, one biomass $\mathrm{CBC}$ engine has the potential to displace 186 tonnes of $\mathrm{CO}_{2}$ per year. This large energy savings is a result of utilizing a renewable energy source, where the $\mathrm{CO}_{2}$ production of burning biomass fuels is recycled into plant growth. 
By compounding the reduction of $\mathrm{CO}_{2}$ emissions with the implementation schedule (over six years with a relatively low number of $\mathrm{CBC}$ engines), it is estimated that 14,035 tonnes of $\mathrm{CO}_{2}$ emissions may be reduced through the successful development of CBC technology (see Table 4.3). More substantial savings would be achieved as greater numbers of $\mathrm{CBC}$ engines are utilized.

Table 4.3 Ten-Year $\mathrm{CO}_{2}$ Emission Reduction Estimate

\begin{tabular}{|c|c|c|c|c|c|c|c|}
\hline Year & $\begin{array}{l}\text { Waste Oil } \\
\text { Units } \\
\text { Implemented }\end{array}$ & $\begin{array}{c}\text { Biomass } \\
\text { Units } \\
\text { Implemented }\end{array}$ & $\begin{array}{c}\text { Total } \\
\text { Waste } \\
\text { Oil } \\
\text { Units }\end{array}$ & $\begin{array}{c}\text { Total } \\
\text { Biomass } \\
\text { Units }\end{array}$ & $\begin{array}{c}\text { Waste Oil Unit } \\
\mathrm{CO}_{2} \\
\text { Emission } \\
\text { Reduction } \\
\text { (tonne/yr) }\end{array}$ & $\begin{array}{c}\text { Biomass Unit } \\
\mathrm{CO}_{2} \\
\text { Emission } \\
\text { Reduction } \\
\text { (tonne/yr) }\end{array}$ & $\begin{array}{c}\text { Total } \\
\mathrm{CO}_{2} \\
\text { Emission } \\
\text { Reduction } \\
\text { (tonne) }\end{array}$ \\
\hline 2004 & 0 & 0 & 0 & 0 & 0 & 0 & 0 \\
\hline 2005 & 0 & 0 & 0 & 0 & 0 & 0 & 0 \\
\hline 2006 & 0 & 0 & 0 & 0 & 0 & 0 & 0 \\
\hline 2007 & 1 & 0 & 1 & 0 & 125 & 0 & 125 \\
\hline 2008 & 2 & 0 & 3 & 0 & 375 & 0 & 500 \\
\hline 2009 & 2 & 0 & 5 & 0 & 625 & 0 & 1125 \\
\hline 2010 & 3 & 0 & 8 & 0 & 1000 & 0 & 2125 \\
\hline 2011 & 6 & 0 & 14 & 0 & 1750 & 0 & 3875 \\
\hline 2012 & 8 & 2 & 22 & 2 & 2926 & 372 & 7173 \\
\hline 2013 & 8 & 10 & 30 & 12 & 4630 & 2232 & 14,035 \\
\hline \multicolumn{3}{|c|}{$\begin{array}{c}\text { Total } \\
\mathrm{CO}_{2} \text { Emission Reduction } \\
\text { (tonne) }\end{array}$} & & & & & 14,035 \\
\hline
\end{tabular}




\subsection{Cost Benefit Considerations}

The CBC engine technology presents not only an energy efficient, environmentally attractive possibility, but also a possibility of being economically viable. A proposed first installation is a hotel in Iqualuit, where space heating may be adapted. Electricity produced by the CBC engine that is not used may be sold to the grid for profit. This is a highly economical option considering that commercial electricity prices on Baffin Island are between $\$ 0.295$ per $\mathrm{kWhr}$ and $\$ 0.546$ per $\mathrm{kWh}$, as compared to $\$ 0.047$ per $\mathrm{kWhr}$ in Ontario [4.1]. A $25 \mathrm{~kW} \mathrm{CBC}$ engine operating 24 hours a day throughout the year has the potential to provide more than $\$ 65,000$ per year worth of electricity (in the following analysis the lower rate has been used to ensure a conservative estimate). In addition, typical bulk diesel oil prices to utilities in the Baffin Islands are in the range of $\$ 0.40$ per litre to $\$ 0.74$ per litre. Utilization of the $5800 \mathrm{~kg}(6000 \mathrm{~L})$ of waste oil (see Section 4.1.4) is likely to save more than $\$ 2500$ per year from the displacement of the diesel fuel. Also, it is estimated that 50 percent of the cost of fuel is due to shipping, which corresponds to a potential savings of $\$ 1200$ per year in shipping waste oil to Southern disposal sites. Moreover, a waste heat recovery system with a conservative efficiency of 60 percent employed at the hotel has the potential to save more than $\$ 1400$ yearly from the utilization of waste oil. This is due to the retail heating oil prices on Baffin Island of $\$ 0.40$ per litre to $\$ 0.65$ per litre.

The cumulative potential yearly savings offered by the CBC engine is more than $\$ 65,000$. This corresponds to the possibility of a payback period of less than two years. The cost of fuel necessary to operate the CBC engine has not been included in the analysis, however, this fuel would be necessary for space heating. It should be noted that the fuel and electricity prices that have been gathered from the RETScreen database [4.1] may be dated. However, the price of oil in the world market has increased drastically, which consequently impacted electricity prices. Therefore, the quantified potential savings offered by the CBC engine should be treated as a very conservative estimate. 


\subsection{CBC Potential for Biomass Fuel Utilization}

The overall goal of developing the CBC engine is to apply the technology to biomass fuels. The development of the technology can therefore lower dependence on fossil fuels in Canada and in Canadian remote communities. Canadian remote communities can especially benefit from the utilization of biomass fuels since there is great potential to lower their dependence on southerly areas, lower the electricity production costs by reducing the price of fuel, produce smaller quantity of waste oils, and provide a sustainable energy source. There are numerous remote communities with adequate forestation to provide the necessary biomass fuel. British Columbia, for example, has over 40 remote communities with over 100 tonnes per hectare of available forest biomass [4.1]. Moreover, there are numerous logging camps, which are not considered remote communities due to a permanent residency requirement, that may benefit from biomass $\mathrm{CBC}$ engines by utilizing the onsite fuel available. With the technology established for waste fuel disposal, the CBC engine may be highly competitive with other technologies since the capital cost would be sufficiently reduced. Southerly areas may find it beneficial to utilize CBC engines for biomass fuels, especially for flaring methane, which is a natural by-product of landfills and sewage treatment. Methane may be collected and burned, potentially being a free energy source that would be otherwise wasted.

Adaptation of a biomass $\mathrm{CBC}$ engine unit will lead to carbon dioxide emissions reductions with a sustainable energy source. If biomass is renewed through sustainable reforestation or agricultural production, then the carbon dioxide produced during combustion is recycled into plant growth. Also, the energy produced with utilization of a CBC engine in landfills and sewage treatment would result in fuel savings in power plants, which would result in $\mathrm{CO}_{2}$ emissions reductions. 
Technologically, adaptation of a biomass gas burning CBC engine unit from a waste oil burning unit would result in modification of only the external combustor and the fuel flow control systems. This modification is a very cost-effective method of adapting different fuel sources since the remaining components do not need to be modified. Adaptation of a wood-chip biomass burning CBC unit from a waste oil burning unit would require a more elaborate method of feeding wood chips into the combustor, and adaptation of the controls system, but no modifications would be required to the remaining components.

\subsection{CBC Market Study Conclusions}

A significant initial market for the CBC engine is offered by Canada's Northern communities, where electricity prices are costly. A market study has concluded that a $\mathrm{CBC}$ engine installed in a large building such as a community centre or a hotel has the yearly savings potential of more than $\$ 65,000$. The high savings potential is partly due to the wide availability of waste fuels that are costly to dispose of. It has been estimated that thirty communities are of sufficient population in order to greatly benefit from the use of the CBC engine for waste oil disposal. It is also expected that a biomass CBC engine could be developed within the next ten years, and initial biomass units could be implemented in remote communities. The estimated sales from these communities may account for an estimated $\$ 1,020,000$ in revenues. The use of a CBC engine should lead to lower consumption of heating fuels, which would result in an energy savings potential of $96,950 \mathrm{GJ}$ over a six-year period. The energy savings potential would translate into $\mathrm{CO}_{2}$ emissions reduction potential of 9195 tonnes of over a six-year period. Moreover, in the longer term the utilization of biomass fuels in $\mathrm{CBC}$ engines would create a renewable energy source that has potential to substantially increase energy savings and emissions reductions. Due to a substantial economic impact, energy efficiency, and beneficial 
environmental impact, Canada's Northern communities provide a viable potential initial market for the $\mathrm{CBC}$ engine.

As a response to the positive market analysis, a technology demonstration $\mathrm{CBC}$ engine is being developed. The ensuing chapters of this thesis detail the developmental process. The following chapter relates to gas turbine thermodynamic calculations, as this is the initial design stage. 


\section{CHAPTER 5}

\section{Closed Brayton Cycle Design Performance Calculation Theory}

\subsection{Introduction}

Design point cycle-performance calculations comprise the initial stage of the design process of a gas turbine engine. These calculations are necessary to determine the design-point operating conditions and component performance requirements to meet the overall engine performance objectives. Moreover, cycle calculations are used to predict cycle efficiencies, estimate fuel schedules, and size components. Operating temperatures and pressures throughout the engine are determined from cycle calculations, which govern mechanical design choices. Also, the mass flow rate required to achieve the desired power output is determined from cycle calculations. The thermodynamic theory required to accurately predict gas turbine performance is described in this chapter. Based on this theory, a cycle-performance program has been written in order to choose designpoint operating parameters. The design-point pressure ratio, turbine inlet temperature, and mass flow rate is chosen based on the quantitative analyses of performance. These results are used to size the turbomachinery and heat exchanger components. 


\subsection{Simplifying Assumptions}

CBC performance is evaluated by developing a real cycle thermodynamic model. A real cycle model differs from an ideal model by accounting for all component losses (efficiency and pressure) and variations in working fluid properties. Several assumptions are required to simplify the $\mathrm{CBC}$ performance model, ensure consistency and accurate prediction.

- The working fluids have been treated as an ideal gas.

- The performance code has been programmed with varying working gas properties. The gas properties have been calculated based on the upstream temperature of the respective component. Based on kinetic theory, monatomic gasses such as helium, argon, and xenon, are assumed to have constant gas properties at the range of operational temperature [5.2].

- The effect of working gas on turbomachinery performance has been neglected. It is known, however, that the turbomachinery performance is a function of four variables: the non-dimensional wheel speed function, the mass flow function, the Reynolds number, and the specific heat ratio. Although accounting for the variation in performance with varying working gas specific heat ratio is possible, as per Reference [5.1], it is expected that performance variation of the compressor and the turbine will be opposite. The net effect on the overall performance is expected to be small, and therefore, the effect of working gas on turbomachinery performance is neglected.

- The amount of mass flow rate required for a specified work output is a function of turbine inlet temperature (TIT), compressor pressure ratio (CPR), and overall efficiency. For a given gas turbine size, the pressure losses generated by the 
components vary with the mass flow rate due to a change in velocity (pressure losses are a function of velocity squared). Therefore, for off-design performance prediction, the variation in pressure losses due to mass flow rate variation on the high-pressure side is modeled as a percentage of compressor outlet pressure. On the low-pressure side, pressure losses are assumed constant to obtain a conservative off-design performance prediction.

- Ducting components will be insulated and therefore are assumed adiabatic.

- The variation in kinetic energy in the inlet and outlet of components is accounted by utilizing stagnation temperatures and pressures.

\subsection{Gas Properties}

\subsubsection{Gas Constant}

The gas constant for a specific gas is given by:

$$
R=\frac{\bar{R}}{M}
$$

where $\bar{R}$ is the universal gas constant and $M$ is the gas molecular weight. Molecular weight of gasses that are considered for application in a CBC engine can be found in Appendix B.

\subsubsection{Specific Heat at Constant Pressure}

For an ideal gas, specific heat is a function of temperature alone. The specific heat increases with temperature for all common gasses except for monatomic gasses. The specific heat of monatomic gasses is nearly constant at the value predicted by kinetic theory [5.2]: 


$$
\bar{C} p_{M}=\frac{5}{2} \bar{R}
$$

Other gasses are modelled using fifth order polynomial curve fit developed by Turns [5.3]. The correlation for specific heat of gasses in molar basis is provided in Equation 5.3 and the coefficients for air, carbon dioxide, and nitrogen are provided in Appendix B. Alternatively, the specific heat may be found in tabular form in numerous references, including [5.4].

$$
\frac{\overline{C p}}{\bar{R}}=\left(a_{o}+a_{1} T+a_{2} T^{2}+a_{3} T^{3}+a_{4} T^{4}\right)
$$

In mass form the specific heat is expressed as:

$$
C p=\frac{\overline{C_{p}}}{M}
$$

\subsubsection{Specific Heat Ratio}

For an ideal gas, the specific heat ratio varies only with temperature and is defined as:

$$
\gamma=\frac{C p(T)}{C v(T)}
$$

The expression more commonly used for performance calculations is expressed in terms of the gas constant, $R$ :

$$
\frac{\gamma-1}{\gamma}=\frac{R}{C p(T)}
$$




\subsubsection{Enthalpy}

Enthalpy rise or drop through a component may be expressed as a product of specific heat and temperature difference. Alternatively, it is more convenient and accurate to evaluate enthalpy rise or drop directly. Enthalpy difference as a function of temperature is expressed as:

$$
h_{a}\left(T_{2}\right)-h_{a}\left(T_{1}\right)=\frac{R_{o}}{M} *\left[\begin{array}{l}
a_{0}\left(T_{2}-T_{1}\right)+\frac{a_{1}}{2}\left(T_{2}-T_{1}\right)^{2}+\frac{a_{2}}{3}\left(T_{2}-T_{1}\right)^{3}+ \\
\frac{a_{3}}{4}\left(T_{2}-T_{1}\right)^{4}+\frac{a_{4}}{5}\left(T_{2}-T_{1}\right)^{5}+C H
\end{array}\right]
$$

The coefficients for air, carbon dioxide, and nitrogen coincide with the coefficients applied for calculating the specific heat. These coefficients are provided in Appendix B. Enthalpy expressions for other gasses may be found in Turns [5.3].

\subsubsection{Other Gas Properties}

Other gas properties have been obtained from literature tables. One effective resource for obtaining thermal conductivity and viscosity of selected gasses and gas mixtures is Reference [5.5] and [5.6] respectively.

\subsection{Component Efficiencies and Performance}

Analysis of individual components yields the temperature and pressure levels throughout the cycle, which is necessary to determine the overall cycle performance. Component arrangement and corresponding numerical nomenclature is depicted in the CBC schematic diagram, Figure 5.1. This nomenclature is utilized for variables such as temperatures and pressures throughout the cycle. Analysis of gas turbine components, which is described in the following sections, is predominantly based on Reference [5.7]. 


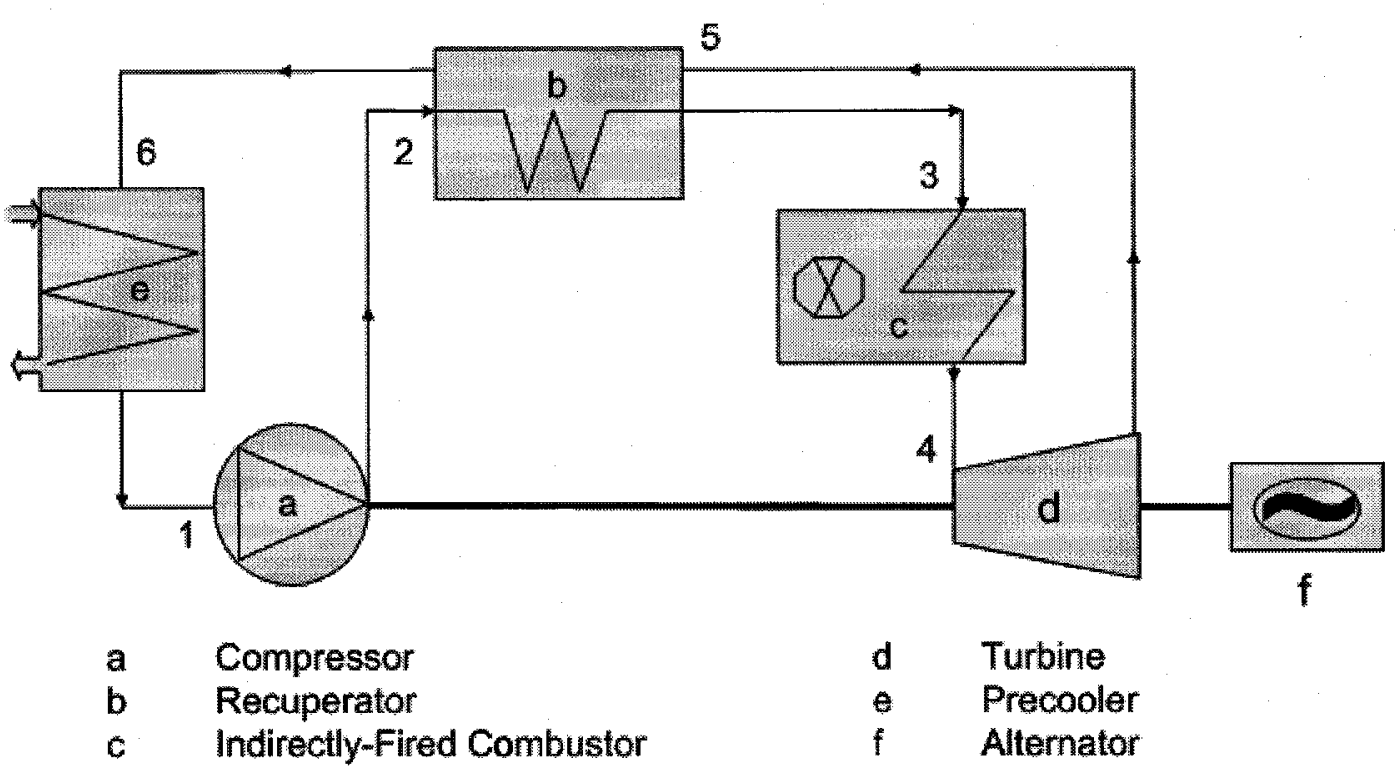

Figure 5.1: Component Nomenclature

\subsubsection{Compressor}

An ideal compressor is adiabatic and reversible, hence isentropic. The compressor isentropic efficiency, $\eta_{c}$, is expressed as a ratio of ideal (isentropic) work, $W_{c}^{\prime}$, to the actual work, $W_{c}$, performed on the working gas. The work may be expressed in terms of the enthalpy rise, which is exclusively a function of temperature rise for an ideal gas. Stagnation enthalpy, $h_{0}$, is used to account for the change of kinetic energy between the inlet and outlet.

$$
\eta_{c}=\frac{W_{c}^{\prime}}{W_{c}}=\frac{\Delta h_{0}^{\prime}}{\Delta h_{0}}
$$

The stagnation enthalpy variation is a product of specific heat and temperature difference due to compression. The specific heat will vary minimally between the difference in actual and ideal total temperature. As a result, the specific heat between actual and ideal conditions may be assumed equal, and the isentropic efficiency is found by the following equation: 


$$
\eta_{c}=\frac{T_{02}^{\prime}-T_{01}}{T_{02}-T_{01}}
$$

The temperature rise across the compressor is of interest since it directly relates the amount of work performed on the working gas. In order to obtain the compressor outlet temperature, it is necessary to estimate the compressor efficiency or obtain the information from a compressor map. Rearranging Equation 5.8, the temperature gain may be found:

$$
T_{02}-T_{01}=\frac{1}{\eta_{c}}\left(T_{02}^{\prime}-T_{01}\right)=\frac{T_{01}}{\eta_{c}}\left(\frac{T_{02}^{\prime}}{T_{01}}-1\right)
$$

An ideal gas isentropic relation may be used to express the temperature difference as a function of pressure:

$$
\frac{T_{02}}{T_{01}}=\left(\frac{P_{02}}{P_{01}}\right)^{\frac{\gamma-1}{\gamma}}
$$

Substituting Equation 5.10 into Equation 5.9, the temperature difference may be expressed as a function of compressor pressure ratio, $P_{02} / P_{01}$, compressor isentropic efficiency, $\eta_{c}$, and inlet temperature, $T_{01}[5.7]$.

$$
T_{02}-T_{01}=\frac{T_{01}}{\eta_{c}}\left[\left(\frac{P_{02}}{P_{01}}\right)^{\frac{\gamma-1}{\gamma}}-1\right]
$$

\subsubsection{Turbine}

Turbine performance calculations are conducted in a similar manner as compressor performance calculations. However, since the turbine extracts power from the working fluid, the turbine isentropic efficiency is defined inversely as the compressor isentropic efficiency. The turbine isentropic efficiency is defined as the ratio of actual work extracted, $W_{t}$, to the ideal work extracted, $W^{\prime}{ }_{t}$. 


$$
\eta_{t}=\frac{W_{t}}{W_{t}^{\prime}}=\frac{\Delta h_{0}}{\Delta h_{0}^{\prime}}
$$

The turbine isentropic efficiency may be expressed in terms of the turbine inlet temperature (TIT), $T_{04}$, and the turbine outlet temperature (TOT), $T_{05}$. As in the compressor analysis (Equation 5.8), the variation of the specific heat between actual and ideal conditions is small enough to neglect, and the turbine isentropic efficiency is related in terms of temperature.

$$
\eta_{t}=\frac{T_{04}-T_{05}}{T_{04}-T_{05}^{\prime}}
$$

Rearranging Equation 5.13 and utilizing Equation 5.10 in a similar manner as for the compressor, the actual temperature drop in the turbine is calculated. The turbine isentropic efficiency is typically found in a turbine performance map.

$$
T_{04}-T_{05}=\eta_{t} T_{04}\left[1-\left(\frac{1}{P_{04} / P_{05}}\right)^{\frac{\gamma-1}{\gamma}}\right]
$$

Turbine inlet and outlet pressures are found by accounting the pressure losses in the heat exchangers and ducts. For this calculation, it is necessary to choose the compressor pressure ratio and the compressor inlet pressure. These design parameters are selected in Sections 6.4 and 6.5.

$$
\begin{aligned}
& P_{04}=\left(P_{02} / P_{01}\right) * P_{01}-\Delta P_{R_{-} C S}-\Delta P_{H}-\Delta P_{D} \\
& P_{05}=P_{01}+\Delta P_{C S H X}+\Delta P_{R_{-} H S}+\Delta P_{D}
\end{aligned}
$$




\subsubsection{Heat Exchanger}

In gas turbine applications, the heat exchanger is typically placed downstream of the compressor for the purpose of preheating the gas prior to entering the combustor. With the gas being preheated by turbine exhaust, a considerable amount of energy, and thus fuel, can be saved. Although numerous forms of heat exchangers are available for gas turbine applications, all types of heat exchangers may be evaluated equivalently in gas turbine performance calculations. A common method of expressing the heat transfer performance level is by introducing the term effectiveness. The recuperator effectiveness, $\varepsilon_{R}$, is the ratio of the actual amount of energy transferred to the cold stream to the maximum amount of energy possible for heat transfer [5.7]. The difference in specific heat is also neglected in this case due to the small effect.

$$
\varepsilon_{R}=\frac{h_{03}-h_{02}}{h_{05}-h_{02}}
$$

Specification of heat exchanger effectiveness enables calculation of heat exchanger outlet enthalpy. Through iteration of the enthalpy equation, Equation 5.6, the cold-side heat exchanger outlet temperature, $\mathrm{T}_{03}$ can be found. The heat exchanger outlet temperature may be considered equivalent to the combustor inlet temperature, since all ducting components are assumed adiabatic. Knowledge of the combustor inlet temperature is essential in determination of the heat input quantity.

\subsubsection{Indirectly-Fired Combustor}

The CBC engine employs an indirectly-fired combustor that can be analysed as a heat exchanger in conjunction with a heat source. The overall heat rise is analysed in terms of the temperature rise through the combustor. Combustor inlet temperature is determined from analysis in Section 5.4.3 and the combustor outlet temperature (also referred to as the TIT) is typically pre-determined by metallurgical considerations or chosen. The working gas heat gain, $q$, is readily calculated by using Equation 5.17. 


$$
q=h_{0}\left(T_{04}\right)-h_{0}\left(T_{03}\right)
$$

As neither the combustion or heat-transfer process is ideal, the heat-transfer loss is accounted for by introducing the hot-side heat exchanger effectiveness, $\varepsilon_{H}$, which is defined by Equation 5.18. The actual heat input is expressed as $q_{r e q}$ :

$$
\mathcal{E}_{H}=\frac{q}{q_{r e q}}
$$

\subsubsection{Cold-Side Heat Exchanger}

The cold-side heat exchanger (CSHE) may be analysed as per Section 5.4.3. Enthalpy (or heat) gained by the secondary (cooling) fluid, $q_{\text {avail }}$, is the product of the heat drop of the primary working gas and the cold-side heat exchanger effectiveness, $\varepsilon_{C S H E}$. The heat gain by the secondary working fluid, $q_{\text {avail }}$, is the amount of heat that is available for space heating. Preliminary design does not involve selection of the working fluid. Therefore, the mass flow rate and the temperature gain of the "cooling" fluid are not determined in initial calculations that are used for design-point selection. For relative cycle comparison, only the heat available for space heating or cooling is calculated.

$$
q_{\text {avail }}=\varepsilon_{\text {CSHE }}\left[h_{0}\left(T_{06}\right)-h_{0}\left(T_{01}\right)\right]
$$




\subsection{Overall Cycle Performance}

\subsubsection{Work Output}

The work output is expressed as the difference in the amount of work generated by the turbine(s) and the work required by the compressor. The amount of work generated by the turbine and the amount of work required by the compressor is expressed in Equation 5.20 and 5.21 respectively. Accurate performance calculations require consideration of the mechanical losses in power transmission to the compressor, which includes losses due to bearing windage. Accountability of mechanical losses is achieved by introducing the mechanical efficiency term, $\eta_{m}$. The specific shaft power output generated, which is the ratio of shaft power output to the mass flow rate is expressed in Equation 5.22.

$$
\begin{aligned}
& w_{t}=h_{0}\left(T_{04}\right)-h_{0}\left(T_{05}\right) \\
& w_{c}=h_{0}\left(T_{02}\right)-h_{0}\left(T_{01}\right) \\
& w_{s h}=w_{t}-\frac{w_{c}}{\eta_{m}}
\end{aligned}
$$

The mechanical (shaft) to electrical power conversion has an associated loss due, to among other effects, heat generated by resistance in stator windings. Introducing the electrical conversion efficiency, $\eta_{g e n}$, an expression for the electrical power output is developed.

$$
w_{e}=\eta_{g e n} w_{s h}
$$

Engine design specifications will dictate the shaft power output requirement, $W_{s h}$, or the electrical power output requirement, $W_{e}$. The generated specific power output will govern the working fluid mass flow rate requirement.

$$
m=\frac{W_{s h}}{w_{s h}}=\frac{W_{e}}{w_{e}}
$$




\subsubsection{Cycle Performance}

Gas turbine mechanical cycle efficiency is defined as a ratio of the specific power output to the specific heat input. The electrical power conversion efficiency is defined similarly, as the ratio of specific electric power output to specific heat input.

$$
\begin{gathered}
\eta_{s h}=\frac{w_{s h}}{q_{r e q}} \\
\eta_{e}=\frac{w_{e}}{q_{r e q}}
\end{gathered}
$$

Overall cycle efficiency includes electrical power and heating power available for utilization from the energy supplied by fuel (based on the calorific value).

$$
\eta_{C H P}=\frac{w_{e}+q_{\text {avail }}}{q_{\text {req }}}
$$

Another measure of gas turbine performance is the Specific Fuel Consumption (SFC). The SFC is a ratio of fuel consumption to power generation measured in $\mathrm{kg}$ fuel per kilowatt-hour.

$$
S F C=\frac{m_{f}}{W_{s h}}=\frac{m_{f}}{m^{*} w_{s h}}
$$

\subsection{Cycle Configuration Alternatives}

The above sections describe the theory used to account for the performance losses of various components in a simple CBC. Such accountability of component performance losses yields to accurate overall performance prediction. Although the above theory is directed towards a simple CBC arrangement, it may be used for variations of the cycle arrangement. One cycle alternative may be the utilization of two turbines: a gas generator turbine and a power turbine. In this case, the theory presented in Section 5.4.2 
is directly applied for each turbine. At steady state, the high pressure (H.P.) turbine power output must be matched to the compressor to prevent acceleration or deceleration of the turbomachinery (see Equation 5.29). With the power output, and hence temperature difference known, Equation 5.14 is used to find the pressure drop across the H.P. turbine. Since the total pressure drop across the turbines is the product of the pressure drop of each turbine, the expansion ratio of the power turbine is directly evaluated using Equation 5.30. The pressure drop across the power turbine is used to find the power output as defined in Section 5.4.3. Bearing windage losses and other mechanical losses in the power turbine are accounted by including the mechanical efficiency. The power turbine specific power output is found in Equation 5.31. Other cycle configuration alternatives that may be potentially applied in a $\mathrm{CBC}$ engine, including addition of an intercooler and reheat combustor, may be analysed according to the theory presented in Section 5.4.

$$
\begin{aligned}
& w_{H P}=\frac{w_{c}}{\eta_{m}} \\
& P R=\Delta P_{H P} * \Delta P_{L P} \\
& w_{N e t}=\eta_{m} w_{L P}=\eta_{m} C p\left(T_{04 b}-T_{05}\right)
\end{aligned}
$$

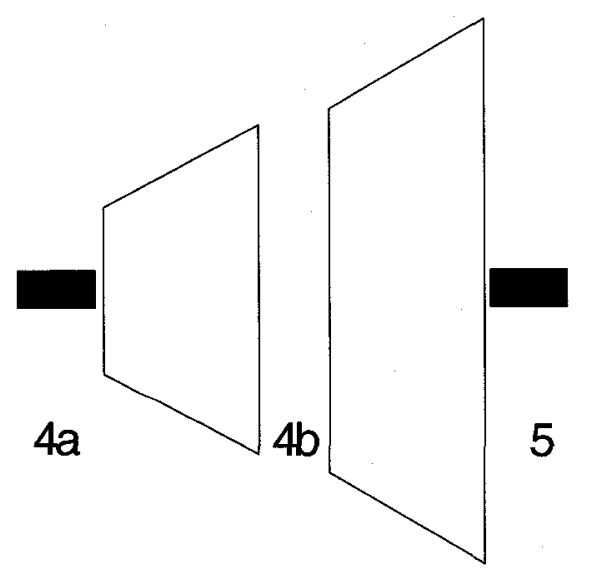

Figure 5.2: Power Turbine Arrangement and Nomenclature 


\subsection{Summary}

The theory presented in this chapter is applied to determine the design-point operating conditions and the overall performance of the $\mathrm{CBC}$ engine. Cycle operating conditions include: the working fluid mass flow rate, temperatures throughout the cycle, and the pressure levels throughout the cycle. Parametric analysis of operating conditions (such as cycle temperatures and pressures) and component performance values provides insight on the effect on the cycle performance. Moreover, accurate prediction of operating conditions is required to perform turbomachinery sizing, heat exchanger sizing, ducting sizing, etc. Performance calculations also present a means of examining the performance benefit of alternate cycle configurations, which can be evaluated based on cost and benefit analysis. Furthermore, accurate prediction of these parameters is critical in achieving a mechanical design with high mechanical integrity. 


\section{CHAPTER 6}

\section{Analysis and Selection of Design-Point Operating Conditions}

\subsection{Introduction}

$\mathrm{CBC}$ configuration and operating conditions are determined through a parametric prediction on the effect on cycle performance. Several operating parameters are chosen in order to predict the cycle performance and provide sufficient information to size the required turbomachinery. The operating parameters that are selected by performing a parametric analysis include the turbine inlet temperature (TIT), the compressor pressure ratio (CPR), compressor inlet pressure (CIP) and temperature (CIT). Moreover, the effect of working fluid on the CBC performance and mechanical design has been investigated and the working fluid has been selected. A quantitative analysis on cycle configuration, including a comparison between the open and closed cycle on performance has been conducted. Typical component performance parameters, as observed in literature, were used initially with the exception of recuperator effectiveness value. A low initial recuperator effectiveness values was used since it is expected that a low-cost recuperator would be used for the technology demonstration engine. The effect of 
component performance values on cycle performance is investigated, and general performance guidelines are formed. The component efficiencies that have used in initial calculations are summarised below. Unless otherwise specified, the following values were used:

Compressor Isentropic Efficiency $\quad 78 \%$

H.P. Turbine Isentropic Efficiency $\quad 74 \%$

L.P. Turbine Isentropic Efficiency $\quad 78 \%$

Recuperator Effectiveness $\quad 70 \%$

Hot-Side Heat Exchanger Effectiveness $\quad 90 \%$

Cold-Side Heat Exchanger Effectiveness $\quad 87 \%$

Mechanical Transmission Efficiency $\quad 98 \%$

(Accessories not included)

Electrical Conversion Efficiency $\quad 98 \%$

Pressure Losses:

Recuperator, Cold Side

$3 \%$ CDP

Hot-Side Heat Exchanger

$3 \% \mathrm{CDP}$

Recuperator, Hot Side $\quad 0.03$ bar

Cold-Side Heat Exchanger $\quad 0.03 \mathrm{bar}$

Compressor Inlet Pressure $1 \mathrm{~atm}$

Compressor Inlet Temperature 273K

Turbine Inlet Temperature $\quad 1100 \mathrm{~K}$

Work Output $20 \mathrm{~kW}$

Fuel Natural Gas 


\subsection{Closed-Cycle Working Fluid Design Choice}

\subsubsection{Effect of Working Fluid on CBC Performance}

The CBC engine has the inherent additional flexibility of being able to utilize diverse working gasses. From a thermodynamic standpoint, all permanent gasses may be utilized in a $\mathrm{CBC}$ engine since the critical temperature is above the operating temperature range. Practical considerations impose requirements in areas such as thermal stability, chemical inertness, non-flammability, and toxicity. From these practical considerations, only inorganic gases are applicable for $\mathrm{CBC}$ utilization. The gasses considered for the $\mathrm{CBC}$ engine are air, carbon dioxide, or monatomic gasses such as helium, argon, xenon, or a gas mixture. The choice of working gas is governed by size and cost, compatibility with off-the-shelf equipment, and performance level [6.1].

From a thermodynamic standpoint, the theoretical thermal efficiency should be identical for all perfect gasses if temperature levels remain constant and there are no pressure losses present in the system. The working gas independence of efficiency is exemplified in Equation 6.1, assuming the variation of specific heat with temperature is neglected and operational temperatures are identical.

$$
\eta=\frac{w_{s h}}{q_{r e q}}=\frac{C p\left(T_{04}-T_{05}\right)-C p\left(T_{02}-T_{01}\right)}{C p\left(T_{02}-T_{01}\right)}=\frac{\left(T_{04}-T_{05}\right)-\left(T_{02}-T_{01}\right)}{\left(T_{02}-T_{01}\right)}
$$

Actually, the choice of working fluid has several indirect effects on component and cycle performance. First, for a given pressure ratio, the working-fluid specific heat ratio will have a direct influence on the temperature gain or drop through the turbomachinery. This conclusion is based on Equation 6.2.

$$
\frac{T_{02}}{T_{01}}=\left(\frac{P_{02}}{P_{01}}\right)^{\frac{\gamma-1}{\gamma}}
$$


Since the compressor and turbine outlet temperatures vary with the choice of working fluid, it is expected that the temperatures throughout the cycle will be affected. Therefore, the variation in temperatures will have an effect on the $\mathrm{CBC}$ performance. The effect of working fluid selection on the CBC performance has been quantitatively studied with the analytical performance program (based on the theory presented in Chapter 5). Component performance levels and operating conditions used initially are described in the previous section. Initial study neglected pressure losses, and the subsequent study included the pressure losses. The free-turbine CBC configuration has been used for the study, since, as will be seen in the next section, this configuration has been chosen. The variation of component efficiencies and pressure losses with the working fluid selection has been neglected.

The effect of working fluid selection on the CBC efficiency as a function of compressor pressure ratio, found by neglecting the pressure losses described in Section 6.1, is shown in Figure 6.1. The results found by accounting the pressure losses described in Section 6.1 are shown in Figure 6.2. The two cases are included to separate the effects of working fluid properties from the effects of the pressure drop magnitude. The effect of working fluid selection on the CBC specific work output as a function of pressure ratio (including pressure losses) is shown in Figure 6.3. The figures show two effects: 1) efficiency and specific power output varies with the choice of working fluid, and 2) the pressure ratio corresponding to peak efficiency and peak specific power output varies with the choice of working fluid.

As seen in Figure 6.1, if pressure losses are neglected, gasses with higher specific heat ratio offer increased efficiencies. This increased efficiency is primarily due to the increased temperature gain in the compressor and increased temperature drop through the turbine. Therefore, for a given turbine inlet temperature, the higher compressor outlet temperature for gasses with higher specific heat corresponds to a relatively lower required heat gain. The lower heat gain, for a given power output, corresponds to a 
higher efficiency. The effect of specific heat ratio on cycle efficiency is substantiated by identical efficiency of helium and argon. These monatomic gasses have identical specific heat ratio, despite a significant variation of molar mass and other fluid properties including thermal conductivity, $k$, specific heat, $C p$, and gas constant, $R$. Monatomic gasses offer the highest cycle efficiency when pressure losses are neglected.

The difference in the compressor pressure ratio (CPR) corresponding to peak efficiency for various working gasses may be attributed to the difference of the workinggas specific heat ratio. Typically, recuperated gas turbines require operation at lower pressures (as compared to un-recuperated gas turbines) to restrict the compressor outlet temperature. Otherwise, heat is transferred from the high-pressure gas stream to the lowpressure gas stream, resulting in negative heat input by the recuperator. For the same reason, the optimum CPR is lower for gasses with higher specific heat ratio. The temperature rise has to be restricted for gasses with higher specific heat ratio to prevent negative heat transfer in the recuperator (heat transfer from high-pressure side to the low pressure side), and to obtain the maximum temperature rise through the recuperator. Therefore, the peak efficiency of monatomic gasses is at relatively lower compressor pressure ratios than for other gasses considered. For all working fluids, the CPR is limited by the excessive temperature drop through the turbine at high turbine pressure ratios. Low turbine outlet temperature restricts the quantity of waste heat available for preheating the compressor outlet gas. Therefore, low efficiencies are attributed to operation at high CPR. 


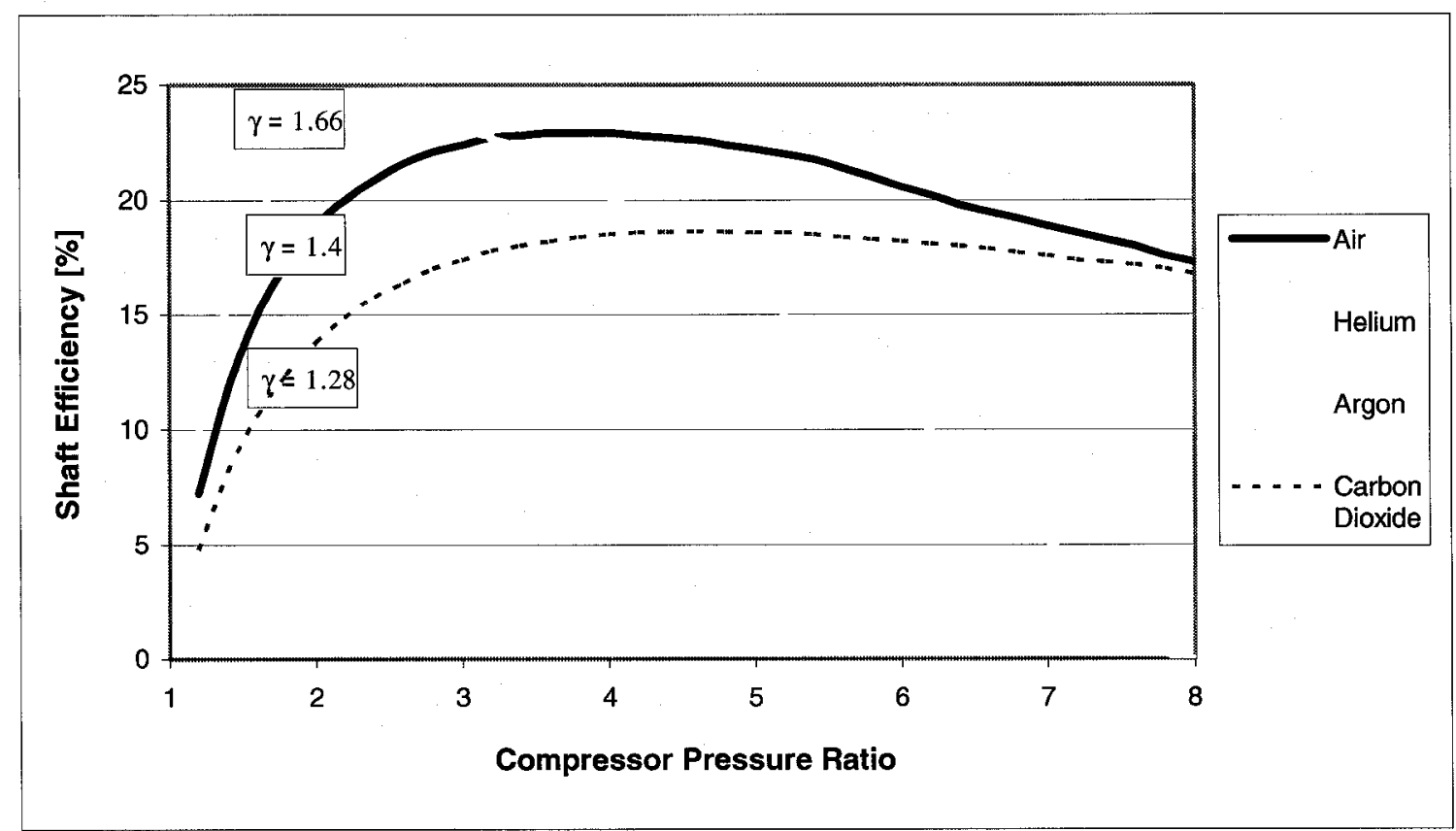

Figure 6.1: Effect of Working Fluid Type on CBC Efficiency for an Ideal Case where Pressure Losses are Neglected

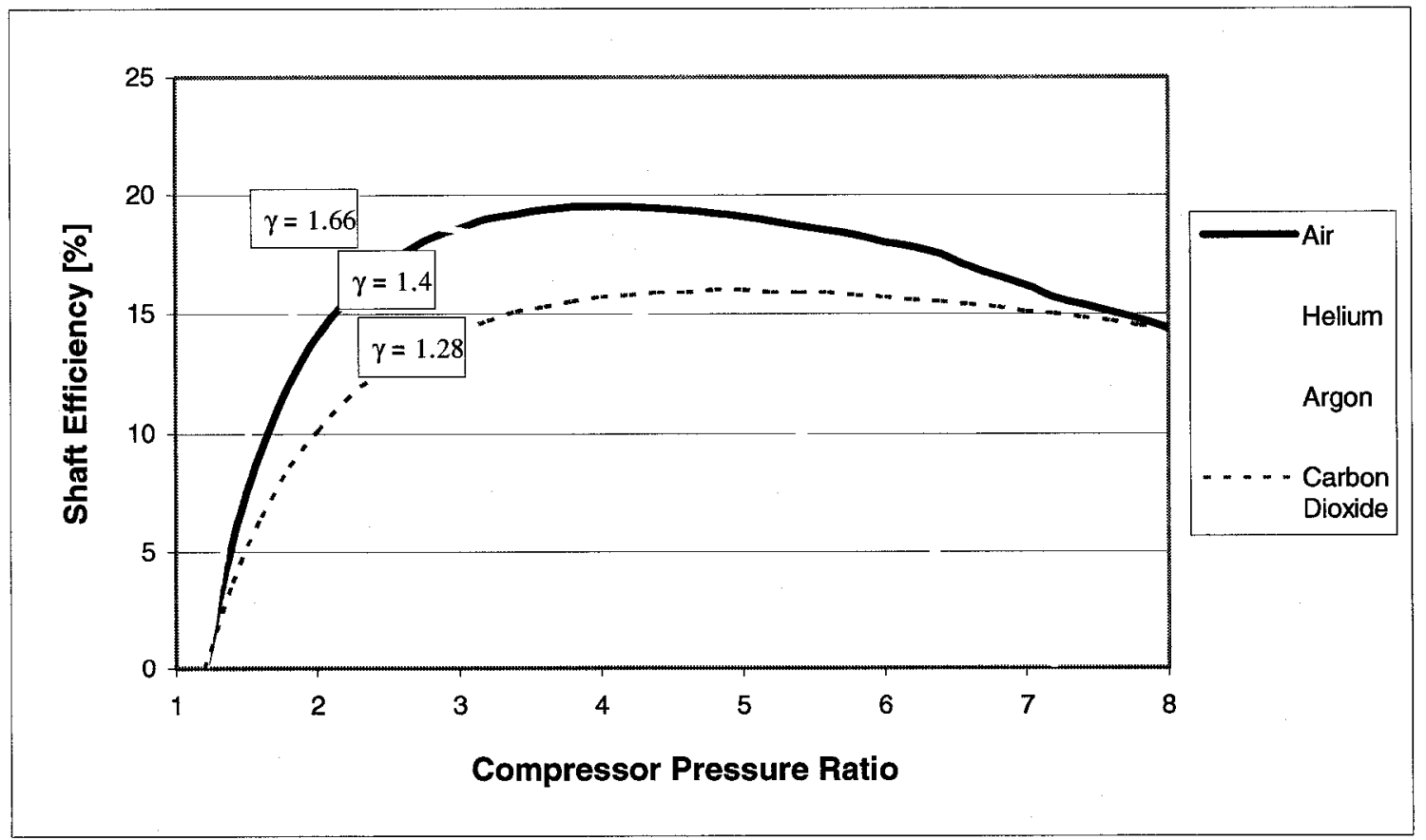

Figure 6.2: Effect of Working Fluid Type on CBC Efficiency for a Realistic Case where Pressure Losses are Accounted 
The optimum CPR for the working gasses analysed is of primary importance when considering the effect of working fluid on $\mathrm{CBC}$ efficiency when pressure losses are accounted. Pressure losses at the low-pressure side are relatively larger in magnitude (as compared to the total pressure) when operating at a low CPR. This is attributed to a greater performance loss of monatomic gasses as compared to other gasses. Table 6.1 depicts the loss in performance due to pressure losses calculated at the optimum pressure ratio for each gas. The comparatively larger loss in performance for monatomic gasses is attributed to air having highest potential efficiency of considered working gasses. The effect of working fluid on cycle efficiency, under the assumed pressure losses specified in Section 6.1, is seen in Figure 6.2. The potential efficiency levels of helium and argon are slightly lower than air. The peak efficiency level of carbon dioxide is significantly lower than other candidate working fluids. Therefore, from a peak efficiency standpoint, air and monatomic gasses are considered optimum working gasses.

The effect of working fluid on CBC specific work output is depicted in Figure 6.3. The variation in working-fluid specific work output is attributed to the magnitude of specific heat, $C p$. Since at steady state, the power output from the first turbine (gas generator) is matched with the compressor, the specific power output is the product of specific heat and temperature drop through the power turbine (second turbine).

$$
w_{s h}=C p *\left(T_{04 b}-T_{05}\right)
$$

The working fluid effect on temperature drop has been previously discussed. Monatomic gasses will have highest temperature drop due to highest specific heat ratio. However, the predominant term in this case is the specific heat. Since specific heat is directly proportional to specific power output, the gasses with highest specific heat will generate power at highest specific power output. Specific heat for all gasses considered is provided in Appendix B. 
Table 6.1: Efficiency Variation when Accounting for Pressure Losses

\begin{tabular}{|c|c|c|c|}
\hline Gas & $\begin{array}{c}\text { Specific Heat } \\
\text { Ratio } \\
\gamma\end{array}$ & $\begin{array}{c}\text { Optimum } \\
\text { CPR }\end{array}$ & $\begin{array}{c}\text { Efficiency Loss when } \\
\text { Accounting for } \\
\text { Pressure Losses }\end{array}$ \\
\hline Carbon Dioxide & 1.28 & 4.6 & $14.0 \%$ \\
\hline Air & 1.4 & 3.4 & $14.8 \%$ \\
\hline Argon & 1.66 & 2.6 & $20.8 \%$ \\
\hline Helium & 1.66 & 2.6 & $20.8 \%$ \\
\hline
\end{tabular}

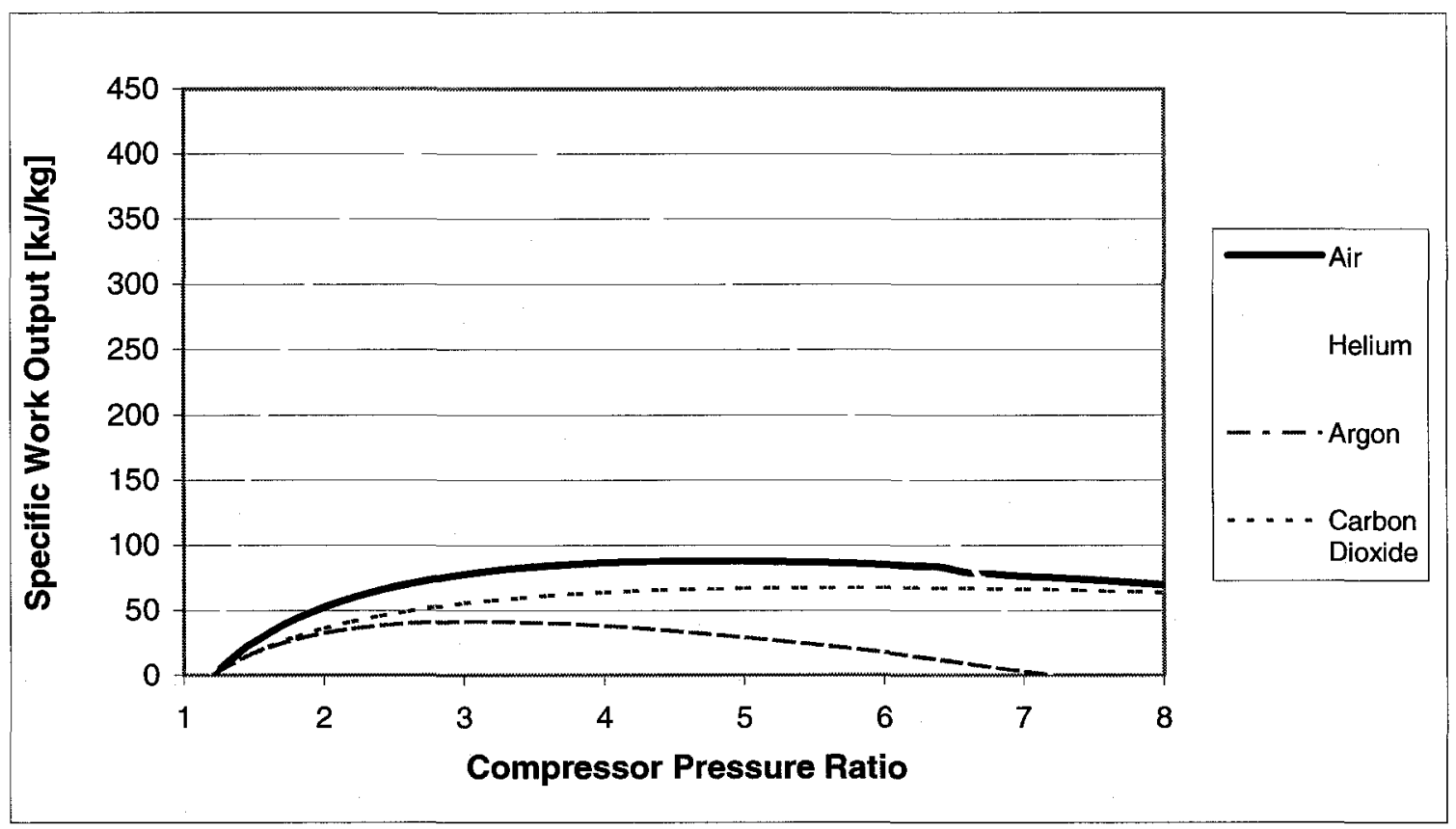

Figure 6.3: Effect of Working Fluid on CBC Specific Power Output 


\subsubsection{Effect of Working Fluid on CBC Component Performance}

The choice of working fluid has a direct influence on the operation and design of all the components. First, for a given specific work output, $w$, the temperature rise in a compressor or drop in a turbine varies inversely with the specific heat (see Equation 6.4). Therefore, the temperature rise or drop with helium as a working fluid is one fifth that of air. Since the temperature rise or drop is proportional to the pressure ratio (see Equations 5.11 and 5.14), a lower temperature rise or drop with helium as a working fluid will result in a lower pressure ratio through the turbomachinery stage. Therefore, for a given pressure ratio requirement, the higher number of compressor and turbine stages is required when operating with gasses with a higher specific heat. Moreover, for a given temperature rise or drop requirement through the turbomachinery, the pressure ratio across the turbomachinery is lower for gasses with a higher specific heat ratio (see Equation 6.5). Therefore, for a given pressure ratio requirement, a larger number of compressor and turbine stages are required for gasses with a higher specific heat ratio [6.2].

$$
\begin{aligned}
& T_{02}-T_{01}=\frac{w}{C p} \\
& \frac{P_{02}}{P_{01}}=\left(\frac{T_{02}}{T_{01}}\right)^{\frac{\gamma}{\gamma-1}}
\end{aligned}
$$

Another contributing factor to the working gas variation with the number of turbomachinery stages required involves the work coefficient. The blade loading or work coefficient is defined as the enthalpy rise or drop across the turbomachine, $h_{0}$, to the square of the wheel speed, $U$ (see Equation 6.6). Operation with gasses with a high specific power output will require a high wheel speed to obtain the same work coefficient. For example, the turbomachinery with helium as a working gas will have to rotate roughly four times faster than air since the specific power output of helium is about 
four times the specific power output of air as the working fluid. Since this is typically not possible due to turbomachinery stress limitations, the required number of stages is larger.

$$
\psi=\frac{\Delta h_{0}}{U^{2}}
$$

Moreover, experiments have also shown that the choice of working fluid has an impact on turbomachinery performance. Studies have shown that even when the speed and flow function can be matched for the turbomachinery, the isentropic exponent, $\gamma$, has an impact on isentropic efficiency. It has been observed that the compressor isentropic peak efficiency is higher at lower isentropic exponent values [6.3]. As a result of the higher compressor isentropic efficiency, the compressor pressure ratio is higher for gasses with lower isentropic exponent. It is predicted that the opposite result occurs for turbines. Therefore, the net effect on cycle efficiency and power output should be small.

In addition, the turbomachinery design limitations are working gas dependant. Typically, small radial compressor and turbine designs are aerodynamically limited by the speed of sound since operation at supersonic speed results in high losses. This is the case for all gasses other than helium. Turbomachinery design for helium, and other gasses with a high speed of sound, is limited by the centrifugal stresses of the rotor. Therefore, small radial turbomachines designed for helium as a working fluid will have higher rotational speeds.

The choice of working gas has a significant effect on the heat exchangers in the CBC. The size, and therefore, cost of the heat exchangers is dependant on the heattransfer coefficient of the $\mathrm{CBC}$ working fluid and the allowable pressure drop across the heat exchangers. High heat-transfer rates are required to minimize the heat exchanger size. However, small heat exchanger size results in high velocities and pressure losses. Minimizing the pressure drop is critical to achieving high cycle efficiencies; however, minimizing the pressure drop for a given working fluid requires low fluid velocities that 
are possible with large-size and high-cost heat exchangers. Although these two requirements are conflicting, it is desirable to utilize a working fluid with high heat transfer and low friction characteristics.

The required surface area for unfired heat exchangers is almost directly proportional to the working fluid heat-transfer coefficient (see Equations 6.7 to 6.9). With fired heat exchangers, the combustion side exerts controlling factor on the surface area. Since combustion in a $\mathrm{CBC}$ engine occurs with air at atmospheric conditions, the required surface area for the hot-side heat exchanger is less strongly affected by the working fluid than the unfired heat exchangers. The effect of working gas selection on the unfired heat exchanger size is quantitatively analyzed. The analysis is conducted through a comparison of the effect of working fluid properties on the tube side heattransfer coefficient. Although a similar result is expected by comparing the heat-transfer coefficient on the shell side, the analysis has been conducted on the tube side since the expressions for pipe flow are readily available and do not require an intensive iterative analysis (such as the Bell-Delaware Method included in Chapter 8) [6.1].

The analysis is performed by introducing the heat transfer and pressure drop equations for pipe flow and simplifying them to determine the influential terms. First, the heat-transfer equation for a heat exchanger is introduced in Equation 6.7. The heat transfer rate is the product of the thermal conductance, $U A$, and the terminal temperature difference $\Delta T_{m}[6.4]$.

$$
Q=U A\left(\Delta T_{m}\right)
$$

The reciprocal of thermal conductance, $U A$, is the product of resistances due to fluid convection of the hot and cold-side fluid $R_{h}$ and $R_{c}$ respectively, thermal resistance due to fouling layer of the hot and cold side fluid $R_{f h}$ and $R_{f c}$, and the thermal resistance of the separating wall, $R_{w}$. The wall and fouling resistances will not vary with the working 
fluid selection. The only variables, that influence heat exchanger size, are the hot and cold side convection resistances that are defined in Equation 6.9a and 6.9b [6.4].

$$
\begin{gathered}
\frac{1}{U A}=R_{i}+R_{f i}+R_{w}+R_{f o}+R_{o} \\
R_{i}=\frac{1}{\left(\eta_{o} h A\right)_{i}} \\
R_{o}=\frac{1}{\left(\eta_{o} h A\right)_{o}}
\end{gathered}
$$

where $A$ is the heat exchanger surface area, $\eta_{o}$ is the overall surface effectiveness that is influenced by fin geometry and fin efficiency, and $h$ is the heat-transfer coefficient. The subscript $i$ refers to the inner tube and the subscript o refers to outer tube. The heattransfer coefficient is the only term that directly varies with the working fluid. The relationship between heat transfer and working fluid type is further analyzed. Assuming turbulent flow, the tube-side heat-transfer rate may be expressed by the following relation [6.4].

$$
N u=0.023 \operatorname{Re}^{0.8} \operatorname{Pr}^{1 / 3}
$$

Where the Nusselt number, $\mathrm{Nu}$, is defined as [6.4]:

$$
N u=\frac{h D_{e}}{k}
$$

The Reynolds number, $\mathrm{Re}$, is defined as [6.4]:

$$
\operatorname{Re}=\frac{G D_{e}}{\mu}=\frac{\rho V D_{e}}{\mu}
$$

And the Prandtl number, Pr, is defined as [6.4]:

$$
\operatorname{Pr}=\frac{C p \mu}{k}
$$


where

$D_{e} \quad=\quad$ Equivalent (or hydraulic) diameter $=4 *$ flow cross-sectional area/ wetted perimeter

$G \quad=\quad$ Mass flow velocity of the working fluid $=\rho * \mathrm{~V}$

$h=$ Heat transfer coefficient of the working fluid

$k=$ Thermal conductivity of the working fluid

$L=$ Length of tubes

$\mu \quad=\quad$ Viscosity of the working fluid

$\rho \quad=\quad$ Density of the working fluid

$\Delta P=$ Pressure drop across tubes

$V \quad=\quad$ Velocity of the working fluid

The pressure drop across the tubes in a turbulent flow is given by [6.4]:

$$
\Delta P=f \frac{L}{D_{e}} \rho \frac{V^{2}}{2 g_{c}}
$$

In the following analysis, the gravitational constant, $g_{c}$, is only utilized in British Units. The friction factor, $f$, for turbulent flow for smooth pipes is given by the Blasius empirical formula [6.4]:

$$
f=\frac{0.3164}{\operatorname{Re}^{0.25}}
$$

Combining Equations 6.12, 6.14 and 6.15 result in an expression for the pressure drop across the tube banks:

$$
\Delta P=0.3164 *\left(\frac{\mu}{G D_{e}}\right)^{0.25} *\left(\frac{L}{D_{e}}\right) *\left(\frac{G^{2}}{2 \rho g_{c}}\right)
$$


Combining Equation 6.10 and 6.16, along with non-dimensional parameter definitions, Equations 6.11 to 6.13 , results in the heat transfer equation [6.1]:

$$
h=0.0534 *\left(\frac{C p \mu}{k}\right)^{-0.667} *\left(\frac{\mu}{D_{e}}\right)^{0.086} *\left(\rho g_{c} \Delta P * \frac{D_{e}}{L}\right)^{0.457} * C p
$$

The substitution of the perfect gas equation $\rho=(P M) /\left(R_{0} T\right)$, where $R_{0}$ is the universal gas constant and $M$ is the molecular weight results in the final heat transfer equation [6.1].

$$
h=0.0534 *\left(\frac{C p \mu}{k}\right)^{-0.667} *(\mu)^{0.086} * D_{e}^{0.371} *\left(\frac{P^{2}}{R_{0} T} * \frac{\Delta P}{P^{*} L}\right)^{0.457} *(C p M)^{0.457} * C p^{0.543}
$$

The Prandtl number for selected pure and ideal gasses is provided in Appendix B, Table B.1. It may be seen that the variation of Prandtl number with the working gas is small and the effect on the heat transfer rate is insignificant. For pure gasses containing equal number of atoms, the molar specific heat $(C p M)$ is also approximately constant, and the viscosity of the working gas will have a negligible effect due to the small power coefficient. For a heat exchanger with constant value of hydraulic diameter, $D_{e}$, operating pressure, $P$, temperature, $T$, and pressure drop parameter per tube length, $\Delta \mathrm{P} / \mathrm{P}^{*} \mathrm{~L}$, the heat transfer rate of the working fluid will vary according to variation of specific heat $C p^{0.543}$ [6.1]. The foregoing analysis exemplifies that for a heat exchanger with the same heat transfer rate, $q$, and mean temperature, $T_{m}$, the heat exchanger surface area, $A$, is a function of only the specific heat.

$$
\begin{aligned}
& h \propto C p^{0.543} \\
& \frac{1}{U_{0}} \propto \frac{1}{h_{c}}+\frac{1}{h_{h}}
\end{aligned}
$$




$$
A \propto \frac{q}{\Delta T_{m}}\left(\frac{1}{h_{c}}+\frac{1}{h_{h}}\right)
$$

The expected relative heat exchanger surface area, based on the working fluid specific heat variation, is calculated and provided in Table 6.2. The heat exchanger surface area is normalized with respect to surface area with air as the working fluid. It may be seen that the expected surface area with helium as the working fluid is $40 \%$ of the surface area with air as the working fluid. Operation with other gasses will yield to larger heat exchanger size due to unfavourable specific heat values. In the foregoing analysis, the fouling and the wall resistance terms are neglected since these terms are expected to be an order of magnitude smaller than the convection resistance parameters. In addition, this analysis is simplified when compared to actual conditions since the geometry, tube length, and hydraulic diameter will vary with the working fluid selection. Moreover, the operating pressures and pressure losses may vary with working fluid choice. Therefore, this comparison should serve only as a guide. A more rigorous comparison would require an iterative approach between $\mathrm{CBC}$ performance and sizing of the heat exchangers.

Table 6.2: Relative Heat Exchanger Surface Area Comparison with Working Fluid Choice

\begin{tabular}{|c|c|c|}
\hline \multirow{2}{*}{ Gas } & Specific Heat, Cp & $\begin{array}{c}\text { Normalized Heat } \\
\text { Exchanger Surface } \\
{[\mathbf{k J} / \mathbf{k g} * \mathbf{K}]}\end{array}$ \\
Area \\
\hline Air & 1.005 & $100 \%$ \\
\hline Argon & 0.520 & $143 \%$ \\
\hline Carbon Dioxide & 0.846 & $110 \%$ \\
\hline Helium & 5.200 & $41 \%$ \\
\hline Nitrogen & 1.039 & $98 \%$ \\
\hline
\end{tabular}




\subsubsection{Material Compatibility}

Compatibility of the candidate working fluids with construction materials must be considered to ensure long-lasting CBC operation, especially in view of the high temperature environment. The corroding effect of the working fluids considered is minimal on ceramic materials such as silicon carbide ( $\mathrm{SiC}$ ) and silicon nitride ( $\mathrm{SiN}$ ). However, metals and alloys are susceptible to surface oxidation as well as grain or chemical structure changes that affect the mechanical properties of materials. The candidate working fluids considered are compatible with typical construction materials. In air, corrosion resistance is offered by creating a protective oxide layer on the metal surface. This protective oxide layer is formed through a chemical reaction between a metal such as chromium and air. Helium and other monatomic gasses have the inherent advantage of being inert toward metallic components. However, high-purity helium should be utilized to prevent carbide formation through impurity reaction with the metal. Carbon dioxide has an oxidizing effect on most metals since a protective oxide surface layer is formed with Iron-Nickel-Chromium alloys. However, carbon monoxide, which may be formed through impurity or metal reaction with carbon dioxide or dissociation of carbon dioxide, has a carburizing effect. Since the formation of carbon monoxide is inevitable, a small percentage of oxygen ( $1 \%$ by mole) should be included to ensure a protective oxidizing layer is formed [6.1]. In conclusion, material considerations impose no restrictions on the selection of working fluid considered for $\mathrm{CBC}$ application. However, in all cases, a high purity gas should be utilized, and a small percentage of oxygen should be implemented initially to enable the formation of a protective oxide surface layer.

\subsubsection{CBC Working Fluid Design Choice}

CBC operation with nitrogen, carbon dioxide, argon, and other high-molecular weight monatomic gasses is uncommon due to unfavourable performance characteristics. As depicted in Figures 6.2 and 6.3, operation with these gasses will result in lower CBC performance than operation with air. Moreover, the lower heat transfer coefficient will 
result in higher heat exchanger size and cost. With the exception of carbon dioxide, these gasses have not been commonly considered for CBC application.

Carbon dioxide has been considered a candidate working gas in $\mathrm{CBC}$ and semiclosed cycle engines owing to the relatively higher gas density and real gas effects. The relatively higher gas density has been considered an attractive working fluid characteristic due to the potential mass flow rate reduction that may lead to component size reduction. However, reduction of component sizes may also be accomplished with other working gasses through pressurization. The real-gas effects that are associated with carbon dioxide have the potential to increase the turbine work fraction relative to the required compressor work. This is a result of increased specific heat at high temperature and pressure levels. Therefore, operation with carbon dioxide as the working fluid has the potential to increase power output and cycle efficiency. However, studies have shown that the real gas effects in $\mathrm{CO}_{2}$ do not dramatically increase the thermal efficiency [6.5]. The calculated CBC performance, which does account for specific heat variation with temperature, is lower when compared to other gasses (refer to Section 6.2.1). In addition, peak performance is calculated at a higher pressure ratio, which would indicate that an increased number of stages would be required with the operation of carbon dioxide. Therefore, based on gas properties, carbon dioxide should not be considered a candidate working fluid.

Carbon dioxide has also been considered a potential working fluid since it may have a positive environmental impact [6.3]. The primary products of combusting hydrocarbons in air are $\mathrm{CO}_{2}$, water, and $\mathrm{NO}_{\mathrm{X}}$. By replacing air as a working gas with $\mathrm{CO}_{2}$, and injecting and mixing a stoichiometric fraction of pure oxygen with hydrocarbon fuel, it is possible to eliminate the smog-producing compound, $\mathrm{NO}_{\mathrm{X}}$, resulting in water and $\mathrm{CO}_{2}$ as the only products of combustion. The excess $\mathrm{CO}_{2}$ produced by combustion may be dried of water and stored for chemical processing, also eliminating direct greenhouse gas production. Although this configuration may be incorporated with the 
$\mathrm{CBC}$ engine, the additional cost and complexity of $\mathrm{CO}_{2}$ extraction is undesirable, as is the significant reduction of efficiency caused by the requirement to produce pure oxygen [6.6]. Considering that it is unlikely that a market for $\mathrm{CO}_{2}$ would exist in remote areas, it is undesirable to utilize $\mathrm{CO}_{2}$ for this $\mathrm{CBC}$ engine application.

Operation with helium as a working fluid is beneficial in terms of cycle performance and component size. However, as described in Section 6.2.2, operation with helium may require multiple turbomachinery stages. Although it is possible to develop a multi-stage $\mathrm{CBC}$ engine, an associated rise in capital cost and complexity is involved. In addition, since most of the turbomachinery is designed for operation with air, the turbomachinery performance with helium as the working fluid would be lower. Moreover, it is expected that the required turbomachinery size would be smaller when utilizing helium than other gasses due to the higher heat-transfer rate and low density of helium. Small-sized turbomachinery produce higher tip clearance losses since the relative magnitude of tip clearance is larger when compared to the blade height. Another factor to consider is that due to the low molecular weight of helium, high pressurization may be required to provide adequate heat-transfer characteristics. High pressurization would result in thick-walled heat exchanger size, thus reducing the capital cost advantage of the small-sized heat exchangers. These foreseen difficulties, along with foreseen potential sealing problems of low molecular-weight helium, make the utilization of helium undesirable. This is especially the case for CBC application in remote locations, where periodic recharging of helium would be costly due to high transportation fees.

Foreseen difficulties of implementing a low molecular-weight gas may be resolved by utilizing a gas mixture. Although the advantages associated with the gas properties of helium are reduced, it is possible to increase the molecular weight of the working gas and retain higher gas properties than available with the application of air. Helium-xenon and helium-argon mixtures are both considered since they are inert. The high molecular weight of xenon is beneficial since a lower molar fraction of xenon is 
required which results in gas-mixture properties closer to helium. However, due to the rarity of the gas, the cost of xenon is unattractively high. As a result, utilization of the helium-xenon mixture has been limited to space applications [6.7]. Argon, on the other hand, is considerably less costly and has been considered as a working gas for CBC engines in marine applications [6.8].

The specific heat and thermal conductivity of the helium-xenon and helium-argon mixtures as a function of molecular weight are provided in Appendix B, Figures B.1 and B. 2 respectively. The properties of these mixtures at the molecular weight of air are marked for direct comparison. At the molecular weight corresponding to that of air, the specific heat of the helium-argon mixture is about twice the specific heat of air and the specific heat of helium-xenon mixture is about four times the value for air. The thermal conductivity of helium-argon mixture and helium-xenon mixture, at the molecular weight of air, is respectively about 40 percent and 200 percent larger than the value for air. The relation of heat-transfer rate to specific heat (Equation 6.19), as derived in Section 6.2.2, does not apply for gas mixtures due to the synergetic effect of the Prandtl number that is present from non-linear variation of physical properties [6.1]. (The non-linearity of physical gas properties with mixture amount can be seen Appendix B, Figures B.1 to B.4). Therefore, the heat-transfer rate will not vary according to Equation 6.19 , as is the case for pure gasses. With a constant hydraulic diameter, operating pressure, temperature, pressure drop, and tube length, the heat transfer coefficient for gas mixtures will vary according to Equation 6.22 . This equation has been simplified by omitting the viscosity due the low power index. The relative heat exchanger surface area for gas mixtures may be estimated by inserting the heat transfer coefficient, $h$, into Equation 6.20 and 6.21 .

$$
h \propto\left(\frac{C p \mu}{k}\right)^{-0.667} *(C p M)^{0.457} * C p^{0.543}
$$


The relative required heat exchanger size, based on the gas-mixture selection, is estimated in Table 6.3. It should be noted that the foregoing analysis is an estimate since it is likely that the hydraulic diameter, tube length, and the pressure drop across the heat exchanger would vary with the working-fluid selection. Nevertheless, this analysis provides an order of magnitude estimate on the required heat exchanger size related to the choice of working gas mixture. It is predicted that utilization of a heliumargon and helium-xenon mixture will reduce the heat exchanger surface area by a factor of 0.75 and 0.37 respectively, as compared to utilizing air. This analysis predicts that the heat exchanger size would be lower when utilizing a helium-xenon mixture as compared to pure helium. Although this result is unlikely and stems from the simplifying assumptions, the analysis shows that the heat exchanger size is lower when utilizing a gas mixture as compared to air. Therefore, from a heat exchanger capital cost standpoint, the application of a helium gas mixture is beneficial.

Irrespective of the benefit in the heat-transfer rate and heat exchanger size, the application of helium-xenon gas mixture is too costly for a technology demonstration prototype. The application of a helium-argon mixture, on the other hand, may be feasible due to lower working-gas cost and lower heat exchanger size. However, mechanical design aspects must be considered when selecting the working fluid. One important aspect is sealing. It is unlikely that sealing in the bearings of the turbocharger would be 100 percent effective. Therefore, the selection of any alternative

Table 6.3: Heat Exchanger Surface Area Comparison of Gas Mixtures and Air

\begin{tabular}{|c|c|c|}
\hline Gas & $\begin{array}{c}\text { Molecular Weight } \\
{[\mathrm{kg} / \mathrm{kmol}]}\end{array}$ & $\begin{array}{c}\text { Relative Heat Exchanger } \\
\text { Surface Area }\end{array}$ \\
\hline Air & 28.97 & $100 \%$ \\
\hline Helium-Argon & 28.97 & $75 \%$ \\
\hline Helium-Xenon & 28.97 & $37 \%$ \\
\hline
\end{tabular}


working gas will require periodical recharging due to small unavoidable gas leakage. Recharging the working gas in remote areas would be inherently costly and undesirable. Moreover, throughout the development and testing phase, it is expected that numerous charges would be lost. In contrast, utilization of readily available air would not require periodical recharging. Although it is required to utilize dry air, this can be accomplished with desiccants. The reduced cost of utilizing air as a working gas may be significantly greater than the higher manufacturing costs of a larger heat exchanger. Since the CBC performance with air as the working fluid is relatively high and least costly, and the gas properties are acceptable, it is recommended to utilize air as the working fluid.

\subsection{CBC Performance Calculations}

\subsubsection{CBC Configuration}

The CBC configuration will have a governing effect on performance and acquisition cost. Several configurations are possible with the $\mathrm{CBC}$ engine that includes the simple cycle, free-turbine cycle, recuperated free-turbine cycle, and the reheat cycle. Intercooled cycles have not been considered since it is expected that a single-stage compressor would be implemented. These configurations are quantitatively analysed and compared in order to evaluate the potential performance benefit and determine whether an additional cost of a more complex cycle is justified.

An analytical evaluation of several CBC arrangements has been conducted with the assumed component efficiencies and cycle operating conditions specified in Section 6.1. In the case of the simple and the regenerative-simple cycle, where a single turbine is utilized, the assumed turbine isentropic efficiency utilized in the calculations corresponds to the H.P. turbine. The isentropic efficiency corresponding to the H.P. turbine is relatively lower as compared to the L.P. turbine. The lower isentropic efficiency is used for the single turbine arrangement since a higher turbine loading yields to operation at a 
decreased efficiency level. The performance results of several $\mathrm{CBC}$ arrangements are shown in Figures 6.4 and 6.5. The lowest performance is offered by the simple cycle. This coincides with the efficiency level of non-recuperated microturbines currently available (see discussion in Section 2.2.4.1) where the maximum efficiency is about 15 percent [6.9].

In the case where compressor pressure ratios are low, higher cycle efficiencies may only be obtained through implementation of a recuperator. The recuperator transfers waste heat extracted from the turbine outlet gas and preheats the compressor outlet gas to reduce the amount of fuel required. The fuel requirement reduction yields a substantial net gain in cycle efficiency. For example, current recuperated microturbines offer thermal efficiencies ranging from 25 to 30 percent as compared to 15 percent for nonrecuperated microturbines [6.9]. Similarly, the implementation of a recuperator in a CBC engine has the potential to double the thermal efficiency (see Figure 6.4). The disadvantage of implementing a recuperator is that the power output may be reduced by as much as 10 percent [6.10]. The power reduction is a result of the increased pressure drop due to the frictional losses in the recuperator. Assuming the operating conditions described in Section 6.1, the specific power output loss, due recuperator implementation, has been calculated at 6\% (see Figure 6.5). Despite the reduced specific power output, the increase in thermal efficiency obtained from recuperator implementation is required to obtain competitive thermal efficiency levels. Therefore, implementation of a recuperator is recommended.

The design choice between simple regenerative cycle and the free-turbine regenerative cycle is considered. Thermodynamically, the two cycles offer similar performance levels. A slight gain in efficiency and specific power output are offered in the free-turbine arrangement since higher turbine isentropic efficiency is expected as a result of the load split between the gas generator turbine and the free turbine. For this reason, the relatively lightly loaded L.P. turbine has been modelled with a higher 
isentropic efficiency. The efficiency difference of about 10 percent (relative) and the specific power output of about 15 percent (relative) is predominantly a result of the above assumption. In general, the design choice between the simple regenerative cycle and free-turbine regenerative cycle is governed by gas turbine application.

The single-shaft arrangement is suitable for fixed speed and fixed load applications, such as base-load power. Applications where a variable-speed load is driven adhere to utilization of a free-turbine arrangement. Variation in application areas with arrangement type is primarily a result of the different control strategy utilized by the free-turbine arrangement as compared to the single-shaft arrangement. Although offdesign performance and associated control strategy will be discussed in the ensuing chapter, the different control strategy of the free-turbine arrangement offers higher partload turbomachinery performance as compared to the single-shaft arrangement in open Brayton cycle engines [6.10]. However, in CBC engines, the turbomachinery performance at part-load does not vary significantly. Therefore, the benefit of utilizing a free-turbine arrangement in a CBC engine may seem negated. For the CBC engine application, the choice of arrangement will be governed by mechanical considerations. Initial technology demonstration $\mathrm{CBC}$ engine will utilize off-the-shelf turbocharger(s) to save capital cost on turbomachinery components. Inspection of numerous turbochargers reveals that the shaft length is insufficient to adapt a generator adjacent to the compressor. Turbocharger modifications such as shaft extension would be difficult to adapt, as would be the development of a high-speed coupling. A simple means of facilitating sufficient shaft space is by replacing the compressor with a generator in the L.P. turbocharger. In this manner, the generator would operate at a lower speed, which would be desirable from a mechanical design standpoint and possibly from a capital cost standpoint. As a result of generator integration limitations, the free-turbine arrangement is chosen for the $\mathrm{CBC}$ engine. 


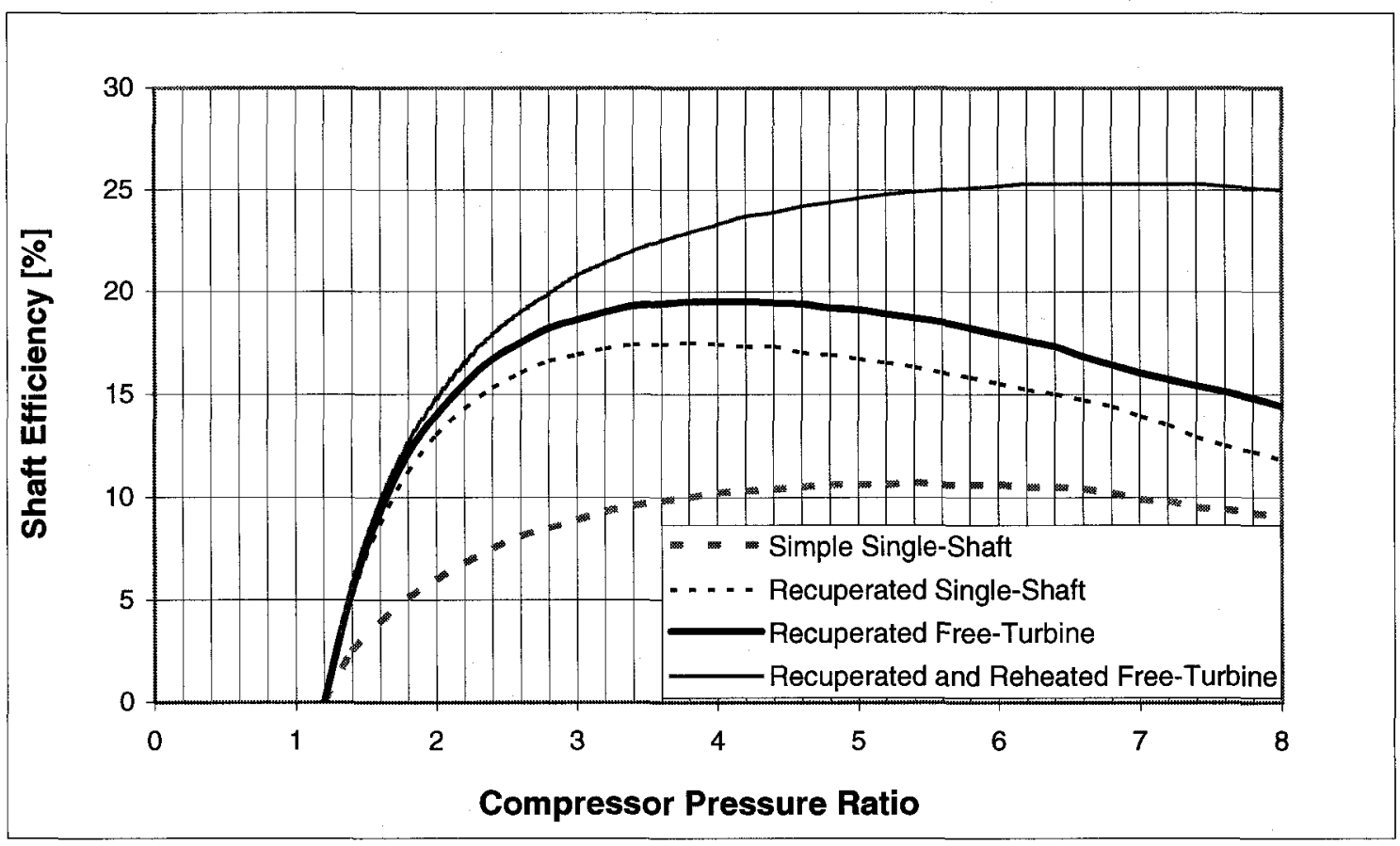

Figure 6.4: Cycle Efficiency as a Function of CBC Configuration and Compressor Pressure Ratio

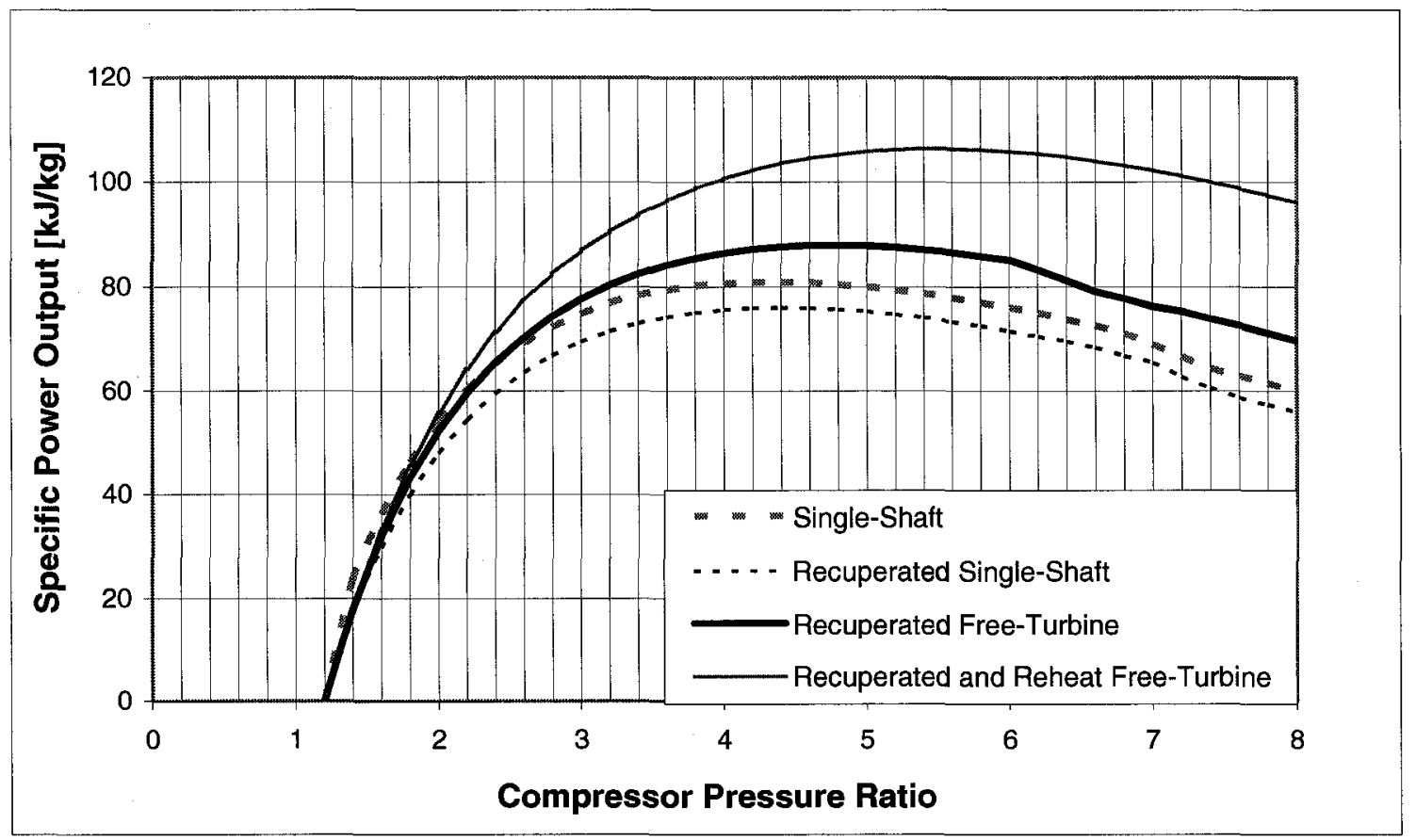

Figure 6.5: Specific Power Output as a Function of CBC Configuration and Compressor Pressure Ratio 
In the case of a free-turbine arrangement, it is possible to reheat the working gas prior to the free-turbine (L.P. turbine) inlet. The potential performance benefit of a free turbine reheat cycle has been investigated with the performance parameters specified in Section 6.1, and a free-turbine inlet temperature equivalent to the gas-generator inlet temperature has been specified. The predicted cycle efficiency of a free-turbine reheat cycle is 25.3 percent as compared to 19.3 percent for the free-turbine non-reheat cycle. Also, the specific power output is predicted to be about 40 percent higher for the reheat cycle. Despite the possible performance improvement of the reheat cycle, design-goal emphasis is placed on development of a low-cost unit that does not necessarily operate at a high efficiency. Implementing a reheat stage would significantly increase the capital cost since an additional high-temperature heat exchanger would be required. For this reason, a reheat stage will not be included in the $\mathrm{CBC}$ engine, and the recuperated freeturbine arrangement is chosen for development.

\subsubsection{CBC Performance versus Open-Gas Turbine Performance}

Open-cycle and $\mathrm{CBC}$ gas turbine performance was compared to justify $\mathrm{CBC}$ engine development from a performance perspective. The free-turbine arrangement has been used for the relative comparison despite the fact that most open-cycle gas turbines (or microturbines) are offered in a simple-cycle configuration. This has been done to clarify the effect of configuration variation. Operating parameters have been used as per Section 6.1 for both cycles. The only difference is that the open-cycle has not been employed with a cold side heat exchanger so that the associated pressure loss is neglected. Moreover, combustion efficiency is higher (modeled at 99\%) than the hot-side heat exchanger effectiveness, and the pressure loss is lower (modeled at $2 \%$ compressor delivery pressure). The predicted performance of the $\mathrm{CBC}$ and $\mathrm{OBC}$ is shown in Figures 6.6 and 6.7.

Due to the lower pressure losses and higher combustion efficiency, the $\mathrm{OBC}$ performance level at full-load is relatively higher than the $\mathrm{CBC}$ performance. The cycle 


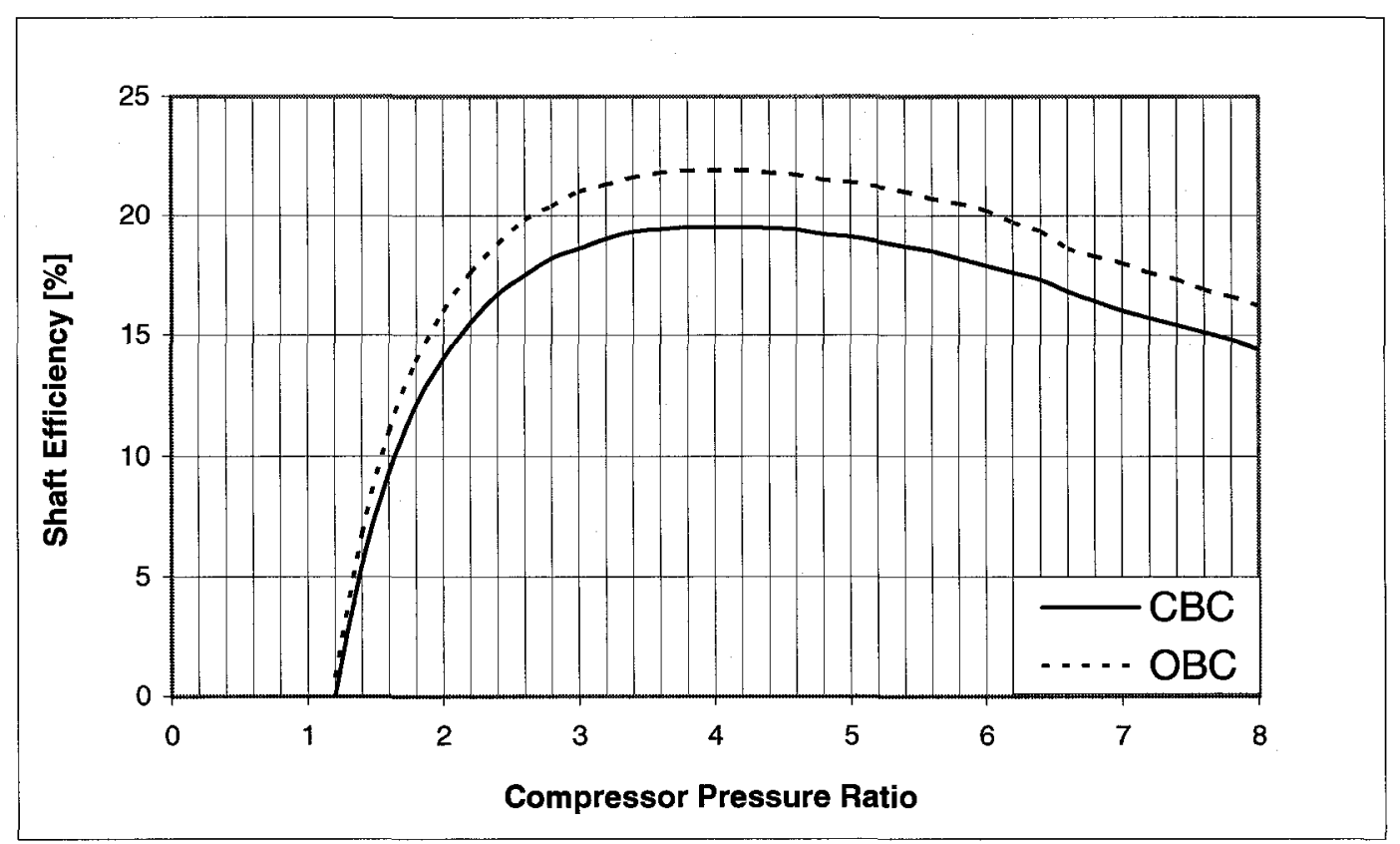

Figure 6.6: Performance Comparison between Open and Closed Brayton Cycles in the Free-Turbine Arrangement

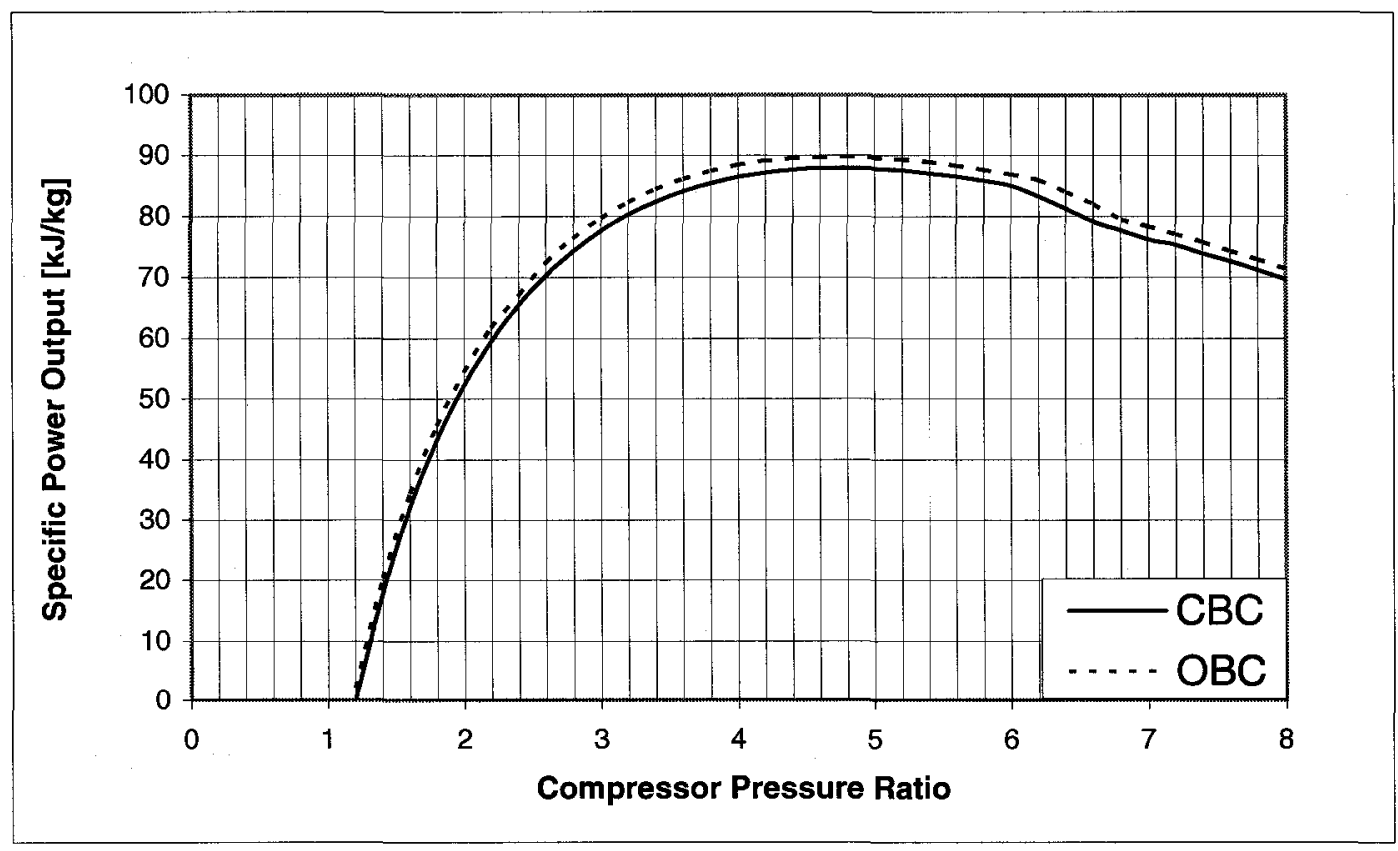

Figure 6.7: Performance Comparison between Open and Closed Brayton Cycles in the Free-Turbine Arrangement 
efficiency of the $\mathrm{OBC}$ engine is predicted to be 12 percent higher than the $\mathrm{CBC}$ engine and the specific power output is predicted to be 2 percent higher than with $\mathrm{CBC}$ engine. The relatively large difference in cycle efficiency is a result of the large difference in combustion efficiency. In the OBC engine, the combustion efficiency accounts for losses due to combustion, whereas in a CBC engine, the combustion efficiency includes heattransfer effectiveness as well as losses due to combustion. Although performance at full load is relatively lower for the $\mathrm{CBC}$ engine, the part-load performance, which is discussed in Chapter 7.5, is higher.

\subsection{Effect of Turbine Inlet Temperature on Cycle Performance}

The turbine inlet temperature (TIT) has a predominant effect on CBC performance and mechanical design choices. High TIT is favourable in terms of CBC performance parameters including efficiency, specific power output, and specific fuel consumption (SFC). However, operation at high temperatures requires application of costly creep-resistant materials. These two conflicting design choices result in a trade-off between capital cost and operations cost. An evaluation of the effect of TIT has been conducted to determine the effect on cycle performance. A CBC with the operating parameters described in Section 6.1 has been analysed at a TIT range of $800 \mathrm{~K}$ to $1300 \mathrm{~K}$ and a pressure ratio range of 1.2 to 8. Performance results are shown in Figure 6.8 and Figure 6.9.

As portrayed in Figure 6.8, a high TIT is essential to generate shaft power at a high efficiency. With the operating parameters described in Section 6.1, efficiency levels exceeding 20 percent are only possible with a TIT approaching $1200 \mathrm{~K}$, which is considered the metallurgical limit of un-cooled turbine blades [6.10]. Higher turbine inlet temperatures could only be possible through the application of ceramic materials in the hot-side heat exchanger and the implementation of turbine-blade cooling, which is 
difficult in radial turbines [6.10]. Although a future option, tooling and manufacturing of complex ceramic shapes is currently very costly and not considered practical for development of a technology demonstrator engine. Moreover, to reduce engine capital costs, it is desirable to utilize off-the-shelf components. Application of turbochargers is favourable since the reduction of development time and component cost is significant. However, as specified by several turbocharger manufacturers, maximum TIT is limited to $1050 \mathrm{~K}[6.11,6.12]$.

Another issue that must be considered when selecting a TIT is the influence on the required heat exchanger size. The size of the hot-side heat exchanger must especially be considered since this component will be costly due to the large quantity of hightemperature alloys. Therefore, any reduction in heat exchanger size will reduce the overall cost. Reducing the amount of required heat input is one method of reducing heat exchanger volume. The maximum efficiency at $1000 \mathrm{~K}$ is predicted to be 16.4 percent as compared to 18.0 percent at a TIT of $1050 \mathrm{~K}$ or 19.5 percent at a TIT of $1100 \mathrm{~K}$. Considering that the design criterion of the technology-demonstration engine is the development of a low capital cost, operational unit, the reduced efficiency is deemed acceptable. Moreover, operation at a lower TIT (than the metallurgical limit) will reduce creep and increase the engine life. Therefore, the steady-state TIT of $1000 \mathrm{~K}$ is selected.

At a given TIT, a wide performance range may be achieved depending on the operating compressor pressure ratio (CPR). The CPR at which the highest efficiency is obtained is referred to as the optimum pressure ratio. For a TIT of $1000 \mathrm{~K}$, the optimum pressure ratio is 3.2. At this pressure ratio, the maximum efficiency of 16.4 percent is predicted and marked in Figure 6.8. As marked in Figure 6.9, the specific power output at the design point is near maximum $(59 \mathrm{~kJ} / \mathrm{kg})$ and the $\mathrm{SFC}$ is near the minimum value of $(0.52 \mathrm{~kg} / \mathrm{kWhr})$. In conclusion, the steady-state operating TIT is chosen as $1000 \mathrm{~K}$ and the optimum compressor pressure ratio of 3.2 is chosen. 


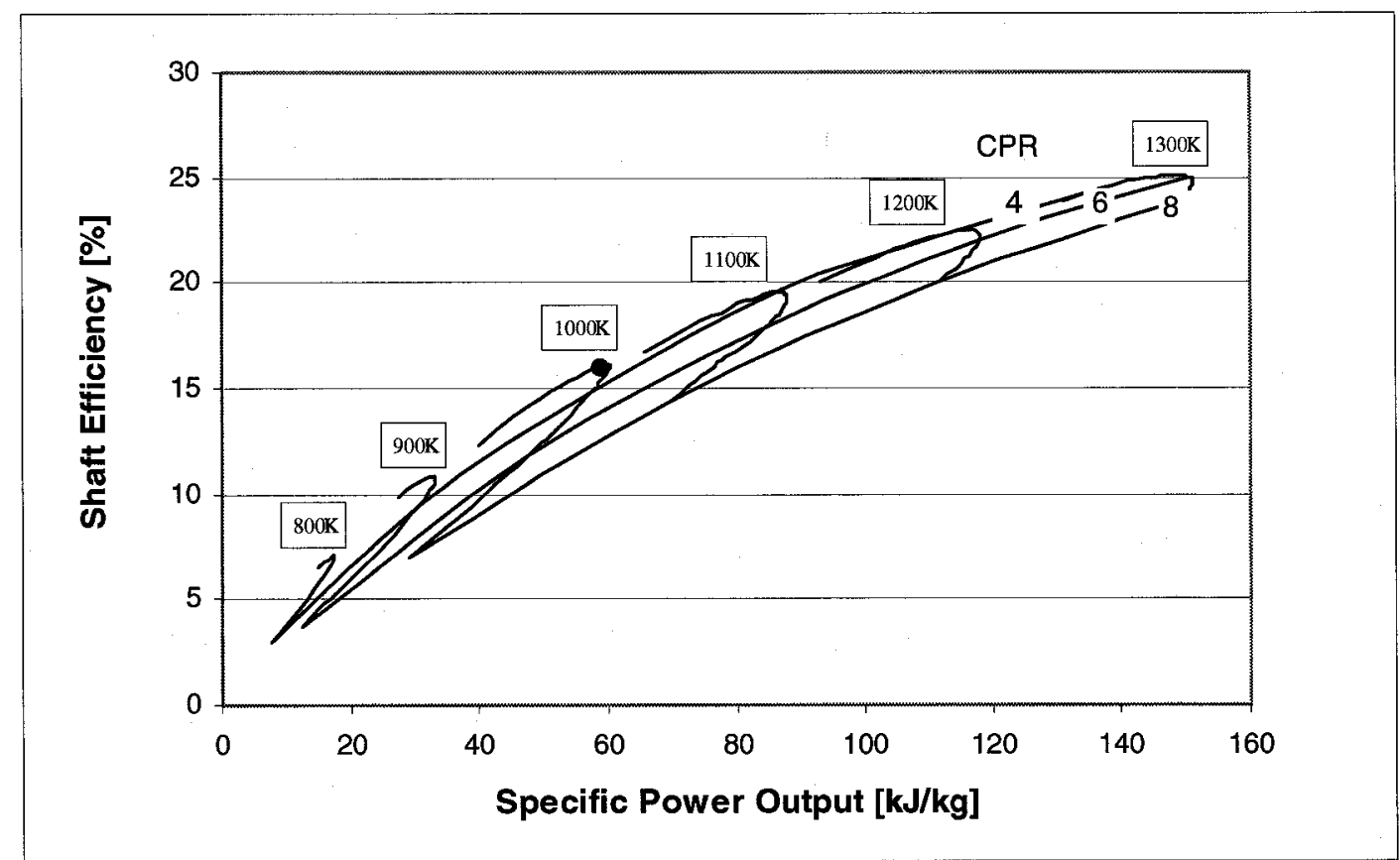

Figure 6.8: Shaft Efficiency versus Specific Power Output for a Range of Turbine Inlet Temperatures and Compressor Pressure Ratios

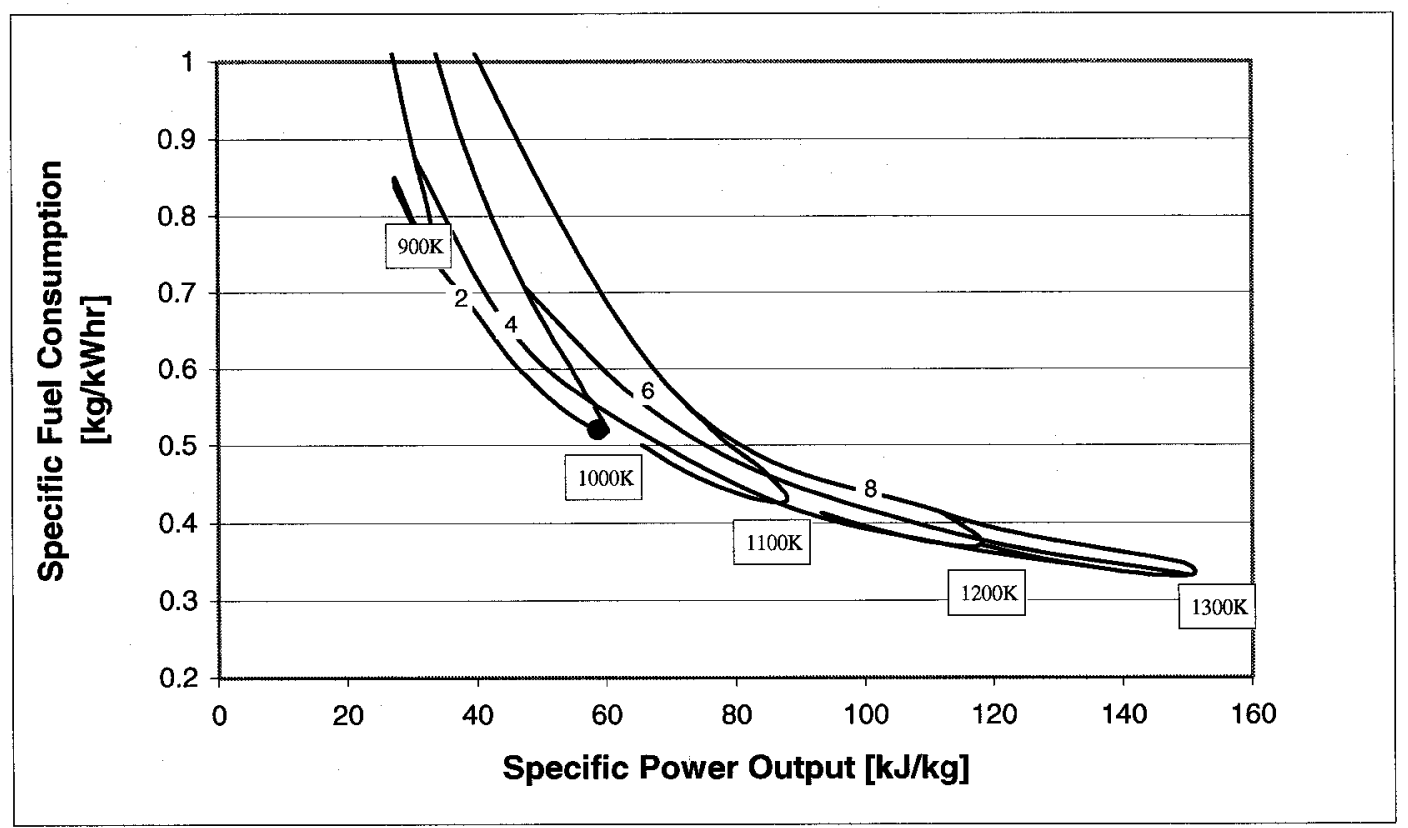

Figure 6.9: Specific Fuel Consumption versus Specific Power Output for a Range of Turbine Inlet Temperatures and Compressor Pressure Ratios 


\subsection{Effect of Compressor Inlet Temperature and Pressure on Cycle Performance}

An inherent advantage of the CBC engine is the possibility of controlling the working gas temperature and pressure at the compressor inlet. Through pressurization, it is possible to significantly reduce the overall size of the engine. However, prior to establishing the relationship between pressurization and size, it is imperative to predict the effect of pressurization on CBC performance. Cycle calculations have been conducted for an engine with operating parameters described in Sections 6.1 and 6.4. Cycle efficiency and specific power output has been calculated for compressor inlet pressure values ranging between $50 \mathrm{kPa}$ and $250 \mathrm{kPa}$. Cycle performance values have been normalized and compared to the performance at atmospheric pressure (101.325 $\mathrm{kPa})$ in Figure 6.10.

Cycle performance parameters are not strongly influenced by the choice of compressor inlet pressure (CIP), provided component performance parameters remain unchanged. As compared to atmospheric conditions, a gain in efficiency and specific power output of 5 percent at an elevated compressor inlet pressure of $250 \mathrm{kPa}$ has been predicted. This increased performance may be attributed to the lower relative pressure drop at high operating pressures. The opposite is true for low operating pressures. Therefore, increasing operating pressure is not beneficial from a performance perspective. Although a reduction in heat exchanger size is possible due to operation at higher operating pressure, the cost reduction due to smaller size may be offset by the requirement to utilize a thicker heat exchanger shell and a thicker turbomachinery casing. Moreover, operation at high pressures will augment difficulties in sealing. In addition, in the case of a technology demonstration engine, the possibility of conducting testing at atmospheric conditions may reduce development costs. Since a large performance benefit is not expected, the compressor inlet will be operated at atmospheric pressure. 


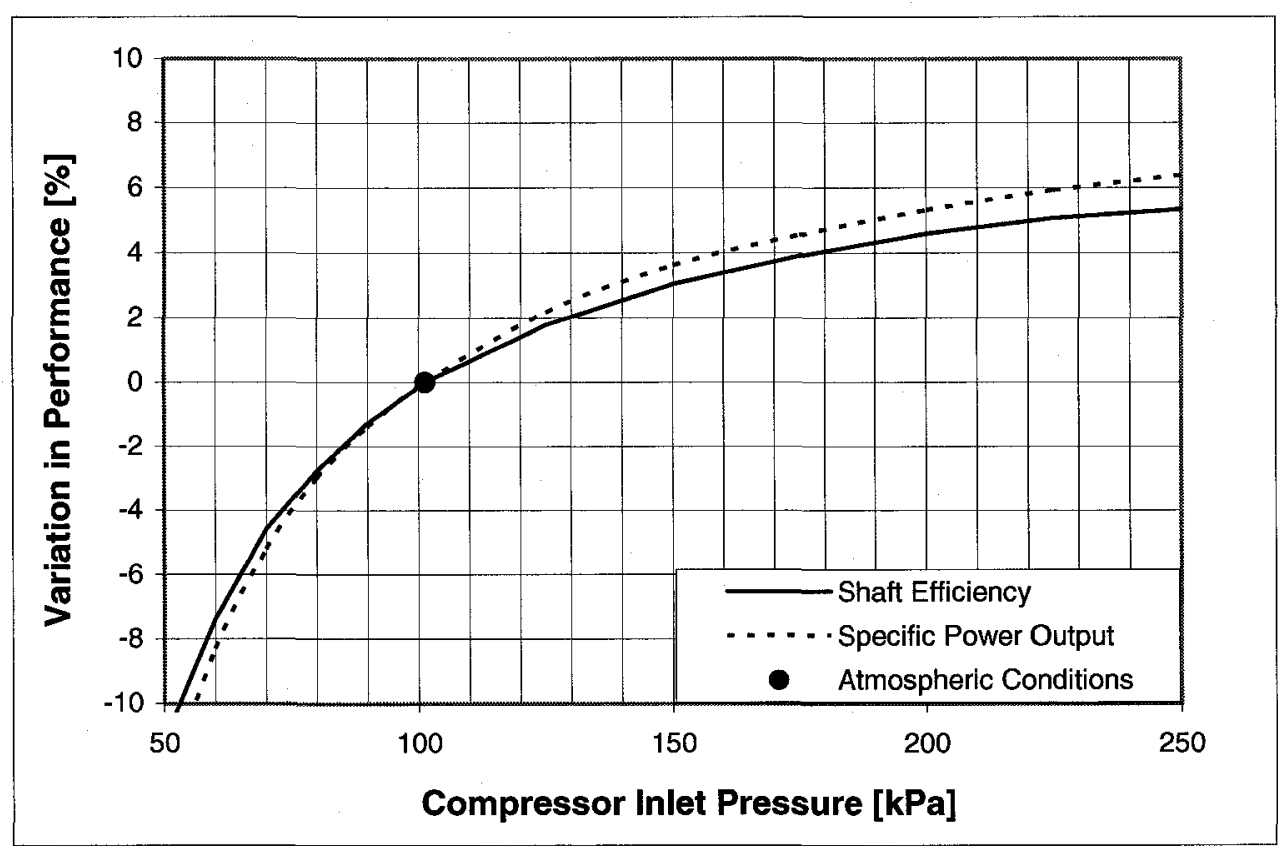

Figure 6.10: Effect of Compressor Inlet Pressure on Efficiency and Specific Power Output

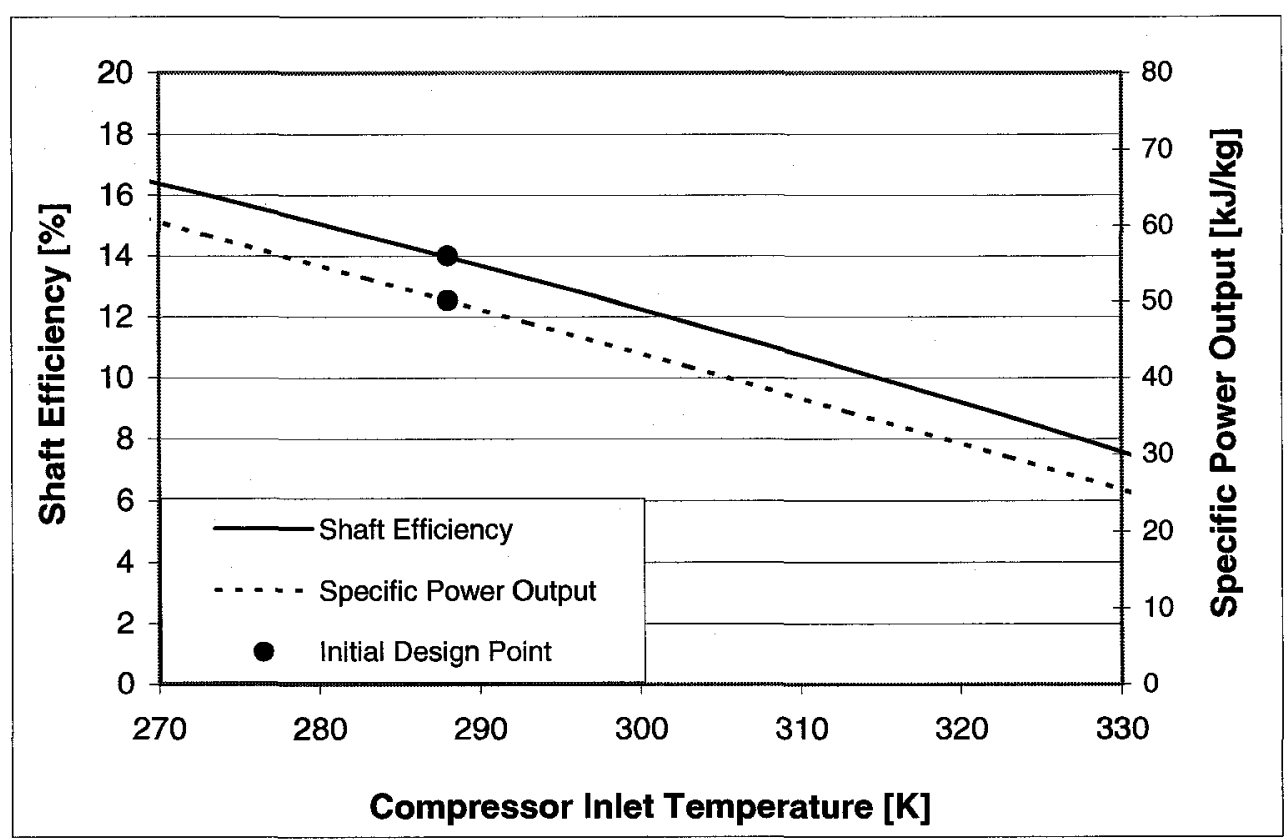

Figure 6.11: Effect of Compressor Inlet Temperature on Efficiency and Specific Power Output 
The effect of compressor inlet temperature (CIT) on CBC performance has also been studied. CIT in the range of $270 \mathrm{~K}$ to $330 \mathrm{~K}$ has been evaluated to determine the effect on shaft efficiency and specific power output. The results of this study are shown in Figure 6.11. CIT is linearly and inversely proportional to the shaft efficiency and specific power output. Therefore, the CIT should be limited to obtain best performance. Control of the CIT will be maintained through the bottoming heat exchanger, which is typically air-to-liquid. Coolant operating temperature range will have a governing effect on the CIT. For preliminary calculations, the CIT is chosen as $283 \mathrm{~K}\left(10^{\circ} \mathrm{C}\right)$.

\subsection{Effect of Component Performance on the CBC Engine}

\subsubsection{Heat Exchangers}

The effect of heat exchanger performance on the cycle performance has been evaluated to determine the acceptable heat exchanger performance specifications. The recuperator and hot-side heat exchanger effectiveness values have been varied independently to assess their effect on cycle efficiency. The effect of recuperator and hot-side heat exchanger pressure loss (on the high pressure side) on the $\mathrm{CBC}$ efficiency has also been investigated to assess acceptable values. Results of this study are shown in Figures 6.12 and 6.13 .

Recuperator and hot-side heat exchanger effectiveness have a strong and nearly linear influence on the cycle efficiency. From an efficiency standpoint, heat exchangers with high effectiveness values are preferred. However, heat exchangers that achieve high effectiveness values require a large surface area, which has a detrimental effect on capital cost and pressure loss. Since the design objective is to develop an operational unit that does not necessarily operate at extremely high efficiency, a trade-off between heat exchanger effectiveness and $\mathrm{CBC}$ efficiency must be made. Therefore, a minimal cycle efficiency target value of 15 percent is chosen. CBC efficiency exceeding 15 percent is 
only possible with recuperator effectiveness exceeding 80 percent. The hot-side heat exchanger effectiveness should be maximized to limit the amount of wasted heat from combustion gasses. In order to achieve a cycle efficiency exceeding 15 percent, hot-side heat exchanger effectiveness of 90 percent is chosen.

The effect of heat exchanger pressure losses, across the high-pressure side, on the cycle efficiency has been investigated. The pressure losses across the low-pressure side have been modelled as constant and the values are summarized in Section 6.1. The effect of pressure losses on overall efficiency is significant, and pressure losses throughout the system should be minimized. In order to achieve the efficiency criteria of 15 percent, the pressure losses should be kept at or below 6 percent of compressor outlet pressure.

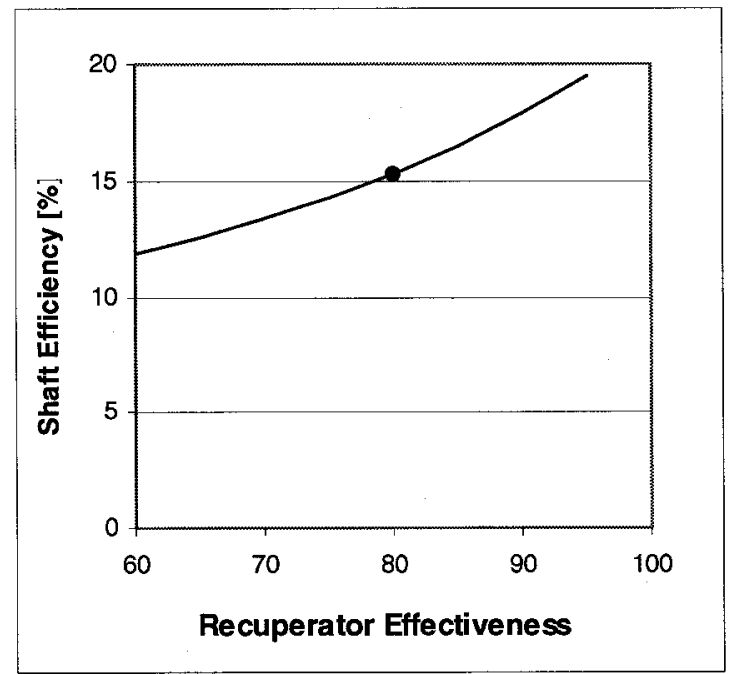

*HSHE Effectiveness is modelled as $90 \%$

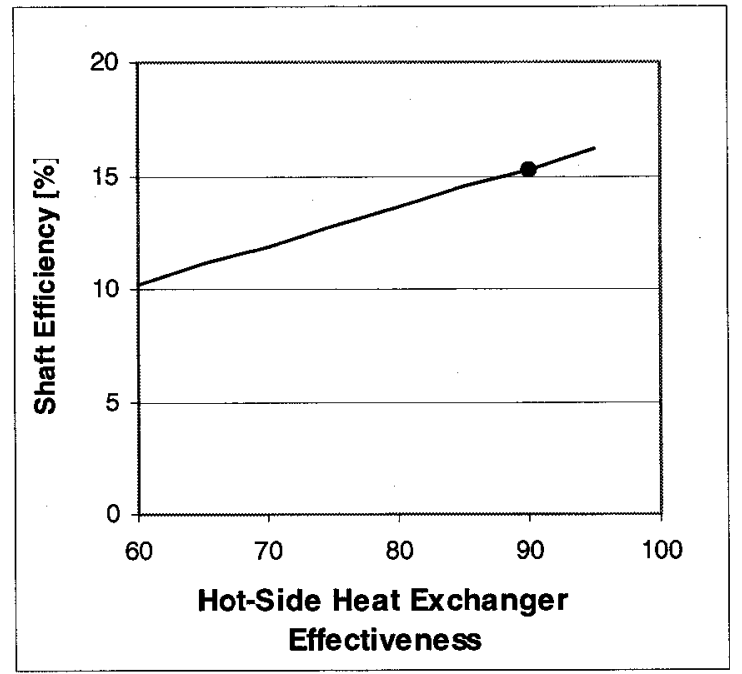

*Recuperator Effectiveness is modelled as $80 \%$

\section{Figure 6.12: Effect of Recuperator and Hot-Side Heat Exchanger Effectiveness on CBC Shaft Efficiency}




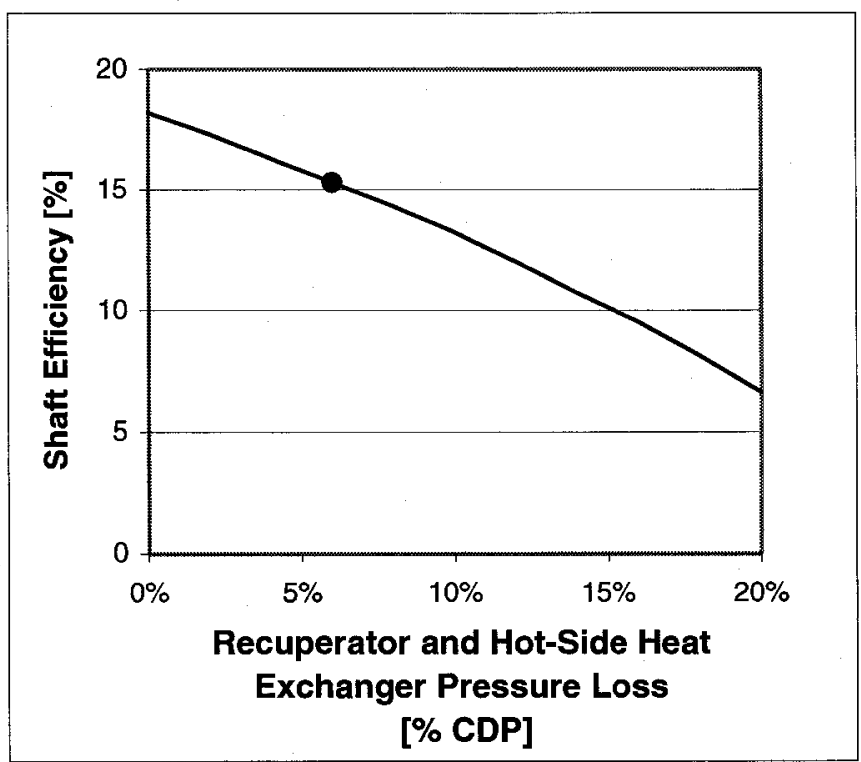

Figure 6.13: Effect of Recuperator and Hot-Side Heat Exchanger Pressure Loss on CBC Shaft Efficiency

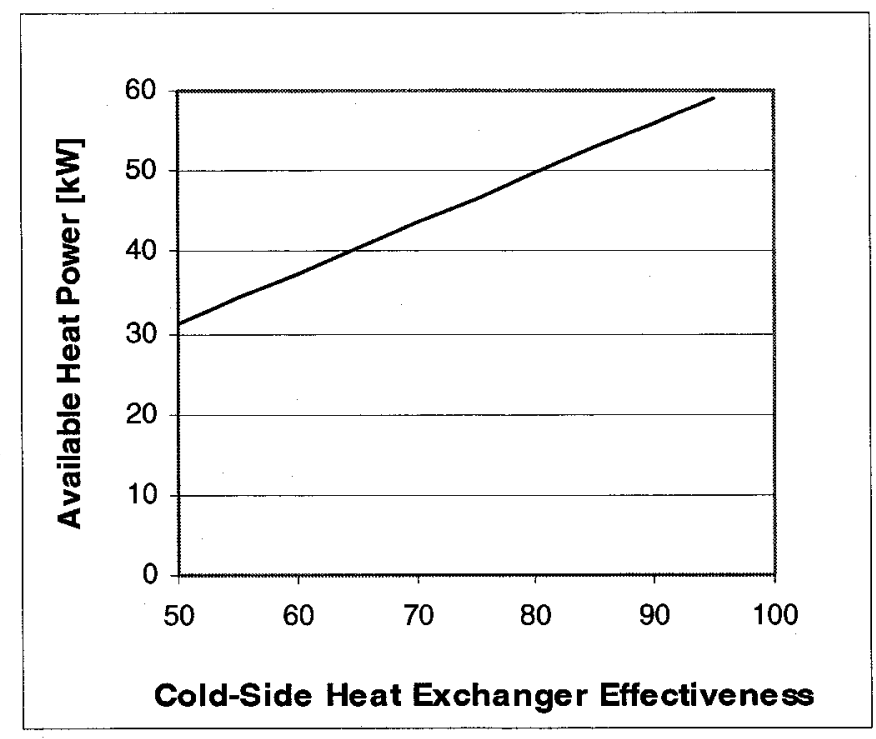

Figure 6.14: Relation between Available Heating Power and CSHX Effectiveness 
The effect of cold-side heat exchanger effectiveness on overall performance has also been analyzed. The analysis has been conducted with constant temperatures on the working-fluid side. Cold-side heat exchanger effectiveness has been varied between 50 percent and 95 percent, and the available power has been calculated. The effect of heat exchanger effectiveness on the heat power available is shown in Figure 6.14. As a result of the wide heating power range available, the cold-side heat exchanger effectiveness will be chosen based on application.

\subsubsection{Turbomachinery}

Although the turbomachinery performance will be governed by market availability of turbochargers, the effect of turbomachinery performance on the CBC performance is quantitatively studied. The design-point performance values are according to baseline values in Section 6.1 and chosen design values as determined in the previous sections. The efficiency of each turbomachine is independently varied and the shaft efficiency is calculated. Results of this study are shown in Figures 6.15 and 6.16. The study results emphasize the necessity to utilize high-efficiency turbomachines in order to generate electricity at reasonable efficiencies. From the results of this study, a requirement is placed to obtain turbines with isentropic efficiencies exceeding 70 percent. This will ensure cycle efficiencies exceeding 15 percent. Likewise, compressor isentropic efficiencies must exceed 72.5 percent to achieve cycle efficiencies exceeding 15 percent. Although these performance requirements are low as compared to modern gas turbines, turbocharger-based turbomachinery will be utilized in the CBC engine, which operate at inherently lower performance levels. Therefore, modern turbochargers, with highest isentropic efficiencies, should be implemented. 

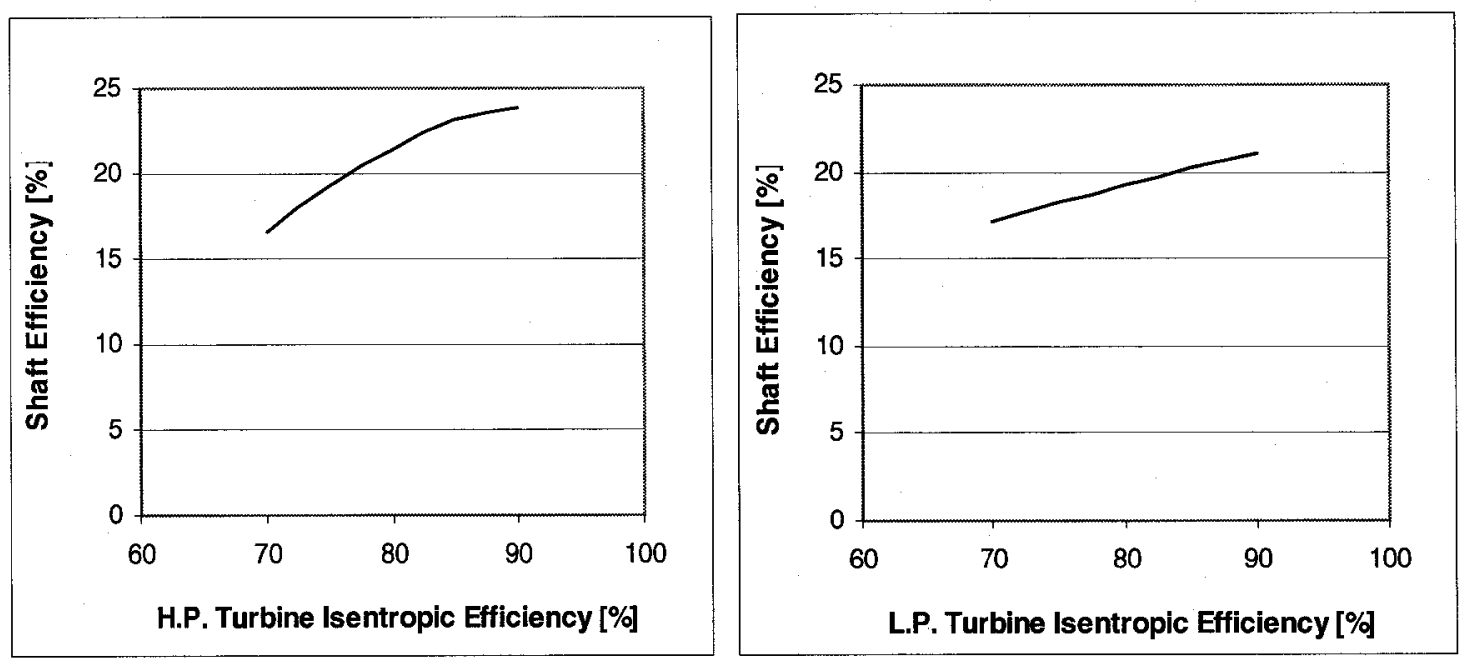

Figure 6.15: Shaft Efficiency as a Function of H.P. and L.P. Turbine Isentropic Efficiencies

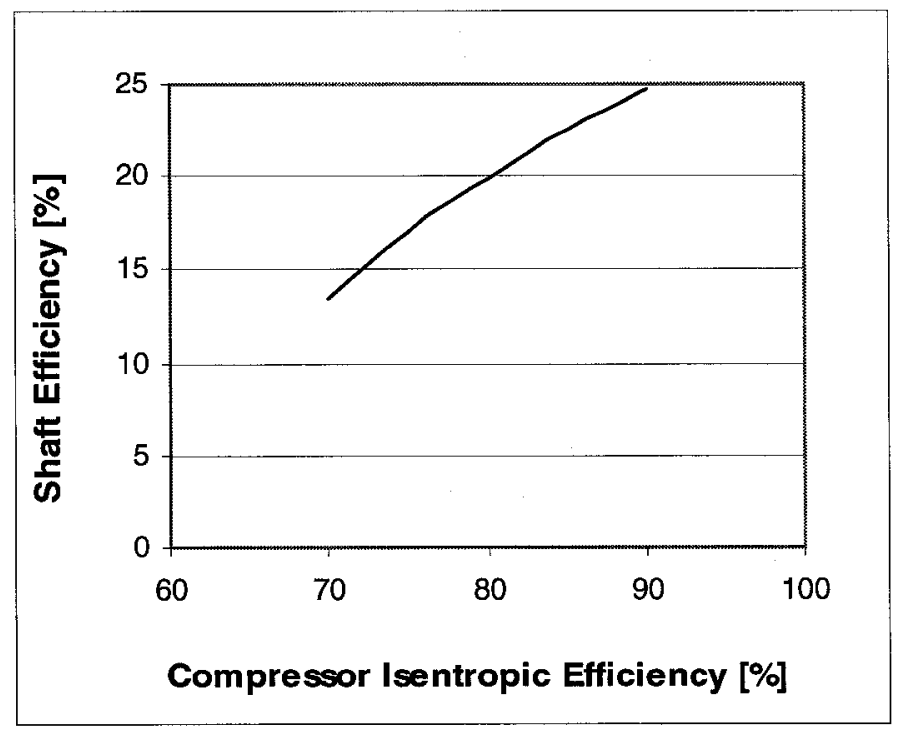

Figure 6.16: Shaft Efficiency as a Function of Compressor Isentropic Efficiency 


\subsection{Conclusions}

The performance of the CBC engine has been analysed and the design-point performance parameters have been chosen. Air has been chosen as the working fluid since it is least costly and is readily available. Other gas options are not readily available which make application in remote communities impractical. Expected performance with air as the working gas is predicted to be higher than operation with other working gasses; however, due to lower specific heat, engine size is expected to be larger with utilization of air than with helium or a helium-mixture working gas.

Several engine configurations have been analysed from a performance perspective, and an engine configuration has been chosen based on predicted performance and relative cost. The free-turbine arrangement has been chosen primarily since this arrangement facilitates sufficient shaft space to easily attach the alternator. Incorporating a recuperator is required to operate at efficiencies exceeding 10 percent. Although higher cycle efficiencies are possible with the reheat cycle, the higher complexity and capital cost of manufacturing and integrating an additional hot-side heat exchanger is unjustified for the technology demonstration unit. Overall, the regenerative free-turbine arrangement offers a compromise between cost and efficiency.

The effect of turbine inlet temperature (TIT) on CBC cycle performance has been analysed to determine an acceptable value. The design-point TIT is selected based on the performance analysis and material considerations. From discussion with turbocharger manufacturers, a TIT of $1050 \mathrm{~K}$ is the upper metallurgical limit. Operation at lower temperature will increase turbocharger life. Moreover, the lower required heat input will reduce the required hot-side heat exchanger surface area. Lower surface area will reduce the heat exchanger capital cost. For this reason, the steady-state design-point TIT of $1000 \mathrm{~K}$ has been selected, which is the lowest TIT that offers satisfactory performance. 
At this TIT, the compressor pressure ratio corresponding to highest cycle efficiency is 3.2 , which is selected as the design-point pressure ratio.

The effect of the compressor inlet pressure on cycle performance has been analysed to justify the additional cost of thicker-walled pressure vessels. Pressurization does not offer a significant performance improvement. However, pressurization will increase the difficulty of sealing the unit and necessitate thicker turbomachinery casing and heat exchanger shell. The potential benefit in pressurization is that the heat exchanger size is reduced. However, in the case of a technology demonstration engine, the possibility of testing at atmospheric conditions may reduce development costs. Furthermore, the low-temperature heat exchanger (waste heat recovery heat exchanger) would not require a design adherent to a pressure code. Since a large performance benefit is not expected, the compressor inlet will be operated at or near atmospheric pressure. The other control variable at the compressor inlet is the compressor inlet temperature (CIT). High compressor inlet temperature has an adverse effect on the cycle efficiency, and therefore, effort should be undertaken to significantly reduce the CIT. Control of the CIT will be maintained through control of liquid temperature in the coldside heat exchanger inlet. For preliminary calculations, the coolant temperature and the CIT are chosen as $283 \mathrm{~K}\left(10^{\circ} \mathrm{C}\right)$, which is comparable to tap water temperature.

Analysis of the effect each component has on the cycle performance has been conducted to determine baseline values to achieve the efficiency target of 15 percent. Compressor isentropic efficiency should exceed 75 percent and the H.P. and L.P. turbine isentropic efficiencies should exceed 70 percent to achieve cycle efficiency levels to achieve the performance target. For the same reason, recuperator and hot-side heat exchanger effectiveness should exceed 80 percent and 90 percent respectively, and the pressure drop should be lower than 6 percent of the compressor outlet pressure. Coldside heat exchanger effectiveness affects the amount of heat power available, and for this reason, the design-point effectiveness will vary with specific application. 
As a result of the strong dependence to turbomachinery performance, the expected CBC performance is not quoted before sizing and selection of turbomachinery components is complete. The design-point operating parameters, such as the compressor pressure ratio, compressor inlet pressure, the CIT, and the TIT, have been selected. Although these values may be slightly varied to ensure stable turbomachinery operation, these operating parameters are required for turbomachinery sizing, which is detailed in the following chapter. With accurate prediction from turbomachinery maps, the CBC performance can be predicted.

Overall, the CBC performance at full-load is slightly lower than the open cycle as a result of the additional pressure losses in the hot-side heat exchanger and the cold-side heat exchanger. However, as seen in the ensuing chapter, the ability to control the turbine and compressor inlet conditions has the potential for relatively higher part-load performance of the $\mathrm{CBC}$ engine as compared to the open cycle gas turbine. 


\section{CHAPTER 7}

\section{Turbomachinery Sizing and Evaluation of Design and Off-Design Performance}

\subsection{Introduction}

An accurate design and off-design performance prediction may only be completed with accurate assessment of turbomachinery performance. Since the performance prediction is required to design the heat exchangers, sizing of the turbomachinery components is regarded as the initial step in the mechanical design process of the CBC engine. Sizing of turbochargers is accomplished through detailed analysis of turbocharger performance maps that have been supplied by the manufacturer. These performance maps detail turbomachinery efficiency levels at a wide range of operating conditions which enable performance evaluation at design and off-design conditions. Turbocharger selection is conducted by a trial and error process to obtain the best possible cycle performance. Due to the large quantity of turbochargers analysed, only the selected turbochargers are described. Based on the turbocharger selection, the cycle performance is predicted at design and off-design conditions. 


\subsection{Turbomachinery Performance Overview}

Turbomachinery performance, as seen in performance maps, is a function of four non-dimensional parameters. The non-dimensional parameters are introduced to reduce the number of independent variables that influence the performance. The eight dimensional variables that effect turbomachinery performance include:

$$
N, D, m, P_{01}, T_{01}, R, \mu, \gamma
$$

Where $N$ is the rotational speed of the turbomachine and $D$ is the characteristic length of the turbomachine (typically the tip diameter), and the other variables have been previously introduced. The subscript 01 refers to the inlet conditions. The eight independent parameters are expressed in terms of four basic dimensions $(\mathrm{kg}, \mathrm{m}, \mathrm{s}, \mathrm{K})$. According to Buckingham's $\Pi$ theorem, the independent parameters can be grouped into four non-dimensional independent groups [7.1]. The four independent groups are:

1) Speed parameter:

$$
N^{*}=\frac{N D}{\sqrt{भ R T_{01}}}=\frac{N}{\sqrt{T_{01}}} \frac{D}{\sqrt{\gamma R}}
$$

The speed parameter is essentially the rotational Mach number.

2) Flow parameter:

$$
m^{*}=\frac{m \sqrt{T_{01}}}{P_{01}} \sqrt{\frac{R}{\gamma}} \frac{1}{D^{2}}
$$

The flow parameter can be interpreted as the Mach number based on the axial velocity through the turbomachine. 
3) Reynolds number:

$$
\operatorname{Re}_{D}=\frac{\rho_{01} N D^{2}}{\mu}
$$

4) Specific heat ratio:

$$
\gamma=\frac{C p}{C v}
$$

The specific heat ratio relates changes in pressure to ideal changes in density and temperature in compressible flow. Therefore, it is also referred to as the isentropic exponent.

In summary, turbomachinery performance parameters are functions of four nondimensional parameters:

$$
\frac{P_{02}}{P_{01}}, \eta, e t c .=f n s\left(N^{*}, m^{*}, \operatorname{Re}_{D}, \gamma\right)
$$

In cases where the performance is compared for a given working fluid and for a given geometry, the fluid properties $\gamma$ and $R$, as well as the geometrical parameter, $D$, are omitted for simplicity. Gas parameters are correlated to account for performance changes due to variation of inlet temperatures and pressures. The speed and flow parameters are directly correlated by the inlet temperature and pressure values or by inlet temperature and pressure reference values, depending on the manufacturer. Therefore, the speed parameter, as observed on a compressor or turbine map, is depicted in the following form:

$$
N^{*}=\frac{N}{\sqrt{T_{01}}} \quad \text { or, } \quad N^{*}=\frac{N}{\sqrt{T_{01} / T_{01 r e f}}}
$$


Similarly, the corrected flow parameter, as observed on a compressor or turbine map, is depicted in the following form:

$$
m^{*}=m \frac{\sqrt{T_{01}}}{P_{01}} \text { or, } \quad m^{*}=m \frac{\sqrt{T_{01} / T_{01 r e f}}}{P_{01} / P_{01 r e f}}
$$

Where $m^{*}$ is the corrected flow rate parameter, $m$ is the actual mass flow rate, $N^{*}$ is the corrected speed parameter, and $N$ is the actual speed. The reference temperatures and pressures, denoted as $T_{01 r e f}$ and $P_{01 r e f}$, vary according to the turbocharger manufacturer and typically correspond to ambient test conditions. The above formula applies to both compressors and turbines, although the reference conditions vary.

A compressor map is presented as the pressure ratio plotted against the mass flow parameter, with lines of constant speed parameter and efficiency shown on the map (see Appendix C, Figure C.1). This map is valid for fixed values of Reynolds number and isentropic exponent (or working gas), and for a given compressor size. The effect of Reynolds number on compressor performance is not significant, except at very low values (below 90,000 for centrifugal compressors). Empirical correlations for Reynolds number discrepancies are available in Reference [7.2].

A turbine performance map is presented as the flow parameter against the pressure ratio and the efficiency against the pressure ratio (see Appendix C, Figure C.2). Again, effects of the Reynolds number are neglected and the performance is valid for the given turbine and working gas. 


\subsection{Turbocharger Sizing}

\subsubsection{Initial Sizing}

As a result of the large availability and flexibility in size, the application of turbochargers is an ideal solution for implementing low capital-cost turbomachinery. Numerous turbochargers are available with the capability of adapting varying compressor sizes to a specific turbine. Careful sizing of turbomachinery is important in order to operate at aerodynamically stable conditions as well as operate at high efficiencies at the design power level. Operation at aerodynamically stable conditions refers to operation at a design point located away from the surge line. Surge line corresponds to operating conditions where compressor stall occurs, and is shown as a dashed line on the left side of the compressor map (see Appendix C, Figure C.1). Compressor stall is a catastrophic breakdown in the flow that must be avoided since it can cause power loss, large pressure transients that may cause large compressor vibrations, and flow reversal. The distance between the operating point and the surge point is referred to as the surge margin [7.3]. A pseudo surge margin, defined according to the design and surge value of mass flow rate, is utilized since a pressure based surge margin definition does not apply for turbocharger compressors. The pseudo surge margin is defined as:

$$
\text { Surge Margin }=\frac{m_{\text {design }}-m_{\text {surge }}}{m_{\text {design }}} * 100
$$

Compressor selection criteria include the ability to operate efficiently at the optimum pressure ratio and the ability to operate at the mass flow rate required to generate $20 \mathrm{~kW}$ of shaft power. Moreover, the design point must be located away from the surge line to ensure stable operation. Numerous performance maps for each turbomachinery component have been obtained from the manufacturer and carefully examined for the above requirements. Based on the above operational requirements, a compressor with the highest isentropic efficiency was selected. The compressor make is 
not disclosed for propriety reasons. However, the compressor map is included in Appendix C, Figure C.1 with the marked (final) design and off-design points. The selected compressor design point corresponds to the point of highest compressor isentropic efficiency at the selected pressure ratio. The predicted compressor isentropic efficiency is 77 percent at the design point. Moreover, stable operation is expected from the compressor since the design point is located at a surge margin of 35 percent. At the design point, the compressor operates at a corrected speed of 105,550 RPM, which corresponds to an actual compressor rotational speed of 102,000 RPM.

Since the high-pressure turbine and the compressor are fixed on the same shaft, the turbine must operate at the same rotational speed as the compressor and the delivered power must be matched to the amount required by the compressor. Power level matching between the compressor and turbine governs the pressure ratio requirement across the H.P. turbine. The mass flow rate through the turbine is the same as the mass flow rate through the compressor since no bleed flow is present. However, the corrected mass flow rate varies as a result of different inlet conditions and reference values. The turbine mass flow rate parameter can be expressed in terms of the compressor mass flow rate parameter in the following form:

$$
\frac{m_{4} \sqrt{T_{04}}}{P_{04}}=\frac{m_{1} \sqrt{T_{01}}}{P_{01}} * \frac{P_{01}}{P_{02}} * \frac{P_{02}}{P_{04}} * \sqrt{\frac{T_{04}}{T_{01}}} * \sqrt{\frac{m_{4}}{m_{1}}}
$$

The pressure ratio $P_{04} / P_{02}$ is the pressure loss through the recuperator and the hotside heat exchanger. The mass flow rate is constant throughout the $\mathrm{CBC}$ engine, therefore, $m_{4}=m_{l}$. Therefore, the turbine mass flow rate parameter may be simplified as:

$$
\frac{m \sqrt{T_{04}}}{P_{04}}=\frac{m \sqrt{T_{01}}}{P_{01}} * \frac{P_{01}}{P_{02}} * \frac{P_{02}}{P_{04}} * \sqrt{\frac{T_{04}}{T_{01}}}
$$

Similarly, the turbine speed parameter is matched to the compressor speed parameter, which is expressed as: 


$$
\frac{N}{\sqrt{T_{04 a}}}=\frac{N}{\sqrt{T_{01 a}}} \sqrt{\frac{T_{01 a}}{T_{04 a}}}
$$

In this manner, the speed and flow parameter compatibility with the compressor is attained. At steady state, the turbine that is compatible with the chosen compressor has the flow parameter of $0.245 \mathrm{~kg} / \mathrm{s}(31.1 \mathrm{lb} / \mathrm{min})$ and the speed parameter of 54,380 RPM. The mass flow parameter has been corrected by the inlet reference temperatures and pressures, as denoted in the right hand side of Equation 7.8. Similarly, the speed parameter is corrected by the inlet reference temperature, as denoted in Equation 7.10. The H.P. turbine pressure ratio is computed based on the compressor power requirement, and is 2.3. The H.P. turbine is selected based on this initial evaluation. The turbine make is not disclosed for proprietary considerations, although the turbine performance map is provided in Appendix C, Figure C.2. The efficiency of this turbine is constant at 70 percent at a wide range of operating conditions. As will be seen in Section 7.3.2, this design point will be modified to match performance specifications.

Component matching must also be performed for the L.P. turbine. First, the L.P. turbine pressure ratio, $P_{04 b} / P_{05}$, will be a function of the H.P. turbine pressure ratio, $P_{04 d} / P_{04 b}$, which is based on compressor work requirement.

$$
\frac{P_{04 b}}{P_{05}}=\frac{P_{04 a} / P_{05}}{P_{04 a} / P_{04 b}}
$$

Also, the mass flow rate leaving the gas generator must equal the mass flow rate at the entry of the power turbine. The mass flow parameter of the power turbine is therefore matched to the mass flow parameter of the gas generator as follows:

$$
\frac{m \sqrt{T_{04 b}}}{P_{04 b}}=\frac{m \sqrt{T_{04 a}}}{P_{04 a}} * \frac{P_{04 a}}{P_{04 b}} * \sqrt{\frac{T_{04 b}}{T_{04 a}}}
$$


Based on the pressure ratio and mass flow rate requirement, several turbine performance maps are analysed. The required total-to-total (or stagnation-to-stagnation) pressure ratio is 1.23 , and the mass flow rate parameter is $0.85 \mathrm{~kg}^{*} \mathrm{~K}^{0.5} / \mathrm{kPa}^{*} \mathrm{~s}$. The selected turbine is not disclosed for propriety reasons; however, the L.P. turbine performance map is provided in Appendix C, Figure C.3. The L.P. turbine isentropic efficiency is predicted at 78 percent. Also, the corrected rotational speed is predicted at 41,000 RPM.

In conclusion, a gas generator turbocharger and a free-turbine turbocharger has been matched and selected based on steady-state operation requirements. The expected compressor, H.P. and L.P. turbine efficiencies are 77 percent, 70 percent, and 78 percent respectively. The turbomachinery performance maps have been obtained and included in Appendix C.

\subsubsection{Design-Point Modification for Turbomachinery Operational Point Matching}

Cycle performance prediction is evaluated based on the selected turbomachinery performance and operating points to confirm whether the overall performance specifications are met. The gas conditions and component performance parameters that have been selected in the previous chapter, and are summarized below are used. Based on these design parameters, the expected CBC engine power output is below the $20 \mathrm{~kW}$ power requirement (predicted at $14.75 \mathrm{~kW}$ ) and below the 15 percent efficiency requirement. Moreover, the selected H.P. turbine operation point does not coincide with the operational line. Therefore, to achieve the $\mathrm{CBC}$ performance specification, the operational points have been modified. 


\section{Component Performance Parameters}

Compressor Isentropic Efficiency $\quad 77 \%$

H.P. Turbine Isentropic Efficiency 70\%

L.P. Turbine Isentropic Efficiency 78\%

Recuperator Effectiveness $\quad 80 \%$

Hot-Side Heat Exchanger Effectiveness $\quad 90 \%$

Cold-Side Heat Exchanger Effectiveness $\quad 87 \%$

Mechanical Efficiency $\quad 98 \%$

\section{Pressure Losses}

$\begin{array}{ll}\text { Recuperator Pressure Drop (Cold Side) } & 3 \% \text { CIP } \\ \text { Hot-Side Heat Exchanger Pressure Drop } & 3 \% \text { CIP } \\ \text { Recuperator Pressure Drop (Hot Side) } & 0.03 \text { bar } \\ \text { Cold-Side Heat Exchanger Pressure Drop } & 0.03 \text { bar }\end{array}$

\section{Gas Conditions}

Compressor Pressure Ratio $\quad 3.2$

Compressor Inlet Temperature $\quad 283 \mathrm{~K}$

Compressor Inlet Pressure $\quad$ : $\quad 101.325 \mathrm{kPa}$

Turbine Inlet Temperature $\quad 1000 \mathrm{~K}$

The H.P. turbine operating point must be matched to coincide with the operational line on the performance map. This involves matching the corrected mass flow rate with the value corresponding to the operating line for the operating H.P. turbine pressure ratio. At the gas conditions and component performance parameters summarized above, the predicted corrected mass flow parameter $(31.1 \mathrm{lbm} / \mathrm{min})$ is below the required value (compressor and H.P. turbine performance maps supplied by the manufacturer utilize Imperial units). According to Equation 7.10, increasing the H.P. turbine corrected mass 
flow rate to the value corresponding to the operating line $(34 \mathrm{lbm} / \mathrm{min})$ requires decreasing the CPR, increasing the pressure drop, or increasing the TIT. As seen in Section 6.6.1, increasing the pressure drop is undesirable due to the negative impact on the overall efficiency. Therefore, performance calculations are conducted to determine the effect of modifying the CPR and TIT on the required H.P. turbine corrected mass flow rate and cycle efficiency. The cycle calculations have been conducted for CPR values in the range of 2.7 and 3.2, and for TIT values of $1000 \mathrm{~K}, 1025 \mathrm{~K}$, and $1050 \mathrm{~K}$. Other gas conditions and component performance values that have been described previously, including turbomachinery performance values since the efficiency does not vary at the analysed $\mathrm{CPR}$ range.

The CPR corresponding to the operational line on the H.P. turbine performance map has been found for the range of TIT values, and the points are marked in Figure 7.1. For the TIT of $1000 \mathrm{~K}, 1025 \mathrm{~K}$, and $1050 \mathrm{~K}$, the H.P. turbine operating point is at the H.P. turbine total-to-total pressure ratio of $2.93,2.96$, and 3 respectively and at the corrected mass flow rate of $34 \mathrm{lbm} / \mathrm{min}$. The cycle efficiency has been calculated for the range of CPR and TIT values. Also, the cycle efficiency at the CPR corresponding to the H.P. turbine operating points has been marked in Figure 7.2. The marked CPR corresponds to peak efficiency values at each TIT. The cycle performance for originally selected TIT of $1000 \mathrm{~K}$ is expected to be 13 percent, which is below design specifications. The required specification of 15 percent may only be met with the TIT of $1050 \mathrm{~K}$. Although this temperature is within the metallurgical limit of the turbochargers, operation at the maximum temperature for elongated periods may significantly reduce the component operational life. To achieve the efficiency target, the median temperature of $1025 \mathrm{~K}$ is selected. Recuperator performance will be modified to reach the efficiency target. 


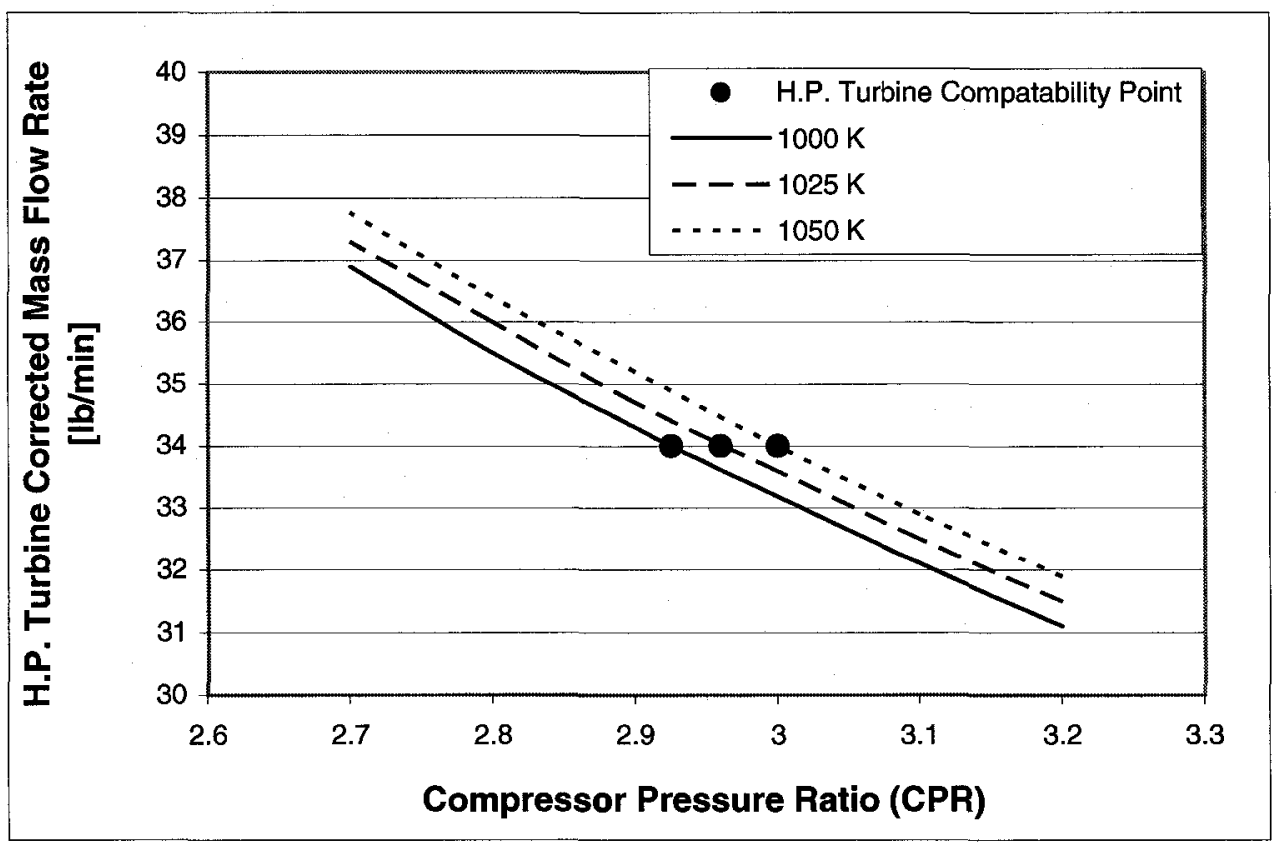

Figure 7.1: H.P. Turbine Corrected Mass Flow Rate as a Function of Compressor Pressure Ratio

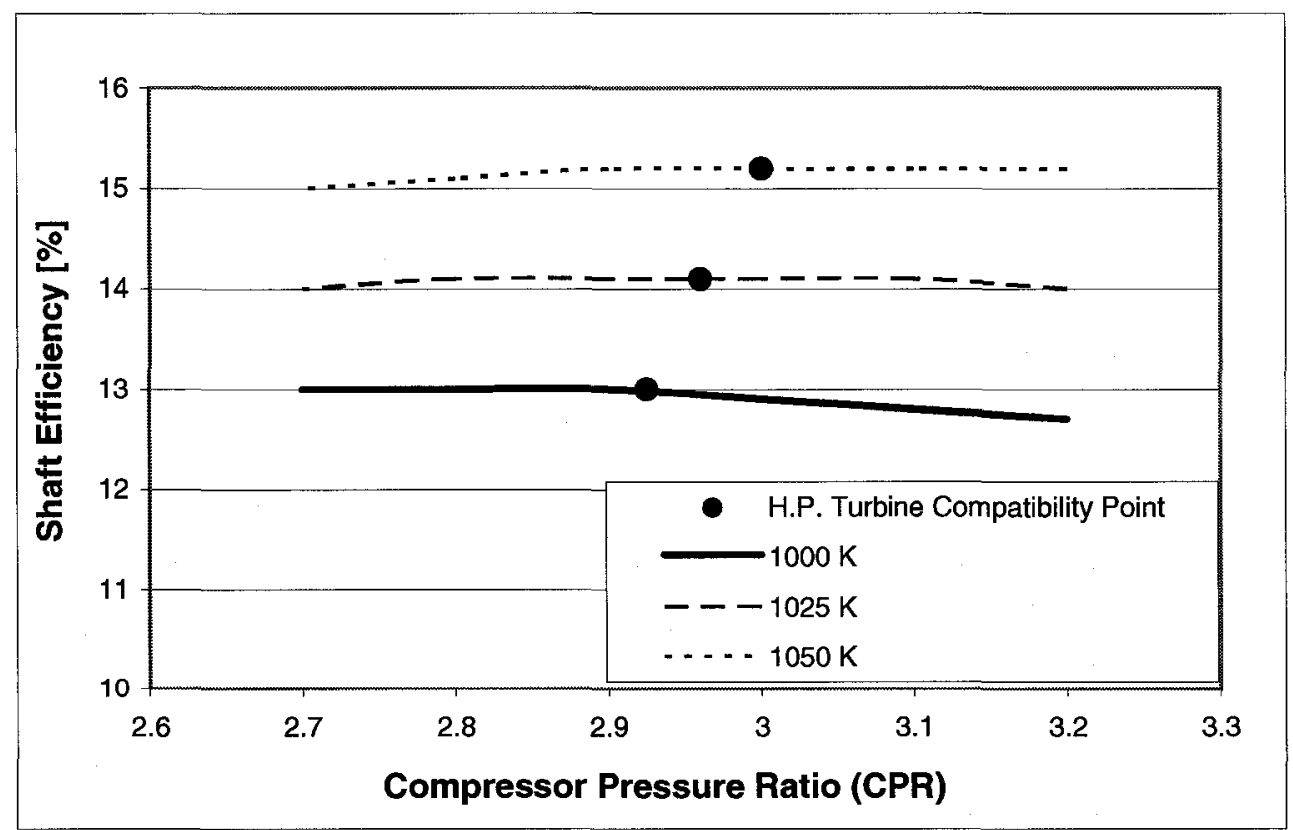

Figure 7.2: Shaft Efficiency as a Function of Compressor Pressure Ratio 
At the selected TIT of $1025 \mathrm{~K}$, the H.P. turbine operating point is at the total-tototal pressure ratio of 2.1 and the corrected mass flow rate of $34 \mathrm{lbm} / \mathrm{min}$. The corrected speed at this calculated as per Equation 7.11 to be 52,950 RPM. This design point is marked on the H.P. turbine performance map provided in Appendix C, Figure C.2.

The L.P. turbine operating point, as found by Equation 7.12 and 7.13 respectively, is located at the total-to-total pressure ratio of 1.25 and the corrected mass flow rate of $0.085 \mathrm{~kg}^{0.5} \mathrm{~kg} / \mathrm{s} * \mathrm{kPa}$. The difference in units is due to the European origins of the L.P. turbine manufacturer. The point coincides with the operating line, and no further analysis is required. The corrected speed does not require matching, and is found from the performance map as 41,000 RPM. This corresponds to an actual rotational speed of 40,570 RPM. The L.P turbine design point is marked on the L.P. turbine performance map provided in Appendix C, Figure C.3.

\subsection{Steady-State Performance Prediction}

CBC engine performance is further analysed at the selected CPR and TIT to ensure the power level requirement and efficiency target is met. The power output at the selected CPR of 2.96 and the TIT of $1025 \mathrm{~K}$, with the previously described gas operating conditions and component performance levels has been predicted to be $14.5 \mathrm{~kW}$. Since the predicted power level is below the target value of $20 \mathrm{~kW}$, an adjustment to the operating conditions must be made. Power level adjustment can be made by increasing the TIT or increasing the mass flow rate. As described in the previous section, increasing the TIT is undesirable due to reduced component life. Directly increasing the corrected mass flow rate is also undesirable since the compressor would operate at low efficiency levels. Operation at high compressor efficiencies and increased corrected mass flow rate would require re-selection of the gas generator turbomachinery. Since the turbochargers have been matched for the mass flow parameter and the speed parameter, are cost- 
effective, and are readily available, they should not be resized. Alternatively, the mass flow rate can be increased without modification of the compressor design point (including the corrected compressor mass flow rate) by increasing the compressor inlet pressure.

A parametric analysis on the effect of CIP on cycle performance has been conducted. CIP values in the range of atmospheric condition (101.325 kPa) and $130 \mathrm{kPa}$ have been analysed. The shaft efficiency and the power output at the CIP range is shown in Figure 7.3. Through the parametric analysis, it is found that the CIP required to generate $20 \mathrm{~kW}$ of power is $119 \mathrm{kPa}$ (2.6 psig). The predicted CBC efficiency is higher at elevated pressure. This is only a result of the relatively lower pressure losses modelled at elevated pressure on the L.P. side. Modelling the L.P. pressure losses as directly proportional to the CIP would result in constant predicted efficiency levels. At the specified pressure losses, the shaft efficiency is predicted to be 14.6 percent. As can be seen by Equation 7.10, the H.P and L.P turbine operating mass flow rate will not vary for a given compressor corrected mass flow rate. Also, the pressure ratio through the cycle does not vary if the CIP is changed. Therefore, for a given compressor corrected mass flow rate, the variation of CIP will not alter the selected turbine operating points.

Variation of CIP should not pose any difficulties in mechanical design due to elevated pressure. Since this CIP is below $15 \mathrm{psig}$, the cold side heat exchanger design will not be required to adhere to ASME Pressure Vessel Code Standards [7.4]. Control of the CBC engine may be simpler since increased design-point CIP enables a wider range of control of the $\mathrm{CBC}$ engine at part load. This is due to the possibility of reducing the pressure to reduce the power loading. Additionally, for future scaling of the CBC engine to higher power levels, higher pressure levels could be applied. Application of higher pressures could result in utilization of identical turbomachinery. Only scaling of heat-transfer components would be required. 


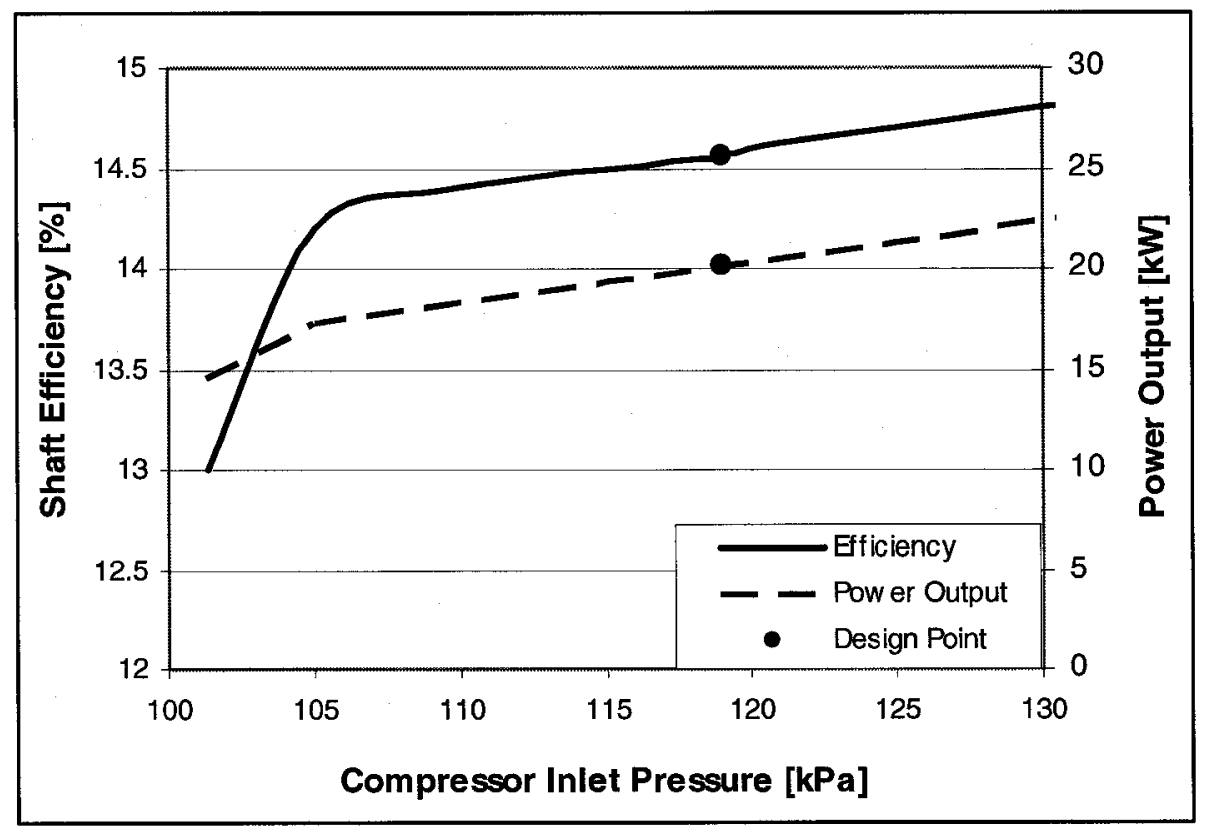

Figure 7.3: Shaft Efficiency and Power Output as a Function of Compressor Inlet Pressure

Table 7.1: Predicted Steady-State Working Gas Conditions

\begin{tabular}{|c|c|c|c|}
\hline Position & $\begin{array}{c}\text { Stagnation } \\
\text { Pressure } \\
{[\mathrm{kPa}]}\end{array}$ & $\begin{array}{c}\text { Stagnation } \\
\text { Temperature } \\
{[\mathrm{K}]}\end{array}$ \\
\hline 1 & Compressor Inlet & 119 & 283 \\
\hline 2 & Recuperator Inlet & 352 & 417 \\
\hline 3 & Hot-Side Heat Exchanger Inlet & 342 & 783 \\
\hline $4 \mathrm{a}$ & H.P. Turbine Inlet & 331 & 1025 \\
\hline 4 & L.P. Turbine Inlet & 158 & 904 \\
\hline 5 & Recuperator Inlet (Hot Side) & 125 & 863 \\
\hline 6 & Cold-Side Heat Exchanger Inlet & 122 & 417 \\
\hline
\end{tabular}


The efficiency criterion of 15 percent is met by increasing the recuperator effectiveness requirement to 82 percent. The hot-side heat exchanger efficiency is not varied since a high value of 90 percent is specified. The turbomachinery operating points are not varied with recuperator effectiveness modification since gas conditions at the turbomachinery inlet and outlet are not modified. At the design point, the compressor, H.P turbine, and L.P turbine efficiency is 77 percent, 70 percent, and 78 percent respectively. At this design point, the efficiency and specific power output is expected to be 15.1 percent, $44.9 \mathrm{~kJ} / \mathrm{kg}$, and the SFC is predicted to be $0.552 \mathrm{~kg} / \mathrm{kW} * \mathrm{hr}$. The power output of the CBC engine is $20 \mathrm{~kW}$, and assuming a cold-side heat exchanger effectiveness of 87.5 percent, the heating power is predicted as $52.5 \mathrm{~kW}$. In addition to calculating the CBC performance, the working gas conditions are established throughout the closed loop, and are depicted in Table 7.1. These working gas conditions must be considered when performing the mechanical design.

The design-point performance prediction has been validated with GASTURB 9, a commercially available software package that is used for performing design and offdesign cycle calculations. The cycle efficiency and SFC values at design-point conditions are predicted to be within 3.3 percent of the values predicted by applying the theory presented in Chapter 5. The discrepancy may be attributed to a possible variation in the coefficient values utilized in calculating gas properties. The steady-state gas conditions predicted by GASTURB 9 correspond to the values presented in Table 7.1. The accuracy of off-design cycle calculations is expected to be within a similar range since the same theory is applied. 


\subsection{Off-Design CBC Performance Prediction}

Detailed off-design cycle performance prediction is conducted and turbomachinery off-design operating points have been selected. Turbomachinery offdesign operating points vary considerably at low power levels and require analysis to ensure flow compatibility, power compatibility, and speed compatibility between components. Compressor off-design operating points are selected to maintain a wide surge margin (over 33 percent) to ensure stable operation of the $\mathrm{CBC}$ engine throughout all power levels. Also, turbine off-design operating points are selected to have the mass flow rate coinciding with the operational line. Turbomachinery operating points are selected for each off-design operating condition to ensure stable operation and present an accurate part-load performance prediction.

The CBC engine offers additional flexibility in the control strategy at part-load conditions since either compressor inlet pressure (CIP) or turbine inlet temperature (TIT) can be varied according to the desired power level. Variation of CIP offers the ability to reduce the actual mass flow rate without modifying the corrected mass flow rate. In this manner, power level variation can be accomplished with turbomachinery operation at the selected design point. Therefore, the turbomachinery operates at design-point efficiency and at the engine design-point TIT, which enables operation at efficiencies comparable to the design-point levels. This control strategy is implemented from the design-point CIP of $119 \mathrm{kPa}$ to $70 \mathrm{kPa}$. The effect of CIP on shaft power and cycle efficiency at the CIP range of $70 \mathrm{kPa}$ and $119 \mathrm{kPa}$ is depicted in Figure 7.6. For the most part, decreased partload efficiency is a result of the modelling assumption of constant pressure loss on the low-pressure side. At the CIP of $70 \mathrm{kPa}$, the part-load efficiency is reduced significantly since the corrected speed of the L.P. turbine decreases from 41,000 RPM to 29,000 RPM, and the L.P. turbine isentropic efficiency is reduced from the design-point isentropic efficiency of 78 percent to 72 percent (see Appendix C, Figure C.3). 
The off-design turbomachinery operating conditions are highly dependant on the L.P. turbine operating mass flow rate. Although the reduction in CIP does not influence the compressor and the H.P. turbine operating point, the L.P. turbine total-to-total pressure ratio is slightly reduced due to relatively higher pressure losses through the lowpressure side (pressure losses on the low-pressure side have been modeled constant). The variation in the L.P. turbine operating point between the design point $\mathrm{CIP}$ and $80 \mathrm{kPa}$ is too minute to be depicted on the L.P. turbine performance map in Appendix C, Figure C.3. With CIP reduction the corrected mass flow rate remains constant, and the L.P. turbine pressure ratio decreases slightly. At CIP below $80 \mathrm{kPa}$, the L.P. turbine pressure ratio is too low to operate at the design point speed curve of 41,000 RPM. All off-design points at a CIP of $70 \mathrm{kPa}$ are located on the corrected speed line of 29,000 RPM. Further reduction in the CIP results in an L.P. turbine corrected mass flow rate that is above the flow rate corresponding to the operating line. Therefore, the power reduction strategy through variation of CIP is limited to the CIP of $70 \mathrm{kPa}$. The power level at the CIP of $70 \mathrm{kPa}$ is 47 percent of design-point power, or $9.4 \mathrm{~kW}$.

Further power reduction below 45 percent of full power $(9 \mathrm{~kW}$ of $20 \mathrm{~kW})$ is achieved through the reduction of TIT. The effect of decreasing the TIT on power output and cycle efficiency is depicted in Figure 7.5. The power and efficiency predictions are calculated at a CIP of $70 \mathrm{kPa}$, since the initial power reduction (from $20 \mathrm{~kW}$ to $9 \mathrm{~kW}$ ) will be accomplished by reducing the CIP from $119 \mathrm{kPa}$ to $70 \mathrm{kPa}$. The effect of TIT on cycle efficiency is nearly linear, and the effect of TIT on power output is linear. Zeropower level is predicted at $950 \mathrm{~K}$, at which point speed parameter compatibility between compressor and H.P. turbine requires operation at a pressure ratio that is too low for expansion in the power turbine (see the $950 \mathrm{~K}$ point marked on the L.P. turbine performance map). At $70 \mathrm{kPa}$ and $950 \mathrm{~K}$, the $\mathrm{CBC}$ engine operates at idle condition. Gas generator operation (idle operation) is also possible at a TIT of $925 \mathrm{~K}$, which is the lowest possible TIT. 
The variation of TIT has a direct effect on the turbomachinery operating point since the turbine speed and mass flow parameters vary with the TIT, as determined by Equation 7.6 and 7.7 respectively. For a pre-determined compressor operating point, the reduction of TIT results in a higher H.P. turbine corrected mass flow rate at a higher turbine operating pressure ratio, and a reduction of the L.P. turbine pressure ratio. Therefore, to maintain the H.P. and L.P. turbine off-design operating point within the mass flow rate corresponding to the operating line, the compressor pressure ratio and corrected mass flow rate must be reduced. The compressor pressure ratio must also be reduced to operate with an adequate surge margin. The off-design operating points are shown on each of the turbomachine performance maps (Appendix C, Figure C.1 to C.3). The off-design points of $925 \mathrm{~K}$ and $950 \mathrm{~K}$ correspond to idle conditions and the $1025 \mathrm{~K}$ point corresponds to the design point.

In addition to off-design performance prediction, the off-design performance calculations were used to predict the fuel flow requirement at varying power levels. The fuel flow requirement has been predicted in the idle to design-point power range, and is shown in Figure 7.6. The fuel flow rate requirement increases nearly linearly with the power generation output level. Any non-linearity may be attributed to variations in the turbocharger efficiency at off-design conditions. The fuel flow rate is based on the calorific value of diesel fuel, which is $43.3 \mathrm{MJ} / \mathrm{kg}$ [7.5]. The CBC output power level is controlled of the power level through tandem variation of CIP and fuel flow rate. 


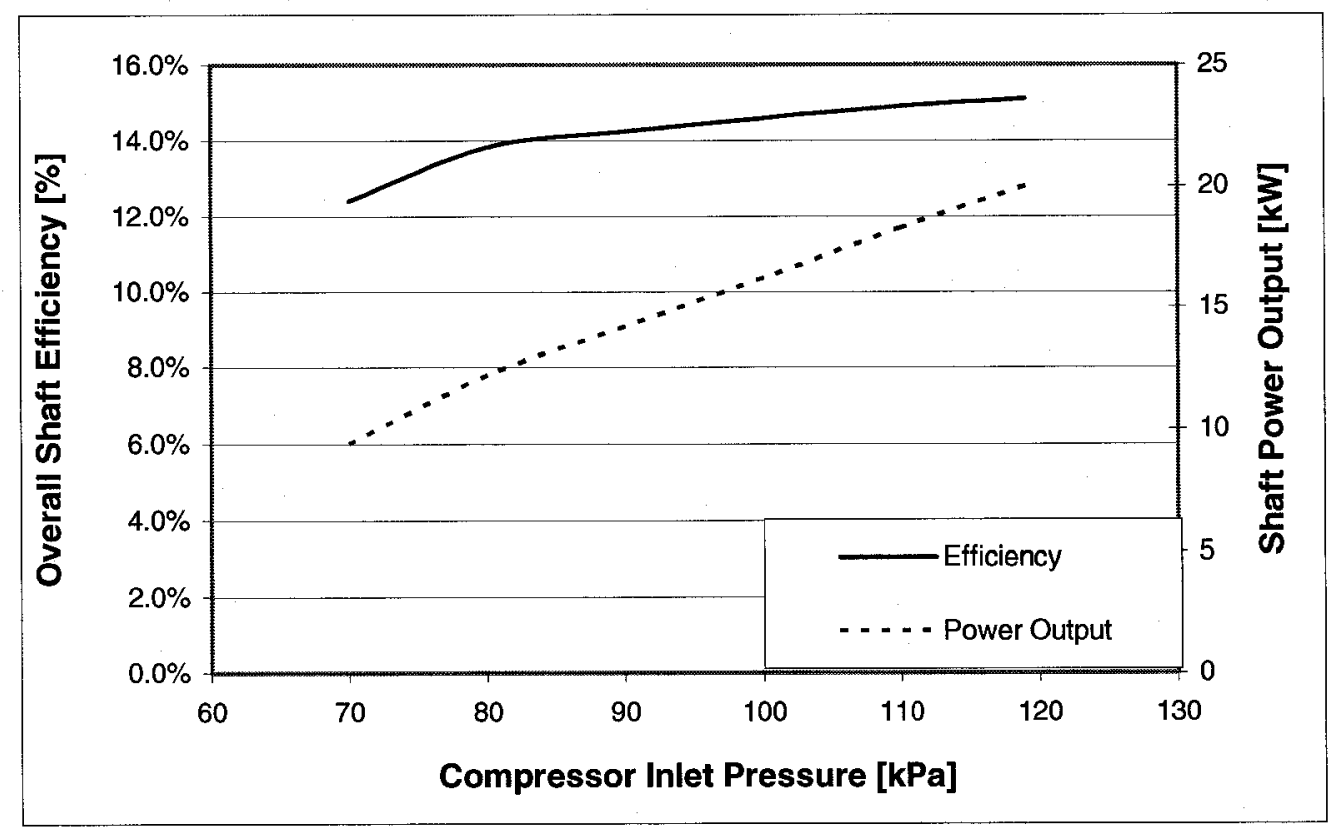

Figure 7.4: CBC Efficiency and Shaft Power Output as Controlled by the Compressor Inlet Pressure from Full to Half Load

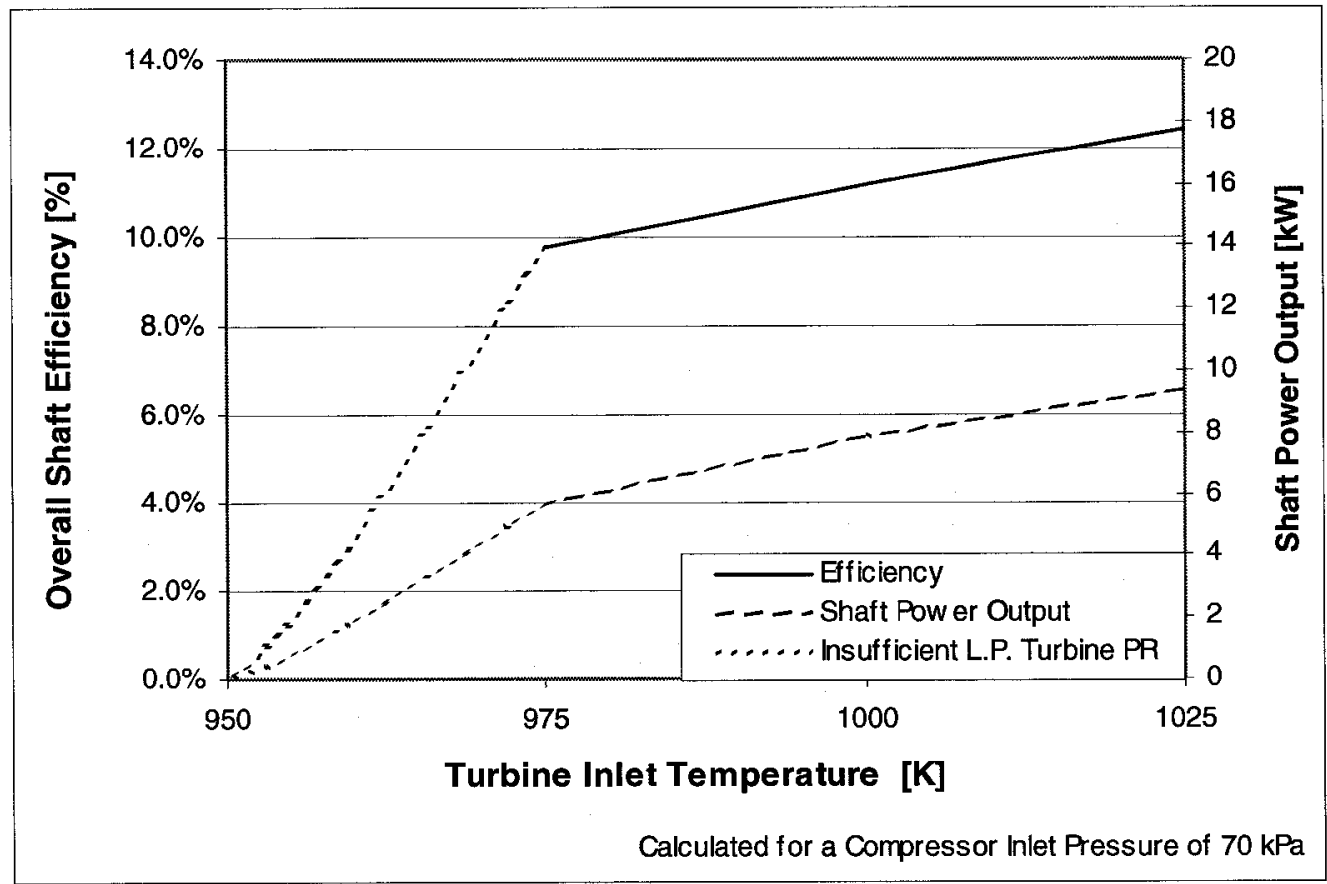

Figure 7.5: CBC Efficiency and Shaft Power Output as Controlled by Turbine Inlet Temperature from Half Load to No Load 


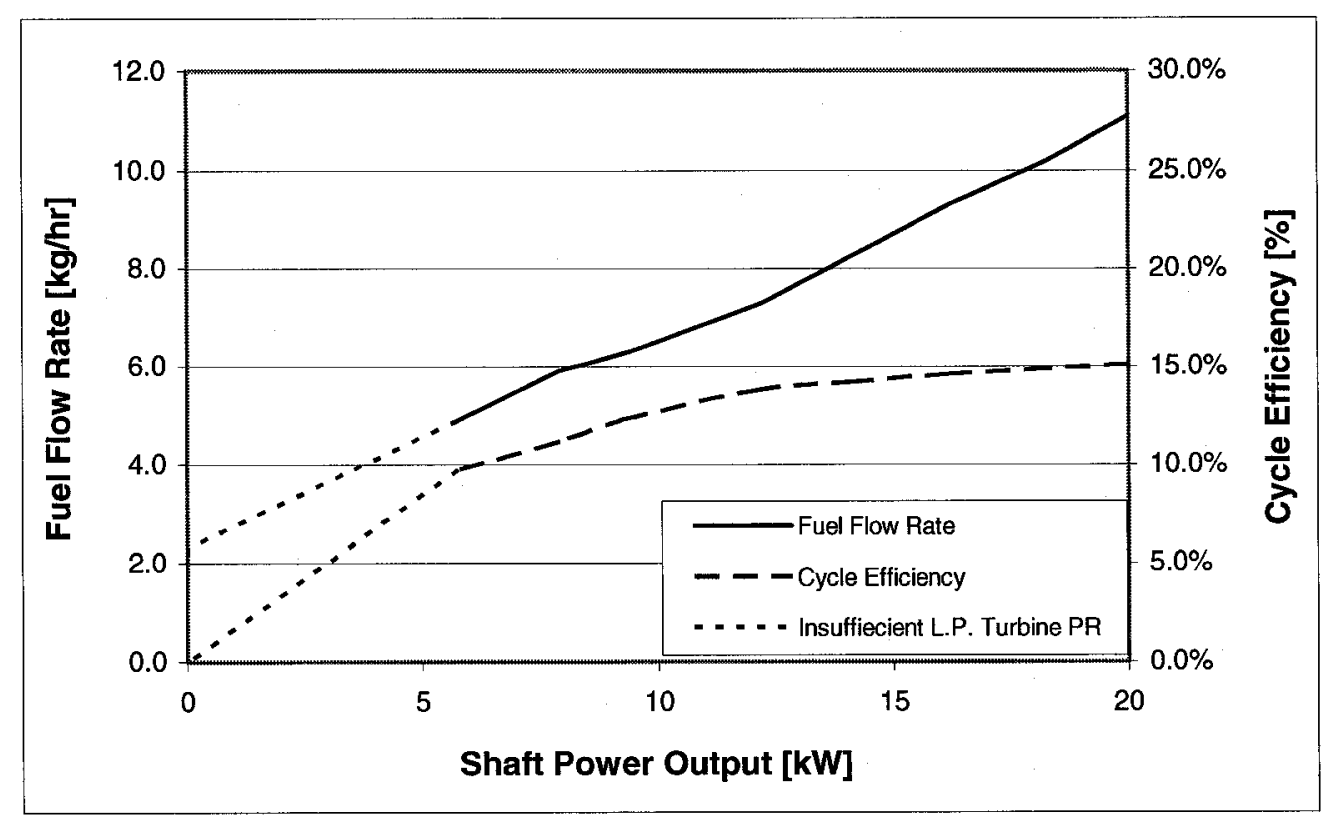

Figure 7.6: Fuel Flow Requirement at Off-Design Conditions

\subsection{Off-Design Performance of a Hypothetical OBC Engine}

The off-design performance of a hypothetical Open Brayton Cycle (OBC) engine has been calculated to compare the predicted performance between the $\mathrm{OBC}$ and the $\mathrm{CBC}$ engine. The components of the hypothetical $\mathrm{OBC}$ are expected to operate at the same performance level and it is assumed that the same turbochargers are utilized as in the $\mathrm{CBC}$ engine. The only exception is that the $\mathrm{OBC}$ will operate at atmospheric pressure (101.325 kPa), and a higher CPR (3) to match the power output (20kW) as well as flow and speed compatibility between the compressor and H.P. turbine. Also, a combustor will be utilized instead of a hot-side heat exchanger. Therefore, the combustion efficiency is expected to be higher than with the $\mathrm{CBC}$, and the pressure drop is expected to be lower than the CBC. The combustor efficiency is modeled at 99 percent with a pressure drop of 2 percent compressor delivery pressure (CDP), which compares to the modeled CBC hot-side heat exchanger effectiveness of 90 percent and a pressure drop of 
3 percent CDP. The higher combustor performance and lower pressure losses result in higher calculated efficiency at full-load, 18.4 percent as compared to 15.1 percent for the CBC engine.

Power output control of the $\mathrm{OBC}$ is achieved solely through variation of the TIT. Decreasing the TIT to achieve lower power levels causes a shift in the H.P. and L.P. turbine operating point. The CPR and the corrected mass flow rate through the compressor is reduced to maintain the H.P. turbine corrected mass flow rate and pressure ratio on the operating line. Turbomachinery part-load operating points for application in an $\mathrm{OBC}$ are depicted in Appendix C, Figures C.4 to C.6. The reduction of TIT has a negative impact on the cycle efficiency. The overall impact of the power level on cycle efficiency is nearly linear. Non-linearity between $3.7 \mathrm{~kW}$ and $18.1 \mathrm{~kW}$ is due to varying isentropic efficiency of the L.P. turbine. The cycle efficiency below $3.7 \mathrm{~kW}$ is reduced to zero since the L.P. turbine pressure ratio too low for power generation.

In contrast, the part-load efficiency curve of the $\mathrm{CBC}$ engine is relatively flatter from 47 percent to 100 percent power ( 9.4 to $20 \mathrm{~kW}$ ). This is a result of the control strategy utilized with constant TIT and varying CIP, which leads to operation at a constant turbomachinery performance level. The small reduction cycle in efficiency at this power range (less than 3 percent) is due to the relatively higher-pressure losses. The efficiency curve slope for the $\mathrm{OBC}$ and $\mathrm{CBC}$ is similar for power levels from 0 to 45 percent since a similar control strategy is used. For power levels of $3.7 \mathrm{~kW}$ to $9 \mathrm{~kW}$, the reduction of TIT results in a relatively steep slope in the efficiency. At low power levels (below $3.7 \mathrm{~kW}$ ), the pressure ratio is not sufficient for efficient L.P. turbine operation, resulting in a rapid deterioration in cycle efficiency. The part-load efficiency as a function of mechanical power output for the $\mathrm{OBC}$ and $\mathrm{CBC}$ is shown in Figure 7.7. At power levels above $11 \mathrm{~kW}, \mathrm{CBC}$ off-design performance is predicted to have a flatter efficiency curve. At power levels below $11 \mathrm{~kW}$, the CBC off-design performance is predicted to be similar to $\mathrm{OBC}$ off-design performance. 


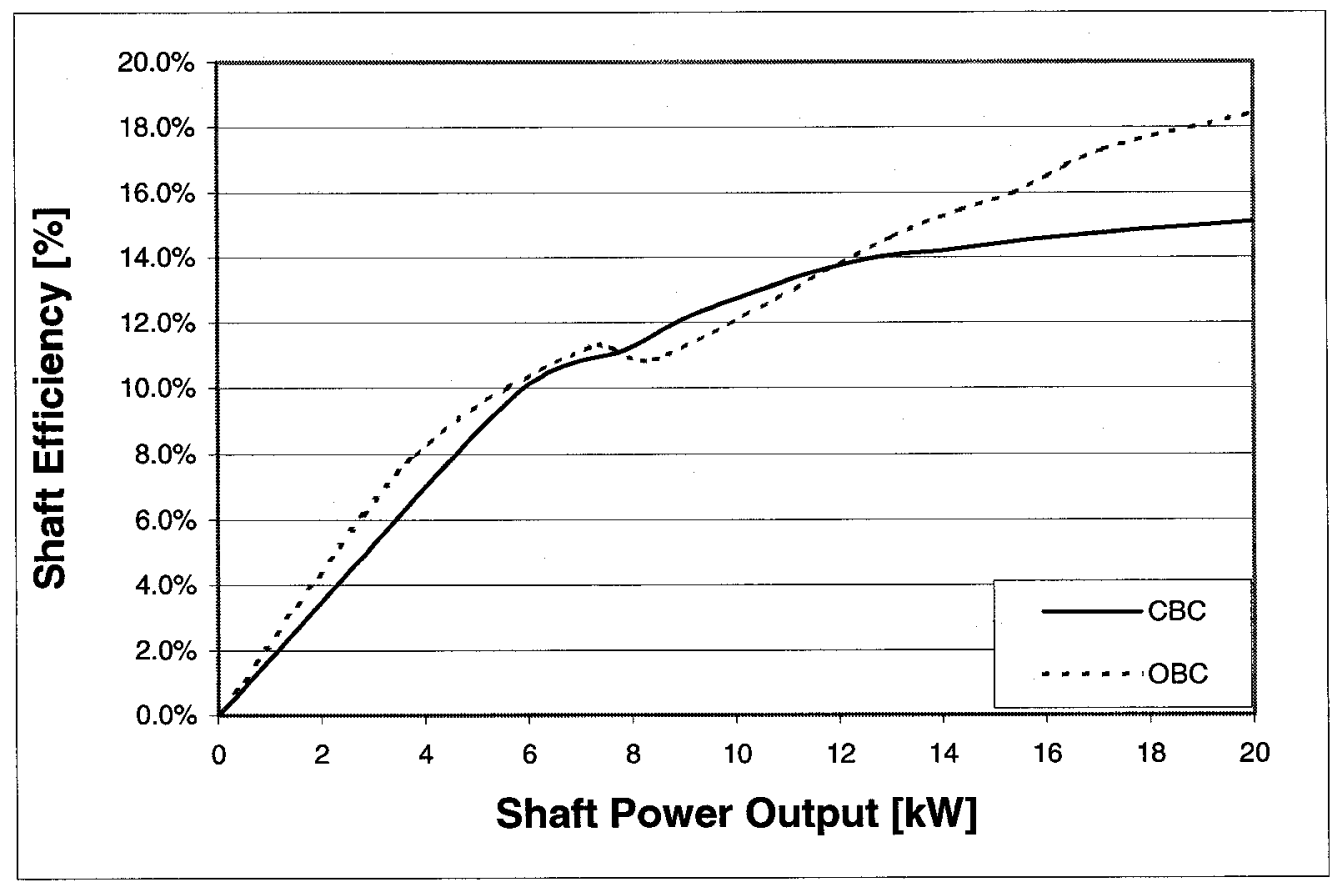

Figure 7.7: Part-Load Efficiency as a Function of Power for the $\mathrm{CBC}$ and the OBC

\subsection{Conclusions}

As a result of the low cost and wide availability, the application of turbochargers for a gas generator and power turbine in a $\mathrm{CBC}$ engine is favourable. Two turbochargers have been selected to operate at the predetermined compressor pressure ratio and corrected mass flow rate. These turbochargers have been selected based on relative comparison of the highest possible efficiency. Performance maps for the turbochargers have been obtained, and the design-point compressor, H.P. turbine, and L.P. turbine isentropic efficiency has been determined as 77 percent, 70 percent, and 78 percent respectively. Based on this data, the cycle efficiency at the design point has been determined to be 15.1 percent. 
Off-design performance calculations have been conducted in conjunction with turbocharger performance maps to ensure accurate performance prediction and stable operation at an adequate surge margin. An off-design control strategy has also been developed. The control strategy involves regulating the CIP from the design-point value of $119 \mathrm{kPa}$ to $70 \mathrm{kPa}$. Regulating the CIP prevents variation of the design-point TIT and variation of turbocharger design-point efficiency. In this manner, 50 percent of the design-point power can be reached with efficiency loss below 20 percent. This compares to an efficiency loss of 35 percent for half power operation with an open cycle engine. The power reduction strategy through variation of CIP is limited to the CIP of $70 \mathrm{kPa}$. At lower CIP values, the total-to-total L.P. turbine pressure ratio lower, and corrected mass flow rate corresponding to the operating line is lower. Reduction of the H.P. turbine mass flow rate is only possible through a reduction in TIT and CPR.

The control strategy of varying the TIT with the power loading requirement is used in the power range of $0 \mathrm{~kW}$ to $9.4 \mathrm{~kW}$. Operation at a lower than design point TIT has a negative impact on the CBC part-load efficiency. The reduction in TIT is possible from $1025 \mathrm{~K}$ to $950 \mathrm{~K}$, at which point no net power is generated and the CBC engine is operating at idle speed. Off-design performance and fuel flow-rate requirement has been calculated for all power levels. The part-load performance of the $\mathrm{CBC}$ engine has a flatter efficiency curve due to the control strategy of regulating the CIP and the TIT. 


\section{CHAPTER 8}

\section{Heat Exchanger Thermal-Hydraulic Theory}

\subsection{General Introduction}

A heat exchanger is a heat-transfer device that transfers internal energy between fluids at different temperatures that are separated by a heat-transfer surface [8.1]. Three heat exchangers are required in the CBC engine: the hot-side heat exchanger (HSHE), the recuperator, and the cold-side heat exchanger (CSHE). The HSHE transfers heat from atmospheric flue gas to the high-pressure gas. The recuperator transfers heat from the low pressure, high temperature turbine outlet working gas to the high pressure, low temperature compressor outlet gas. The CSHE removes remaining heat from the lowpressure gas to return the gas to the CIP state.

Several of the heat exchanger types are introduced in this chapter. Thermalhydraulic design algorithms have been developed for the most appropriate HSHE types. The thermal-hydraulic design algorithm enables heat exchanger sizing. Detailed sizing is required to determine the most suitable heat exchanger type for the $\mathrm{CBC}$ application, based on heat exchanger design target size and performance. 
The HSHE is considered the most critical component in the $\mathrm{CBC}$ engine design due to operation at high temperature and substantial pressure. Since the recuperator also operates at a high service temperature and pressure, the selected heat exchanger type should be similar to the HSHE. Therefore, the thermal hydraulic design algorithm presented in this chapter will be applicable for both the HSHE and the recuperator.

\subsection{Heat Exchanger Classifications Considered for CBC Application}

\subsubsection{Plate-Fin Heat Exchanger}

Heat exchangers are typically characterized according to their method of construction. Numerous heat exchangers are available, although only a few are applicable to the high temperature and pressure requirements of a Brayton-cycle engine. The most commonly used heat exchanger in the gas turbine industry is the plate-fin exchanger. The plate-fin heat exchanger is a type of compact heat exchanger consisting of alternate flat plates, (called parting sheets) and fin corrugations, brazed together as a block [8.1]. Fluid streams flow along the passages formed by corrugations between the parting sheets, which serve as both secondary heat transfer surfaces and mechanical supports (see Figure 8.1). Since the corrugations form high-density heat transfer surface area, plate-fin heat exchangers are very compact. This compactness amounts to about 25 times more surface area per equipment weight than the shell and tube heat exchangers. As a result, typical applications include areas where compactness and weight is critical, including aerospace and transport applications. Other cases where plate-fin heat exchangers are utilized include cryogenic applications [8.1], as well as, air-to-air regenerators in microturbines and small sized gas turbines (under $10 \mathrm{MW}$ ) [8.2].

Plate-fin heat exchangers are commonly used for gas-to-gas applications since they offer a highly effective means for heat transfer. Provided correct materials are selected, operational temperature capability may range from near absolute zero $(0 \mathrm{~K})$ to 
more than $800^{\circ} \mathrm{C}$. The upper temperature level is somewhat limited by the fin thickness, the type of fin-to-plate bonding, and the materials employed. Upper pressure level is also limited by the same conditions, and the maximum upper pressure limit is about $1000 \mathrm{kPa}$ (150 psig). Maximum size is limited only by brazing furnace dimensions, and by furnace weight capacity limits. The main limitation of the plate-fin heat exchanger is that the small flow passage size requires operation in relatively clean working fluids [8.1]. Since the CBC engine application area is intended for the combustion of waste oils, which will result in flue gasses with highly contaminated fouling particulates, the plate-fin heat exchanger is unsuitable for CBC application as the HSHE. Moreover, the plate-fin heat exchanger is costly to manufacture due to the large manufacturing time requirement of the large number of high-precision corrugated fins. Also, the only suitable method of joining plate and fin corrugations is by brazing, which prevents in-house manufacturing of this heat exchanger. Due to the difficulty in manufacturing and cleaning of fouling particulates, the plate-fin heat exchanger is not considered for application in the CBC engine.

\subsubsection{Tube-Fin Heat Exchanger}

A tube-fin heat exchanger utilizes a number of finned-tubes as the primary heat transfer surface area, and to separate the tube-side working fluid from the shell-side working fluid. The tube-fin heat exchanger is widely utilized in industry in a variety of application areas. It is typically employed when one fluid stream is at a higher pressure and/or has significantly higher heat-transfer coefficient as compared to the other fluid stream. Applications involve gas-liquid heat exchangers, where the liquid has high heattransfer coefficient as compared to the gas. Typical arrangement involves liquid on the tube side and gas on the shell side, where fins provide increased surface area for heat transfer. These heat exchangers are extensively employed as condensers and evaporators in air-conditioning and refrigeration applications, air-cooled exchangers in process and power industries [8.1], and heat recovery units in process industry [8.3]. This type of heat exchanger is considered for application as Cold-Side Heat Exchanger. 
The tube-fin heat exchanger is also considered for application as a HSHE in the $\mathrm{CBC}$ engine as a result of the possible compactness that may be achieved with the application of finned tubes. Although the heat exchanger size is typically larger than the plate-fin heat exchanger, the hydraulic diameter on the tube side is also significantly larger. Large hydraulic diameter (or passage area) on the tube side can accommodate passage of fouling particulate matter from the waste-oil flue gas. Moreover, a large tube diameter facilitates the possibility of mechanical or chemical cleaning of the particulate matter inside the tubes [8.1]. Unlike the plate-fin heat exchangers, tube-fin heat exchangers may be utilized in a fouling environment.

Similarly to the plate-fin heat exchanger, the application of finned tubes has a limiting factor on the operational temperature and pressure as a result of the low fin thickness and the additional bonding requirement between the tube and the fins. However, this limitation is beyond operational limits of the heat exchanger. The fins can be manufactured from high-temperature stainless steel and joined by the manufacturer by brazing to withstand high temperatures and pressures. Although the brazing process is costly, the increased surface area of finned tubes presents a possibility of implementing significantly fewer tubes. Installation of fewer tubes may significantly reduce capital and manufacturing costs. Therefore, thermal-hydraulic design of the tube-fin heat exchanger is conducted to estimate the size and performance of the heat exchanger. Size and performance of the tube-fin heat exchanger, which will indicate the relative material and manufacturing cost, is compared to the size and performance of other heat exchanger types to determine the most applicable and cost effective heat exchanger type.

\subsubsection{Shell and Tube Heat Exchanger}

Shell and tube heat exchangers are the most versatile and commonly used heat exchangers in industry. Over 90 percent of heat exchangers used in industry are shell and tube type since they offer great flexibility to meet almost any service requirement. Shell and tube heat exchangers are used in conventional and nuclear power generation, 
chemical and process industry [8.1]. This type of heat exchanger consists of a bundle of tubes fixed in a tubesheet and placed inside a cylindrical shell. One fluid stream flows through the tubes and the other along or across the tubes. An illustration of a shell and tube heat exchanger is provided in Figure 8.1. This illustration is indicative of the general arrangement of shell and tube heat exchangers, although variations in straight or U-shaped tubes, shell types, inlet headers, and outlet headers are available depending on application area [8.4].

The shell and tube heat exchanger is considered for CBC engine application. The exchanger is flexible in operation and environmental conditions. No temperature or pressure limitations exist provided suitable materials are selected and provision for thermal expansion is incorporated. Shell and tube heat exchangers are accommodating to operation with fouling fluids, provided access for cleaning is allotted. Tube inner-surface may be cleaned mechanically or chemically. The shell-side may also be cleaned if the design allows for tube-bundle removal [8.1].

Despite the large size, cost of shell and tube heat exchangers is typically modest. This is partly due to established procedures for design and manufacturing for a wide variety of materials. Satisfactory, durable, and long-life service is offered by shell and tube heat exchangers as a result of extensive experience record and wide availability of codes and standards. The application of established technology may prove cost effective in terms of design, manufacturing, and maintenance costs [8.1]. Therefore, the thermalhydraulic design of the shell and tube heat exchanger is conducted to estimate the size and performance of the heat exchanger. Size and performance comparison, as well as ease of manufacturing and relative cost of the shell and tube heat exchanger is compared with the tube-fin heat exchanger to determine the most applicable and cost effective heat exchanger type and design. 


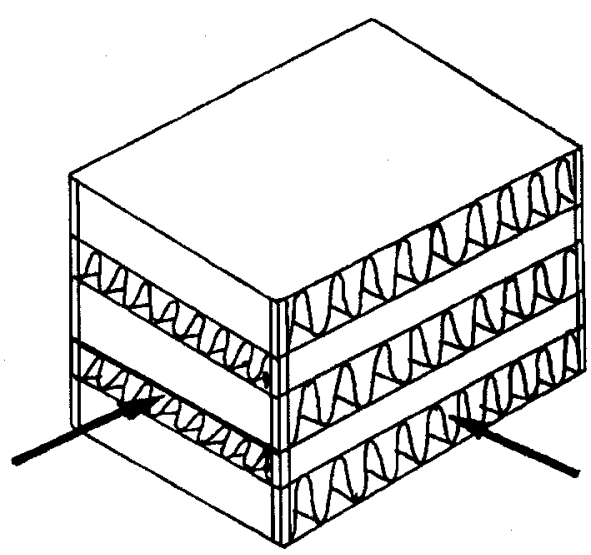

(a)

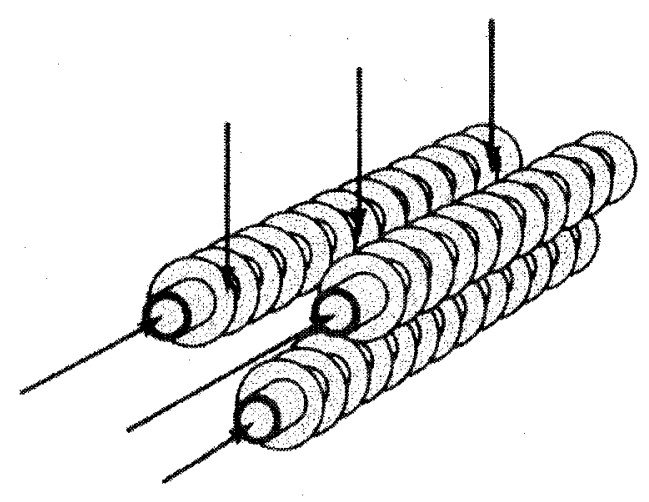

(b)

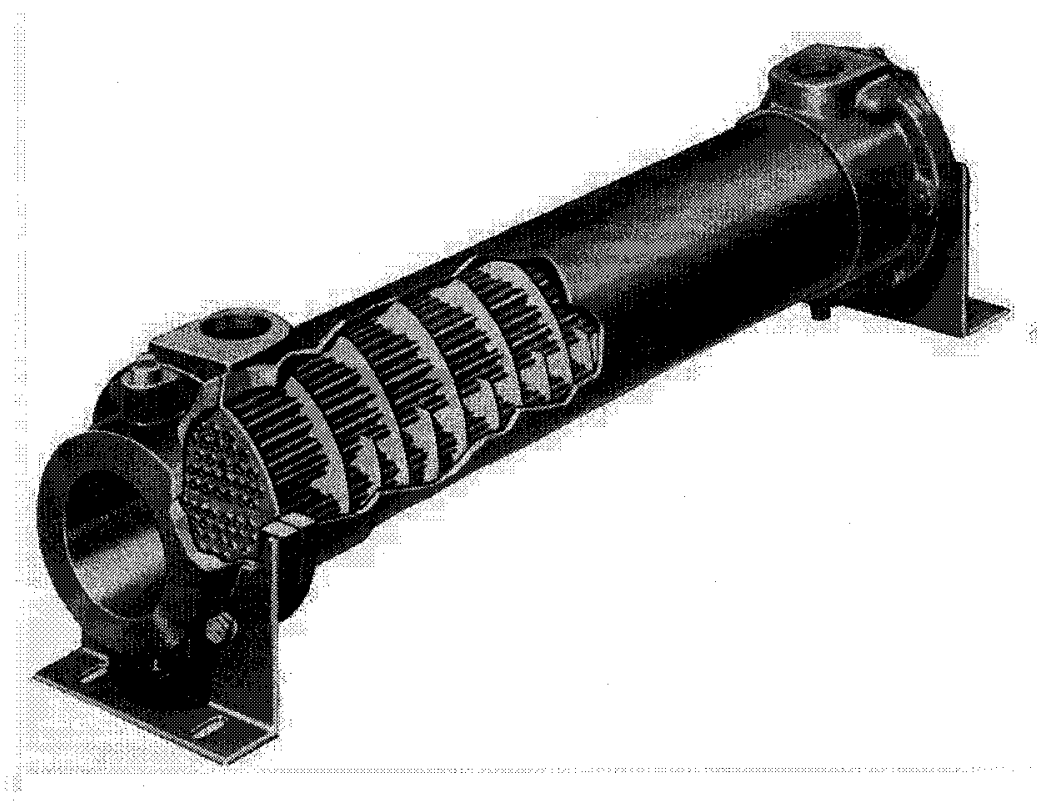

(c)

Figure 8.1: Heat Exchanger Configurations: (a) Plate-Fin, (b) Fin-Tube, and (c) Shell and Tube Heat Exchanger [8.1], [8.5] 


\subsubsection{Other Heat Exchangers}

Although numerous other types of heat exchangers exist, they have not been considered for $\mathrm{CBC}$ engine application for several reasons. The heat exchanger selected for $\mathrm{CBC}$ engine application must withstand high temperature and pressure, as well as, severe fouling conditions. High performance must be possible, which includes high heat exchanger effectiveness and a low-pressure loss. Construction of the heat exchanger must be simple for in-house fabrication, and the heat exchanger must be low cost. Based on these considerations, only the shell and tube heat exchanger and the tube-fin heat exchanger are considered candidate heat exchangers for $\mathrm{CBC}$ engine application. Following the thermal-hydraulic design, the type of heat exchanger will be selected based on size, performance and relative cost.

\subsection{General Fluid Flow and Heat Transfer Relations}

Several non-dimensional fluid flow and heat-transfer relations are defined in this section. First, the shell-side Reynolds number relates the inertial energy to viscous energy. It is calculated to determine whether the flow is laminar or turbulent. Moreover, the magnitude of Reynolds number impacts heat-transfer rate [8.5]. The Reynolds number for tube flow, $\mathrm{Re}_{\mathrm{di}}$, and shell-side flow, $\mathrm{R}_{\mathrm{do}}$ or $\mathrm{Re}_{\mathrm{D}}$ is defined below:

$$
\begin{aligned}
& \operatorname{Re}_{d_{i}}=\frac{G_{t} d_{i}}{\mu} \quad \text { for Tube Flow } \\
& \operatorname{Re}_{d_{o}}=\frac{G d_{o}}{\mu}=\frac{G d_{r}}{\mu} \quad \text { or } \quad \operatorname{Re}_{D}=\frac{G D_{h}}{\mu} \quad \text { for Shell-Side Flow }
\end{aligned}
$$

The mass velocity, $G$, is defined in Equation 8.2a for tube-side flow, and 8.2b for shell-side flow. The mass velocity is typically used in shell-side heat-transfer empirical equations with the value corresponding to the maximum mass velocity at the minimum flow area. 


$$
\begin{aligned}
& G_{t}=(\rho U)_{t}=\frac{m}{\frac{\pi}{4} d_{i}^{2} N_{t}} \\
& G=\frac{m}{A_{o}}=\rho U \frac{A_{F r}}{A_{o}}
\end{aligned}
$$

The Reynolds number length scales that may be used for shell-side flow are the tube outer diameter (O.D.), $d_{0}$, the root diameter, $d_{r}$, or the hydraulic diameter, $D_{h}$. If the tube-side Reynolds number is evaluated, the inner diameter (I.D.), $d_{i}$, is used for the length scale. Choice of length scale between O.D. and root diameter depends on the manufacturing method involved. For simplicity, it is assumed that the two diameters are equivalent, i.e., $d_{0}=d_{r}$. In general, either the O.D. or the hydraulic diameter are used as the characteristic length scale in heat transfer and pressure drop correlations. It is essential to distinguish which characteristic length scale is applied in each correlation [8.1].

The Prandtl number is a non-dimensional parameter that relates the relative thickness of the hydrodynamic and thermal boundary layers. The kinematic viscosity of the fluid relates the rate at which momentum may diffuse through the fluid due to molecular motion. The thermal diffusivity, $\alpha$, relates diffusion of heat in the fluid. Therefore, the Prandtl number conveys the relative magnitude of diffusion of momentum to the diffusion of heat in the fluid. The Prandtl number is defined as [8.5]:

$$
\operatorname{Pr}=\frac{v}{\alpha}=\frac{\mu / \rho}{k / \rho C p}=\frac{C p \mu}{k}
$$

The Nusselt number is a non-dimensional expression of the heat-transfer coefficient correlated by a length scale and working gas heat transfer properties. It is defined as:

$$
N u=\frac{h D_{h}}{k}
$$




\subsection{Heat Exchanger Thermal-Hydraulic Design Theory}

The procedure for sizing a heat exchanger that is described in this section involves iterative calculation of the heat-transfer surface area and the overall heat-transfer coefficient. The overall heat-transfer coefficient is a function of the heat exchanger type, arrangement, and surface area. Therefore, detailed calculations vary for the shell and tube heat exchanger type and the tube-fin heat exchange type. However, the basic equations for heat transfer analysis are applicable for every heat exchanger type, flow arrangement, and fluid type. In every heat exchanger, energy conservation between two fluid streams applies. Therefore, the heat transfer rate is expressed as:

$$
Q=m C p\left(T_{h, 1}-T_{h, 2}\right)=m C p\left(T_{c, 2}-T_{c, 1}\right)
$$

The above equation may be simplified by using one of several common heat exchanger design methods. The LMTD method has been chosen for application since it is commonly used for shell and tube heat exchangers. The total heat transfer rate, $\mathrm{Q}$, between the fluids is expressed by the product of thermal conductance, $U A$, and the mean temperature difference, $\Delta T_{m}$.

$$
Q=U A \Delta T_{m}
$$

The thermal conductance, $U A$, is a product of the overall heat transfer coefficient, $U$, and the heat transfer surface area, $A$. The mean temperature between hot and cold fluid is inconvenient to use since the temperature distribution is an exponential function of area, which is unknown. It is therefore convenient to express the temperature difference between hot and cold fluids as a difference in the terminal temperatures. This is known as the log mean temperature difference, or $L M T D$, and is expressed as:

$$
L M T D=\Delta T_{l m}=\frac{\left(T_{h, 1}-T_{c, 2}\right)-\left(T_{h, 2}-T_{c, 1}\right)}{\ln \left[\left(T_{h, 1}-T_{c, 2}\right) /\left(T_{h, 2}-T_{c, 1}\right)\right.}
$$


The overall heat transfer equation is expressed as a function of $L M T D$ as:

$$
Q=U A F \Delta T_{l m}
$$

$F$ is the correction between the true mean temperature difference, $\Delta T_{m}$, and $L M T D$, and is defined in Equation 8.9. This correction factor is dimensionless, and unity for true counterflow exchanger. For other arrangements, $F$ is generally less than unity. A value approaching unity does not signify a highly efficient heat exchanger, however, it does reflect close approach to counterflow fluid behaviour. $F$ is a function of thermal effectiveness, $P$, heat capacity ratio, $R$, number of transfer units, $N T U$, and the flow arrangement. The value is typically extracted from $F-P-R-N T U$ figures that are commonly found in literature such as Reference [8.1].

$$
F=\frac{\Delta T_{m}}{\Delta T_{l m}}
$$

The thermal effectiveness, $P$, is the ratio of the temperature rise or drop of the tube-side fluid (regardless whether it's the hot or cold fluid) to the difference in inlet temperature of the two fluids.

$$
P=\frac{T_{t, 2}-T_{t, 1}}{T_{s, 1}-T_{t, 1}}
$$

The heat capacity ratio, $R$, is the ratio of the tube-side temperature difference to shell-side temperature difference. The value of $R$ ranges from zero to infinity, zero being pure vapour condensation and infinity being pure liquid evaporation.

$$
R=\frac{T_{s, 1}-T_{s, 2}}{T_{t, 2}-T_{t, 1}}
$$


Application of the above equations leads to the thermal conductance as the only unknown. The thermal conductance is the product of overall heat-transfer coefficient, $U$, and the heat-transfer surface area, $A$. The thermal conductance of inner-tube and outertube fluid stream is equivalent (i.e., $U A=U_{i} A_{i}=U_{o} A_{o}$ ). The overall inner-tube and outertube heat-transfer coefficient is determined by:

$$
\begin{aligned}
& U_{i}=\frac{1}{\frac{1}{h_{i}}+R_{f i}+A_{i} R_{w}+\frac{R_{f o}}{\eta_{o}} \frac{A_{i}}{A_{o}}+\frac{1}{\eta_{o} h_{o}} \frac{A_{i}}{A_{o}}} \\
& U_{o}=\frac{1}{\frac{A_{o}}{A_{i}} \frac{1}{h_{i}}+\frac{A_{o}}{A_{i}} R_{f i}+A_{o} R_{w}+\frac{R_{f o}}{\eta_{o}}+\frac{1}{\eta_{o} h_{o}}}
\end{aligned}
$$

where:

$\begin{array}{ll}A_{i} & \text { Tube-side surface area } \\ A_{o} & \text { Shell-side surface area } \\ h_{i} & \text { Film coefficient of tube side fluid (due to convection) } \\ h_{o} & \text { Film coefficient of shell side fluid (due to convection) } \\ R_{f i} & \text { Tube-side fouling resistance } \\ R_{f o} & \text { Shell-side fouling resistance } \\ R_{w} & \text { Tube wall resistance (due to conduction) } \\ \eta_{o} & \text { Overall surface effectiveness }\end{array}$

As seen in Equation 8.12, the overall heat-transfer coefficient is a function of the heat transfer surface area. Therefore, an iterative solution of the heat exchanger size is required since both the heat-exchanger surface area and the overall heat-transfer coefficient are related and unknown. The heat exchanger thermal design is performed according to the following iterative procedure. 
1) Approximate the heat-exchanger surface area using Equation 8.8. An approximate value of the overall heat transfer coefficient is used. The value for a typical gas-to-gas heat exchanger is in the range 10$40 \mathrm{~W} / \mathrm{m}^{2 \circ} \mathrm{C}[8.5]$.

2) Define the heat-exchanger geometry according to the approximate heattransfer surface area initially found in step- 1 and subsequently found in step-5.

3) Determine the shell-side convective heat-transfer coefficient, $h_{o}$, the tube-side convective heat-transfer coefficient, $h_{o}$, the tube conductive heat transfer coefficient, $R_{w}$, and the fouling resistances, $R_{f i}$ and $R_{f o}$, for the defined geometry.

4) Determine the overall heat-transfer coefficient as per Equation 8.12.

5) Calculate a more-accurate heat-transfer surface area using Equation 8.8 and the overall heat-transfer coefficient that is found in step-4.

6) Iterate Steps 2 to 5 until the difference in the heat-transfer surface area value between iterations is negligible. 


\subsection{Input Data - Required Geometrical Parameters}

The geometrical parameters that are required to evaluate the initial heat-transfer surface area for tube-fin heat exchanger and shell and tube heat exchanger are described in this section. The required initial parameters include the shell configuration and size, tube geometry and layout, as well as baffle geometry and layout. The geometry and configuration must be consistent with Tubular Exchanger Manufacturing Association (TEMA) Standards [8.6], which are introduced in this section. It should be noted that manufacturing dimensions will be described in imperial units and non-manufacturing dimensions in SI units.

\subsubsection{Shell Configurations}

\subsubsection{Shell and Tube Heat Exchanger}

Major components of the shell and tube heat exchanger are the front head, the shell, and the rear head, which are classified in alphabetic format by the TEMA Standards. There are seven major types of shells, five types of front heads, and eight types of rear heads, which are shown in Figure 8.2 [8.6]. The head sections do not influence the heat transfer characteristics, and the design choice will be governed by mechanical considerations. However, the shell type has a governing effect on the flow path, and therefore, on the heat transfer rate. As a result, the heat-transfer and pressuredrop relations will vary according to the selected shell configuration [8.1]. Therefore, shell-type selection is the initial step in the design process.

The TEMA E shell is the most commonly used shell since it is simple and the most cost effective to manufacture. Fluid passes through the shell once, with the entry and exit nozzles attached to the opposite ends of the shell. Tubes may pass several times through the shell, although single-pass straight tubes are most commonly applied. The tubes are supported by transverse baffles, which also guide the shell-side flow to a near crossflow arrangement [8.1]. 
The flow arrangement in the TEMA F shell consists of two passes on the shell side, and typically, two passes on the tube side. The TEMA F shell is essentially a TEMA E shell, with a longitudinal baffle welded along the centre. The longitudinal baffle enables two flow passes, which results in flow reversal at one end. The location of entry and exit nozzles is at the opposite end to the location of flow reversal. Although from a heat transfer point of view the TEMA $F$ shell is a desirable flow arrangement, several problems are associated with the implementation of a longitudinal baffle. One problem is that there will be conduction along the longitudinal baffle. Also, in the case the longitudinal baffle is not continuously welded to the shell or sealing is not incorporated, fluid leakage from the high pressure to the low-pressure side will occur. Both these factors will reduce the heat exchanger effectiveness. Also, welding of the longitudinal baffle prevents the ability to withdraw the tube bundle for inspection and cleaning. Due to these drawbacks, the TEMA F shell is rarely utilized [8.1].

The TEMA G shell or split flow exchanger constitutes of one central inlet and one central outlet nozzle. A longitudinal baffle is positioned in the centre, which splits the flow into two streams that flow to the shell ends. The $\mathrm{G}$ shell is popular due to high heat transfer characteristics and low incurred pressure drop [8.1]. However, the associated drawbacks of utilizing a longitudinal baffle are incurred.

The TEMA H shell or double split flow exchanger is similar to the TEMA G shell, except that two inlet nozzles and two outlet nozzles are applied. This shell type is used when the allowable pressure drop is very limited [8.1].

The TEMA J shell or divided flow exchanger has a single nozzle at the midpoint of the shell and two nozzles near the tube ends. The single or the double nozzle may be used for either inlet or outlet. Typically, the single nozzle is used as the inlet, and the flow is split into two streams. The streams flow in longitudinal directions along the length of the heat exchanger and exit from the two nozzles. In this arrangement, the flow 
velocity is half the velocity in TEMA E shell, which results in a pressure drop of oneeighth of the TEMA E exchanger. Therefore, this shell is used for low pressure drop applications [8.1]. Common practice is to utilize the $\mathbf{J}$ shells in stacked pairs, usually with single nozzles as inlet and outlet.

The TEMA K shell or kettle type reboiler is used for partially vaporizing the shell fluid or as a chiller is the refrigeration industry. The configuration consists of a horizontal bundle of U-tubes placed in an oversized shell, with nozzles placed at the bottom to drain excess liquid. This shell is not suitable for application as an air-to-air heat exchanger [8.1].

The TEMA X shell is a pure crossflow arrangement. No baffles are implemented, and support plates are used to prevent tube vibration. Nozzles are positioned as in the G shell. Shell side fluid is divided into many sub-streams by the support plates, which then flows through each tube bundle. These heat exchangers are prone to flow maldistribution. Pressure drop is low for the $\mathrm{X}$ shell heat exchanger [8.1]. The $\mathrm{X}$ shell is mostly used in condensing applications, and occasionally used for low pressure gas heating and or cooling [8.7].

Typically, the E and F shells are used for single-phase fluids as a result of the relatively long flow path. In this case, the $\mathrm{E}$ shell is preferred since it is easier to manufacture, tubes can be withdrawn and cleaned, and it can operate with high effectiveness. For single-phase flow, $\mathrm{G}$ and $\mathrm{H}$ shells are not used since there is no benefit in heat transfer. These exchangers are typically used for phase-change applications. The $\mathrm{J}$ shell will not be used since there is no advantage to divide the flow in the recuperator and HSHE. Also, due to the potential flow maldistribution problems and the short flow length, the $\mathrm{X}$ shell will not be applied for this application [8.1]. Therefore, it is recommended to utilize the $\mathrm{E}$ shell, which is the simplest, easiest to manufacture, cost effective, and most widely applied shell configuration. 

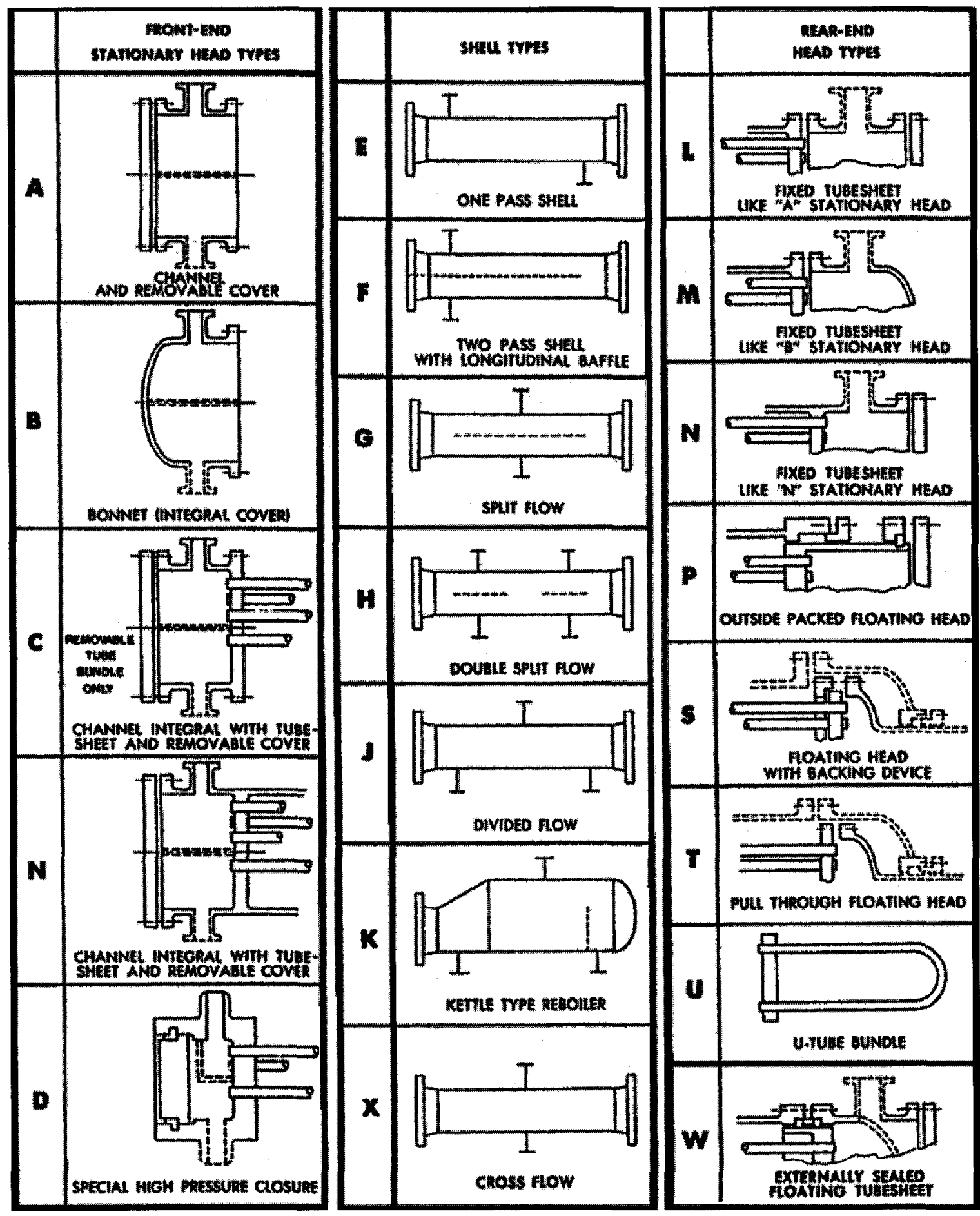

Figure 8.2: TEMA Front Head, Rear Head, and Shell Geometry Designations [8.6] 


\subsubsection{Tube-Fin Heat Exchanger}

The only possible tube-fin heat exchanger shell configuration is rectangular. The dimensions of the shell are $L_{1}$ in the tube-flow direction, $L_{2}$, in the shell-flow direction, and $L_{3}$ in the no-flow direction. The rectangular tube sheet dimensions are $L_{2}$ by $L_{3}$.

\subsubsection{Tube Geometry}

Tube dimensions are described in the same manner for shell and tube heat exchangers and tube-fin heat exchangers. Tube dimensions are specified to determine the heat-transfer surface area required to calculate the conductive and convective heat transfer rates. Tubes with various cross-sectional geometries are available, including circular, elliptical, and rectangular. Circular tubes are utilized since lowest tube thickness is required for pressure containment, and friction losses are lower then elliptical tubes [8.5]. Bare-tube dimensions are specified according to TEMA standards and include the tube outer diameter (O.D.), $d_{o}$, the tube thickness, $t$, and tube length, $L_{l}$. The tube dimension specifications are applicable for both the tube-fin heat exchanger and shell and tube heat exchanger.

\subsubsection{Tube Outer Diameter}

Most heat exchangers utilize tubes within the range of $1 / 4$ inch $(6.25 \mathrm{~mm})$ to 2 inches (5.8mm) O.D. TEMA sizes include: $1 / 4,3 / 8,1 / 2,5 / 8,3 / 4,7 / 8,1,1-1 / 4,1-1 / 2$, and 2 inches $(6.35,9.53,12.70,15.88,19.05,22.23,25.40,31.75,38.10$, and $50.80 \mathrm{~mm})$. Standard tube sizes for copper and copper alloy tubes, carbon steel, aluminium, and aluminium alloy tubes are provided in TEMA Standards RCB-2.21 [8.6]. Most popular tubes are the $3 / 8$ inch and the $3 / 4$ inch O.D. since they are most economical in most applications. It is recommended to use $1 / 4$ inch tubes for clean fluids [8.1]. For mechanical cleaning, the smallest practical tube size is $3 / 4$ inch $(19.05 \mathrm{~mm})$. Diameters larger than 1 inch are typically used for fouling service [8.1]. 


\subsubsection{Tube Thickness}

Tube thickness, $t$, is also specified by TEMA Standards, RCB-2.21, which uses the Birmingham wire gauge (BWG) [8.6]. The tube thickness must be checked against internal and external pressure, or pressure differential. Also, the tube thickness must provide an adequate margin against corrosion, fretting wear due to flow-induced vibration, and axial strength [8.1].

\subsubsection{Tube Length}

Since the heat exchanger size (especially the tube length) must be compatible with installation location size, a length restriction is placed on the tubes. If possible, long tubes should be used since heat exchangers are most economical with long tube lengths and small shell diameter [8.1]. According to TEMA Standards, RCB-2.1, standard lengths are 96, 120,144, 196, and 240 inches [8.6]. Other lengths may be used, although it is likely that tube cost would be higher due to lower availability of tubes in less common sizes.

\subsubsection{Number of Tubes}

The number of tubes, $N_{t}$, is typically specified. If the shell inside diameter is known, the maximum number of tubes can be found in tube-count tables (see Reference [8.7]) or calculated based on the shell inside diameter, tube diameter, and tube pitch (see Reference [8.8] for detailed procedure).

\subsubsection{Fin Geometry}

Finned-tubes can be used to increase the heat-transfer surface area for a given number of tubes, and can be applied to both the tube-fin and the shell and tube heat exchanger. Numerous tube geometries are available and sizes typically depend on the manufacturer. Shell and tube exchangers may employ low-finned, high-density tubes. Tube-fin heat exchangers may employ low, medium, or high-finned tubes of variable density and geometry. Possible fin geometries include plain circular fins, segmented fin, 


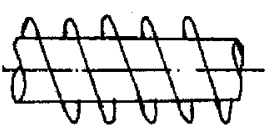

Helical

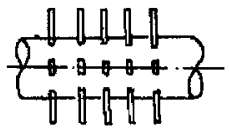

Studded
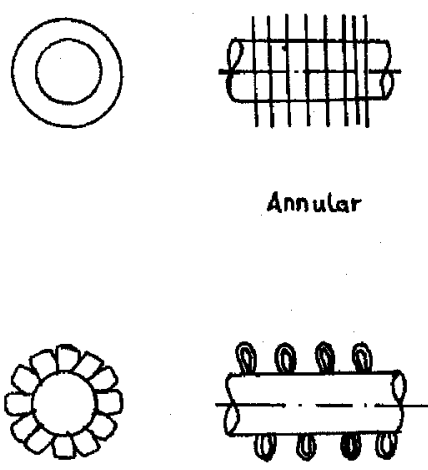

Wire loop

Annular
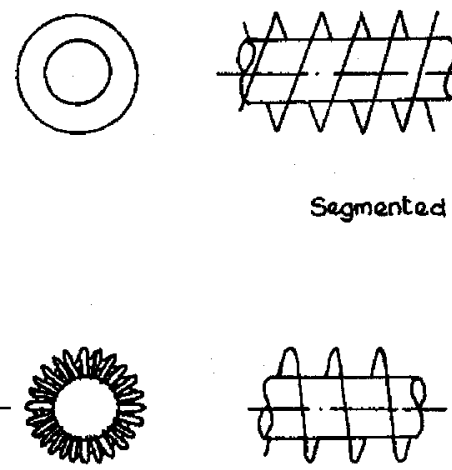

Slotted halical

Segmented
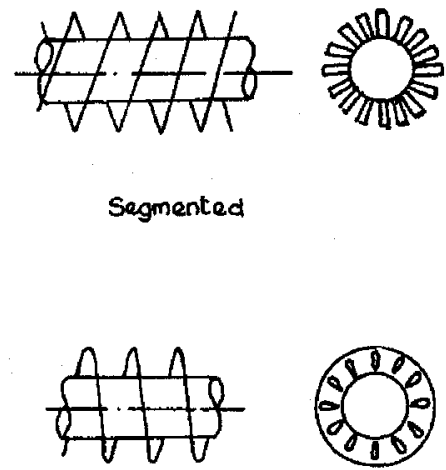

Figure 8.3: Typical Fin Geometries [8.1]

studded fin, wire-loop extended fin, and slotted fins (slots inside a plain circular fin). These fin geometries are shown in Figure 8.3. Fin geometry is described in the same manner for shell and tube heat exchanger and tube-fin heat exchanger despite the difference in fin types. Generally, fin geometry is expressed in terms fin height, $l_{f}$, fin thickness, $t_{f}$, and the fin pitch (number of fins per unit length), $N_{f}$. Fin surface area, $A_{f}$, may also be provided for fins with complicated geometry.

\subsubsection{Tube Arrangement}

\subsubsection{Tube Layout}

\section{a) Shell and Tube Heat Exchanger}

Four standard types of tube layout patterns, $\theta_{t p}$, may be employed in the shell and tube heat exchanger: the triangular layout $\left(30^{\circ}\right)$, the rotated triangular layout $\left(60^{\circ}\right)$, square $\left(90^{\circ}\right)$ layout, and rotated square $\left(45^{\circ}\right)$ layout. The angle is defined in relation to the flow direction. The $30^{\circ}, 45^{\circ}$ and $60^{\circ}$ layouts are known as staggered arrangements, and the $90^{\circ}$ layout is known as an inline arrangement. 

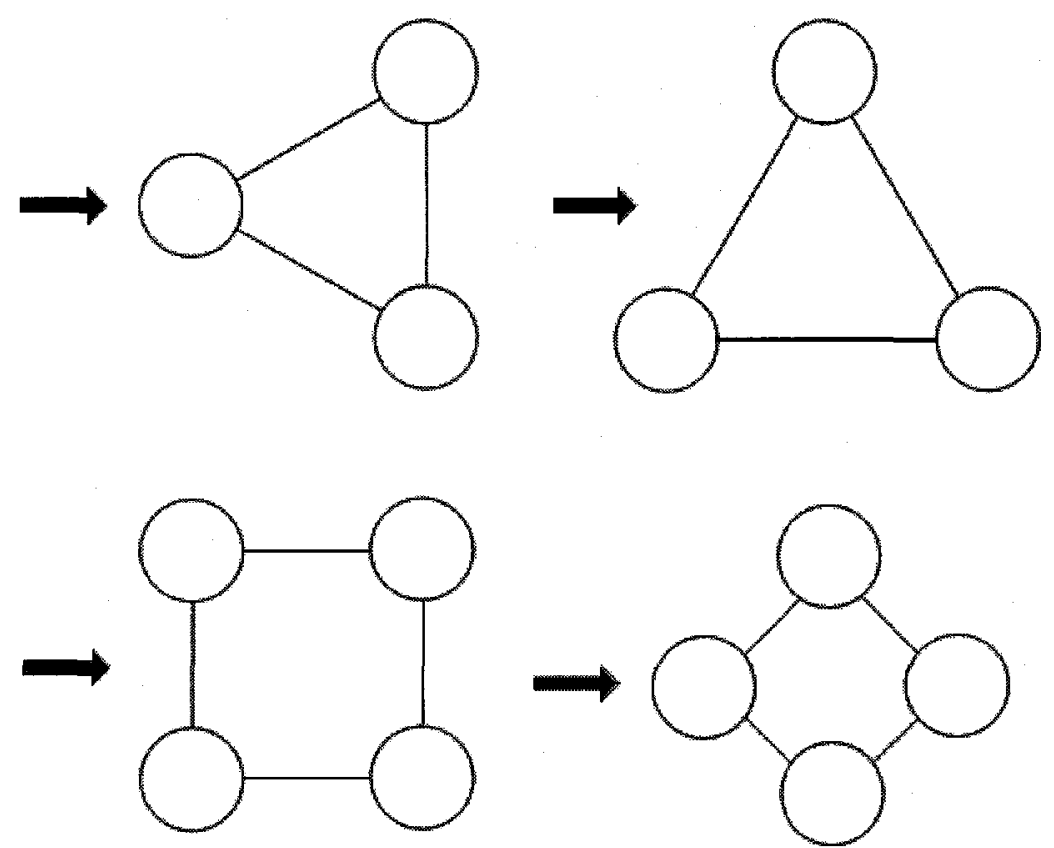

Figure 8.4: Tube Layout Patterns: (a) $30^{\circ}$, (b) $60^{\circ}$, (c) $90^{\circ}$, (d) $45^{\circ}$

\section{b) Tube-Fin Heat Exchanger}

Two tube layout patterns are typically used in a tube-fin heat exchanger: the staggered arrangement $\left(60^{\circ}\right)$ and the inline arrangement $\left(90^{\circ}\right)$. The most common arrangement is the staggered arrangement with equilateral triangular pitch. The inline arrangement is less common and consists of a rectangular layout. A possible variation of the staggered arrangement is the equivelocity layout, where the flow area in the transverse and diagonal direction is set as equivalent by adjusting the transverse and longitudinal pitch. In this manner, the layout angle for finned tubes increases from $30^{\circ}$ to $50^{\circ}$ (exact angle depends on specific fin geometry). Application of the equivelocity layout minimizes pressure losses due to acceleration and deceleration of the fluid stream though the tube bank. 


\subsubsection{Tube Pitch}

The tube pitch is described in the same manner for shell and tube heat exchanger and tube-fin heat exchanger. Tube pitch is the centre-to-centre distance between tubes, $L_{t p}$. This geometrical parameter governs the spacing between tubes as well as the compactness of the heat exchanger. Tube pitch is defined in terms of the longitudinal direction, $P_{l}$, (parallel to the flow), and transverse direction, $P_{t}$, (perpendicular to the flow), which varies according to the tube layout (see Figure 8.5). The tube pitch influences the heat-transfer rate and the pressure drop as well as the mechanical strength of the tubesheets. According to TEMA standard RCB-2.5, the minimal tube pitch should be 1.25 times the outside diameter of the tube to provide for adequate tube sheet strength [8.6].
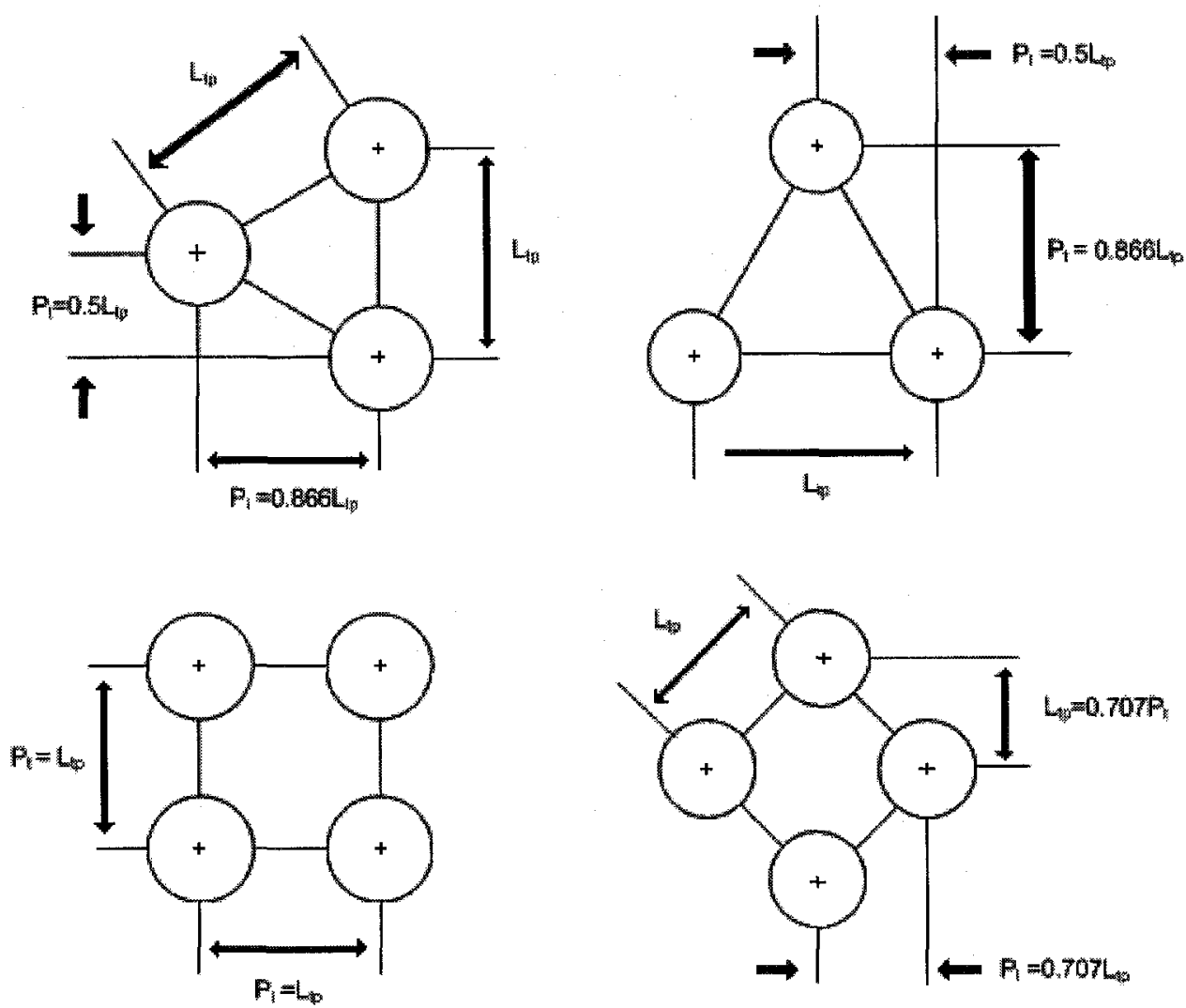

Figure 8.5: Tube Pitch for Tube Layout Patterns: (a) $30^{\circ}$, (b) $60^{\circ}$, (c) $90^{\circ}$, (d) $45^{\circ}$ [8.1] 


\subsubsection{Baffle Geometry}

Baffles are only implemented in the shell and tube heat exchanger.

\subsubsection{Baffle Type Selection}

Baffles are tube support structures that are used in shell and tube heat exchangers to maintain tube spacing and direct shell-side fluid across or along the tube bundle in a desired manner. Baffles may be transverse or longitudinal with respect to the shell. TEMA E shell employs only transverse baffles. The transverse baffles are positioned perpendicularly to the tubes, which are positioned through the baffle hole for support. Transverse baffles direct the shell-side fluid into the tube bundle at approximately right angles to the tubes. Flow reversal caused by baffles increases the turbulence of the shell fluid. Generally, there are two types of transverse baffles: plate baffles and rod baffles. Plate baffles utilize plates that are positioned normal to the tubes, whereas rod baffles do not guide the flow. As a result, plate baffles guide the shell-side flow in crossflow direction to the tubes, whereas when utilizing rod baffles, the flow is parallel to the tubes. Plate baffles include the segmental, disk and doughnut, and orifice baffle type, which are shown in Figure 8.6. Segmental baffles are most widely used type in shell and tube heat exchangers and orifice baffles are rarely used.

The segmental baffle is a circular disk with a segment removed to direct the shellside flow. The baffles are rotated at $180^{\circ}$ relative to each other. Tubes may or may not be placed through the area where the segment is removed. Greatest tube support and longest baffle spacing is possible for the arrangement that no tubes are present in the baffle cut. This arrangement is referred to as the no tube in window (NTIW) arrangement. Segmental baffles are the most common type of baffle applied in shell and tube heat exchangers [8.1].

The disk and doughnut baffle is, as the name implies, a baffle arrangement where a disk baffle supports inner tubes and a doughnut baffle supports the outer tubes. The 
disk and doughnut baffles are typically used in the nuclear industry. This baffle type provides a lower pressure drop as compared to the single segmental baffle type, and no tube bundle to shell bypass streams is present (the importance of which will be described in Section 8.7.2) [8.1].

In an orifice baffle, the tube-to-baffle clearance is large, which results in a large volume of flow through this region. These baffles do not support the tubes, and therefore, an alternate support mechanism is required to prevent flow-induced vibration. Moreover, operation in a fouling fluid is not practical due to the probability of tube-tobaffle clearance-hole plugging. This baffle type is rarely used since it does not provide tube support [8.1].

The single segmental baffle will be considered for application since it is the most commonly used baffle type. It provides simple fabrication and installation, as well as provides adequate tube support. The heat-transfer relations are based on the application of the single segmental baffle. 

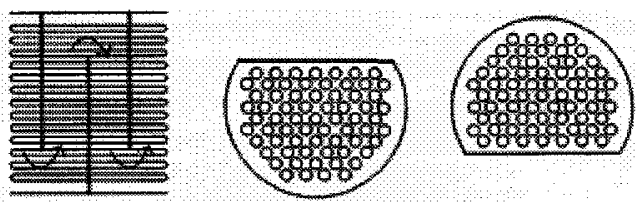

Single-Segmental Baffle
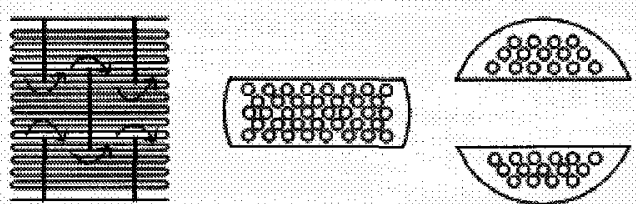

Double-Segmental Baffle
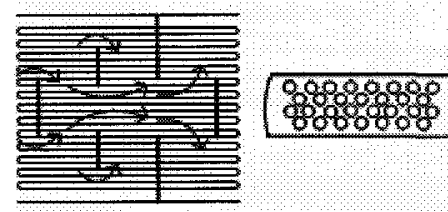

8088888

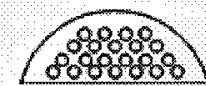

109888

989899

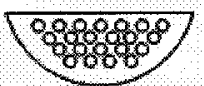

Triple-Segmental Baffle
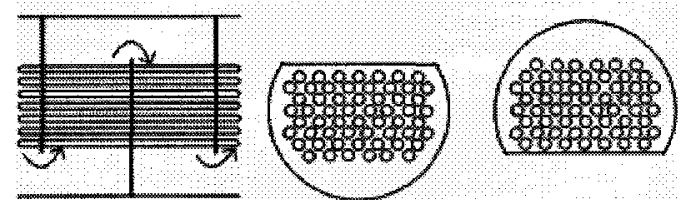

No Tubes in Window Segmental Baffle
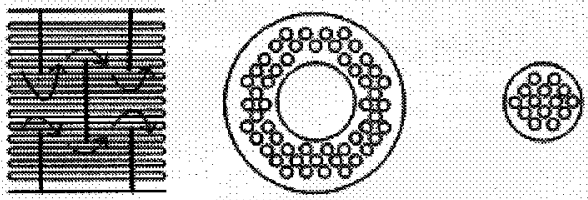

Disk and Doughnut Baffle

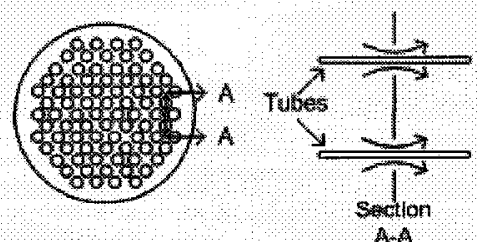

Orifice Baffle

Figure 8.6: Geometry of Plate Baffles [8.4] 


\subsubsection{Baffle Cut}

The amount of material removed from the baffle, or baffle cut, $l_{c}$, is expressed as a percentage of the inside shell diameter, $D_{i}$. Baffle cuts is generally 20 to 49 percent, with most common being 20 to 25 percent. Segmental baffle geometry is shown in Figure 8.7. Optimum baffle cut is typically regarded as 20 percent. Baffle cut smaller than 20 percent results in a high pressure drop. Baffle cut larger than 20 percent results in flow deviation from crossflow, and may cause stagnant regions or regions with low flow velocity, which reduces overall heat transfer.

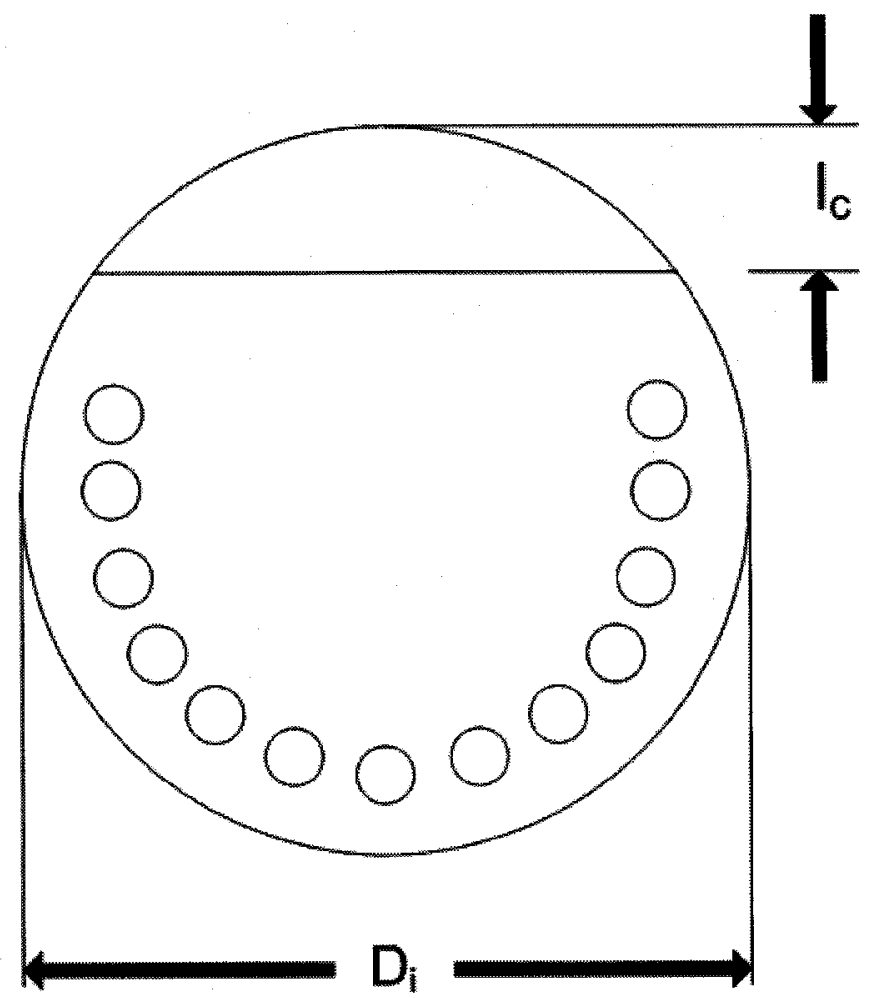

Figure 8.7: Baffle Cut 


\subsubsection{Baffle Spacing}

Baffle spacing, $L_{b c}$, must be specified according to TEMA Standards RCB-4.52, which provides maximum baffle spacing for various tube outer diameters, tube materials, and the maximum allowable temperature limit for several materials. The values typically range from $1 / 5$ to 1 shell diameter, although 40 to 50 percent shell diameter is considered optimum [8.6]. Inlet and outlet baffle spacing ( $L_{b i}$ and $L_{b o}$ respectively) must also be specified since it is typically larger than the central baffle spacing to accommodate for nozzles (see Figure 8.8).

\subsubsection{Baffle Thickness}

Although the baffle thickness does not influence heat-transfer characteristics, a nominal value should be chosen to geometrically define the shell and tube heat exchanger. The thickness is specified according to TEMA Standards R-4.41 and CB4.41. The required thickness is a function of baffle spacing and shell inner diameter, and ranges between $1 / 8$ " and $5 / 8$ " [8.6].

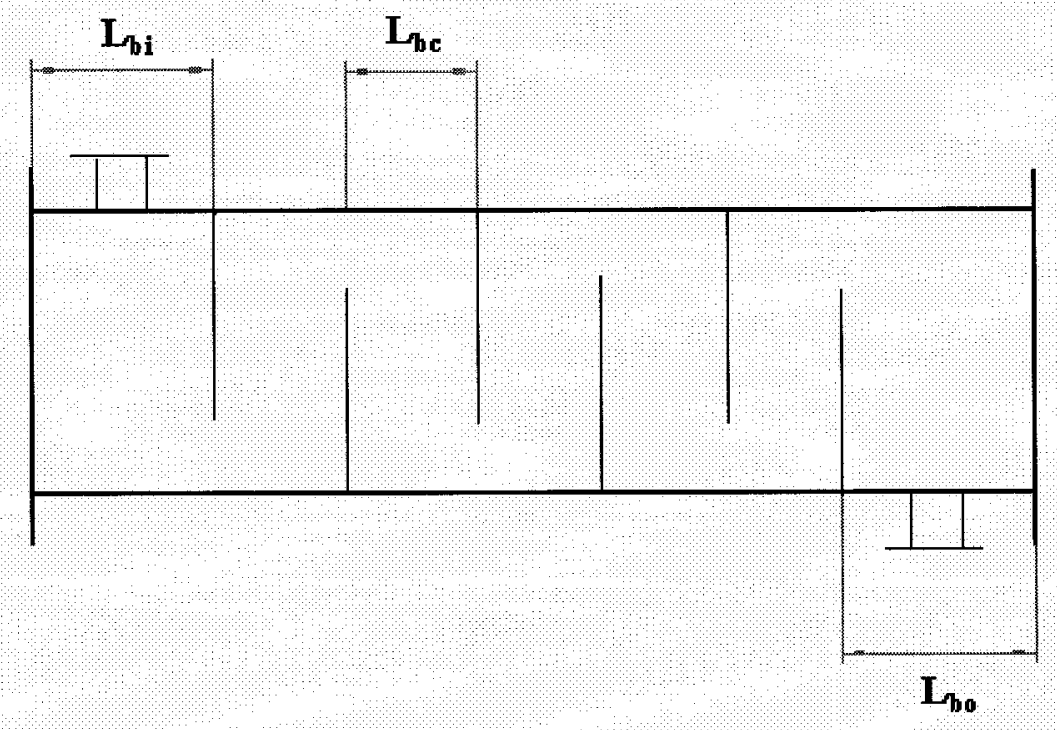

Figure 8.8: Baffle Spacing 


\subsubsection{Number of Sealing Strips}

Sealing strips may be placed only in shell and tube heat exchangers between the tube bundle and the shell to prevent bypassing flow (described in Section 8.7.2). A sealing strip is a piece of metal slightly larger than the tube bundle-to-shell clearance that spans the length of the heat exchanger. Since the sealing strip prevents bypass flow and the amount of bypass flow influences the overall heat-transfer coefficient, the number of sealing strips, $N_{s s}$, must be specified. Implementation of sealing strips should be considered if the tube bundle-to-shell diameter exceeds 2.25 inches $(30 \mathrm{~mm})$. Typically, one sealing strip is installed every four tube rows in the bundle periphery [8.1].

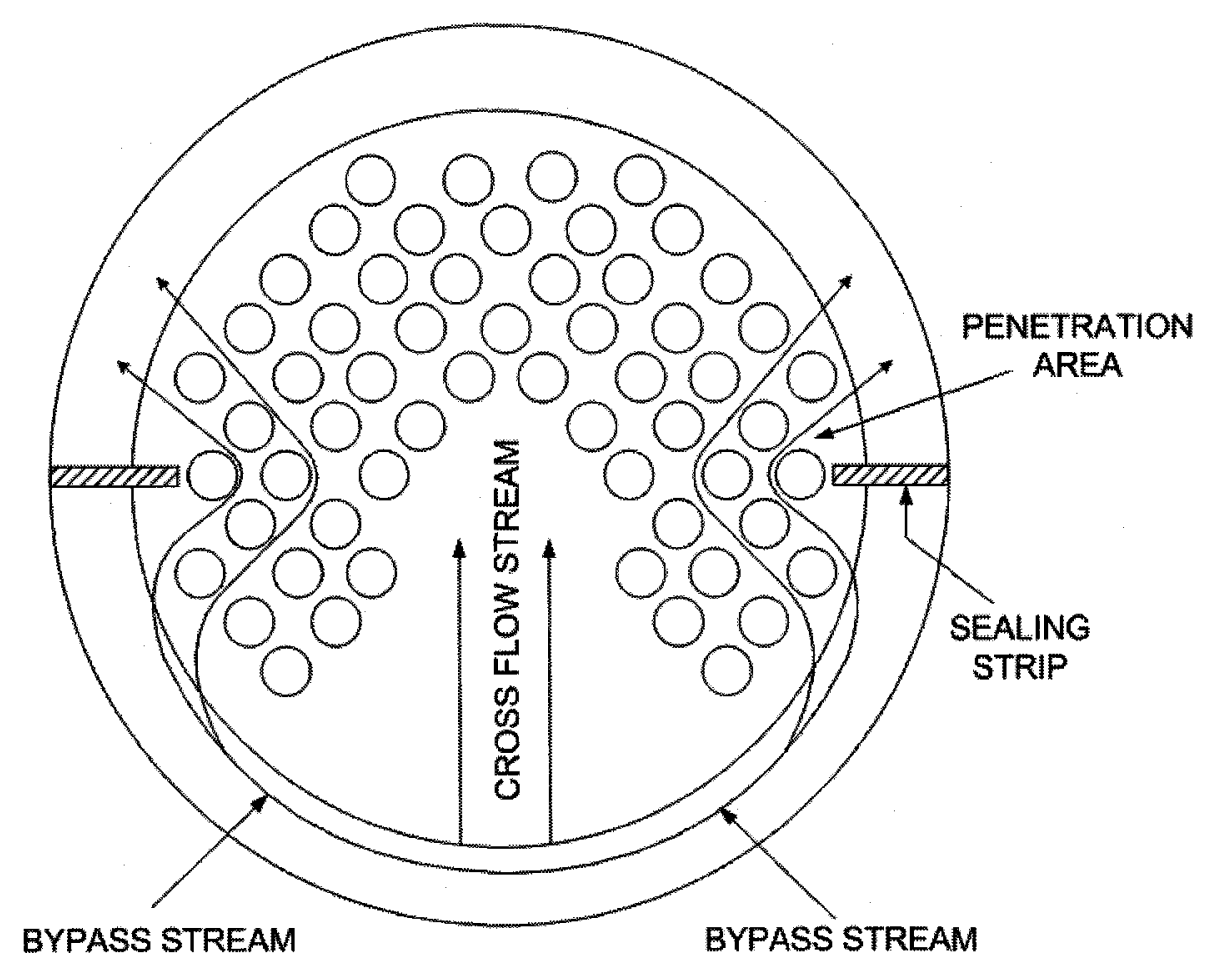

Figure 8.9: Sealing Strip Orientation [8.1] 


\subsection{Tubular Heat Exchanger Convective Heat Transfer and Pressure Drop Relations for Shell-Side Flow}

\subsubsection{Geometrical Relations}

Calculation of the convective heat transfer rate requires evaluation of several geometrical parameters such as the hydraulic diameter, heat-transfer surface area, and free-flow area. Evaluation of the hydraulic diameter is necessary to obtain the length scale for the Reynolds number. The general relation for the shell side hydraulic diameter, $D_{h}$, as defined in Reference [8.4], is:

$$
D_{h}=\frac{4 A_{F F} L_{2}}{A}
$$

where $A$ is the total heat-transfer surface area, and $A_{F F}$ is the free-flow area, which is the unobstructed (by tubes or fins) shell-side flow area. Several geometric specifications are required to determine the heat-transfer surface area and the free-flow area. Heat exchanger size is defined by the tube length, $L_{1}$, shell-side flow length, $L_{2}$, and no-flow length, $L_{3}$. The tube dimensions are specified as the tube outer diameter, $d_{0}$, tube thickness, $t$, and if applicable, fin dimensions specifications including fin height, $l_{f}$, fin thickness, $t_{f}$, and number of fins per unit length, $N_{f}$. Also, tube-positioning relations including the tube pitch in transverse direction, $P_{t}$, and tube pitch in longitudinal direction, $P_{l}$, as well as the tube arrangement is specified. From this information, the total heat-transfer area and the free-flow area is determined for bare-tube and finned-tube types as well as for staggered and inline arrangements. 


\subsubsection{Bare-Tube Bank}

The total heat-transfer area of bare tubes is the outer surface area of all tubes:

$$
A=\pi d_{o} L_{1} N_{t}
$$

where the maximum number of tubes, $N_{t}$, that can be accommodated is:

$$
N_{t}=\frac{L_{2} L_{3}}{P_{t} P_{l}}
$$

The frontal area, $\mathrm{A}_{\mathrm{Fr}}$, of the heat exchanger is:

$$
A_{F r}=L_{1} L_{3}
$$

\section{a) Inline Arrangement}

The inline arrangement consists of a rectangular tube layout with equal number of tubes in each row (see Figure 8.10). The minimum free-flow area, $A_{F F}$, corresponds to the minimal area between the tubes. For an inline arrangement, the free-flow area is expressed as the product of the distance between the tubes and the number of tubes in each row, multiplied by the tube height:

$$
A_{F F}=\left(P_{t}-d_{o}\right) N_{t}^{\prime} L_{1}
$$

where the number of tubes in one row, $N_{t}{ }^{\prime}$, is determined by:

$$
N_{t}^{\prime}=\frac{L_{3}}{P_{t}}
$$




\section{b) Staggered Arrangement}

The staggered arrangement consists of a triangular tube layout with one less tube in alternate rows (see Figure 8.11). The minimal free-flow area for the staggered arrangement is either the area between transversal tubes or the diagonal area between longitudinal tubes, depending on the relative magnitude of the transverse and longitudinal tube pitch. The free-flow area is the product of the minimal free-flow area per unit length and the tube length, $L_{1}$. The free flow area per unit length is defined as the product of the number of tubes in the smaller tube row, $\left(L_{3} / P_{t}-1\right)$, to the minimal distance between the tubes, $z$. The last term, $\left(P_{t}-d_{o}\right)$, corresponds to the free-flow area between the last tube at each end and the heat exchanger wall.

$$
A_{F F}=\left[\left(\frac{L_{3}}{P_{t}}-1\right) z+\left(P_{t}-d_{o}\right)\right] L_{1}
$$

$\mathrm{z}$ is the minimal distance between the tubes and is defined as:

$$
\begin{array}{lll}
z=2 x & \text { if } & 2 x<2 y \\
z=2 y & \text { if } & 2 y<2 x
\end{array}
$$

As seen in Figure 8.12, $2 x$ is defined as the distance between the transversal tubes and $y$ is defined as the distance between longitudinal tubes. These values can be calculated by Equation $8.20 \mathrm{a}$ and $8.20 \mathrm{~b}$.

$$
\begin{gathered}
2 x=\left(P_{t}-d_{o}\right) \\
y=\left[\left(P_{t} / 2\right)^{2}+\left(P_{l}\right)^{2}\right]^{0.5}-d_{o}
\end{gathered}
$$

With assessment of the total heat-transfer area and the free-flow area, the hydraulic diameter can be calculated by applying Equation 8.13 . 


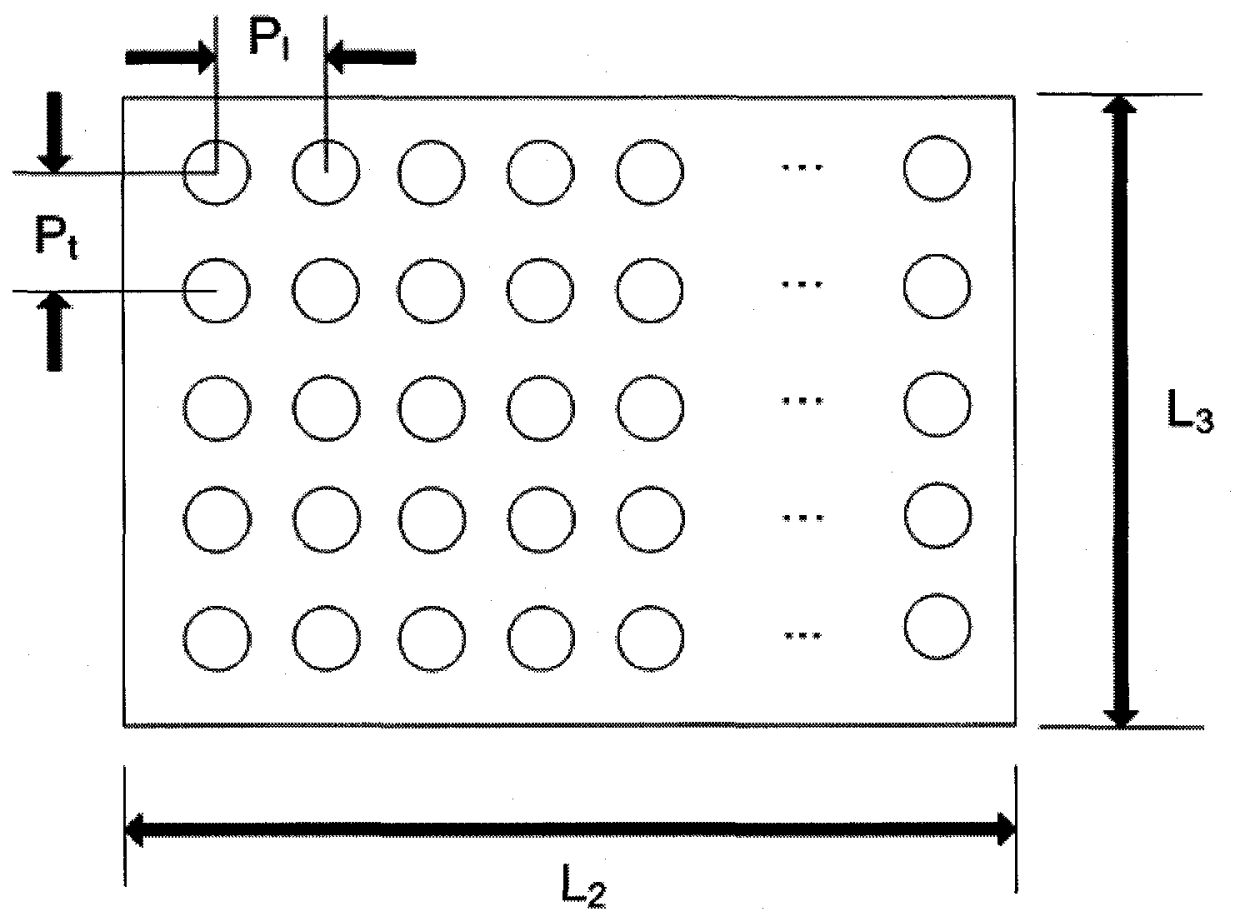

Figure 8.10: Inline Tube Bank Geometry

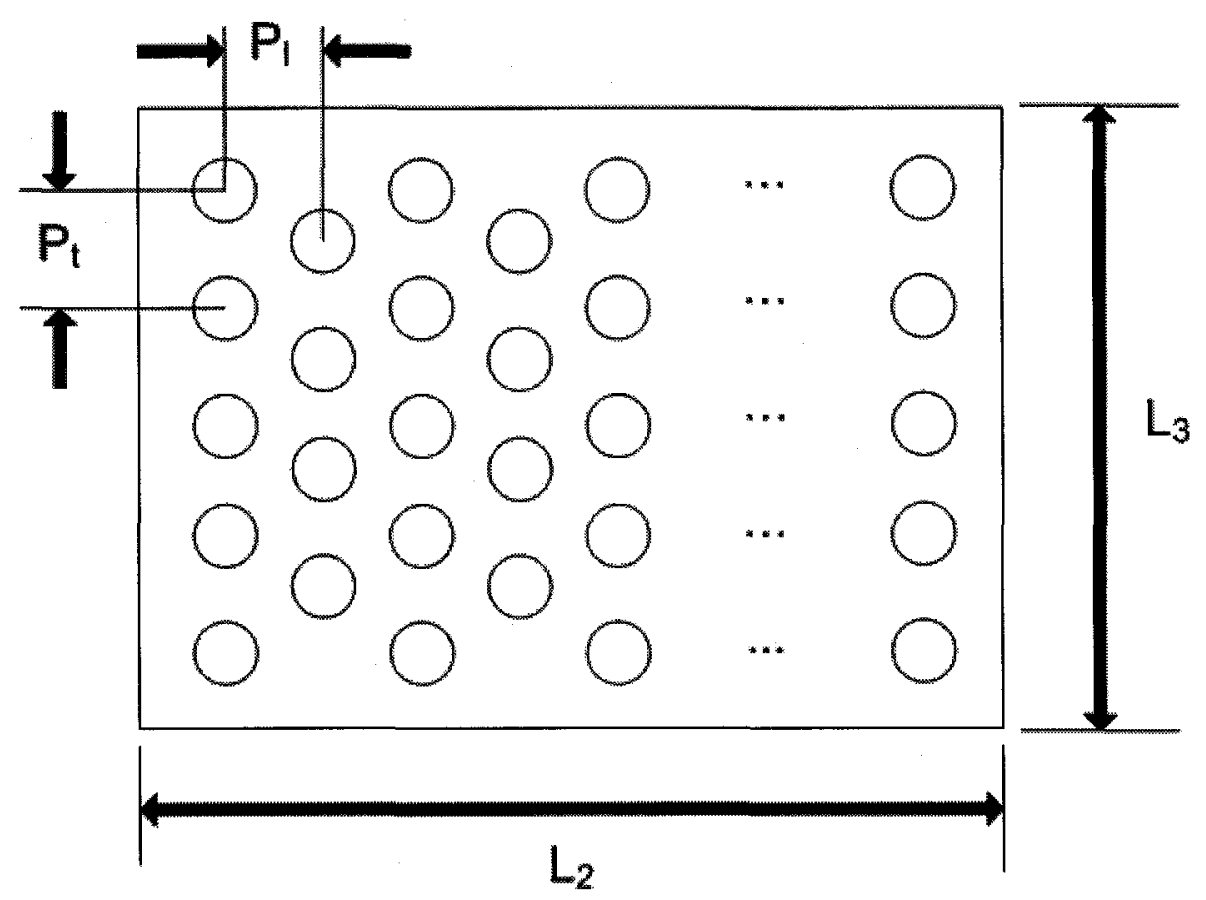

Figure 8.11: Staggered Tube Bank Geometry 


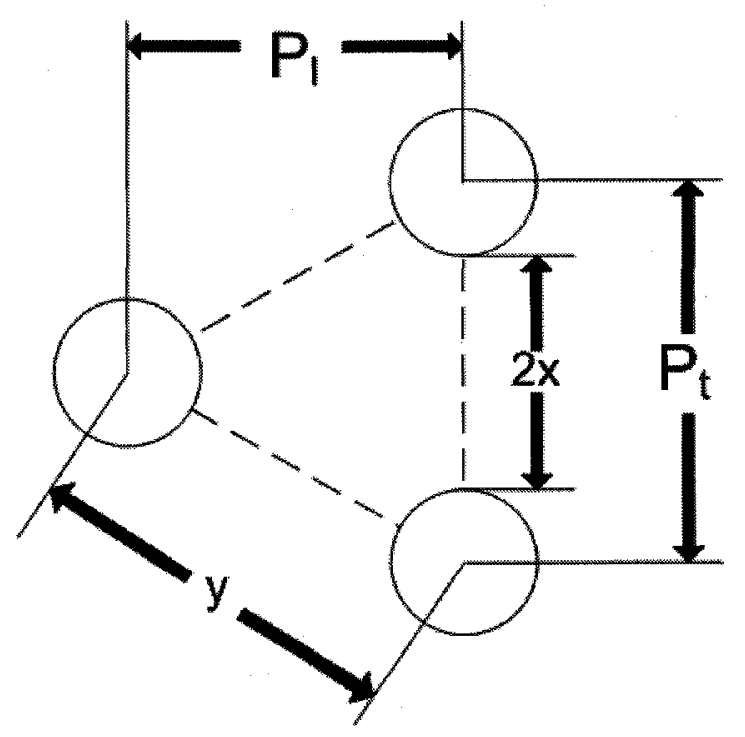

Figure 8.12: Staggered Unit Cell Arrangement and Associated Nomenclature

\subsubsection{Circular Finned-Tube Bank}

Finned tubes are geometrically described by the root diameter, $d_{r}$, and the fin-tip diameter, $d_{f}$. Depending on manufacturing method, the root diameter may be equivalent to the tube outside diameter plus two fin-collar thicknesses or to the tube outside diameter, which is assumed in this case. The total heat transfer area consists of the exposed tube area (primary area) and exposed fin area (secondary area).

$$
A=A_{p}+A_{f}
$$

The primary area, $A_{p}$, is the tube surface area minus the area blocked by the fins:

$$
A_{p}=\pi d_{r}\left(L_{1}-t_{f} N_{f} L_{1}\right) N_{t}
$$

where $N_{f}$ is the number of fins per unit length, and $t_{f}$ is the fin thickness. The fin surface area is determined by:

$$
A_{f}=\left[2 \pi\left(d_{f}^{2}-d_{r}^{2}\right) / 4+\pi d_{f} t_{f}\right\rfloor N_{f} L_{1} N_{t}
$$




\section{a) Inline Arrangement}

The free-flow area in an inline arrangement is the area between the transverse tubes, as in Equation 8.17, minus the area blocked by the fins.

$$
A_{F F}=\left[\left(P_{t}-d_{r}\right) L_{1}-\left(d_{f}-d_{r}\right) t_{f} N_{f} L_{1}\right] N_{t}^{\prime}
$$

\section{b) Staggered Arrangement}

The free-flow area for finned tubes in a staggered arrangement could be either the area between transverse tubes or the area between longitudinal tubes. The free-flow area is found similarly as the free-flow area for bare tubes, Equation 8.19a, minus fin crosssectional area.

$$
A_{F F}=\left[\left(\frac{L_{3}}{P_{t}}-1\right) z^{\prime}+\left(P_{t}-d_{o}\right)-\left(d_{f}-d_{r}\right) t_{f} N_{f}\right] L_{1}
$$

similarly, $z$ ' is defined as:

$$
\begin{array}{lll}
z^{\prime}=2 x^{\prime} & \text { if } & 2 x^{\prime}<2 y^{\prime} \\
z^{\prime}=2 y^{\prime} & \text { if } & 2 y^{\prime}<2 x^{\prime}
\end{array}
$$

where $2 x^{\prime}$ is the distance between the transversal tubes, $\left(d_{r}\right.$ to $\left.d_{r}\right)$, and $y^{\prime}$ is defined as the distance between longitudinal tubes $\left(d_{r}\right.$ to $\left.d_{r}\right)$. This is similar to Equation $8.19 \mathrm{~b}$ and $8.19 \mathrm{c}$ minus the fin cross-sectional area.

$$
\begin{gathered}
2 x^{\prime}=\left(P_{t}-d_{r}\right)-\left(d_{f}-d_{r}\right) t_{f} N_{f} \\
y^{\prime}=\left\lfloor\left(P_{t} / 2\right)^{2}+\left(P_{l}\right)^{2}\right]^{0.5}-d_{r}-\left(d_{f}-d_{r}\right) t_{f} N_{f}
\end{gathered}
$$

The relations for the total heat-transfer surface area and shell-side free-flow area are presented above to determine the shell-side hydraulic diameter (Equation 8.13). The convective heat-transfer rate and pressure drop relations presented in the following sections are based on the shell-side hydraulic diameter. 


\subsubsection{Heat Transfer and Pressure Loss Correlations for Shell-Side Flow}

\subsubsection{Cross Flow across Bare Tubes}

For bare tubes in staggered and inline arrangement, the non-dimensional heattransfer relation is found by Equation 8.27. The values of constant, $C$, and exponent, $n$, have been presented in Reference [8.5] and are included in Appendix D, Table D.1. This data applies to tube banks with 10 or more rows in the flow direction. A factor is included in Table D.2 for tube banks with fewer than 10 rows in the flow direction [8.5].

$$
N u=C \operatorname{Re}_{d}^{n} \operatorname{Pr}^{1 / 3}
$$

The pressure drop for flow of gasses through a tube bank is calculated by [8.5]:

$$
\Delta P=\frac{2 f^{\prime} G^{2} N_{t}^{\prime \prime}}{\rho}\left(\frac{\mu_{w}}{\mu_{t}}\right)^{0.14}
$$

where

$$
\begin{array}{ll}
f^{\prime} & \text { Friction Factor } \\
G & \text { Mass velocity at minimum flow area } \\
\rho & \text { Density at free-stream conditions } \\
N_{t}{ }^{\prime} & \text { Number of transverse tube rows } \\
\mu_{t} & \text { Average free-stream viscosity } \\
\mu_{w} & \text { Average wall viscosity }
\end{array}
$$

The empirical friction factor for staggered tube arrangement given as presented in Reference [8.5] is:

$$
f^{\prime}=\left\{0.25+\frac{0.118}{\left[\left(P_{t}-d_{o}\right) / d_{o}\right]^{1.08}}\right\} \operatorname{Re}_{d}^{-0.16}
$$

and for inline arrangement the friction factor is:

$$
f^{\prime}=\left\{0.044+\frac{0.08 P_{l} / d_{o}}{\left(P_{t}-d_{o}\right) / d_{o}^{0.43+1.13 d_{o} / P_{l}}}\right\} \operatorname{Re}_{d}^{-0.15}
$$


It should be noted that the Reynolds number in heat transfer (Equation 8.27) and pressure drop correlations (Equations 8.29, and 8.30) are based on the maximum velocity through the tube bank, which is the velocity through the minimum-flow area.

\subsubsection{Cross Flow across Circular Finned Tubes}

Fins are used to increase the surface area to enhance the total heat-transfer rate by conduction and convection. The conductive heat transfer rate of finned tubes is presented in Section 8.9. The non-dimensional convective heat transfer rate for finned tubes in cross-flow is expressed by the Briggs and Young Correlation, Equation 8.31 [8.1]. The correlation is valid for all tube banks in staggered configuration with a standard deviation of 5.1 percent.

$$
N u=0.134 \operatorname{Re}_{d}^{0.681} \operatorname{Pr}^{1 / 3}\left(\frac{s}{l_{f}}\right)^{0.200}\left(\frac{s}{t_{f}}\right)^{0.1134}
$$

where the un-finned tube length, $s$, is defined as:

$$
s=\left(L_{1}-N_{f} t_{f}\right) / N_{f}
$$

Considerably fewer correlations are available for inline tube banks, and no general relation that is applicable for a wide range of conditions has been found. Typically, the heat transfer coefficient is expected to be 30 percent to 100 percent higher for tubes in staggered arrangement as compared to the inline arrangement, depending on the size of fins (tubes with longer fins achieve higher benefits) [8.7]. The lack of available heat-transfer correlations for finned inline tube banks could be attributed to the ability to increase the heat-transfer rate more cost-effectively by resorting to a staggered arrangement.

Both conductive and convective heat transfer rates are generally higher at the fins due to thin material thickness, flow penetration on both material sides, and a longer boundary layer. Therefore, the fin surface temperature is generally lower than the 
temperature at the tube, and the fin transfers less heat as compared to the tube. Lower fin heat-transfer rates are accounted by introducing fin temperature effectiveness or fin efficiency. The fin temperature effectiveness is defined as the ratio of actual heat transfer, $q$, through the fin to the heat transfer that would be obtained if the entire fin were at the base metal temperature:

$$
\eta_{f}=\frac{q}{q_{i}}
$$

Correlations for fin effectiveness are available for numerous geometries. For plane circular fins, the fin effectiveness may be found by the Schmidt method:

$$
\eta_{f}=\frac{\tanh \left(m^{*} l^{*}\right)}{m^{*} l^{*}}
$$

where for thin sheet fins, $m^{*}$ is defined as:

$$
m^{*}=\sqrt{\frac{2 h}{k_{f} t_{f}}}
$$

and $l^{*}$ is given by:

$$
l^{*}=\left(r_{e}-r_{o}\right)\left[1+\frac{t_{f}}{2\left(r_{e}-r_{o}\right)}\right]\left[1+0.35 \ln \left(r^{*}\right)\right]
$$

In Equation 8.34, $r *$ is defined as the ratio of fin-tip radius, $r_{e}$, to the fin-root radius, $r_{o}$, (outer tube radius), and $t_{f}$ is the fin thickness. The Schmidt correlation is recommended for values of $0.5 \leq r^{*}<1$ and $1<r^{*} \leq 8$, since the predicted fin efficiency is found to be less than 1 percent of the exact fin efficiency value. The overall surface efficiency that is used to find the overall heat-transfer coefficient is found by:

$$
\eta_{o}=1-\frac{A_{f}}{A}\left(1-\eta_{f}\right)
$$


The pressure drop across finned tube banks is found as per Equation 8.28. The friction factor for finned tubes is found with Robinson and Briggs Correlations, Equation 8.38 for triangular pitch and Equation 8.39 for isosceles triangular layout. Again, the availability of friction factor data for an inline arrangement is limited and no correlation that may be used for a wide range of conditions has been found.

$$
\begin{gathered}
f^{\prime}=9.465 \operatorname{Re}_{d}^{-0.316}\left(\frac{P_{t}}{d_{o}}\right)^{-0.927} \\
f^{\prime}=9.465 \operatorname{Re}_{d}^{-0.316}\left(\frac{P_{t}}{d_{o}}\right)^{-0.927}\left(\frac{P_{t}}{P_{l}}\right)^{0.515}
\end{gathered}
$$

The above relations are used to calculate the shell-side heat-transfer coefficient and pressure drop for a tubular heat exchanger. The shell-side heat-transfer coefficient is used in conjunction with Equation 8.12 to find the overall heat transfer coefficient, which is used to find the heat-transfer surface area. 


\subsection{Shell and Tube Convective Heat Transfer and Pressure Drop Relations for Shell-Side Flow}

\subsubsection{Shell and Tube Heat Exchanger Sizing - Introduction to the Bell-Delaware Method}

The Bell-Delaware method (or Delaware method) is considered the most suitable open-literature method for evaluating the shell-side performance, and is based on experimental work performed throughout the 1950s and 1960s. The method is confined to the design of a fully tubed, E-shell heat exchanger with bare tubes, although corrections are available for low-finned tubes. Also, with slight modifications in geometrical parameters, this method may be applied to F-shells. The Bell-Delaware method is a rating method, since the majority of geometrical parameters must be defined to find the possible heat-transfer rate, or the heat-transfer rate must be defined to find the heat exchanger geometry $[8.1,8.7]$. In the case of the heat exchanger design for the $\mathrm{CBC}$ engine, the heat-transfer rate is pre-determined from engine cycle calculations, and the heat exchanger geometry is calculated iteratively (see Section 8.4 for iteration procedure) with application of the Bell-Delaware method to match the pre-determined heat-transfer rate. Additionally, the Bell-Delaware method may be used to estimate the shell-side pressure drop. The Bell-Delaware method, as presented in this section, is based on References [8.1], [8.3], and [8.7].

\subsubsection{Shell-Side Flow Mechanism}

The Bell-Delaware method is based on an idealized shell-side flow representation that is shown in Figure 8.13. Shell-side flow is characterised into five distinct flow streams, which are classified alphabetically. These idealized flow streams are described below. In reality, the shell-side flow is quite complicated due to mixing of the streams. The Bell-Delaware method neglects mixing of streams due to the difficulties in modelling turbulent flow structures. 
A-stream is classified as the clearance flow between the tube and the baffle, which flows from one baffle to the next. This leakage flow is a result of the pressure difference across the baffle that occurs due to pressure losses in the high-swirling flow around the baffle. The A-stream flow has a relatively small impact on the overall heat transfer coefficient.

B-stream is the crossflow stream flowing normal to the tube bundle. The Bstream is the main flow that is responsible for heat transfer and pressure drop. This is the desired flow pattern in shell and tube heat exchangers.

C-stream is classified as the annular space between the tube bundle and the shell. This stream is circumferential and contacts the outermost tubes in the bundle (furthest tubes from the shell centre). This stream is not very effective for heat transfer since there is limited contact area between the shell-side flow and the tubes.

E-stream is the flow through the clearance between the shell and the baffle. This stream does not contact tubes, and does not contribute to heat transfer.

F-stream is classified as the flow through the tube bundle channels in the tubepass partitions lanes that are positioned within the tube layout. The flow is in the crossflow direction to the tubes and is in contact with few inner tubes. As a result of the small contact area, it is slightly more effective than the C-stream. The F-stream is a function of tube layout and baffle type. The F-stream is not present for single-segmental baffle type with even tube distribution.

The size of each stream varies with the flow conditions and the shell, tube, and baffle geometry. The size of each stream is such that the total pressure loss of each stream must equal. As a result of the different flow nature, the heat-transfer rate and the friction factors vary for each stream. Therefore, to accurately predict the total heat- 
transfer rate and the total pressure drop, the heat-transfer rate and the pressure drop for each stream should be predicted and relative size of each stream should be determined. Typical relative magnitude of each stream is in the range shown in Table 8.1. The flow fractions are based on extensive test data [8.1]. It should be noted that in a typical shell and tube heat exchanger, the crossflow fraction is 65 percent. Therefore, analysis of individual streams that is conducted by the Bell-Delaware method is justified.

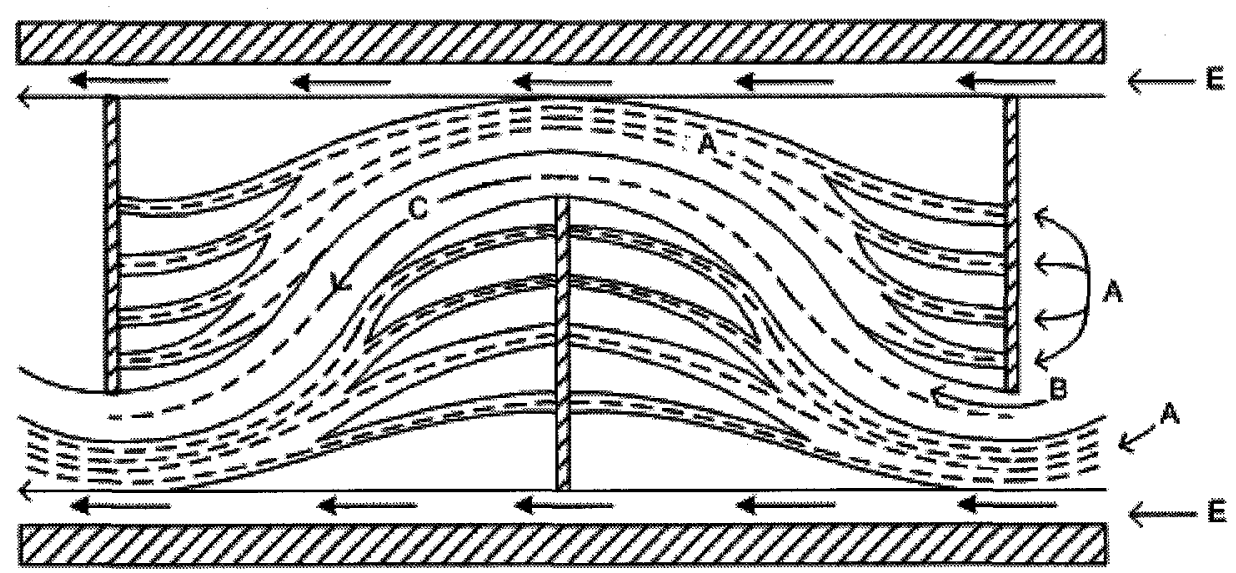

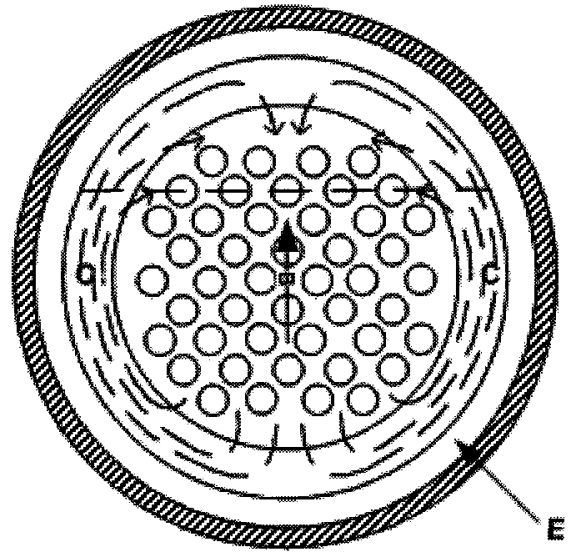

(a)

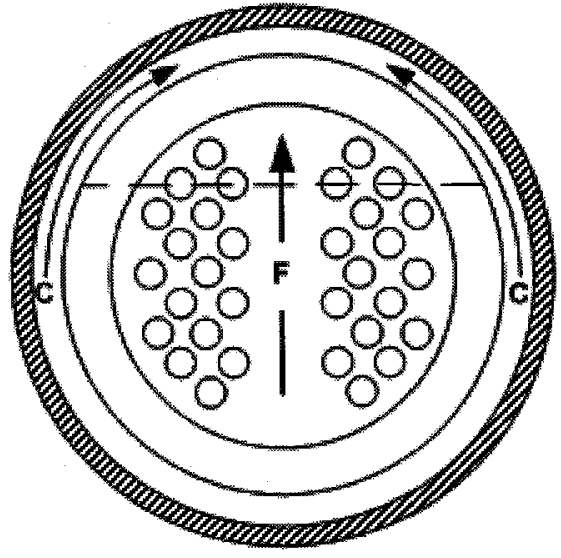

(b)

Figure 8.13: Bypass and Leakage Flow Paths: a) Single Pass Baffle, b) Two-Pass Baffle [8.3] 
Table 8.1, Summary of Typical Flow Fractions [8.1]

\begin{tabular}{|l|c|c|}
\hline Flow Stream & Turbulent Flow & Laminar Flow \\
\hline A-Stream, Tube-to-Baffle leakage & $9 \%-23 \%$ & $0 \%-10 \%$ \\
\hline B-Stream, Crossflow & $30 \%-65 \%$ & $10 \%-50 \%$ \\
\hline C-Stream, Bundle-to-shell bypass & $15 \%-35 \%$ & $30 \%-80 \%$ \\
\hline E-Stream, Baffle-to-shell leakage & $6 \%-21 \%$ & $6 \%-48 \%$ \\
\hline
\end{tabular}

\subsubsection{Shell-Side Heat Transfer Overall Relation}

The approach undertaken by the Bell-Delaware method is to determine the heattransfer coefficient for an ideal tube bank and correct for leakage and bypass flow. In this manner, the overall heat-transfer coefficient and total pressure drop across a shell and tube heat exchanger is determined. The ideal tube bank heat-transfer coefficient corresponds to the heat-transfer rate of the B-stream. The effect of leakage and bypass flow (A, C, E, F-streams) is then evaluated and correction factors for heat-transfer rate and pressure drop are applied. The average heat-transfer rate coefficient is computed by the following equation [8.7]:

$$
h_{o}=h_{\text {ideal }} J_{c} J_{l} J_{b} J_{s} J_{r}
$$

$h_{\text {ideal }}$ is the heat-transfer coefficient for pure crossflow in an ideal tube bank. The ideal tube bank corresponds to the tube array at the centreline of the heat exchanger. No clearance is present between tubes and baffles, baffles and shell, or outer tubes and shell. The flow corresponds exclusively to the B-stream [8.7].

$J_{c}$ is the correction factor for flow deviation from pure crossflow in the baffle window. In this region, flow reversal around the baffles may results in higher or lower velocity regions, depending on the size of baffle cut. In addition to velocity variation, the effect of directional change of fluid flow influences the heat transfer rate. The baffle effects require a correction to the heat transfer coefficient. The factor is a function of the 
number of tubes that are in the window and the size of the baffle cut. No correction is required for no-tube-in-window designs since the shell-side flow is predominantly in crossflow across the wetted tube surface [8.7].

$J_{l}$ is the correction factor for the heat-transfer loss due to leakage flow around the baffle. The leakage flow around the baffle includes both the A-stream and the E-stream. The $J_{l}$ factor is defined as the tube-to-baffle leakage area to the total crossflow area in each baffle, and total shell-to-baffle leakage area to the total crossflow area. The shell-tobaffle leakage flow does not contribute to heat transfer, and therefore, it is weighted more heavily. Reducing the clearance size maximizes the value of $J_{l}$. Typical values of $J_{l}$ are in the range of 0.7 to 0.8 [8.7].

$J_{b}$ is the correction factor for the heat-transfer loss due to low tube-wetting area of the tube bypass flow (C-stream). $J_{b}$ is a function of the clearance between the outermost tube periphery and the shell. Small correction is required for tight clearances. Application of longitudinal sealing strips between and outside of the bundle and shell reduces the amount of tube bypass flow, and increases the correction factor. Typical value of $J_{b}$ is in the range of 0.7 to 0.9 [8.7].

$J_{s}$ is the correction factor for the variation of baffle spacing in the inlet and outlet of heat exchanger. Increased spacing in the inlet and outlet region is typically required to accommodate nozzles and headers. Increased spacing results in a low flow velocity that reduces the heat-transfer rate. The correction factor accounts for the reduced heattransfer rate. $J_{s}$ values are typically in the range of 0.85 and 1.0 [8.7].

$J_{r}$ is the correction factor for adverse temperature gradient in deeply laminar flow. The adverse temperature gradient resists conductive heat transfer, which reduces the local and average heat transfer rate with increased distance from the heating-fluid inlet. The correction factor applies for shell-side Reynolds numbers below 100, with a maximum 
value corresponding to deeply laminar flow that is characterised by Reynolds numbers below 20 .

The Bell-Delaware method for calculating the total shell-side pressure drop consists of finding the pressure drop across the crossflow section, the window section, and the entrance and exit sections. An ideal pressure drop is found in each section and the values are corrected for leakage and bypass flow (A, C, E, F-streams). The leakage and bypass flow reduces the contact area between the flow and the tubes, which in effect reduces the magnitude of the overall pressure drop. The correction factors applied for the pressure drop include:

$R_{l}$ is the pressure drop correction factor for leakage flow around the baffle. The leakage flow around the baffle includes both the A-stream and the E-stream. $R_{1}$ is used to correct the crossflow pressure drop and window pressure drop. Typical value of $R_{1}$ is in the range of 0.4 to 0.5 , depending on the baffle clearance spacing.

$R_{b}$ is the pressure drop correction factor for the low tube-wetting area of the tube bypass flow (C-stream). $R_{b}$ is applied to pressure drop in the interior crossflow section and varies with the same geometrical parameters as $J_{b}$. Typical value of $R_{b}$ is in the range of 0.5 to 0.8 , with higher values for tight-clearance heat exchangers [8.1].

$R_{s}$ is the correction factor for variation in baffle spacing in the inlet and outlet of the heat exchanger. The correction factor accounts for difference in the inlet and outlet pressure loss due to velocity variation in this region. For single-pass shell, $R_{s}$ values are typically in the range of 0.5 and 2.0, depending whether the flow is laminar or turbulent [8.1].

The correction factors reduce the actual heat-transfer coefficient from the ideal tube bank values. Also, the correction factors reduce actual pressure drop from the ideal 
tube bank values. The actual heat-transfer coefficient for a well-designed heat exchanger should be 60 percent of the value for ideal cross-flow with no leakage. The total nozzleto-nozzle shell-side pressure drop should in the range of 20 percent to 30 percent of the pressure drop that would be calculated for a heat exchanger without leakage and bypass effects.

\subsubsection{Geometrical Relations}

Stream size and associated correction factor are a function of leakage and bypass areas, which must be determined to evaluate the overall shell-side heat-transfer coefficient. The relations used to determine the significant heat exchanger geometrical dimensions as well as the leakage and bypass areas are presented in this section.

\subsubsection{Tube Bundle Geometry}

Tube bundle geometry is defined in terms of the circumferential positioning with respect to the tubesheet, baffle, and/or shell. The tube bundle diameter, $D_{c t}$, which is the (tube) centre-to-centre distance of the outer tube bundle (see Figure 8.14), is found by the following equation [8.1]:

$$
\begin{array}{lll}
D_{C T L}=\sqrt{\frac{1}{0.78} C_{l} N_{t} P_{t}^{2}}+d_{o} & \text { if } & \mathrm{P}_{\mathrm{t}}>\mathrm{P}_{1} \\
D_{C T L}=\sqrt{\frac{1}{0.78} C_{l} N_{t} P_{l}^{2}}+d_{o} & \text { if } & \mathrm{P}_{1}>\mathrm{P}_{\mathrm{t}}
\end{array}
$$

where the tube layout constant, $C_{l}$ is [8.1]:

$$
\begin{array}{lll}
\mathrm{C}_{1}=0.86 & \text { for } & \theta_{\mathrm{tp}}=30^{\circ} \text { and } 60^{\circ} \\
\mathrm{C}_{1}=1.0 & \text { for } & \theta_{\mathrm{tp}}=45^{\circ} \text { and } 90^{\circ}
\end{array}
$$


The tube bundle outer diameter, which is the outer-to-outer distance of the tube bundle periphery, is defined by [8.1]:

$$
D_{o t l}=D_{c t l}+d_{o}
$$

The clearance between the tube bundle and the shell is defined as:

$$
L_{b b}=D_{i}-D_{o t t}
$$

The recommended maximum clearance between the shell I.D. and the baffle O.D. is provided by TEMA Standard RCB-4.3 and included in Table 8.2 [8.6]. The values vary according to the shell size. Although the shell inner diameter is unknown, the value of the outer tube bundle diameter, $D_{\text {ott }}$, as found in Equation 8.40, can be used due to the small size difference. The clearance values are the maximum values permissible by TEMA Standards, and will result in an overestimate in leakage area size. The clearance between tube bundle and shell is the sum of the clearance between shell I.D. and baffle O.D., $\mathrm{L}_{\mathrm{sb}}$, and the distance between the baffle O.D. and outer tube bundle. For initial shell-sizing, it is assumed that the baffle O.D. is equivalent to the outer tube bundle.

Table 8.2: Standard Shell Inner Diameter-to-Baffle Outer Diameter Clearance [8.6]

\begin{tabular}{|c|c|}
\hline $\begin{array}{c}\text { Nominal Shell I.D } \\
\mathrm{D}_{\mathrm{i}}\end{array}$ & $\begin{array}{c}\text { Design I.D. of Shell Minus Baffle O.D. } \\
\mathrm{L}_{\mathrm{sb}}\end{array}$ \\
\hline $6-17$ & $1 / 8$ \\
\hline $18-39$ & $3 / 16$ \\
\hline $40-54$ & $1 / 4$ \\
\hline $55-60$ & $5 / 16$ \\
\hline
\end{tabular}

*All Dimensions in Inches 


\subsubsection{Baffle Spacing}

The overall shell length, $L_{t o}$, which is also the tube length, is defined in terms of the distance between the tubesheets, $L_{t i}$, and the tube sheet thickness, $L_{t s}$. The tubesheet thickness is determined by performing heat exchanger mechanical design, which is calculated according to TEMA Standard RCB-7.1. For initial thermal-hydraulic calculations, the tubesheet thickness is assumed as 1 inch $(25.4 \mathrm{~mm})$.

$$
L_{t o}=L_{t i}+2 L_{t s}
$$

Inner shell geometry is controlled by the baffle spacing, and the length between tubesheets, $L_{t i}$. Typically, the inlet baffle spacing, $L_{b i}$, and outlet baffle spacing, $L_{b o}$ is larger than the central baffle spacing, $L_{b c}$, to allow for even flow distribution in the inlet and outlet. The number of baffles, $N_{b}$, is a function of the baffle spacing and the total shell length, and is found by [8.7]:

$$
N_{b}=\frac{L_{t i}-L_{b i}-L_{b o}}{L_{b c}}+1
$$

The number of baffles, as found in Equation 8.43, is rounded off to a lower integer value, and the central baffle spacing is corrected.

$$
L_{b c}=\frac{L_{t i}}{N_{b}+1}
$$

The baffle spacing should be checked against TEMA Standard RCB-4.51. The TEMA Standard indicates that baffles should not be spaced closer than 1/5 of the shell I.D. or 2 inches whichever may indicate closer spacing. In addition, TEMA Standard RCB-4.52 regulates the maximum unsupported tube span for several tube materials [8.6]. 


\subsubsection{Baffle Geometry}

The centriangle of the baffle cut, $\theta_{d s}$, is the angle between the intersection of the baffle cut and inner shell wall. The angle is shown in Figure 8.14 and is defined by:

$$
\theta_{d s}=2 \cos ^{-1}\left[1-\frac{2\left(l_{c} / D_{i}\right)}{100}\right]
$$

The upper centriangle of the baffle cut, $\theta_{c t}$, is the angle between the intersection of the baffle cut and the tube bundle diameter. The angle is shown in Figure 8.14, and is defined by:

$$
\theta_{c l l}=2 \cos ^{-1}\left[\frac{D_{i}}{D_{c t l}}\left(1-\frac{2\left(l_{c} / D_{i}\right)}{100}\right)\right]
$$

\subsubsection{Number of Effective Tube Rows in Crossflow and in Baffle Window}

The number of effective tube rows that are positioned between the baffle cuts in a given window, $N_{t c c}$, is the distance between the baffle cuts divided by the longitudinal pitch (longitudinal with respect to the flow).

$$
N_{t c c}=\frac{D_{i}}{P_{l}}\left(1-\frac{2\left(l_{c} / D_{i}\right)}{100}\right)
$$

The effective number of tube rows in longitudinal direction that are outside the baffle cuts in a given tube window, $N_{t c w}$, is given by Equation 8.50 . 


$$
N_{t c w}=\frac{0.8}{P_{l}}\left[\frac{D_{i}\left(l_{c} / D_{i}\right)}{100}-\frac{D_{i}-D_{c t l}}{2}\right]
$$

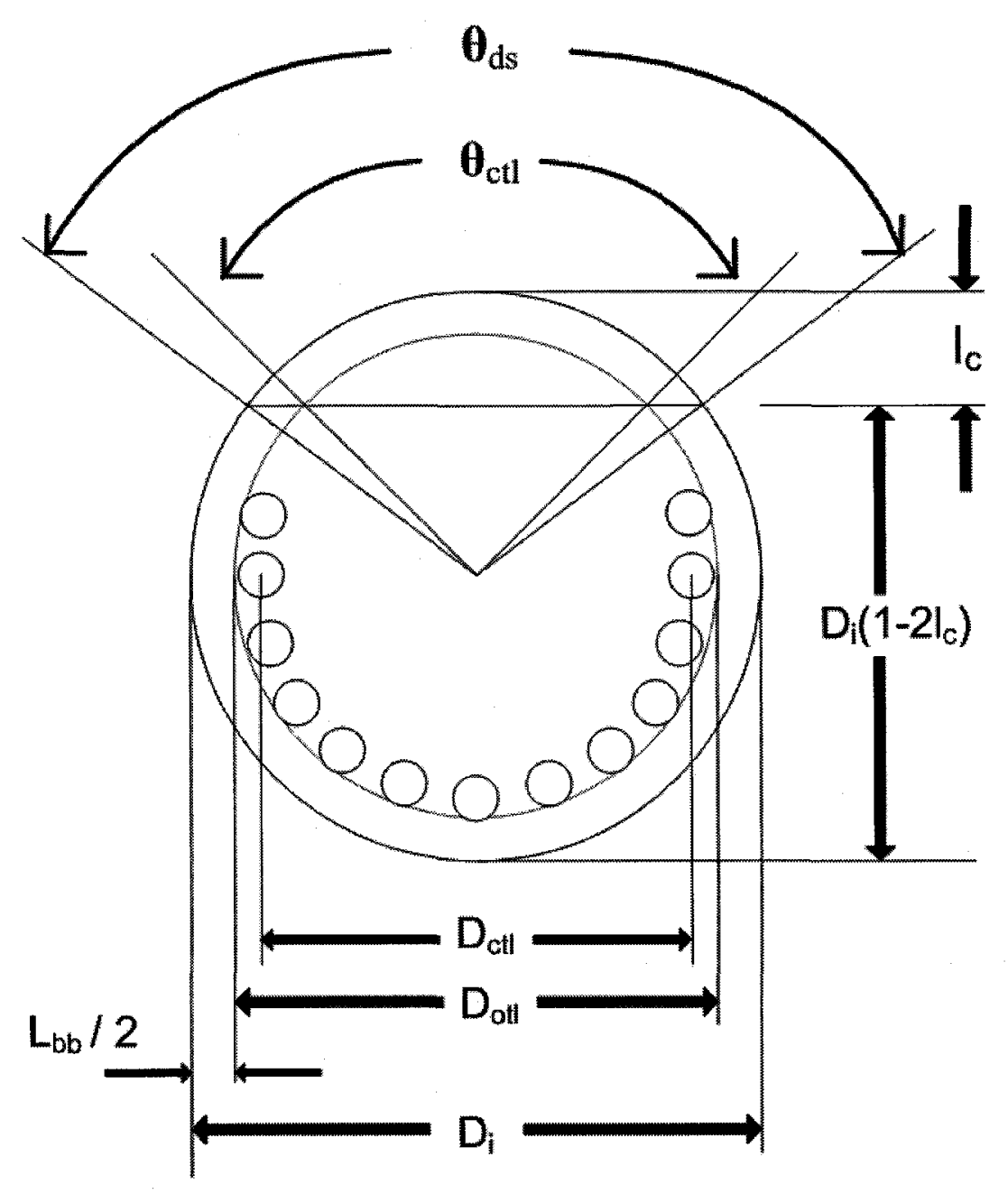

Figure 8.14: Segmental Baffle Geometry [8.1] 


\subsubsection{Flow and Leakage Areas}

The crossflow area and leakage areas are determined for each stream to evaluate the ideal heat-transfer rate, pressure drop, and correction factors.

\subsubsection{Shell-Side Crossflow Area}

The shell-side crossflow area near the centreline of a single window, $S_{m}$, is calculated as:

$$
S_{m}=L_{b c}\left[L_{b b}+\frac{D_{c t l}}{L_{t p, e f f}}\left(L_{t p}-d_{o}\right)\right]
$$

where the effective tube pitch normal to the flow, $\mathrm{L}_{\mathrm{tp} \text {,eff }}$ is a function of the tube layout:

$$
\begin{array}{lll}
\mathrm{L}_{\mathrm{tp}, \mathrm{eff}}=\mathrm{L}_{\mathrm{tp}} & \text { for } & \theta=30^{\circ}, 60^{\circ} \& 90^{\circ} \\
\mathrm{L}_{\mathrm{tp}, \text { eff }}=0.707 \mathrm{~L}_{\mathrm{tp}} & \text { for } & \theta=45^{\circ}
\end{array}
$$

\subsubsection{Baffle Window Flow Area}

The total flow area in all windows, $S_{\mathrm{wg}}$, neglecting the area occupied by tubes, is expressed as:

$$
S_{w g}=\frac{\pi}{4} D_{i}^{2}\left(\frac{\theta_{d s}}{2 \pi}-\frac{\sin \theta_{d s}}{2 \pi}\right)
$$

The baffle window area occupied by tubes is proportional to the number of tubes positioned in the window. The fraction of tubes in baffle window, $F_{w}$, is found by:

$$
F_{w}=\frac{\theta_{c t l}}{2 \pi}-\frac{\sin \theta_{c t l}}{2 \pi}
$$


The correction factor for baffle cut and spacing is proportional to the number of tubes in pure crossflow between the baffle cuts (indicated as $D_{i}-2 l_{c}$ in Figure 8.14). The fraction of tubes in pure crossflow is found by:

$$
F_{c}=1-2 F_{w}
$$

The baffle window area occupied by the tubes, $S_{w t}$, is found by:

$$
S_{w t}=N_{t} F_{w} \frac{\pi}{4} d_{o}^{2}
$$

The net crossflow area through one baffle window, $S_{w}$, is the difference between the total flow area without tubes, $S_{w g}$, and the area occupied by the tubes, $S_{w t}$.

$$
S_{w}=S_{w g}-S_{w t}
$$

\subsubsection{Hydraulic Diameter}

By definition, the hydraulic diameter is four times the crossflow area divided by the wetted perimeter. The hydraulic diameter is required only for pressure drop calculations in laminar flow. The hydraulic diameter of the segmental baffle window, $D_{w}$, expressed according to the nomenclature above, is defined as [8.1]:

$$
D_{w}=\frac{4 S_{w}}{\pi d_{o} N_{t w}+\pi D_{i} \theta_{d s} / 2 \pi}
$$

\subsubsection{Tube Bundle-to-Shell Bypass Area}

The bypass area between the tube bundle and the shell, $S_{b}$, is found by:

$$
S_{b}=L_{b c}\left(D_{i}-D_{o t l}\right)
$$


The correction factor for the heat-transfer loss due to leakage flow around the baffle, $J_{l}$, and due to bundle bypass flow, $J_{b}$ is related to the fraction of bypass leakage flow area to the shell-side crossflow area, $F_{s b p}$. The fraction bypass flow area is found by:

$$
F_{s b p}=\frac{S_{b}}{S_{m}}
$$

\subsubsection{Shell-to-Baffle Leakage Area}

The correction factor for heat transfer loss due to leakage flow around the baffle, $J_{l}$, is related to the shell-to-baffle leakage area. The shell-to-baffle leakage area is a function of the maximum recommended clearance between shell I.D and baffle O.D, $L_{s b}$, which is provided in Table 8.2. The shell-to-baffle leakage area around a single baffle, $S_{s b}$, is found by:

$$
S_{s b}=\pi D_{i} \frac{L_{s b}}{2}\left(\frac{2 \pi-\theta_{d s}}{2 \pi}\right)
$$

\subsubsection{Tube-to-Baffle Hole Leakage Area}

According to TEMA Standard RCB-4.2, for unsupported tube length of 36 inches or less, or tube diameter larger than 1-1/4 inches, the standard tube-to-baffle diametrical clearance, $L_{t b}$, is $1 / 32$ inch. For unsupported tube length exceeding 36 inches or tube diameter 1-1/4 inches or smaller, the standard tube-to-baffle diametrical clearance is $1 / 64$ inches [8.6]. The tube-to-baffle leakage area for one baffle, $S_{t b}$, is found by Equation 8.62. The baffle leakage correction factor, $J_{l}$, is related to the tube-to-baffle leakage area.

$$
S_{t b}=\frac{\pi}{4}\left[\left(d_{o}+L_{t b}\right)^{2}-d^{2}\right] N_{t}\left(1-F_{w}\right)
$$




\subsubsection{Shell-Side Crossflow Velocity and Reynolds Number}

The shell-side crossflow velocity used to determine the heat transfer and pressure drop, according to the Bell-Delaware method, is found in Equation 8.63.

$$
U_{s}=\frac{\dot{m}_{s}}{\rho_{s} S_{m}}
$$

The shell-side mass velocity, $G_{s}$, is found by definition [8.1]:

$$
G_{s}=\frac{\dot{m}_{s}}{S_{m}}
$$

The shell-side Reynolds number, $R e_{s}$, is also found by definition [8.1]:

$$
\operatorname{Re}_{s}=\frac{d_{o} G_{s}}{\mu}
$$

\subsubsection{Heat-Transfer and Pressure Drop Correction Factor Correlations}

\subsubsection{Correction Factor for Baffle Cut and Spacing, $J_{c}$}

The segmental baffle cut correction factor, $J_{c}$, for baffle cut range $\left(l_{c} / \mathrm{D}_{\mathrm{i}}\right)$ of 15 percent to 45 percent is expressed as [8.1]:

$$
J_{c}=0.55+0.72 F_{c}
$$

The correction factor accounts for flow deviation from crossflow to the tubes due to the size of the baffle cut. The value is equal to 1.0 for a NTIW design since the flow is in pure crossflow across the tubes and no correction is required. Typical values may be as low as 0.52 for large baffle cuts where velocity is low and as high as 1.15 for small baffle cuts, where the heat transfer is augmented due to the high velocity region. Typical value for a well-designed heat exchanger approaches 1.0. High values are undesirable due to an associated high-pressure drop caused by high velocities. 


\subsubsection{Correction Factor for Baffle Leakage Effects, $\boldsymbol{J}_{l}$}

The $J_{l}$ and $R_{l}$ correction factors account for leakage flow through the baffles in the tube-to-baffle clearance area and shell-to-baffle clearance area. The correction factors are related to the clearance size and crossflow area between the baffles, which is related to the baffle spacing. The heat transfer correction factor, $J_{l}$, and pressure drop correction factor, $R_{l}$, are based on a curve fit found by [8.1]:

$$
\begin{aligned}
& J_{l}=0.44\left(1-r_{s}\right)+\left[1-0.44\left(1-r_{s}\right)\right] e^{-2.2 r_{l m}} \\
& R_{l}=\exp \left[-1.33\left(1+r_{s}\right)\right] r_{l m}^{x_{l}}
\end{aligned}
$$

where $r_{s}$ and $r_{l m}$ is defined in terms of the shell-to-baffle leakage area, $S_{s b}$, tube-tobaffle leakage area, $S_{t b}$, and the crossflow area, $S_{m}$ :

$$
\begin{aligned}
& r_{s}=\frac{S_{s b}}{S_{s b}+S_{t b}} \\
& r_{l m}=\frac{S_{s b}+S_{t b}}{S_{m}}
\end{aligned}
$$

and the exponent, $\mathrm{x}_{1}$, is:

$$
x_{l}=\left[-0.15\left(1+r_{s}\right)+0.8\right]
$$

Typical value of $J_{l}$ for a well-designed heat exchanger is in the range of 0.7 to 0.9 . If a lower value is calculated, the baffle spacing should be increased or the tube pitch should be increased. A typical value for $R_{1}$ is 0.4 to 0.5 , although lower values are possible in heat exchangers with short distance between the baffles [8.1].

\subsubsection{Correction Factor for Bundle Bypass Effects, $J_{b}$}

$J_{b}$ is the correction factor for the heat transfer loss due to the low tube-wetting area of the tube bypass flow (C-stream). $J_{b}$ varies with the clearance between the outermost tube periphery and the shell. Also, $J_{b}$ varies with the number of longitudinal 
sealing strips used between and outside of the bundle and shell. The heat transfer correction factor, $J_{b}$, and the pressure drop correction factor, $R_{b}$, is found by [8.1]:

$$
\begin{aligned}
& J_{b}=\exp \left\{-C_{b h} F_{s b p}\left[1-\left(2 r_{s s}\right)^{\frac{1}{3}}\right]\right\} \\
& R_{b}=e^{\left\{-C_{b p} F_{s b p}\left[1-\left(r_{s s}\right)^{1 / 3}\right]\right\}}
\end{aligned}
$$

where the baffle constant for heat transfer and pressure drop, $C_{b h}$ and $C_{b p}$ respectively, is defined as a function of Reynolds number:

$$
\begin{aligned}
& C_{b h}=1.25 \text { for laminar flow, } R e_{s} \leq 100, \text { with a limit of } J_{b}=1 \text { at } r_{s s} \geq 0.5 \\
& C_{b h}=1.35 \text { for turbulent and transition flow, } R e_{s}>100
\end{aligned}
$$

$C_{b p}=4.5$ for laminar flow, $\operatorname{Re}_{s} \leq 100$, with a limit of $R_{b}=1$ at $r_{s s} \geq 0.5$

$C_{b p}=3.7$ for turbulent and transition flow, $R e_{s}>100$

$r_{s s}$ is a function of the number of sealing strips, $N_{s s}$, and the number of effective tube rows that are positioned between the baffle cuts in a given window, $N_{t c c} . r_{s s}$ is defined as:

$$
r_{s s}=\frac{N_{s s}}{N_{t c c}}
$$

Typical value of $J_{b}$ is in the range of 0.7 for large clearance and 0.9 for small clearance. Sealing strips greatly increase the value of $J_{b}$, resulting in a lower correction from ideal heat-transfer conditions. A typical pressure loss correction for bundle bypass effects, $R_{b}$, ranges from 0.5 to 0.8 , depending upon the clearance size and number of sealing strips. Large values coincide with small clearance values and large number of sealing strips [8.1]. 


\subsubsection{Correction Factor for Unequal Baffle Spacing at Inlet and Outlet, $J_{s}$}

Heat-transfer correction factor for variable baffle spacing at the inlet and outlet with respect to the central baffle spacing is found by Equation 8.77 .

$$
J_{s}=\frac{\left(N_{b}-1\right)+\left(L_{i}^{*}\right)^{1-n}+\left(L_{o}^{*}\right)^{1-n}}{\left(N_{b}-1\right)+L_{i}^{*}+L_{o}^{*}}
$$

where

$$
L_{i}^{*}=\frac{L_{b i}}{L_{b c}} \quad \text { and } \quad L_{o}^{*}=\frac{L_{b o}}{L_{b c}}
$$

Typically, the correction factor value is in the range of 0.85 and 1.0, depending on the size of inlet and outlet baffle spacing relative to the central baffle spacing. The correction factor is 1.0 if the inlet and outlet baffle spacing is equivalent. The exponent $\mathbf{n}$ is 0.6 for turbulent flow $\left(\operatorname{Re}_{s}>100\right)$ or 1/3 for laminar flow $\left(R e_{s}<100\right)$. The $J_{s}$ correction factor for laminar flow is typically a median of the $J_{s}$ value computed for turbulent flow conditions and 1.0.

The pressure-drop correction factor due to relatively larger baffle spacing at the inlet and outlet as compared to the central baffle spacing is corrected by Equation 8.79.

$$
R_{s}=\left(\frac{1}{L_{i}^{*}}\right)^{2-n}+\left(\frac{1}{L_{o}^{*}}\right)^{2-n}
$$

Typically, the pressure drop correction factor value is in the range of 0.50 and 2.0, depending on the size of inlet and outlet baffle spacing relative to the central baffle spacing. The correction factor is 1.0 for laminar flow and 0.57 for turbulent flow if the inlet and outlet baffle spacing is twice the central spacing. If the inlet and outlet baffle spacing is equivalent to the central spacing, the correction factor is 2.0. The exponent $\mathbf{n}$ is 0.2 for turbulent flow $\left(R e_{s}>100\right)$ or 1.0 for laminar flow $\left(R e_{s}<100\right)$. 


\subsubsection{Correction Factor for Adverse Temperature Gradient in Laminar Flow, $J_{r}$}

$J_{r}$ is the correction factor applied for an adverse temperature gradient that resists conduction. The correction factor is valid only for laminar flow, and varies with the Reynolds number. The correction factor is expressed as:

$$
\begin{aligned}
& J_{r}=\frac{1.51}{N_{c}^{0.18}} \quad \text { if } \quad \operatorname{Re}_{\mathrm{s}}<20 \\
& J_{r}=\frac{1.51}{N_{c}^{0.18}}+\left(\frac{20-\operatorname{Re}_{s}}{80}\right)\left(\frac{1.51}{N_{c}^{0.18}}-1\right) \quad \text { if } \quad 20 \leq \mathrm{Re}_{\mathrm{s}}<100
\end{aligned}
$$

where $N_{c}$ is the total number of tube rows that cross the entire heat exchanger.

$$
N_{c}=\left(N_{t c c}+N_{t c w}\right)\left(N_{b}+1\right)
$$

For turbulent flow $\left(R e_{s}>100\right)$, the correction factor is 1.0, and for laminar flow, the minimum correction factor value is 0.4 .

\subsubsection{Overall Heat Transfer Coefficient Correlation}

The ideal shell-side heat transfer coefficient is calculated by:

$$
h_{i}=\frac{j_{i} C p_{s} G_{s}\left(\phi_{s}\right)^{n}}{\operatorname{Pr}_{s}^{2 / 3}}
$$

The Coulburn $j_{l}$ factor for an ideal tube bank is typically provided in graphical form in terms of the shell-side Reynolds number, tube layout, and pitch size. Such graphs can be found in Reference [8.4]. For computerized analysis, curve fit correlations are available in the following form [8.4]:

$$
j_{1}=a_{1}\left(\frac{1.33}{P_{t} / d_{o}}\right)^{a}\left(\operatorname{Re}_{s}\right)^{a_{2}}
$$


where:

$$
a=\frac{a_{3}}{1+0.14\left(\operatorname{Re}_{s}\right)^{a_{4}}}
$$

The correlation coefficients $a_{1}$ to $a_{4}$ vary according to the Reynolds number and tube layout. The coefficients are provided in Appendix D, Table D.3.

The term $\left(\varphi_{\mathrm{s}}\right)^{\mathrm{n}}$ is the viscosity correction factor due to variation of temperature at bulk mean temperature of the fluid and the wall. The viscosity correction factor is defined as:

$$
(\phi)^{n}=\left(\frac{\mu_{s}}{\mu_{w}}\right)^{0.14}
$$

For gasses, the viscosity correction factor in S.I. units is a function of the shellside temperature and wall temperature, $T_{s}$ and $T_{w}$ respectively.

For gasses being cooled: $\quad(\phi)^{n}=1.0$

For gasses being heated: $\quad(\phi)^{n}=\left[\frac{T_{s}+273.15}{T_{w}+273.15}\right]^{0.25}$

The shell-side heat transfer coefficient is the product of the ideal heat transfer coefficient and the correction factors. It is expressed as:

$$
h_{s}=h_{i} J_{c} J_{l} J_{s} J_{b} J_{r}
$$

\subsubsection{Correlations for Total Shell-Side Pressure Drop}

Similarly to the heat-transfer correlations, the Bell-Delaware method for calculating the total shell-side pressure drop consists of finding the pressure drop across an ideal tube bundle and correcting the total pressure drop for bypass and leakage flow, as well as, inlet and exit geometry. The total pressure drop across the shell-side of a shell and tube heat exchanger, $\Delta p_{s}$, is the summation of the pressure drop in the crossflow 
section, $\Delta p_{c}$, in the window section, $\Delta p_{w}$, and in the entrance and exit sections, $\Delta p_{e}$. The regions are depicted in Figure 8.15 and the total pressure drop calculated is found by Equation 8.84 .

$$
\Delta p_{s}=\Delta p_{c}+\Delta p_{w}+\Delta p_{e}
$$

The pressure drop due to crossflow is a function of the ideal pressure drop, $\Delta p_{b, i}$, and correction factor for bundle bypass, $R_{b}$, and baffle leakage, $R_{l}$.

$$
\Delta p_{c}=\left(N_{b}-1\right)\left(\Delta p_{b, i} R_{b} R_{l}\right)
$$

The pressure drop across an ideal tube bank in crossflow is defined as

$$
\Delta p_{b, i}=2 f_{s} N_{t c c} \frac{G_{s}^{2}}{g_{c} \rho_{s}}\left(\phi_{s}\right)^{-n}
$$

The term $f_{s}$ is the shell-side friction factor, which varies with the Reynolds number, tube layout, and tube pitch. The values for the friction factor are available in graphical form in numerous references, including Reference [8.4]. Curve fits, in the form of Equation 8.91, are also available for numerical friction factor evaluation. Friction factor coefficients, $b_{1}$ to $b_{4}$, are provided in Appendix D, Table D.4.

$$
f_{s}=b_{1}\left(\frac{1.33}{P_{T} / d_{o}}\right)^{b}\left(\operatorname{Re}_{s}\right)^{b_{2}}
$$

where:

$$
b=\frac{b_{3}}{1+0.14\left(\operatorname{Re}_{s}\right)^{b_{4}}}
$$

The pressure drop in the entrance and exit sections is a function of the inlet and outlet baffle spacing as well as the bypass flow. The pressure drop in this section is found by:

$$
\Delta p_{e}=2\left(\Delta p_{b, i}\right)\left(1+\frac{N_{t c w}}{N_{t c c}}\right) R_{b} R_{s}
$$


For a single ideal baffle window, the pressure drop is found by:

$$
\begin{array}{ccc}
\Delta p_{w}=\frac{\left(2+0.6 N_{t c w}\right) G_{w}^{2}}{2 g_{c} \rho_{s}} & \text { if } & \operatorname{Re}_{\mathrm{s}} \geq 100 \\
\Delta p_{w}=26 \frac{G_{w} \mu_{s}}{g_{c} \rho_{s}}\left(\frac{N_{t c w}}{L_{t p}-d_{o}}+\frac{L_{b c}}{D_{w}^{2}}\right)+2 \frac{G_{w}^{2}}{g_{c} \rho_{s}} & \text { if } & \operatorname{Re}_{\mathrm{s}}<100
\end{array}
$$

where $G_{w}$, is the window mass velocity defined by:

$$
G_{w}=\frac{\dot{m}_{s}}{\sqrt{S_{m} S_{w}}}
$$

The pressure drop in all windows is:

$$
\Delta p_{w, T O T}=\Delta p_{w} N_{b} R_{l}
$$

The total nozzle-to-nozzle shell-side pressure drop, as found per Equation 8.88 is in the range of 20 percent to 30 percent of the pressure drop that would be calculated for a heat exchanger without leakage and bypass effects.

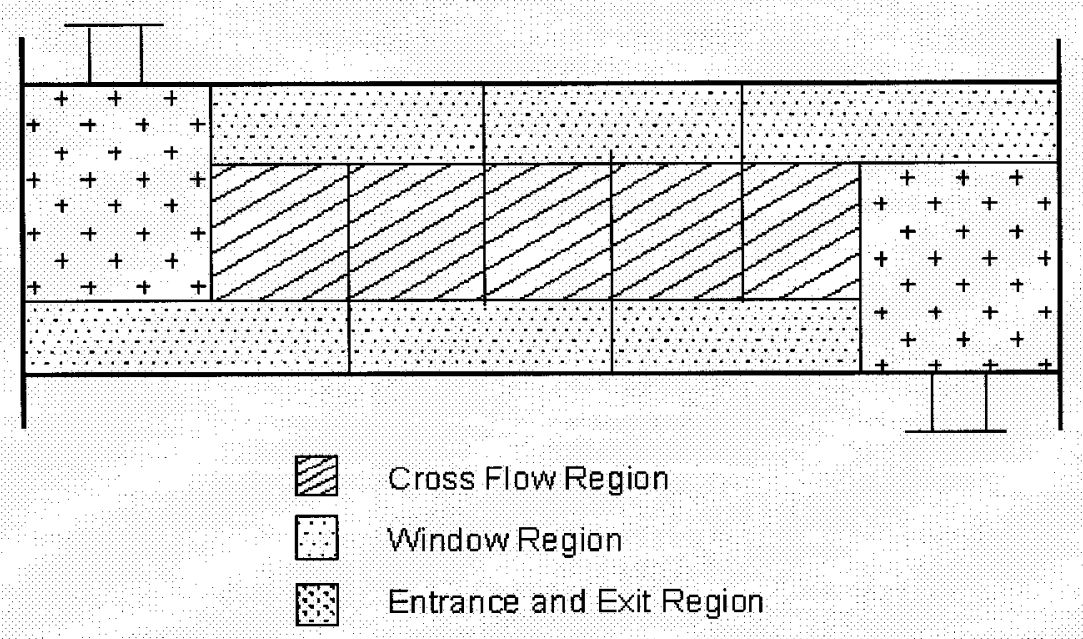

Figure 8.15: Regions for Shell-Side Pressure Drop Calculations 


\subsubsection{Accuracy of the Bell-Delaware Method}

Although the Bell-Delaware method is the most widely used rating and sizing open-literature method, it is considered not very accurate. The Bell-Delaware method has been shown to predict heat-transfer coefficients from 50 percent low to 100 percent high and a pressure drop from 50 percent low to 200 percent high. A mean error of 15 percent should be expected for the heat-transfer coefficient. A mean error in the range of 5 percent at high Reynolds number (above 1000) to about 100 percent at Reynolds numbers below 10 should be expected for the pressure drop [8.7].

\subsection{Heat Transfer and Pressure Loss Correlations for Tube-Side Flow}

The tube-side convective heat transfer coefficient is found by analytical calculations for laminar flow and experimental calculations for turbulent flow. The nondimensional heat-transfer coefficient is analytically calculated for laminar tube flow (where the Reynolds number is below 2100) by Equation 8.97 (see Reference [8.5] for detailed derivation).

$$
N u_{d_{i}}=4.364
$$

For fully-developed turbulent flow, where the Reynolds number exceeds 10,000, the Nusselt number is calculated according to the Sieder and Tate Equation [8.1]:

$$
N u_{d_{i}}=0.027 \operatorname{Re}_{d_{i}} \operatorname{Pr}_{t}^{1 / 3}\left(\frac{\mu_{t}}{\mu_{w}}\right)^{0.14}
$$

All properties are calculated at bulk-temperature conditions, except for $\mu_{\mathrm{w}}$. The ratio $\left(\mu_{\mathrm{w}} / \mu_{\mathrm{w}}\right)$ accounts for viscosity variation between the bulk-temperature and the wall temperature. 
At the transition region, where the Reynolds number ranges between 2100 and 10,000 , the correlation does not follow a straight line. In this region, Kern [8.1] has proposed the following relation:

$$
N u_{d_{i}}=0.116\left[\operatorname{Re}_{d_{i}}^{2 / 3}-125\right] *\left[1+\left(\frac{d_{i}}{L_{1}}\right)^{\frac{2}{3}}\right] \operatorname{Pr}_{t}^{1 / 3}\left(\frac{\mu_{t}}{\mu_{w}}\right)^{0.14}
$$

The above relations account only for forced convective heat transfer where the fluid is forced through the heat-transfer surface. Free-convection is observed as a result of density changes of the working fluid arising from heating or cooling. The density changes cause fluid movement due to buoyancy forces of the working gas. These buoyancy forces cause free-convection currents that influence the overall heat transfer rate [8.5].

Similarly to the Reynolds number where the transition from laminar to turbulent flow can be predicted, free convection is present when a certain magnitude of Grashof number is attained. The Grashof number is a dimensionless group physically representing the ratio of buoyancy forces to the viscous forces in the free-convection system. It is defined for tube flow as [8.5]:

$$
G r_{d_{i}}=\frac{g_{c} \beta\left(T_{w}-T_{t}\right) d_{i}^{3} \rho^{2}}{\mu^{2}}
$$

where $\beta$ is the volume coefficient of expansion. For ideal gasses, $\beta$ is equivalent to $1 / T$, where $T$ is the absolute temperature of the working gas.

If the Grashof number exceeds 25,000 , the Nusselt number must be corrected to account for free-convection. The correction factor is expressed in Equation 8.101 [8.1].

$$
N u_{d_{i}}^{*}=0.8\left(1+0.015 G r_{d_{i}}^{1 / 3}\right) N u_{d_{i}}
$$


The film coefficient of the tube-side fluid, $h_{i}$, is found by definition of the Nusselt number, Equation 8.4, and used in Equation 8.12 to find the overall heat transfer coefficient.

The pressure drop in tubes is found empirically by:

$$
\Delta P_{t}=f_{t}\left(\frac{L_{1}}{d_{i}}\right) \frac{G_{t}^{2}}{2 g_{c} \rho} \frac{1}{(\phi)^{r}}
$$

where

$$
\begin{array}{lll}
(\phi)^{r}=\left(\frac{\mu_{t}}{\mu_{w}}\right)^{0.14} & \text { for } & \operatorname{Re}_{\mathrm{t}}>2100 \\
(\phi)^{r}=\left(\frac{\mu_{t}}{\mu_{w}}\right)^{0.25} & \text { for } & \operatorname{Re}_{\mathrm{t}}<2100
\end{array}
$$

The friction factor, $f$, for smooth pipes in fully-developed laminar flow, where Reynolds number does not exceed 2100 , is [8.5]:

$$
f_{t}=\frac{64}{\mathrm{Re}_{t}}
$$

The friction factor for smooth pipes in turbulent flow condition is determined by the Blasius empirical formula [8.5]:

$$
f_{t}=\frac{0.3164}{\operatorname{Re}_{t}^{0.25}}
$$

The above relations account only for the pressure drop in the tubes. Pressure losses through the expansion and contraction headers are not estimated initially since the geometry is unknown. 


\subsection{Conductive Heat Transfer Relations for Tubular and Shell and Tube Heat Exchangers}

Conduction is a heat transfer process where energy is transferred from a high temperature region to a low temperature region due to presence of a temperature gradient. The general definition of conductive heat transfer is:

$$
q=-k A \frac{\partial T}{\partial r}
$$

where $q$ is the heat transfer rate, $\partial T / \partial r$ is the temperature gradient in the direction of heat flow (radial direction), $k$ is the thermal conductivity of the material, and $A$ is the area in the heat-flow direction [8.5]. For a number of tubes, $N_{t}$, of length $L_{l}$, the heat transfer area is:

$$
A=2 \pi r L_{1} N_{t}
$$

Applying the boundary conditions of:

$$
\begin{array}{lll}
T=T_{i} & \text { at } & r=r_{i} \\
T=T_{o} & \text { at } & r=r_{o}
\end{array}
$$

The conductive heat transfer rate is found:

$$
q=\frac{2 \pi k L_{1} N_{t}\left(T_{i}-T_{o}\right)}{\ln r_{o} / r_{i}}
$$

In heat exchanger thermal hydraulic design, it is more convenient to express heat transfer rate in terms of thermal resistance. The wall resistance due to conduction, $R_{w}$, is generally defined as [8.1]:

$$
R_{w}=\frac{\left(T_{i}-T_{o}\right)}{\frac{q}{A}}
$$


Wall resistance for plain circular tubes with an O.D. of $d_{o}$, I.D. of $d_{i}$, tube length, $L_{1}$, and material thermal conductivity of $\mathrm{k}_{\mathrm{w}}$ is defined by [8.1]:

$$
R_{w}=\frac{\ln \left(r_{o} / r_{i}\right)}{2 \pi k_{w} L_{1} N_{t}}=\frac{\ln \left(d_{o} / d_{i}\right)}{2 \pi k_{w} L_{1} N_{t}}
$$

when substituting into Equation 8.12a and 8.12b, the wall resistance may be simplified to Equation $8.111 \mathrm{a}$ and $8.111 \mathrm{~b}$ respectively:

$$
\begin{aligned}
& A_{i} R_{w}=\pi d_{i} L_{1} N_{t}\left(\frac{\ln \left(d_{o} / d_{i}\right)}{2 \pi k_{w} L_{1} N_{t}}\right)=\frac{d_{i} \ln \left(d_{o} / d_{i}\right)}{2 k_{w}} \\
& A_{o} R_{w}=\pi d_{o} L_{1} N_{t}\left(\frac{\ln \left(d_{o} / d_{i}\right)}{2 \pi k_{w} L_{1} N_{t}}\right)=\frac{d_{o} \ln \left(d_{o} / d_{i}\right)}{2 k_{w}}
\end{aligned}
$$

The above equations assume that heat transfer is only in the radial direction, $\partial T / \partial r$, and that there is no conductivity in the axial direction, i.e., $\partial T / \partial L_{1}=0$. Although conductive heat transfer will be present in the longitudinal direction, it is expected that the amount will be several orders of magnitude smaller due to the small cross-sectional area for longitudinal conduction:

$$
\pi\left(r_{0}^{2}-r_{i}^{2}\right)<2 \pi r L_{1}
$$

For circumferentially finned tubes, the total resistance due to conduction is the summation of tube resistance and wall resistance:

$$
R_{w}=\frac{\ln \left(r_{o} / r_{i}\right)}{2 \pi k_{w} L_{1} N_{t}}+\frac{\ln \left(r_{f} / r_{o}\right)}{2 \pi k_{f} t_{f} N_{f} L_{1} N_{t}}
$$

The conduction contribution of circumferentially finned tubes, found by Equation 8.112, is applied to find the overall heat-transfer coefficient, $\mathrm{U}$, using Equation 8.12. 


\subsection{Fouling Resistance}

Fouling is defined as the formation of undesired deposits on heat transfer surfaces, which impedes heat transfer and fluid flow. Fouling effect on heat transfer occurs in several forms. The fouling layer has a high thermal resistance with respect to resistance from conductive and convective heat transfer. The increased resistance to heat transfer rate reduces the overall heat exchanger effectiveness and increases the surface area requirement. Also, the formation of deposits causes restriction to the cross-sectional flow area, which increases the pressure drop throughout the heat exchanger. To prevent underperformance of the heat exchanger, allowance for fouling must be made in the design stage [8.9].

The additional requirement of heat exchanger size due to the fouling is considered when calculating the overall heat-transfer coefficient by introducing the terms: the thermal resistance due to fouling on the shell side, $R_{f o}$, and in the tube side, $R_{f i}$. These terms are applied to the overall heat transfer coefficient relation, Equation 8.12, which is used to find the heat exchanger surface area (Equation 8.8). Application of an accurate value of fouling resistance is critical, considering that a fouling resistance of 0.001 to $0.002 \mathrm{hr}-\mathrm{ft}^{2}-\mathrm{F} / \mathrm{Btu}$ will normally increase the heat transfer surface area by 20 to 50 percent, as compared to a clean heat exchanger [8.9]. Numerous factors affect the fouling resistance including the type of operating parameters, heat exchanger design parameters, and fluid properties.

Operating parameters that influence fouling include fluid velocity, surface temperature, and bulk fluid temperature. According to Reference [8.9], fluid velocity may be the most important factor affecting fouling behaviour. It has been observed that as the fluid velocity increases, the rate of fouling decreases. This is mainly due to the increased wall shear stress (at high velocities) that promotes removal of deposits at a higher rate than deposition. Surface temperature has an impact on the size of the fouling 
layer. High temperature promotes crystallization, chemical reaction, and corrosion, which increases the size of the fouling layer and adds to the difficulty in fouling removal. Similarly, the bulk fluid temperature affects the rate of polymerization, the rate of chemical reaction, and the rate of crystallization, which also increases the rate of fouling [8.10].

Heat exchanger parameters including surface material, surface roughness, and type of heat exchanger influences the rate of fouling. Surface material affects the corrosion fouling of heat exchanger walls. Surface roughness provides a nucleation site that promotes initial deposition, and promotes eddy diffusion deposition. Simply, a rough surface promotes deposition. Tubes with fine surface finish delay fouling and are easier to clean. Heat exchanger type also influences the rate of fouling since it has an effect on the flow velocity and turbulence level. In finned-tube exchangers, fin height does not have much influence on deposit build-up, although fin density is an important parameter. In comparison, there is no difference in the size of fouling layer for plain finned and segmented finned tubes, although segmented tubes are easier to clean [8.9].

Fluid properties, including the nature of fluid and nature of dissolved compounds have an effect on fouling. In combustion gasses, minimizing the quantity of trace elements such as vanadium, molybdenum, and sulphur is critical to minimizing the rate of precipitation and corrosive fouling. In general, the nature of the working fluid will not be governed by fouling; however, the amount of impurities should be kept to a minimum [8.9].

Despite the numerous known factors that influence fouling, little data is available for accurate assessment of the degree of fouling that can be expected for a given heat exchanger design, operating conditions, and fluid conditions. The Tubular Exchanger Manufacturers Association (TEMA) provides an experience-based listing of fouling resistances for various fluids [8.6]. However, limited information is provided on exhaust 
gas fouling factors. Weierman provides a more comprehensive list of fouling factors for gasses, which are based on operating experiences. These fouling resistances are found in Reference [8.9] and are provided in Appendix E, Table E.1, along with the TEMA fouling resistances. The fouling factors from both sources do not account for variation of fouling resistance with heat exchanger configuration, operating conditions, and fluid properties. For this reason the Weierman fouling factors are provided as a range of possible values. Also, no allowance is provided for time-dependence behaviour of fouling, which results in oversized heat exchanger when operating initially in a clean environment.

Since the technology demonstration CBC engine will operate with natural gas, the HSHE side that is exposed to flue gas should be modelled with the fouling resistance value in the range of 0.0005 to $0.003 \mathrm{hr}-\mathrm{ft}^{2}-\mathrm{R} / \mathrm{Btu}$. The selected fouling resistance factor is the median recommended Weierman value, $R_{\mathrm{f}}=0.002 \mathrm{hr}-\mathrm{ft}^{2}-\mathrm{R} / \mathrm{Btu}$ (all fouling resistance values that are provided in literature are in imperial units). The fouling resistance value for clean working fluids in the recuperator and HSHE is $0.000 \mathrm{hr}-\mathrm{ft}^{2}$ R/Btu. These values are applied to Equation 8.12 to find the overall heat-transfer coefficient, which governs the overall heat exchanger size.

\subsection{Conclusion}

Thermal-hydraulic design algorithms have been presented for the shell and tube and the tube-fin heat exchanger. The thermal hydraulic design algorithm is used to size both types of heat exchangers for recuperator and HSHE application, which is presented in Chapter 9. Sizing is used to select the candidate heat exchanger type based on practicality, performance, and relative cost. 
The heat transfer theory for tube-fin heat exchanger has been validated using the ESCOE Engineering Manual, freeware available from Fintube Technologies Inc. [8.11]. It has been found that the available heat-transfer surface area is in agreement within 3.5 percent of the required surface area found using the ESCOE Engineering Manual. The HSHE design, as determined by the thermal-hydraulic design theory presented in this chapter, is slightly larger since tube length is incremental in size. The actual required heat-transfer area is in agreement with the ESCOE Engineering manual analysis to 0.03 percent. It should be noted that errors of up to $15 \%$ may be possible with utilizing either design algorithm since both programs utilize experimental curve fits.

The heat-transfer theory for the shell and tube heat exchanger has been widely established and accuracy of the Bell-Delaware method is well-known. The Bell Delaware method is considered the only open-literature method for shell and tube heat exchanger sizing. Validation may only be accomplished with commercially available software packages. Due to the high cost of these design software packages, validation has not been performed. However, the shell and tube heat exchanger size is comparable to the tube-fin heat exchanger size and within the expected range. 


\section{CHAPTER 9}

\section{Heat Exchanger Sizing and Selection}

\subsection{Introduction}

The tube-fin heat exchanger and the shell and tube heat exchanger are sized for CBC engine application as a HSHE and a recuperator. Sizing of the heat exchangers is performed by applying the thermal-hydraulic theory presented in Chapter 8 . Each heat exchanger type is optimized for high heat-transfer rate and low heat exchanger size. Each heat exchanger is also designed within the permitted pressure drop. Design point operating parameters are analysed with respect to heat exchanger size and pressure drop. Heat exchanger type is selected for HSHE application based on size (i.e. material costs) and simplicity of mechanical design and fabrication. Similar design is used for the recuperator as the HSHE, although the size is scaled based on requirements. 


\subsection{Heat Input Split}

In a CBC engine, the heat input required to achieve a desired TIT is split between the recuperator and the HSHE. The recuperator extracts the high temperature turbine outlet heat and preheats the compressor outlet air, thus reducing the amount of heat required by the HSHE. The recuperator effectiveness governs the amount of heat transferred from the high temperature turbine outlet stream to the low temperature compressor outlet stream. Therefore, the recuperator effectiveness influences the potential cycle efficiency (as described in Section 6.6.1) and the relative size of each heat-transfer component. The heat input requirement from the recuperator and HSHE at varying recuperator effectiveness values is shown in Figure 9.1. The heat input requirement will indicate the relative size of each component if the same type of heat exchanger is utilized for the recuperator and HSHE. Recuperator effectiveness of 82 percent is required to achieve efficiency target of the $\mathrm{CBC}$ engine.

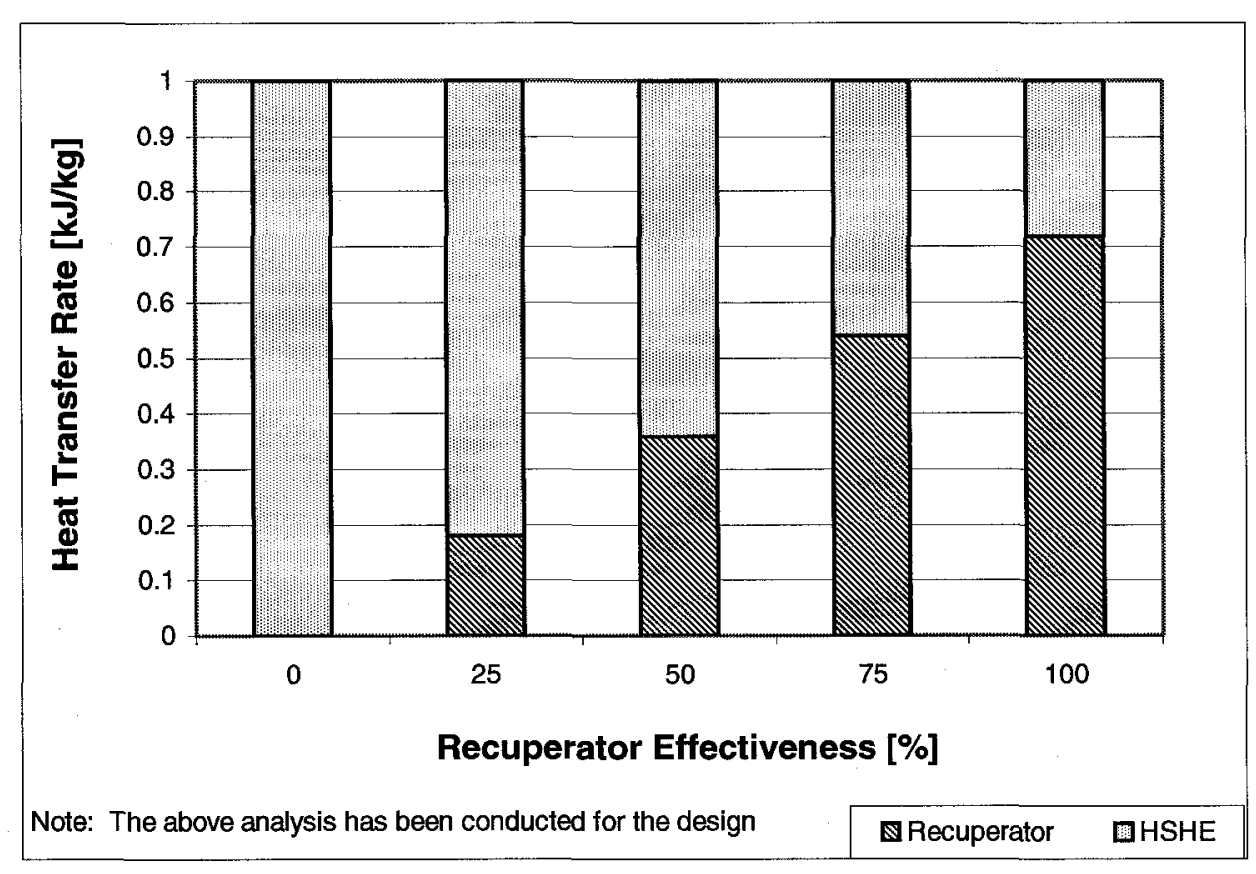

Figure 9.1: Heat-Transfer Rate Requirement for Each Heat Exchanger as a Function of Recuperator Effectiveness 
At design recuperator effectiveness of 82 percent, the relative heat-transfer rate requirement by the recuperator and HSHE is 60 percent and 40 percent respectively. Therefore, it is expected that the heat exchanger size would be in similar relation. It should be noted that unlike the open Brayton cycle, the recuperator is required in a CBC engine since recuperator omission (as exemplified by recuperator effectiveness of 0 percent) would require total heat-transfer input exclusively by the HSHE. This would result in an excessive HSHE size requirement.

\subsection{Tube-Fin Heat Exchanger Sizing for HSHE Application}

\subsubsection{Initial Specifications}

Heat exchanger geometry is dependant on flow arrangement and fluid placement on the tube and shell side. The basic flow arrangements are the parallel flow, counterflow, and crossflow. Selection of flow arrangement is dependant upon the desired thermal effectiveness, fluid flow paths, and desired packaging envelope. Extended surface heat exchangers typically utilize a crossflow arrangement since the flow does not enter and exit in the same region, which greatly simplifies the header design.

Flow placement in shell-side or tube-side is determined based on pressure and fouling drop considerations. Tube-side flow has a low pressure drop in relation to shellside flow. Also, inner tubes are easier to clean than finned outer tubes and the shell. Considering that the $\mathrm{CBC}$ engine is developed for operation with waste oils and biomass fuels, which precipitate large quantities of residue, selection of flow orientation should be governed by fouling considerations. Therefore, HSHE should be designed with the flue gas placed on the tube side. Despite the relatively greater pressure drop, the working fluid placed on the shell side.

Two tube layouts are possible with tube-fin heat exchangers: staggered and inline. Most commonly used is the staggered arrangement since the heat-transfer rate is of the 
order of $70 \%$ greater than with the inline arrangement. Due to the higher heat-transfer rate, the staggered layout will be utilized. Applications that require the use of inline arrangement are limited to extreme fouling applications on the shell side, and applications requiring very low pressure drop.

Tube geometry and initial tube arrangement is selected based on a parametric analysis of the effect on heat exchanger size. The parametric analysis is detailed in the following section. Shell dimension is selected based on tube length and tube bundle size.

\subsubsection{Parametric Analysis of Tube Geometry and Tube Arrangement on Heat Exchanger Size}

\subsubsection{Selection of Tube Diameter and Type}

There are three categories of heat exchanger tubing (1) Plain tubes, (2) Integral Low-Fin tubes, and (3) High-Finned tubes. Plain tubes offer lowest heat-transfer rates and offer the lowest cost alternative since no machining or welding of fins is required. Also, the plain tubes offer compactness since the tubes may be placed in very close proximity. Integral Low-Fin tubes provide higher heat-transfer rates than the plain tubes with the similar compactness. These tubes may be specified with finned and un-finned portions, although for comparative purposes it has been assumed that the entire tube is finned. High-Finned tubes are typically used in heat recovery systems in order to raise the heat-transfer rate on the gaseous shell side to match the heat-transfer rate on the liquid tube side. These tubes offer highest heat-transfer rates and highest cost due to the additional cost of fin material and welding. 


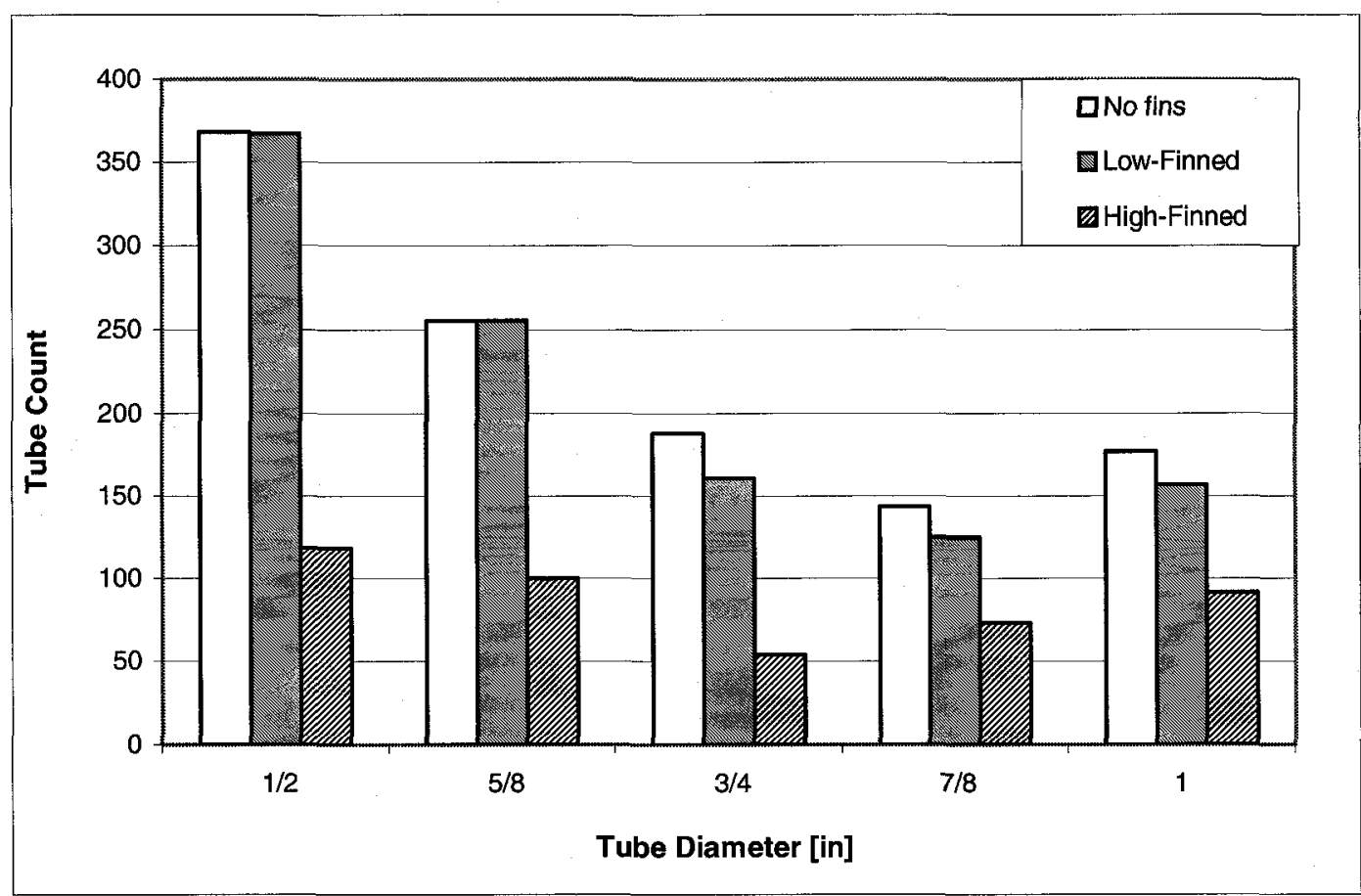

Figure 9.2: Tube Count as a Function of Tube Type and Tube Diameter

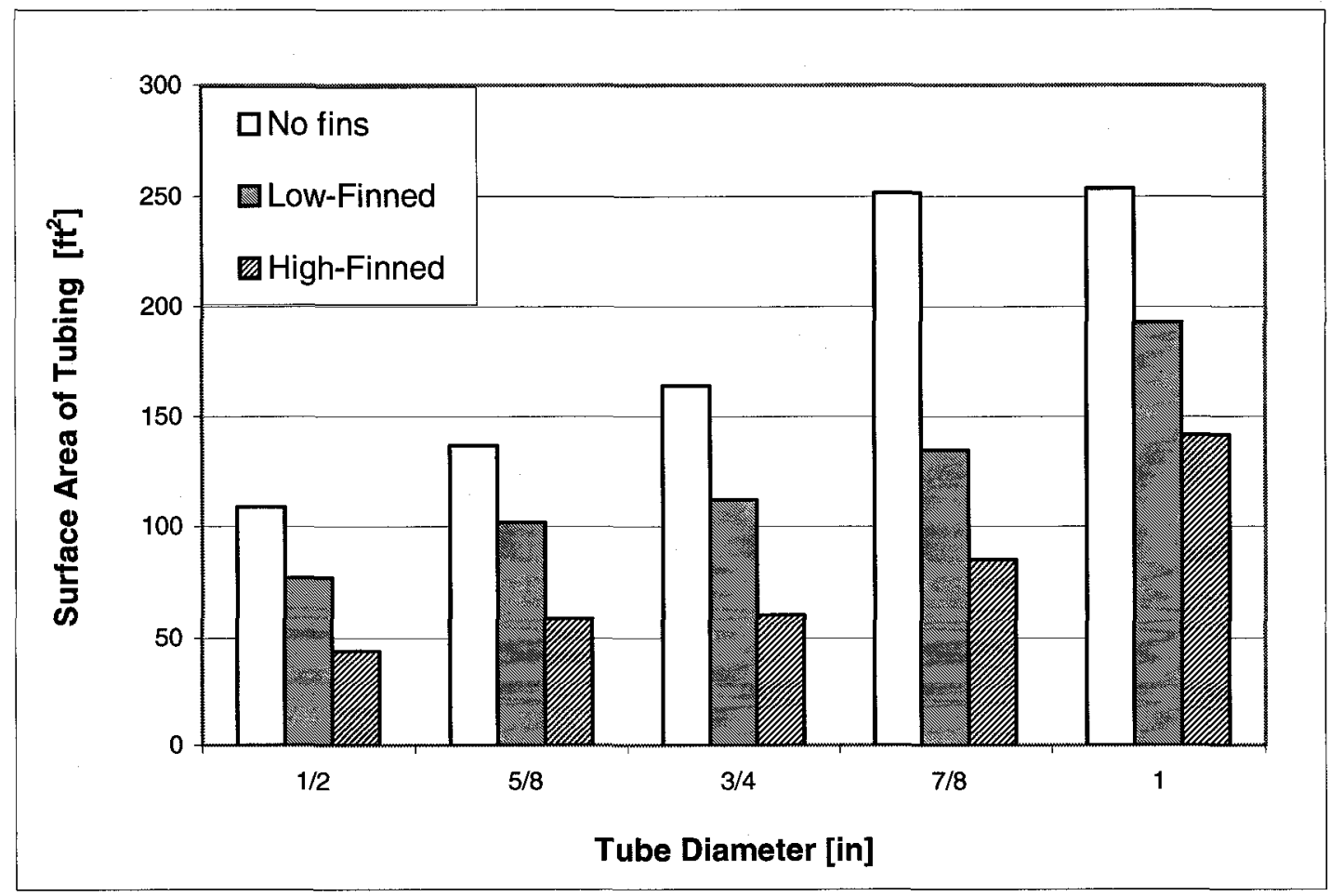

Figure 9.3: Surface Area as a Function of Fin Type and Tube Diameter 
The tube type and diameter selection is dependant on the size of the heat exchanger and therefore, the associated material and manufacturing cost. A parametric analysis of the effect on tube count and surface area is conducted for a range of tube diameters with bare, low finned, and high finned tubes. Tube diameters analysed include $1 / 2,5 / 8,3 / 4,7 / 8$, and 1 inch. Tube thickness of 0.109 inch was used for all tube sizes. Fin geometry of a typical low-finned tube was applied, with a fin height of 0.035 inches, fin thickness of 0.012 inches, and a fin pitch of 28 fins per inch. Fin geometry of an average sized high-finned tube was applied, with a fin height of 0.375 inches, fin thickness of 0.035 inches, and a fin pitch of 12 fins per inch.

As depicted in Figure 9.2, the lowest tube count and tube surface area is offered by the high-finned tubes. The reduction in tube count offered by using high finned tubes as compared to plain or low-finned tubes is between $209 \%$ for $1 / 2$ " tubes to $80 \%$ for 1 " tubes. This reduction in tube count has the potential to lower the manufacturing costs by reducing the tubing installation costs (i.e. welding tubes to tubesheets). Therefore, it is highly recommended that high-finned tubes are utilized for the tube-fin heat exchanger.

In general, the tube count is also reduced with application of tubes with large diameter. This however, does not signify that the size of the heat exchanger is reduced. Since the tube size and the distance between the tubes is larger, the size of the heat exchanger increases. Figure 9.3 depicts the corresponding increase in surface area with large tube diameter. It is desirable to design a heat exchanger with a low surface area to reduce material costs and with a low tube count to reduce manufacturing costs. The two design parameters are conflicting and a median tube size should be selected. Other design criteria influence the tube sizing decision. First, the tube side of the HSHE will be susceptible to fouling. Simplest means of cleaning the fouling layer will be by a mechanical means. According to TEMA Standards, the smallest permissible tube diameter is $3 / 4$ inch [9.4]. The other constraint is integrating the heat exchanger with the remaining system. Large diameter tubes will result in a large heat exchanger, which 
requires large headers and transition sections. According to the parametric analysis performed, the lowest tube count is for a heat exchanger with high-finned $3 / 4$ inch tubes. The $3 / 4$ inch tubes offer the lowest tube surface area among tube sizes compatible with mechanical cleaning techniques. Therefore, the high-finned $3 / 4$ inch tubes are selected for HSHE application.

\subsubsection{Selection of Heat Exchanger Dimensions and Fin Height}

As introduced in Section 8.5.3, numerous fin geometries are commercially available. The heat-transfer rates will vary according to selected tube-fin geometry. Surface area of annular and helical tubes is comparable, and therefore, the two fin geometries should provide comparable heat-transfer rates. Segmented, studded, wire loop, and slotted helical geometries have a smaller heat-transfer surface area and a dissimilar boundary layer, which will influence the heat-transfer rate. The segmented, studded, wire loop, and slotted helical fin geometries have an inherently lower mechanical strength, and will not be applied for a technology demonstration CBC engine. Therefore, annular fin geometry is applied for initial heat exchanger sizing. The effect of fin height on heat transfer is parametrically analyzed to determine the optimal fin height. Fin heights in the range of $1 / 4$ to $1 / 2$ inch, in increments of $1 / 16$ inch, are commercially available [9.2]. The fin size is parametrically studied to determine the effect on tube count and tube surface area.

As seen in Figure 9.4, the number of tubes required and the tube surface area required is reduced with application of fins with a large height. Utilization of a tube with a high fin height increases the heat-transfer surface area per tube unit length, thus reducing the total tube surface area requirement. However, the heat exchanger size is larger as a result of the larger tube spacing required to accommodate the fins. Calculated heat exchanger size requirement is compared in Table 9.1. The required tube length as a function of fin height is provided for a shell-side flow length and a no-flow length of 1 by 1 feet, 1.25 by 1.25 feet, and 


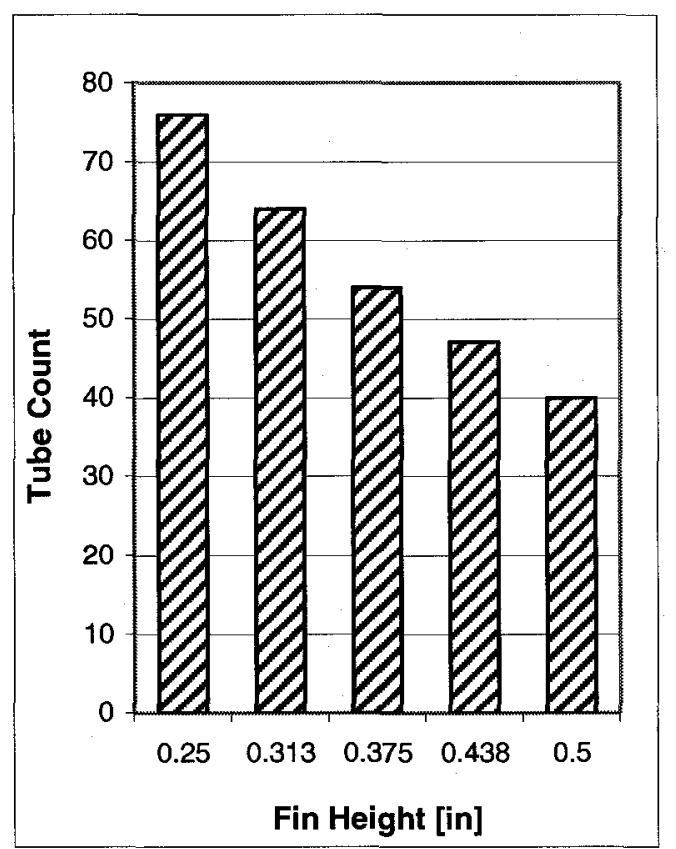

(a)

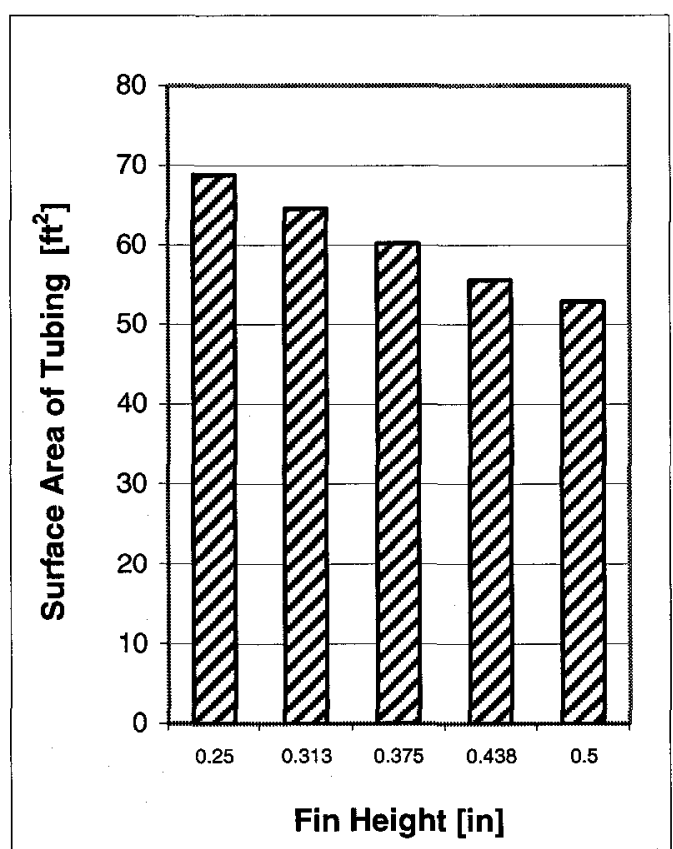

(b)

Figure 9.4: Effect of Fin Height on (a) Tube Count, (b) Surface Area of Tubing

Table 9.1: Heat Exchanger Size as a Function of Fin Height

\begin{tabular}{|c|c|c|c|c|c|c|c|c|c|}
\hline $\begin{array}{c}\text { H.E. } \\
\text { Size } \\
\mathrm{L}_{2} * \mathrm{~L}_{3}\end{array}$ & \multicolumn{3}{|c|}{$1 \mathrm{ft} * 1 \mathrm{ft}$} & \multicolumn{3}{|c|}{$1.25 \mathrm{ft} * 1.25 \mathrm{ft}$} & \multicolumn{3}{c|}{$1.5 \mathrm{ft} * 1.5 \mathrm{ft}$} \\
\hline $\begin{array}{c}\text { Fin } \\
\text { Height } \\
{[\text { in] }}\end{array}$ & $\begin{array}{c}\text { Tube } \\
\text { Length } \\
{[\mathrm{ft}]}\end{array}$ & $\begin{array}{c}\text { Tube } \\
\text { Count }\end{array}$ & $\begin{array}{c}\text { Tube } \\
\text { Surface } \\
\text { Area } \\
{\left[\mathrm{ft}^{2}\right]}\end{array}$ & $\begin{array}{c}\text { Tube } \\
\text { Length } \\
{[\mathrm{ft}]}\end{array}$ & $\begin{array}{c}\text { Tube } \\
\text { Count }\end{array}$ & $\begin{array}{c}\text { Tube } \\
\text { Surface } \\
\text { Area } \\
{\left[\mathrm{ft}^{2}\right]}\end{array}$ & $\begin{array}{c}\text { Tube } \\
\text { Length } \\
{[\mathrm{ft}]}\end{array}$ & $\begin{array}{c}\text { Tube } \\
\text { Count }\end{array}$ & $\begin{array}{c}\text { Tube } \\
\text { Surface } \\
\text { Area } \\
{\left[\mathrm{ft}^{2}\right]}\end{array}$ \\
\hline 0.25 & 6.5 & 76 & 68.8 & 5.75 & 119 & 95.3 & 5 & 171 & 119.1 \\
\hline 0.313 & 7.25 & 64 & 64.6 & 5.75 & 100 & 80.1 & 5.25 & 144 & 105.2 \\
\hline $\mathbf{0 . 3 7 5}$ & 8 & 54 & 60.2 & 6 & 85 & 71 & 5.5 & 122 & 97.7 \\
\hline 0.438 & 8.5 & 47 & 55.6 & 6.5 & 73 & 66.1 & 5.5 & 105 & 80.4 \\
\hline 0.5 & 9.5 & 40 & 52.9 & 7 & 64 & 62.4 & 5.75 & 92 & 73.7 \\
\hline
\end{tabular}

* Selected heat exchanger size and fin geometry is shown in bold 
1.5 by 1.5 feet. From this parametric analysis, it is concluded that the tube length requirement is lower for larger shell-side flow length and no-flow length, as well as shorter fin height. Tube fin selection and tube length selection is selected based on desired heat exchanger size.

Tube length must be modest in order to prevent flow induced vibration of the tubes and allow for accommodation in a building envelope. This later underlying constraint limits tube length to 6 feet, considering typical ceiling heights. For a tube length of 6 feet or shorter, lowest surface area and lowest tube count is offered by the heat exchanger with dimensions of 6 feet by 1.25 feet by 1.25 feet, with a fin height of 0.375 inches. This heat exchanger size and fin height is selected since lowest tube count and tube surface area will reduce the material and manufacturing costs.

\subsubsection{Selection of Fin Pitch}

Fin frequency, or fin spacing must be sized correctly to maximize the heattransfer rate. Low fin frequency will result in low heat-transfer rate since the surface area is limited. Likewise, tight fin spacing will also result in low heat-transfer rate since the main stream cannot penetrate the spaces between fins. Tight fin spacing results in no variation in the size of the thermal boundary layer. Moreover, tight fin spacing results in an excessive pressure drop as a result of transition to laminar flow [9.3]. A parametric analysis has been conducted to determine the effect of fin-spacing on the heat exchanger size. It should be noted that the theory presented in Chapter 8 does not include thermal boundary layer calculations. The thermal-hydraulic theory is based on curve fits established from experimental data. However, a fin height/spacing correction is included in the heat-transfer rate and pressure drop curve fits. The parametric analysis has been conducted for a heat exchanger with geometric parameters selected in the previous sections. Commercially available fin pitch sizes, in the range of 4 to 14 fins per inch (fpi), have been analyzed [9.2]. Results of the fin pitch parametric analysis are provided in Figure 9.5. 
The results of the parametric study indicate that application of tubes with high fin pitch results in requirement of a shorter tube length for the selected shell-side flow length and no-flow length. The drawback to utilizing tubes with a high fin pitch is that pressure drop increase exponentially. These results are in agreement with literature findings [9.3]. Selection of fin pitch is primarily based on manufacturing limitations and pressure drop considerations. The manufacturing limitation is placed by a tube-fin manufacturer (such as Unity Tubes Inc.) that specifies that a tube pitch of 12 fpi is the maximum fin pitch that may be brazed to a tube. Pressure drop allowance for both the HSHE and recuperator has been 6 percent of compressor delivery pressure (see Section 6.6.1). This requirement fixes the fin pitch size to a maximum of 9 fpi. The fin pitch of 9 fpi is selected since it offers the lowest heat-transfer surface area that adheres to the pressure drop requirements.

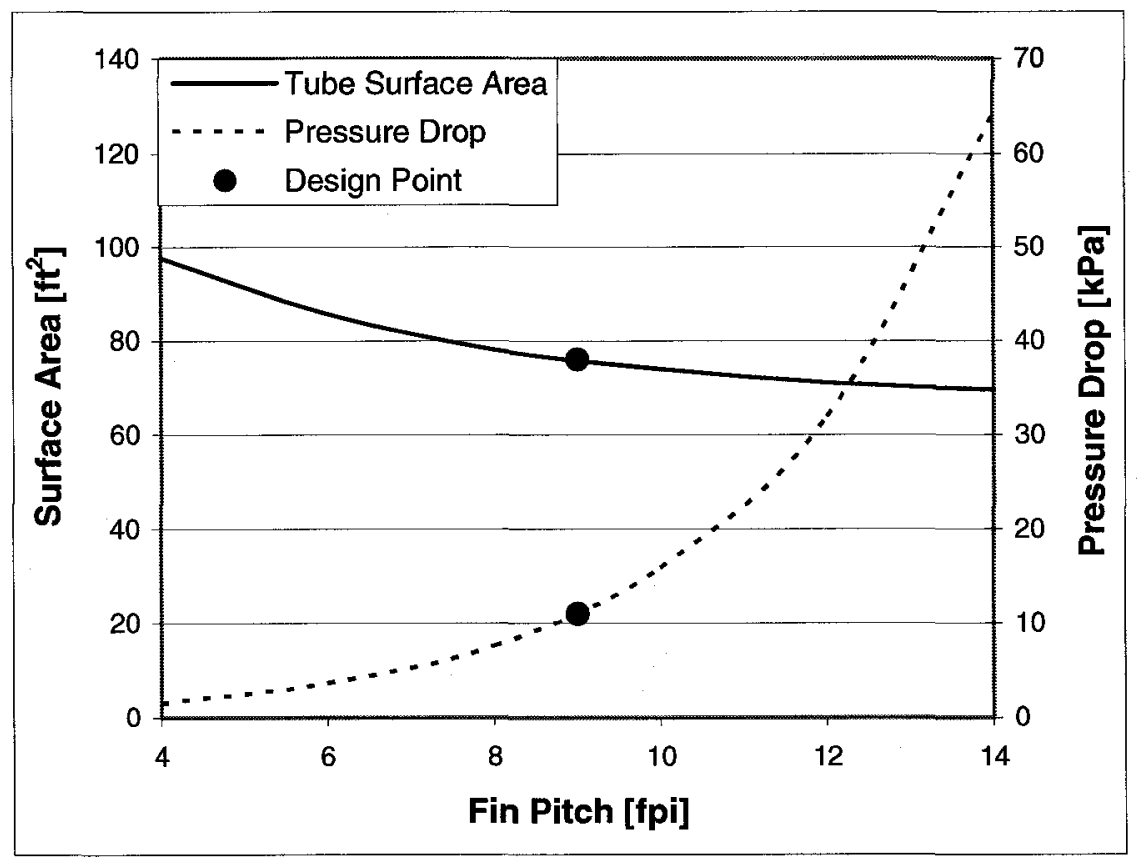

Figure 9.5: Effect of Fin Pitch on Heat Exchanger Surface Area and Pressure Drop 
Application of a fin pitch of 9 fpi results in a tube length of 6.5 feet, for the selected shell-side flow length of 1.25 feet and the no-flow length of 1.25 feet, which exceeds the 6 feet maximum requirement. Reduction of tube length to 6 feet is accomplished by increasing the shell-side flow length to 1.33 feet and the no-flow length to 1.33 feet. For this heat exchanger size, the required number of tubes is 96 , with 9 tube rows in shell-side flow direction. The predicted pressure drop is $11 \mathrm{kPa}$, or 2.9 percent of compressor delivery pressure, which is within the 3 percent requirement.

\subsubsection{Selection of Tube Pitch}

Tube pitch is the centre-to-centre distance between tubes, and is used as a measure of tube compactness. Tube compactness indirectly affects the shell size of the heat exchanger. The tube pitch has no effect on heat-transfer conditions if the flow velocities are comparable [9.3]. However, comparable flow velocities are difficult to realize since varying the tube pitch will inevitably vary the cross-sectional area and therefore, the flow velocity. Selection of tube pitch size has a considerable effect on the pressure drop. Increasing the tube pitch decreases the pressure drop through the heat exchanger. The opposite is true if the tube pitch is increased.

A parametric study, utilizing the thermal hydraulic theory presented in the previous chapter, has been conducted to quantify the effect of tube pitch on the sizing and pressure drop of the heat exchanger. Fin spacing of $0,1 / 8,1 / 4,3 / 8$, and $1 / 2$ inches is used for the parametric analysis, which corresponds to a tube pitch of 1.5 inch fin diameter plus the above fin spacing. For the tube pitch range analyzed, the actual heat exchanger size, including the tube count requirement, is depicted in Table 9.2. The pressure drop results have been presented in Figure 9.6.

Heat exchanger size requirement increases with large tube pitch since spacing between the tubes is greater. For a given core size, the number of tubes that can be fitted is smaller, and the required tube length is larger. It is apparent 
Table 9.2: Effect of Tube Pitch on Heat Exchanger Size

\begin{tabular}{|c|c|c|c|c|}
\hline $\begin{array}{c}\text { Tube Pitch } \\
{[\mathrm{in}]}\end{array}$ & $\begin{array}{c}\text { Tube Length } \\
{[\mathrm{ft}]}\end{array}$ & $\begin{array}{c}\text { Shell-Side } \\
\text { Flow Length } \\
{[\mathrm{ft}]}\end{array}$ & $\begin{array}{c}\text { No-Flow } \\
\text { Length } \\
{[\mathrm{ft}]}\end{array}$ & Tube Count \\
\hline 1.500 & 6 & 1.33 & 1.33 & 113 \\
\hline $\mathbf{1 . 6 2 5}$ & $\mathbf{6}$ & $\mathbf{1 . 3 3}$ & $\mathbf{1 . 3 3}$ & $\mathbf{9 6}$ \\
\hline 1.750 & 7 & 1.33 & 1.33 & 83 \\
\hline 1.875 & 8 & 1.33 & 1.33 & 72 \\
\hline 2 & $91 / 4$ & 1.33 & 1.33 & 63 \\
\hline
\end{tabular}

* Selected heat exchanger size and tube pitch is shown in bold

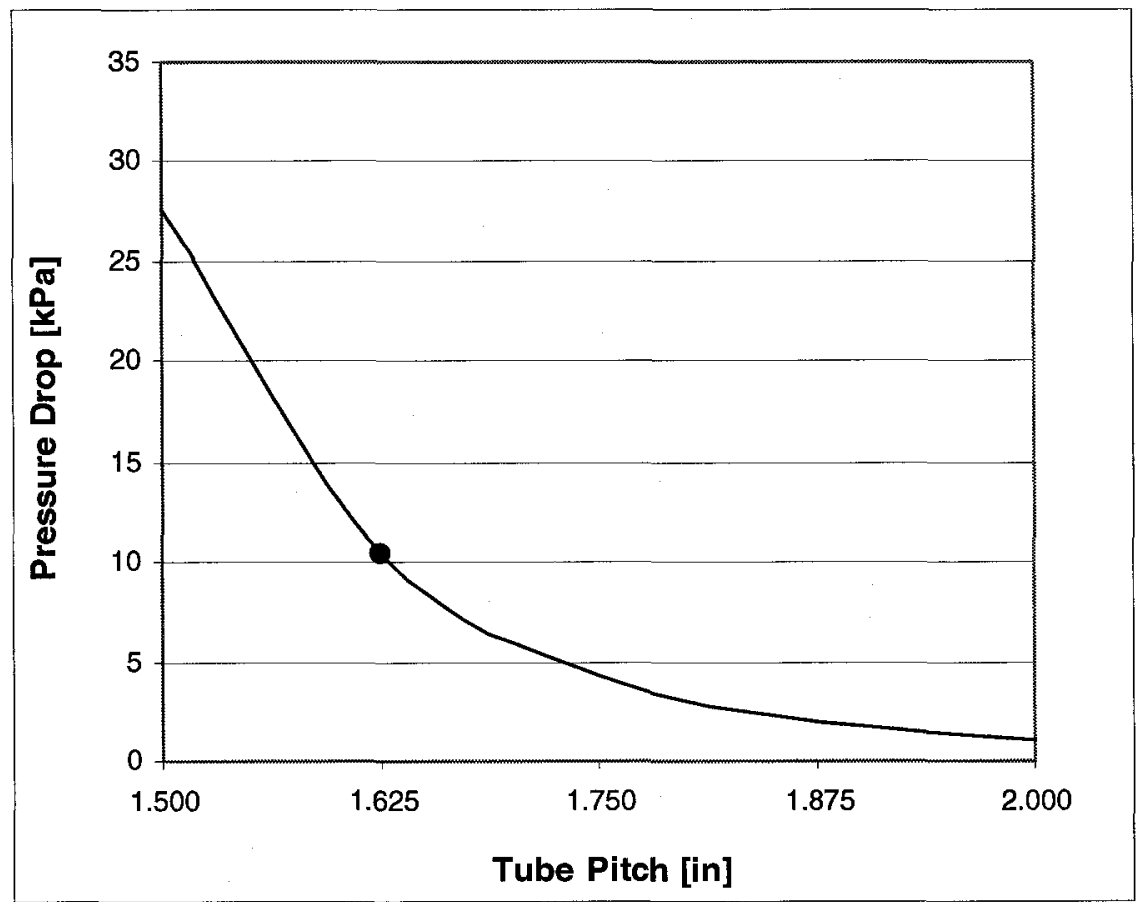

Figure 9.6: Effect of Tube Pitch on Heat Exchanger Pressure Loss 
from Figure 9.6 that utilizing a larger tube pitch will significantly reduce the predicted pressure drop. Although a larger tube pitch size is beneficial to decrease the pressure drop, the additional heat exchanger cost due to size increase is not justified. The tube pitch is selected based on the heat exchanger size constraints and pressure drop design target. Tube pitch of $1 \frac{5}{8}$ inch ( $1 / 8$ inch fin spacing) is selected since the heat exchanger required length is within 6 feet, and the pressure drop is below the 3 percent CDP design target. Selection of tube pitch that is greater than $1 \frac{5 / 8}{\mathrm{inch}}$ is undesirable due to excessive heat exchanger size. Tube pitch selection smaller than $1 \frac{5}{8}$ inch is also undesirable due to the excessive predicted pressure drop.

\subsubsection{Tube-Fin Heat Exchanger Geometry Considered for Application as a HSHE}

The tube-fin heat exchanger has been sized to meet the heat-transfer rate requirement, effectiveness, and pressure drop target of the HSHE. The heat exchanger has been sized to meet the 90 percent effectiveness target of the HSHE, and the pressure drop design target of 3 percent. Key dimensions determined from the thermal hydraulic analysis are summarized below.

\section{Shell Size}

Tube-Side Flow Length: $\quad 6$ feet

Shell-Side Flow Length: 1.33 feet

No-Flow Length: $\quad 1.33$ feet

\section{Tube Size}

$\begin{array}{ll}\text { Fin Type: } & \text { Plain Circular, High-Finned } \\ \text { Length : } & 6 \text { feet } \\ \text { Tube Outer Diameter: } & 3 / 4 " \\ \text { Fin Height: } & 3 / 8 " \\ \text { Fin Pitch } & 9 \text { fins/in }\end{array}$


Tube Bundle Layout

$\begin{array}{ll}\text { Tube Layout: } & \text { Staggered } \\ \text { Number of Tubes: } & 96 \\ \text { Number of Tube Rows } & 9 \\ \text { Tube Pitch: } & 1.625 \text { in }\end{array}$

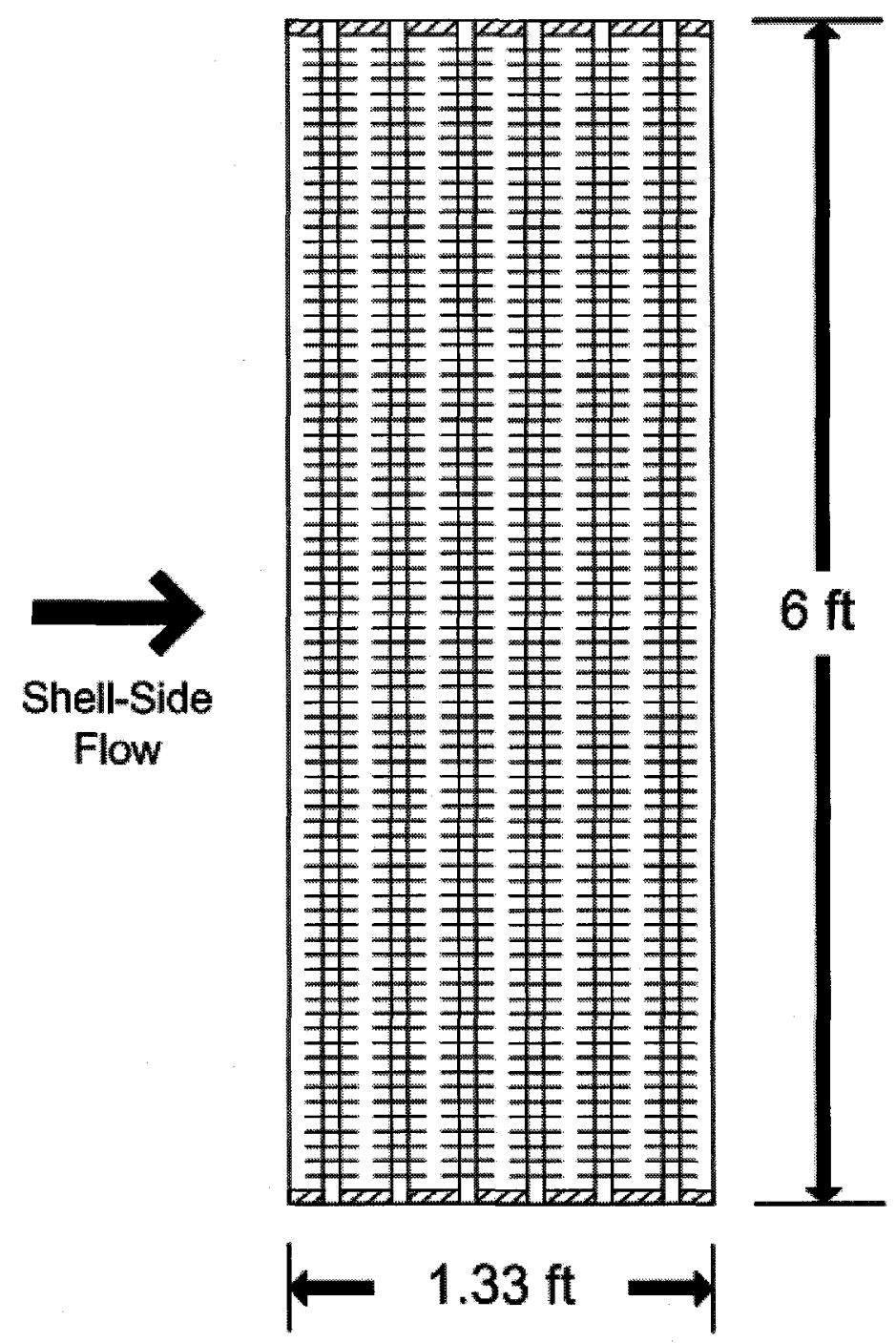

Figure 9.7: Outer Geometry of the Tube-Fin Heat Exchanger 


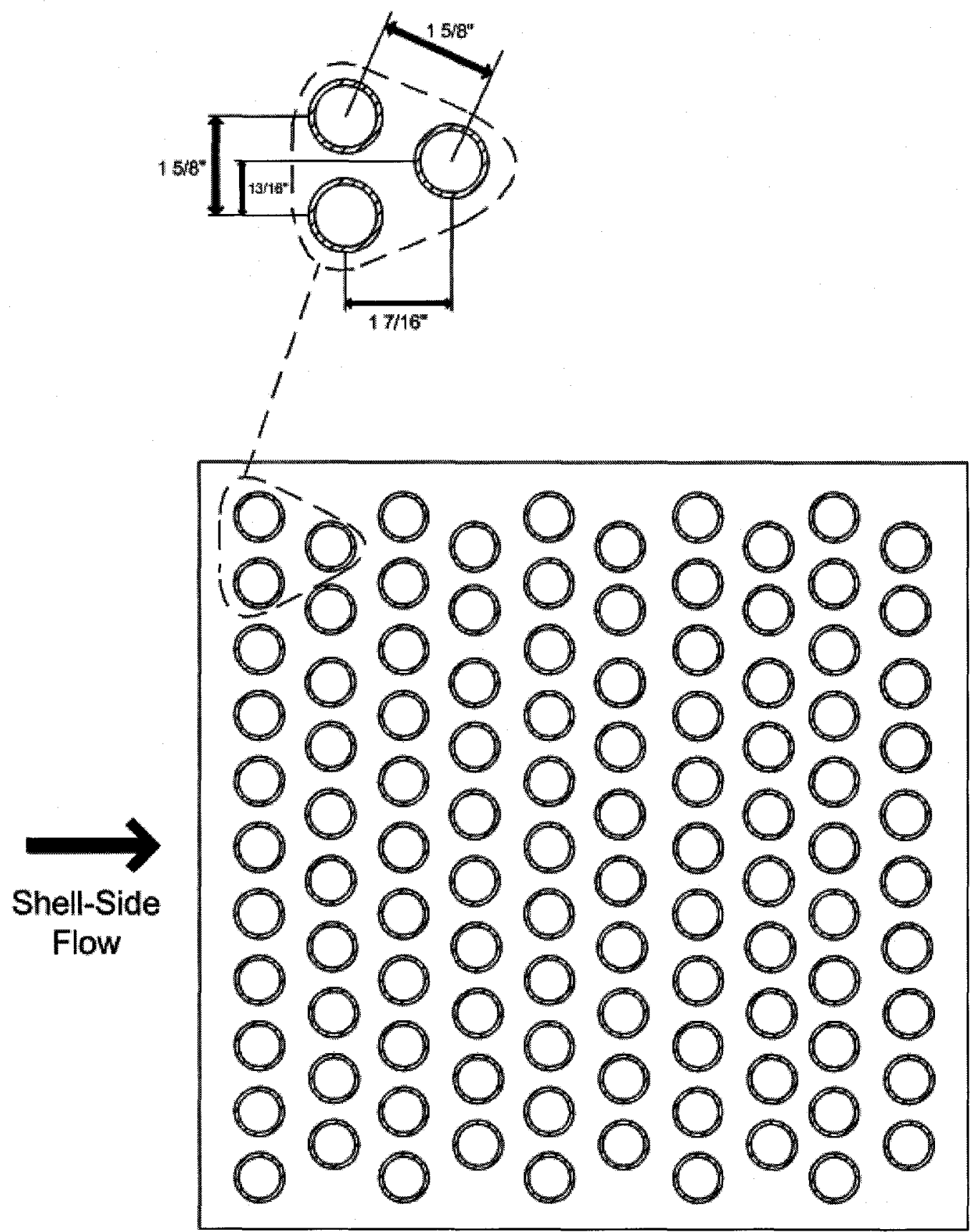

Figure 9.8: Tube Layout Corresponding to the Tube-Fin Heat Exchanger Design 


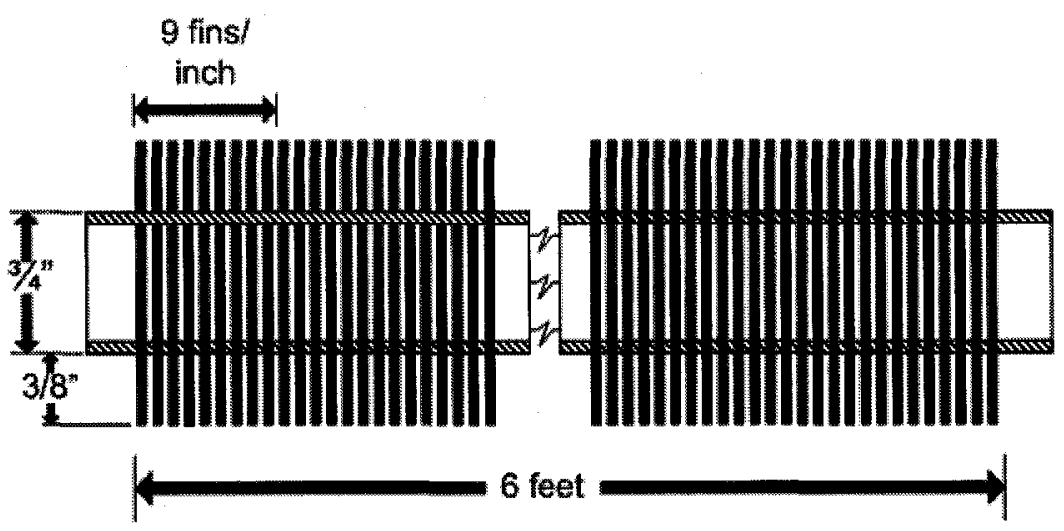

Figure 9.9: Finned Tube Geometry

\subsection{Shell and Tube Heat Exchanger Sizing for HSHE Application}

\subsubsection{Initial Specifications}

Heat exchanger geometry is dependant on shell type and fluid placement on the tube and shell side. The basic flow arrangement is dependant on the selected shell type (typical shell geometries have been described in Section 8.5.1.1). For HSHE application, the TEMA E shell has been selected (also described in Section 8.5.1.1). As in the tubefin heat exchanger, positioning of flue gas on the shell-side or tube-side is determined by fouling considerations. To simplify cleaning of particulate deposits, the HSHE should be designed with the flue gas placed on the tube side. Despite the relatively higher pressure drop, the working fluid is placed on the shell side. The overall heat exchanger geometry is determined by performing a parametric analysis of numerous geometrical parameters. The parametric analysis is performed to select a heat exchanger of minimal size and acceptable pressure drop. 


\subsubsection{Parametric Analysis of Tube Geometry and Tube Arrangement on Heat Exchanger Size}

\subsubsection{Selection of Tube Diameter and Length}

Tube geometry selection is sized to minimize the required tube surface area and tube count. Circular plain tubes, with outer diameter in the range of $1 / 2$ inch to 1 inch, have been parametrically studied to determine the effect on the total required tube surface area and tube count. Also, the effect of tube length selection on the required total tube surface area and tube count has been parametrically studied. Tube lengths of 60 inches to 240 inches have been analysed. Other geometrical parameters, including the tube layout, tube pitch, and baffle cut were not varied to preserve an independent analysis. For preliminary calculations, tubes are positioned in the 30 degree arrangement, with a tube pitch of 1.33 times the tube diameter, and a baffle cut of 20 percent.

The required heat-transfer surface area is significantly affected by the tube geometry. As depicted in Figure 9.8 and 9.9, small diameter tubes offer a requirement of low total heat-transfer surface area with a large number of tubes, whereas large diameter tubes offer a requirement of high heat-transfer surface area with a small number of tubes. A tube diameter should be selected to minimize the total surface area requirement, thus reducing material costs, and to minimize the number of tubes required to reduce the tube installation costs. Moreover, tube diameter selection should be compatible with mechanical cleaning methods to enable periodic cleaning of the fouling layer. According to TEMA Standards, the smallest practical tube O.D. for mechanical cleaning is $3 / 4$ inch [9.4].

The $3 / 4$ inch O.D. tube size is practical from mechanical cleaning standpoint and offers the lowest required surface area among tubes that are compatible with mechanical cleaning methods. According to Reference [9.3], the most common tube diameter for shell and tube heat exchanger application is $3 / 4$ inch since highest performance at lowest 
cost is offered. A lower tube count, of the order of 15 percent, is offered by utilizing a tube diameter of 1 inch. Also, as seen in Figure 9.10, a lower pressure drop is offered by utilizing a tube diameter of 1 inch. However, the lower tube count (41 tubes of 1 inch O.D. as compared to 49 tubes of $3 / 4$ inch O.D.) is offset by a higher tube price (for a given tube length) expected of large diameter tubes as well as a higher cost of a larger shell diameter. Moreover, a larger heat-transfer surface area is required for large diameter tubes. The $3 / 4$ inch O.D. tube size is selected for the shell and tube heat exchanger application. This size offers the highest heat-transfer rate and lowest cost for tubes that are compatible with mechanical cleaning methods.

Tube length selection affects the required heat-transfer surface area as well as the required number of tubes. As seen in Figure 9.8 and 9.9 respectively, the required heattransfer surface area and the number of tubes required are exponentially reduced with the required tube length. Therefore, a significant reduction in capital cost is offered by utilizing a heat exchanger with long tubes. Long tubes within practical limits of the installation location and the fabricators shop dimensions should be utilized. Tube length of 6 feet has been determined as the longest practical size (see Section 9.3.2.2). A shell and tube heat exchanger of this length would be uneconomical due the requirement of a large heat-transfer surface area, large number of tubes, and large shell diameter.

Design of a shell and tube heat exchanger that is within the height requirement and with a heat-transfer surface area and shell diameter corresponding to a long-flow heat exchanger can be accomplished by utilizing two shells of short flow length that are positioned in series. Although twice the number of tubes is required as compared to a long flow heat exchanger, the tube quantity required is fewer than for a short-flow heat exchanger. This is a result of the exponential proportionality of the tube count to the overall flow length. Also, since the heat-transfer surface area is exponentially proportional to the tube length, a significantly lower surface area is required as compared to a heat exchanger with a short flow length. Therefore, a heat exchanger design with 


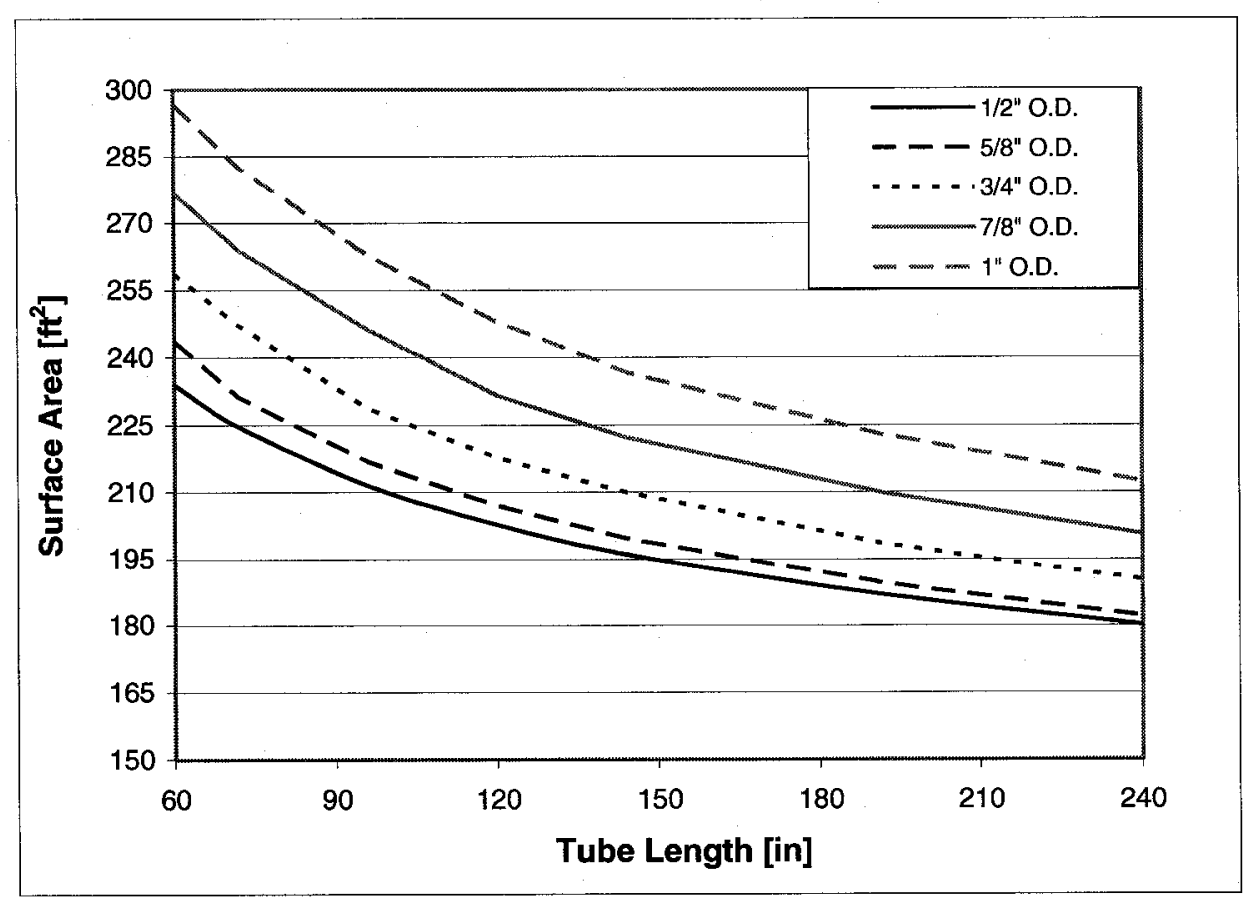

Figure 9.10: Heat-Transfer Surface Area as a Function of Tube Length for Various Tube Sizes

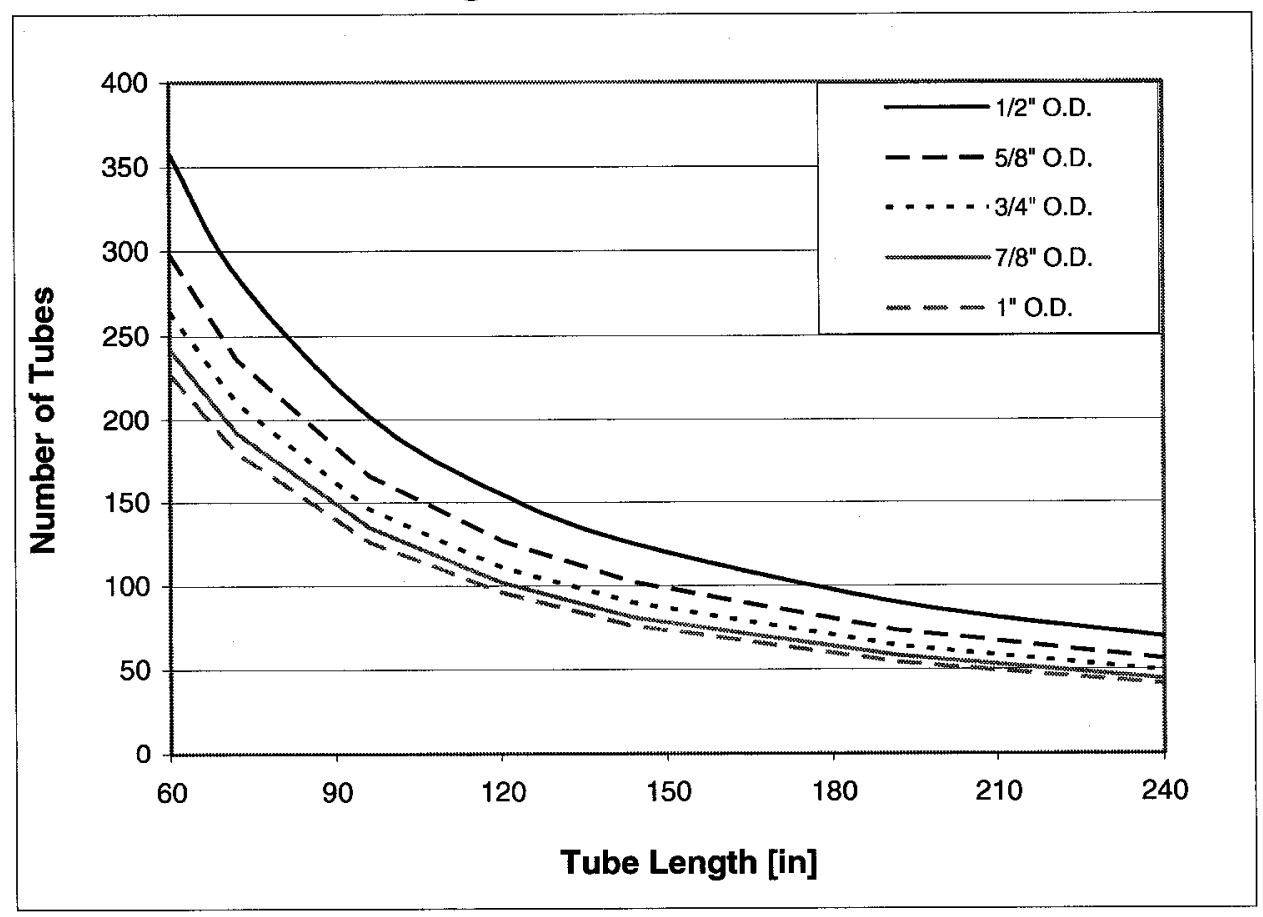

Figure 9.11: Tube Count as a Function of Tube Length and Tube Size 


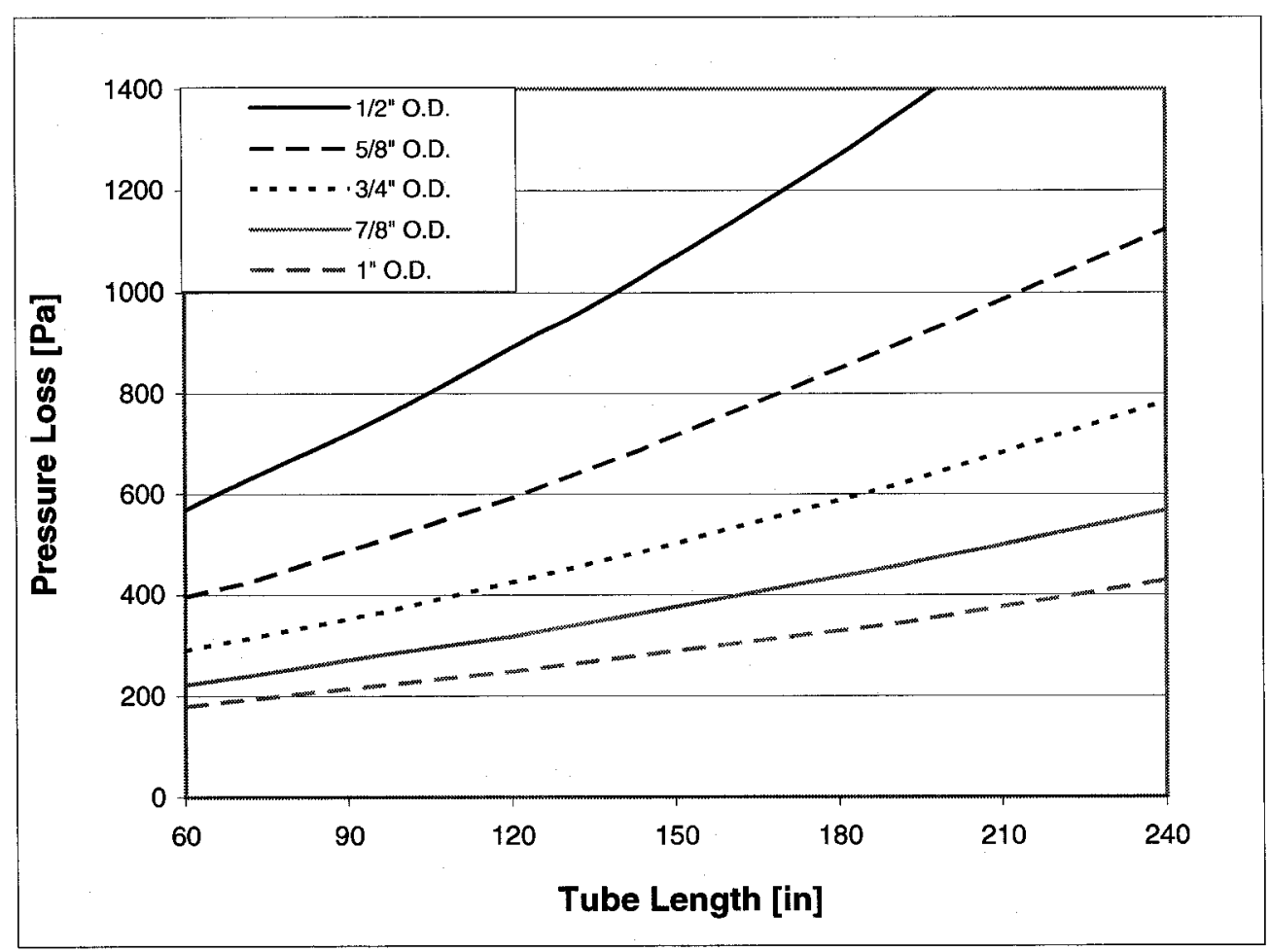

Figure 9.12: Shell-Side Pressure Drop Function of Tube Length and Tube Size

two identical shells of 6 foot length are selected. From a thermal hydraulic design perspective, this corresponds to a heat exchanger with an overall length of 144 inches.

\subsubsection{Selection of Tube Layout}

As described in Section 8.5.4.1a, four tube layouts are possible with the shell and tube heat exchanger: the triangular layout $\left(30^{\circ}\right)$, the rotated triangular layout $\left(60^{\circ}\right)$, square $\left(90^{\circ}\right)$ layout, and rotated square $\left(45^{\circ}\right)$ layout. These angles are defined in relation to the flow direction. For identical tube pitch and flow rates, the tube layouts in decreasing order of shell-side heat-transfer coefficients and pressure drop are $30^{\circ}, 45^{\circ}, 60^{\circ}$, and $90^{\circ}$ [9.3]. Therefore, the $30^{\circ}$ arrangement will have highest shell-side heat-transfer rate (or lowest heat-transfer surface area requirement) and the highest shell-side pressure drop. This literature finding is verified by performing a parametric analysis of tube layout on 
the required heat-transfer surface area and pressure drop. The tube layouts analyzed include the 30 degree, 45 degree, and 90 degree. The 60 degree layout has not been analyzed since the constants for the curve fit correlation corresponding to the Coulburn factor have not been found in literature for this layout angle. The required surface area and the pressure drop for varying tube layouts is provided in Figures 9.11 and 9.12 respectively.

The parametric analysis findings are consistent with literature findings [9.3]. The parametric analysis findings predict that lowest surface area requirement is offered by the 30 degree layout and the highest heat surface area is required for the 90 degree layout. Also, the study findings coincide with literature findings in that the pressure drop is lowest for the 90 degree layout and highest for the 30 degree layout. The predicted surface area requirement for the 45 degree tube layout is of the order of 2 percent higher than the 30 degree layout. The predicted pressure drop for the 45 degree layout is of the order of 50 percent lower than for the 30 degree layout. The 45 degree layout is recommended since it offers a combination of a low surface area (comparable the 30 degree layout) and a low pressure drop (comparable to the 90 degree layout). 


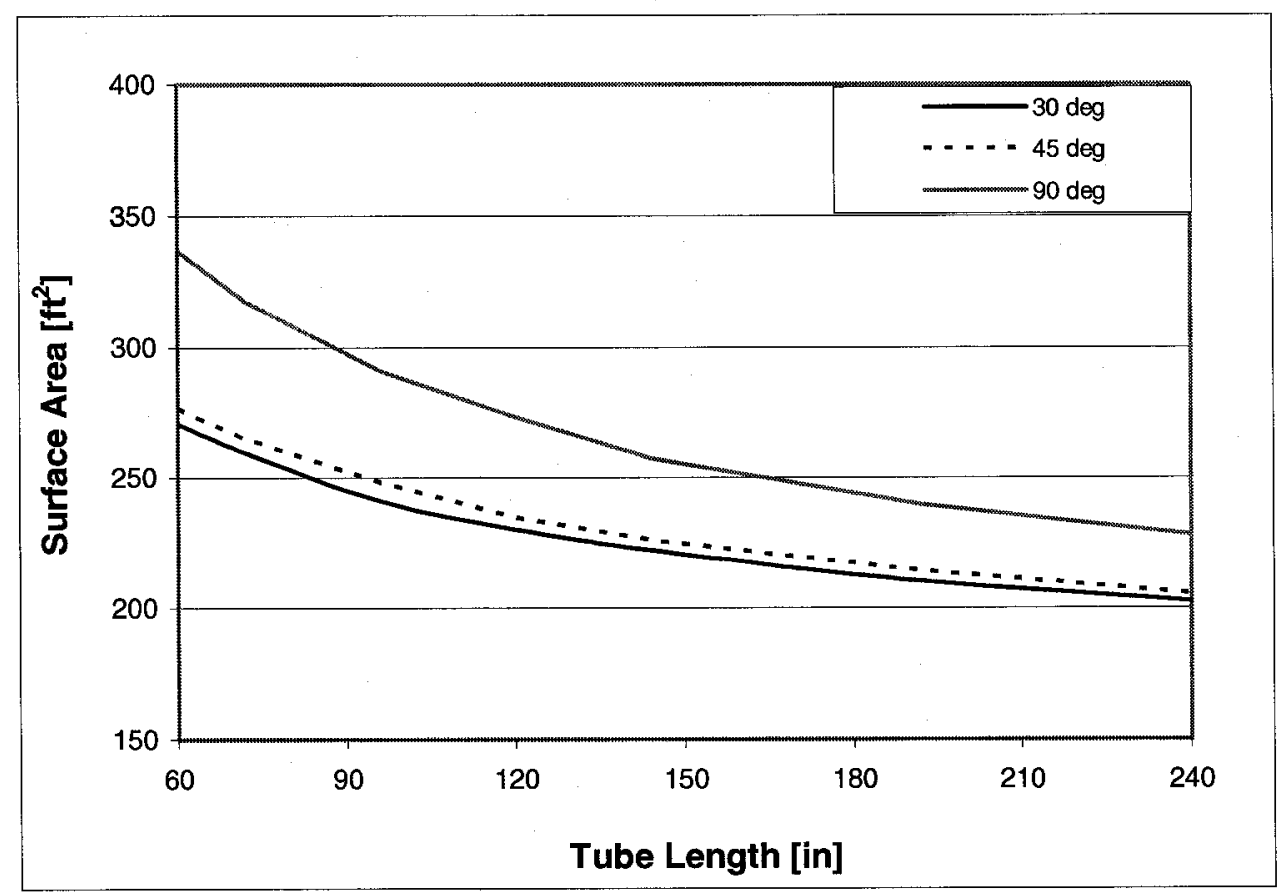

Figure 9.13: Heat-Transfer Surface Area as a Function of Tube Length for Various Tube Arrangements

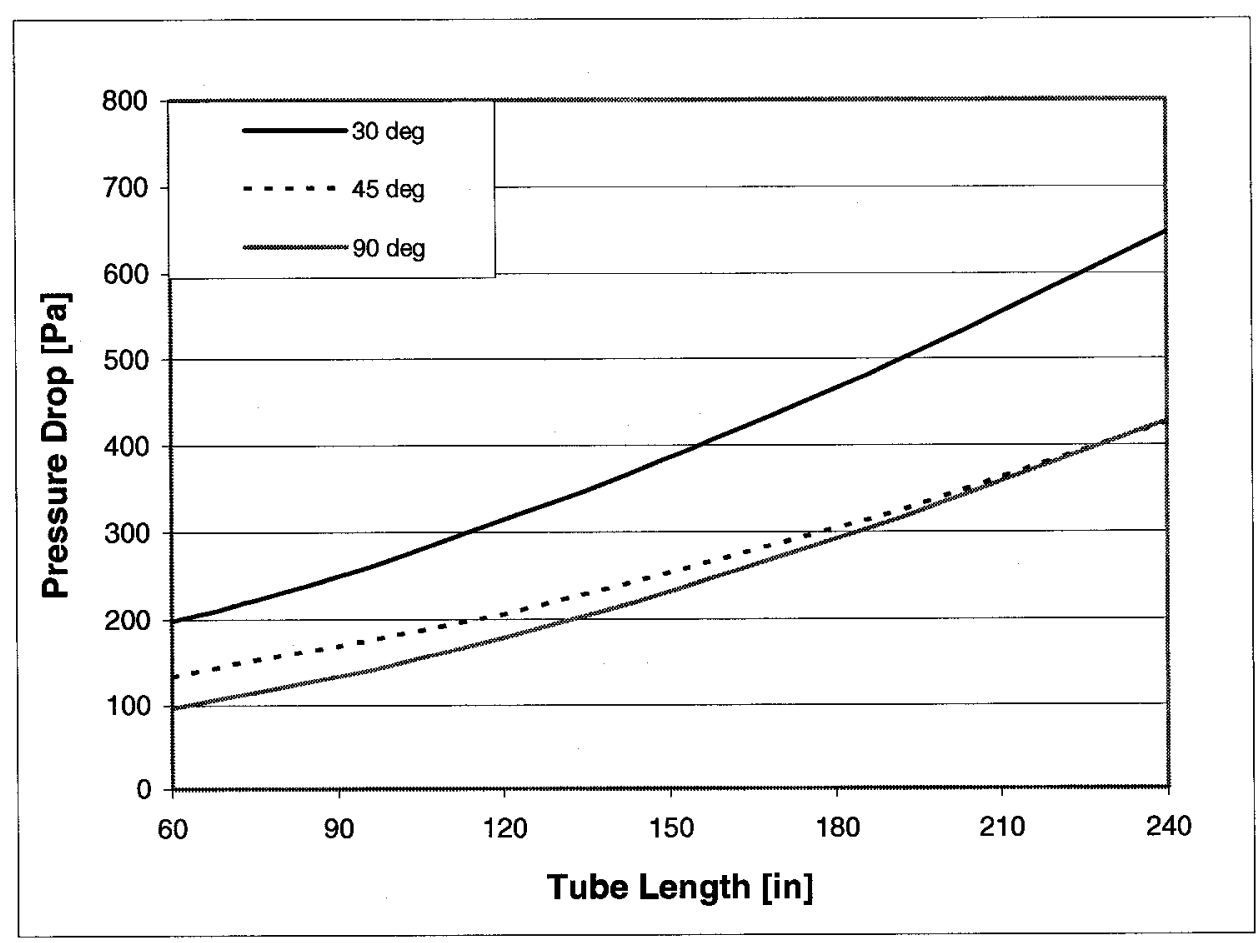

Figure 9.14: Shell-Side Pressure Drop Function of Tube Length and Tube Size 


\subsubsection{Selection of Tube Pitch Size}

The tube pitch size, or the centre-to-centre distance between tubes, has been parametrically studied to determine the effect on the heat exchanger size and pressure drop. Tube pitch size in the range of 1.15 to 1.35 times the outer tube diameter has been analyzed for a range of tube lengths. The analysis is performed for the selected tube diameter and tube layout. The effect of tube pitch size on the required heat-transfer surface area, required number of tubes, and pressure drop is shown in Figures 9.13, 9.14, and 9.15 respectively. It is concluded that the required heat-transfer surface area and the tube count, as well as the shell diameter (not shown), is reduced by reducing the tube pitch. The predicted shell-side pressure drop increases with tighter tube spacing.

A small tube pitch size should be selected to reduce the heat exchanger size, and therefore, cost. TEMA Standards RCB- 2.5 recommends that the tube pitch size should not be smaller than 1.25 the outside tube diameter [9.4]. This recommendation is placed in order to ensure sufficient strength in the tubesheet. Tubesheets are located at the shell ends and provide a principal barrier between the shell-side fluids and tube-side fluids. Sufficient strength is required to withstand internal pressures and provide tube support. In accordance to TEMA Standard recommendation, a tube pitch size of 1.25 times the tube O.D., or greater should be selected. This corresponds to a tube pitch size of 15/16 inch. A tube pitch of 1 inch is selected to ensure sufficient tubesheet mechanical strength and facilitate straightforward manufacturing. 


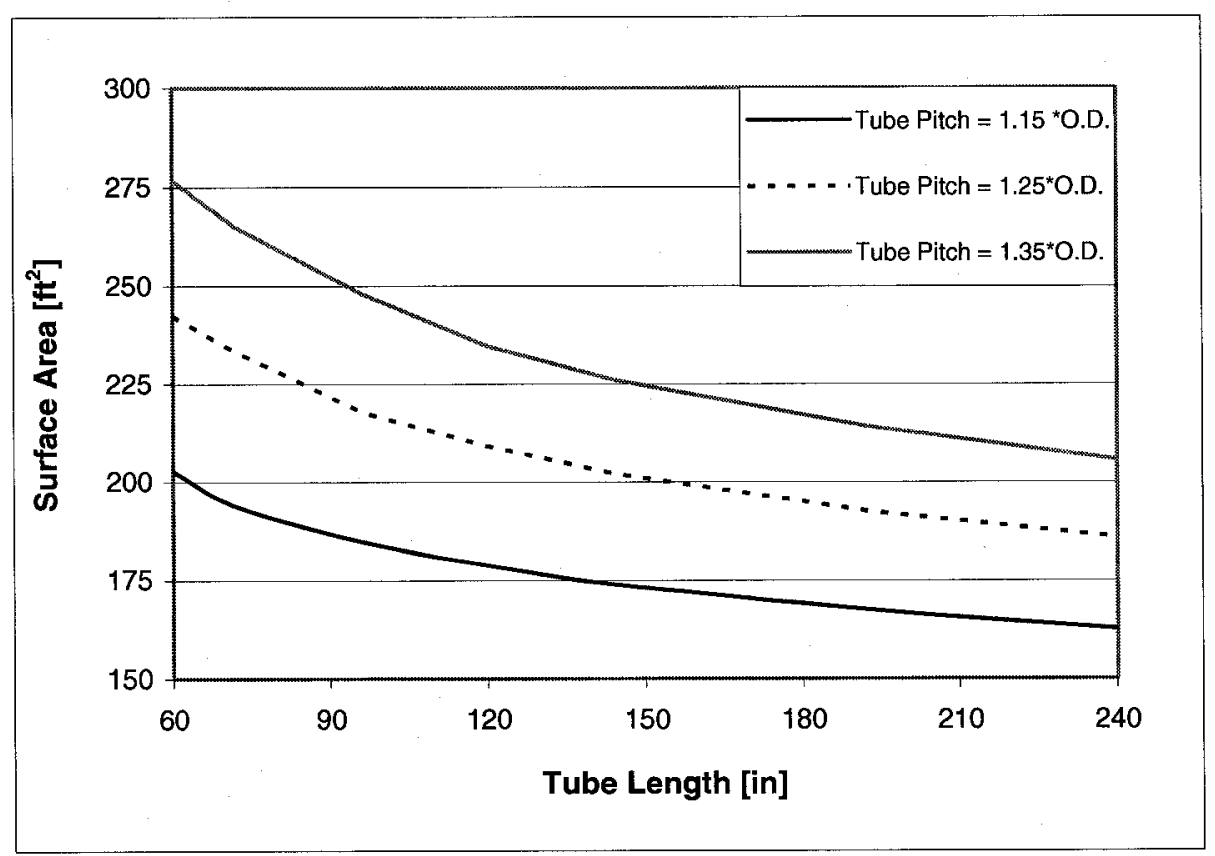

Figure 9.15: Heat-Transfer Surface Area as a Function of Tube Length for Tube Pitch Sizes

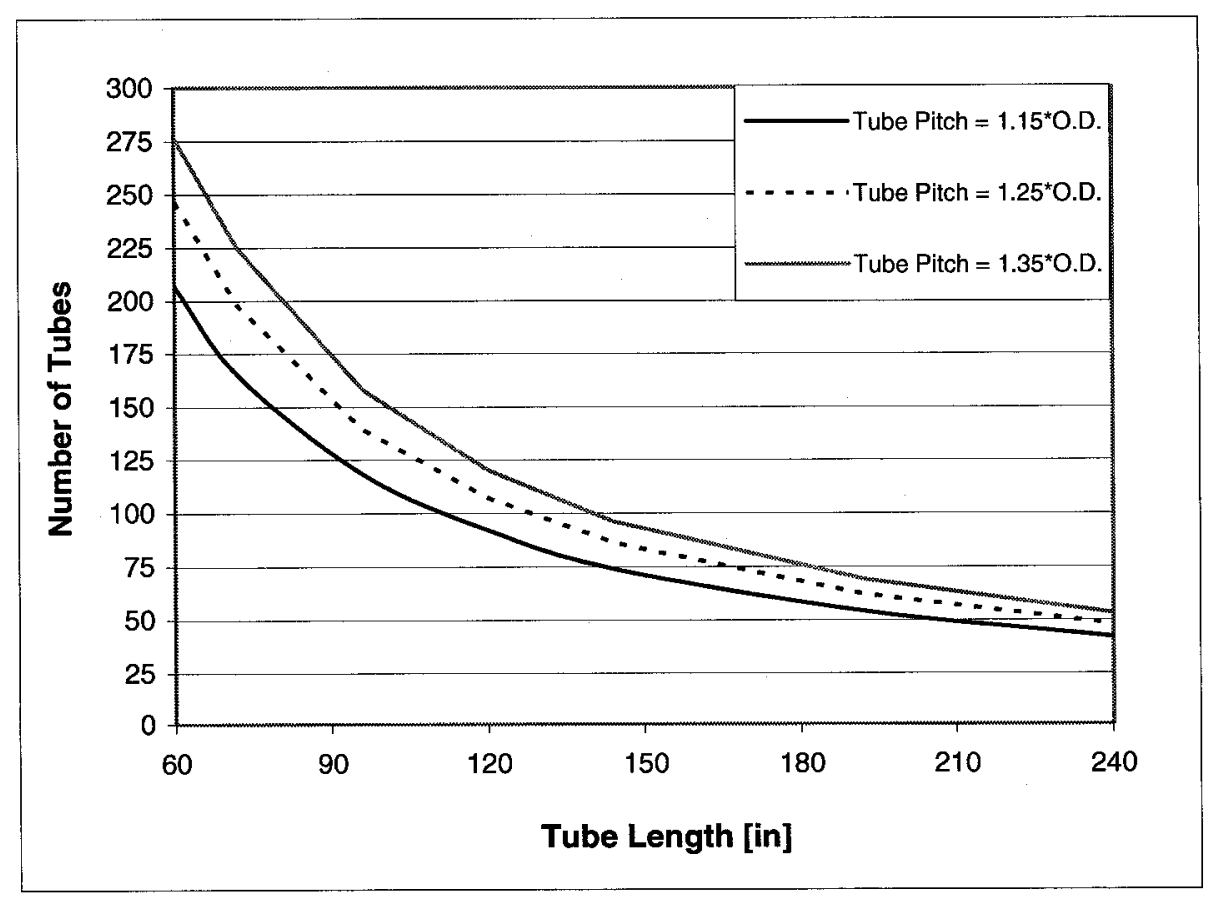

Figure 9.16: Tube Count as a Function of Tube Length for Various Tube Pitch Sizes 


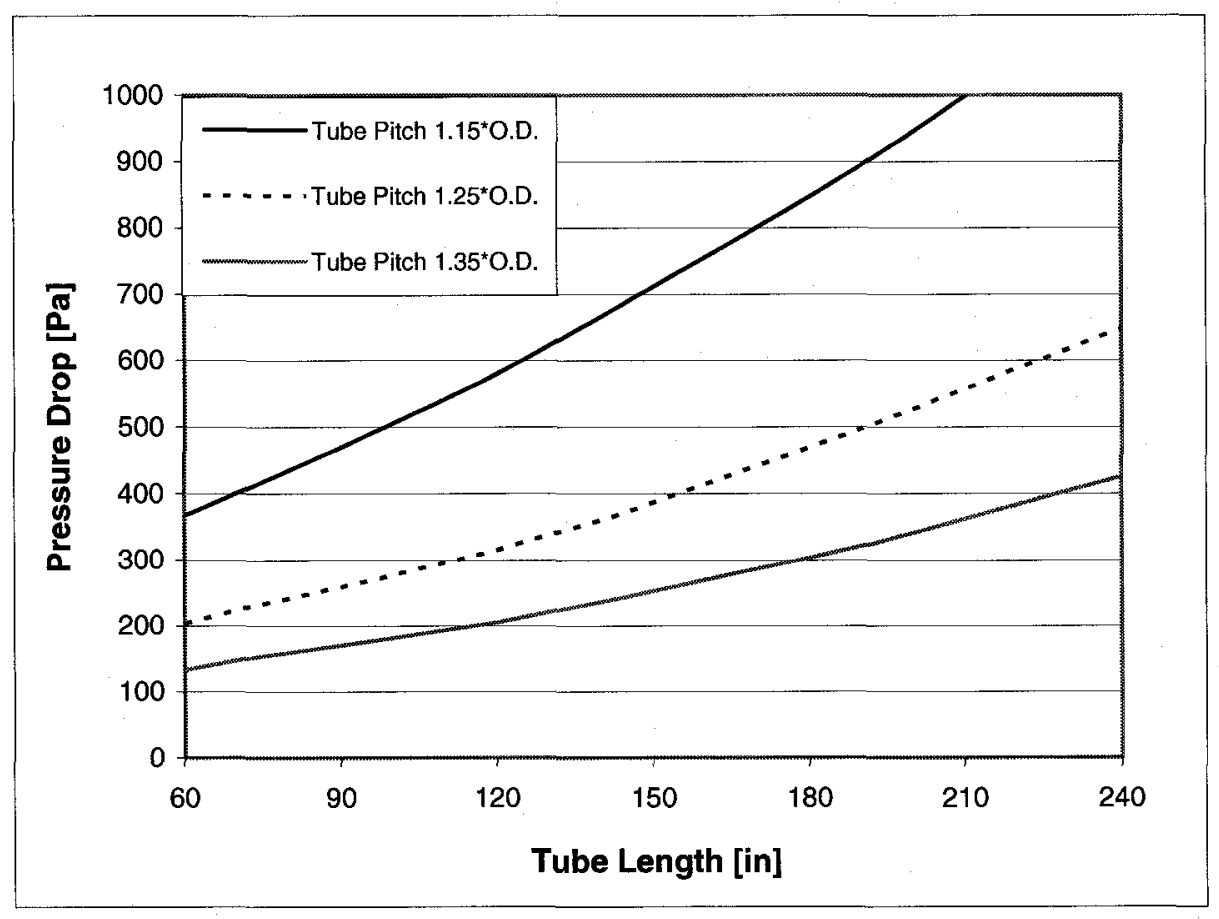

Figure 9.17: Shell-Side Pressure Drop Function of Tube Length for Various Tube Pitch Sizes

\subsubsection{Selection of Baffle Cut Size}

The majority of shell and tube heat exchangers utilize segmental baffles. These are cut circular disks located in the shell and used to support the tubes and to maintain tube spacing. The baffles are also used to direct the shell-side fluid across the tube bundle. The amount of baffle material that is cut is expressed as a percentage of the shell inside diameter. The heat transfer and pressure drop of crossflow bundles are affected by the baffle cut. These cuts vary from 20 percent to 49 percent, although most common cuts are in the range of 20 percent to 25 percent. It is generally accepted that the optimum cut is typically 20 percent since it corresponds to a compromise of high heattransfer rate and a modest pressure drop [9.3]. Smaller baffle cuts typically produce a high pressure drop, due to the high fluid velocities present in the baffle cut cross-section 


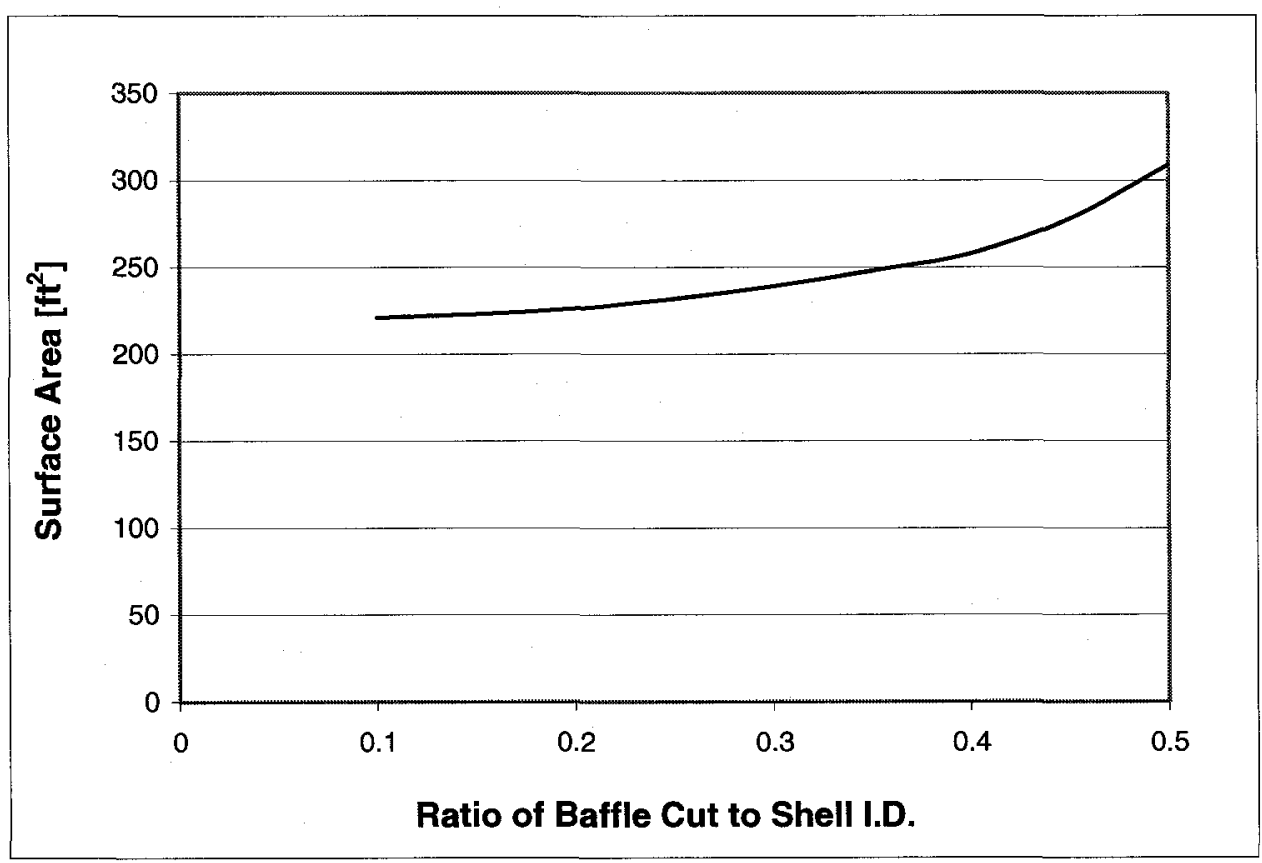

Figure 9.18: Surface Area as a Function of Baffle Cut

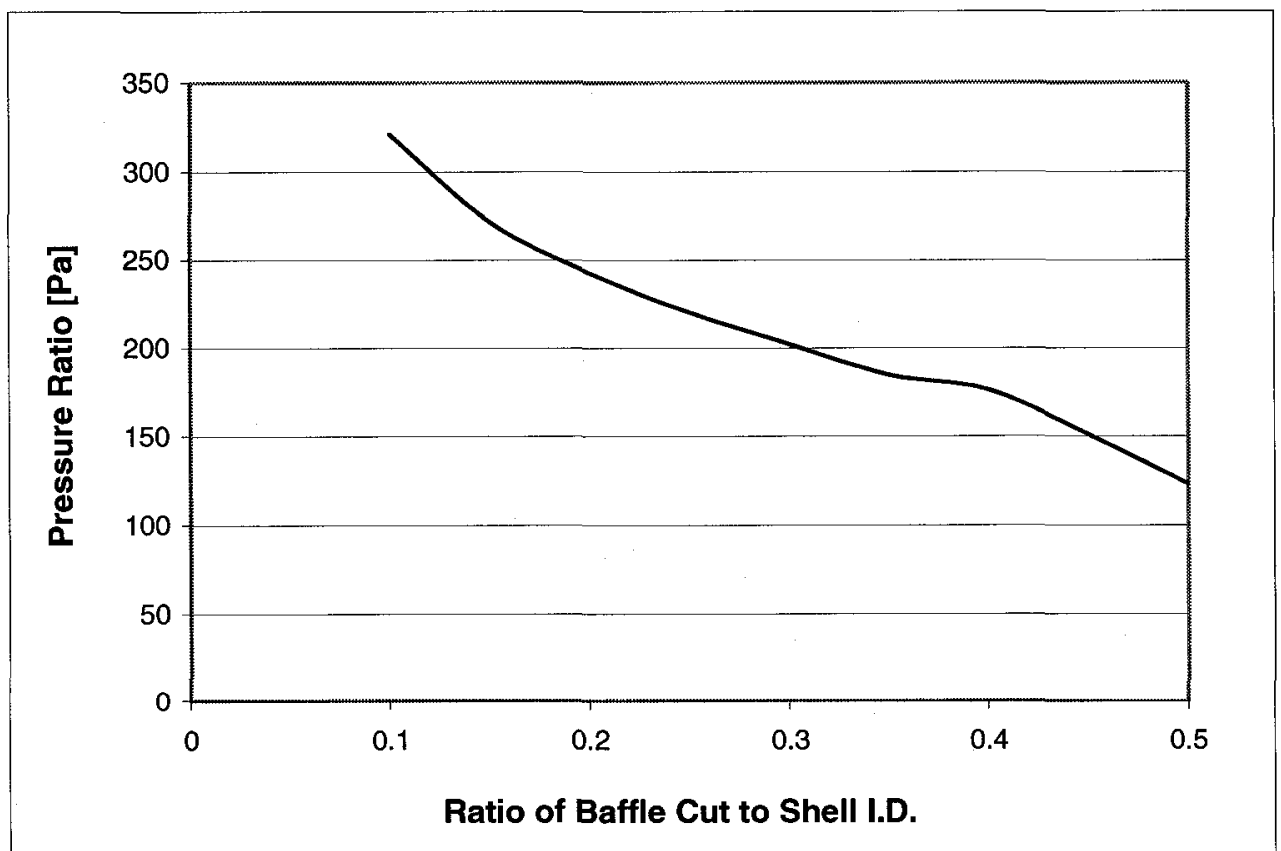

Figure 9.19: Pressure Ratio as a Function of Baffle Cut 
region. Large baffle cuts yield to low heat-transfer rates due to flow deviation from the crossflow arrangement. Moreover, stagnant regions or regions with low flow velocities may result with utilization of large baffle cuts, which results in a low thermal effectiveness.

Baffle cut size is parametrically studied to design a heat exchanger with a high heat-transfer rate and a low pressure drop. Baffle cuts in the range of 10 to 49 percent are analyzed to determine the effect on heat-transfer surface area and the pressure drop. The heat-transfer surface area and the pressure drop for the baffle cut range is shown in Figure 9.16 and 9.17 respectively. These results correspond to the heat exchanger geometry defined in previous sections. Consistent with literature findings, small baffle cuts result in high heat-transfer rates, which corresponds to a low surface area, as well as a high pressure drop. Large baffle cuts result in a high surface area requirement and a low pressure drop. The surface area exponentially increases with the baffle cut due to flow deviation from crossflow. The most appropriate baffle cut is 20 percent since a low surface area requirement is offered at a modest pressure ratio. This is consistent with literature findings.

\subsubsection{Selection of Baffle Spacing}

Baffle spacing is selected according to TEMA Standard RCB-4.51 and RCB-4.52, which specifies that the minimum and maximum permitted unsupported tube spacing. Minimum tube spacing should not be closer than 1/5 of shell I.D. or 2 inches, whichever is greater, and the maximum unsupported spacing for a $3 / 4$ inch tube O.D. should not exceed 60 inches [9.4]. In accordance with TEMA Standards, the baffle spacing may be in the range of 3 inches and 60 inches. Although the baffle spacing will be selected based on mechanical design, including flow induced vibration considerations (heat exchanger mechanical design is beyond the scope of this thesis), the effect of baffle spacing on the heat exchanger size requirement and pressure drop is evaluated. 
Central baffle spacing in the range of 3 inches to 50 inches has been evaluated for the heat exchanger geometry defined above. The inlet and outlet baffle spacing is typically larger to accommodate the nozzles. An inlet and outlet baffle spacing that is 20 percent greater than central baffle spacing was used for the analysis. Heat exchanger geometrical parameters that have been defined in the previous sections are used. Predicted surface area and tube count requirement results are provided in Figure 9.18 and predicted pressure drop is provided in Figure 9.19. It is found that surface area and tube count requirement is lowest for small baffle spacing, and increases with baffle spacing size. The maximum surface area and tube count requirement is for a baffle spacing of 37 inches. The shell-side pressure drop is high at tight baffle spacing, and decreases exponentially as the baffle spacing is increased. To ensure pressure drop performance specifications are met, baffle spacing minimum of 10 inches should be used. Baffle spacing selection is made by flow induced vibration considerations. To ensure adequate heat exchanger performance, it is recommended to select baffle spacing in the range of 10 inches to 20 inches to limit the heat exchanger surface area and pressure drop. 


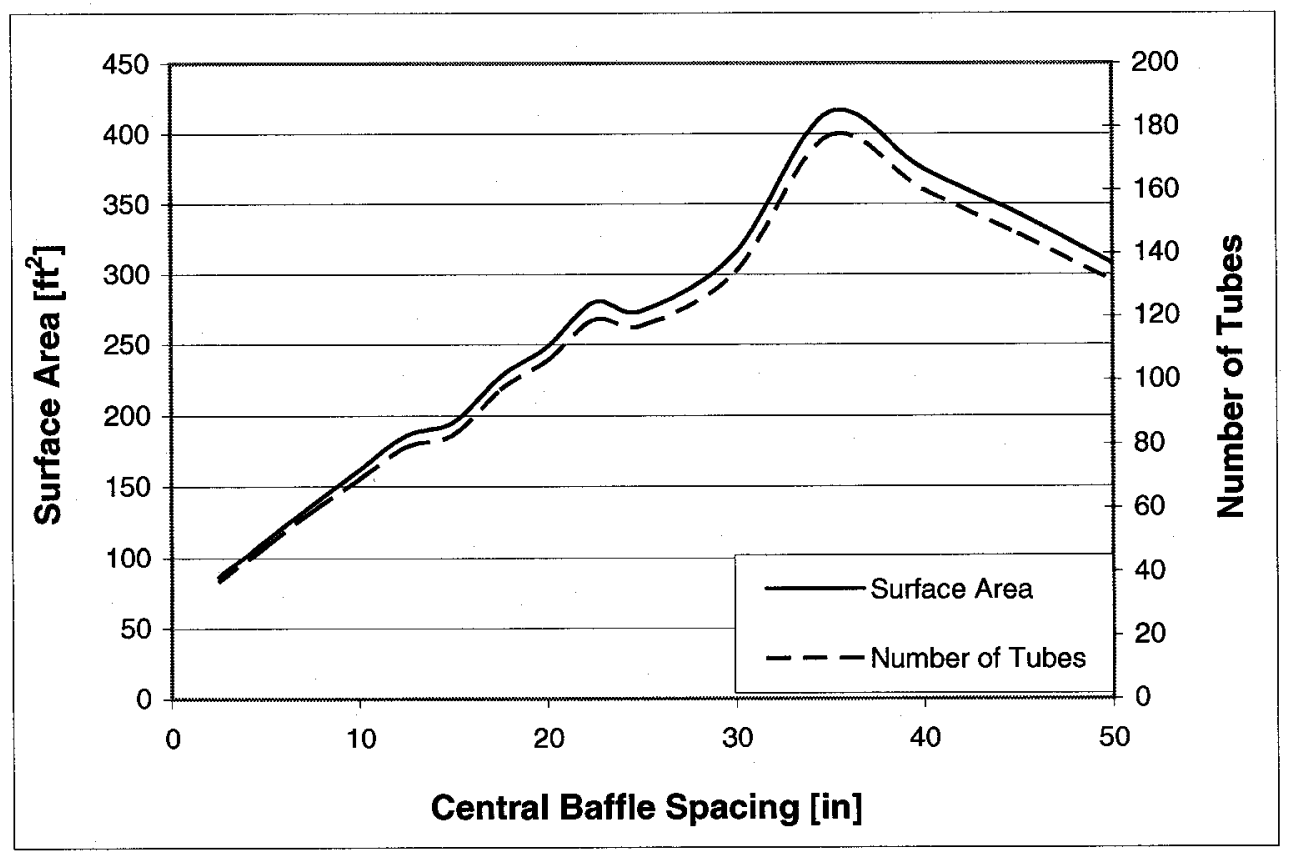

Figure 9.20: Surface Area and Tube Count Requirement as a Function of Central Baffle Spacing

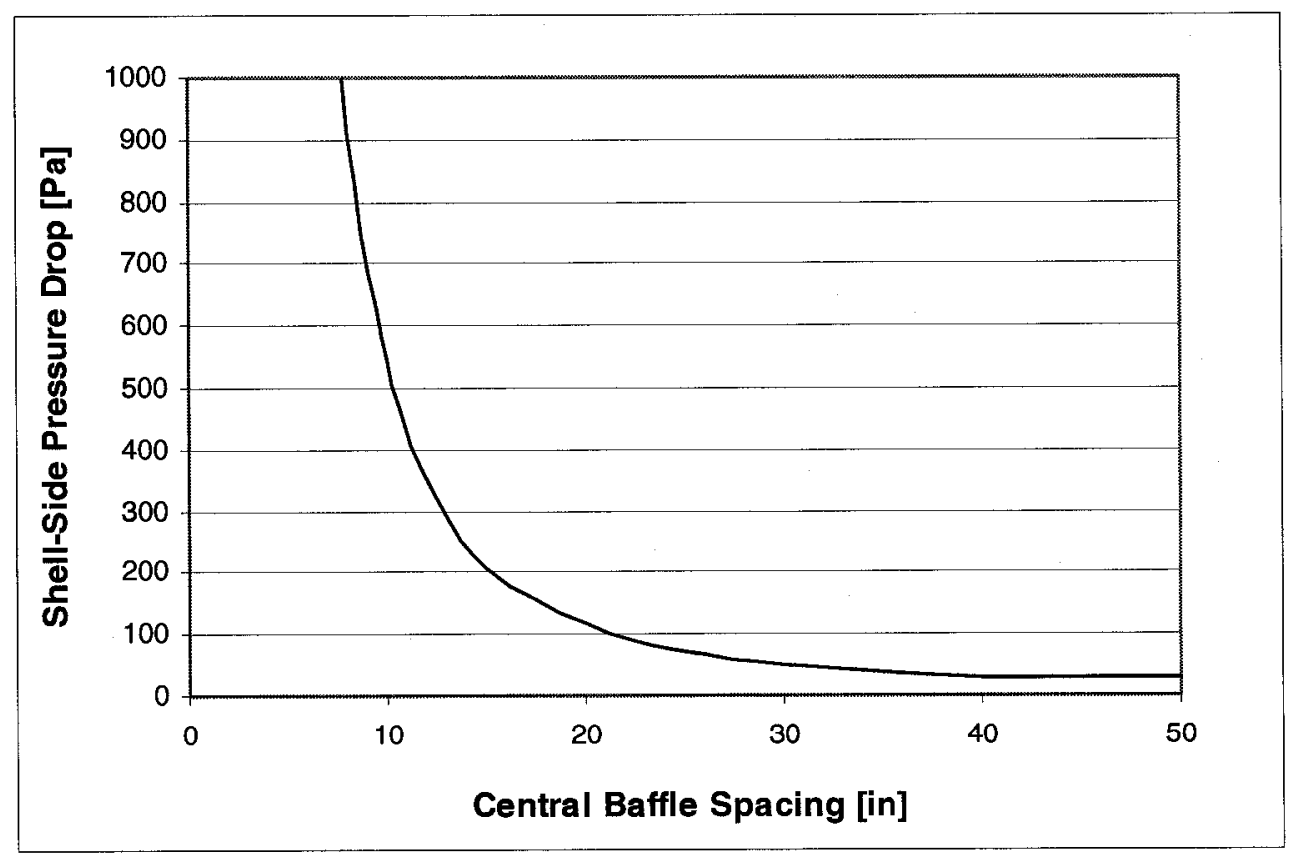

Figure 9.21: Predicted Pressure Drop as a Function of Central Baffle Spacing 


\subsubsection{Selection of Number of Sealing Strips}

Sealing strips are implemented in shell and tube heat exchangers to prevent bypass flow around the bundle by blocking the clearance area between outermost tubes and the inside of the shell. Control of the bypass flow fraction around the bundle is achieved by implementing a desired number of sealing strips. The effect of the number of sealing strips on heat exchanger surface area requirement and pressure drop is parametrically analyzed. Heat exchanger geometry that has been specified in the previous sections has been used for the analysis. Tube baffle spacing of 15 inches has been used for the study. Predicted surface area and number of tubes required is depicted in Figure 9.20 and predicted pressure drop is depicted in Figure 9.21.

Sealing strips reduce the heat-transfer surface area requirement, which has the potential to reduce materials and manufacturing costs. Maximum heat-transfer surface area reduction is available through the application of 6 sealing strips. More than 6 sealing strips did not predict a further reduction in heat-transfer surface area since it is predicted that no bypass flow is present and the bundle bypass correction factor, $\mathrm{J}_{\mathrm{b}}$ is maximum value of 1 . Sealing strips increase the pressure drop through the shell-side due to increased flow fraction across the tubes. Maximum pressure drop is predicted to be for 6 or more sealing strips since no bypass flow is predicted.

It is recommended to apply 4 sealing strips in the shell and tube heat exchanger. Application of more than 4 sealing strips would not greatly affect the heat-transfer surface area requirement but would significantly increase the pressure drop. According to Reference [9.3], rectangular sealing strips are most effective. The sealing strips should be positioned in 90 degrees to each other and inline with the baffles. 


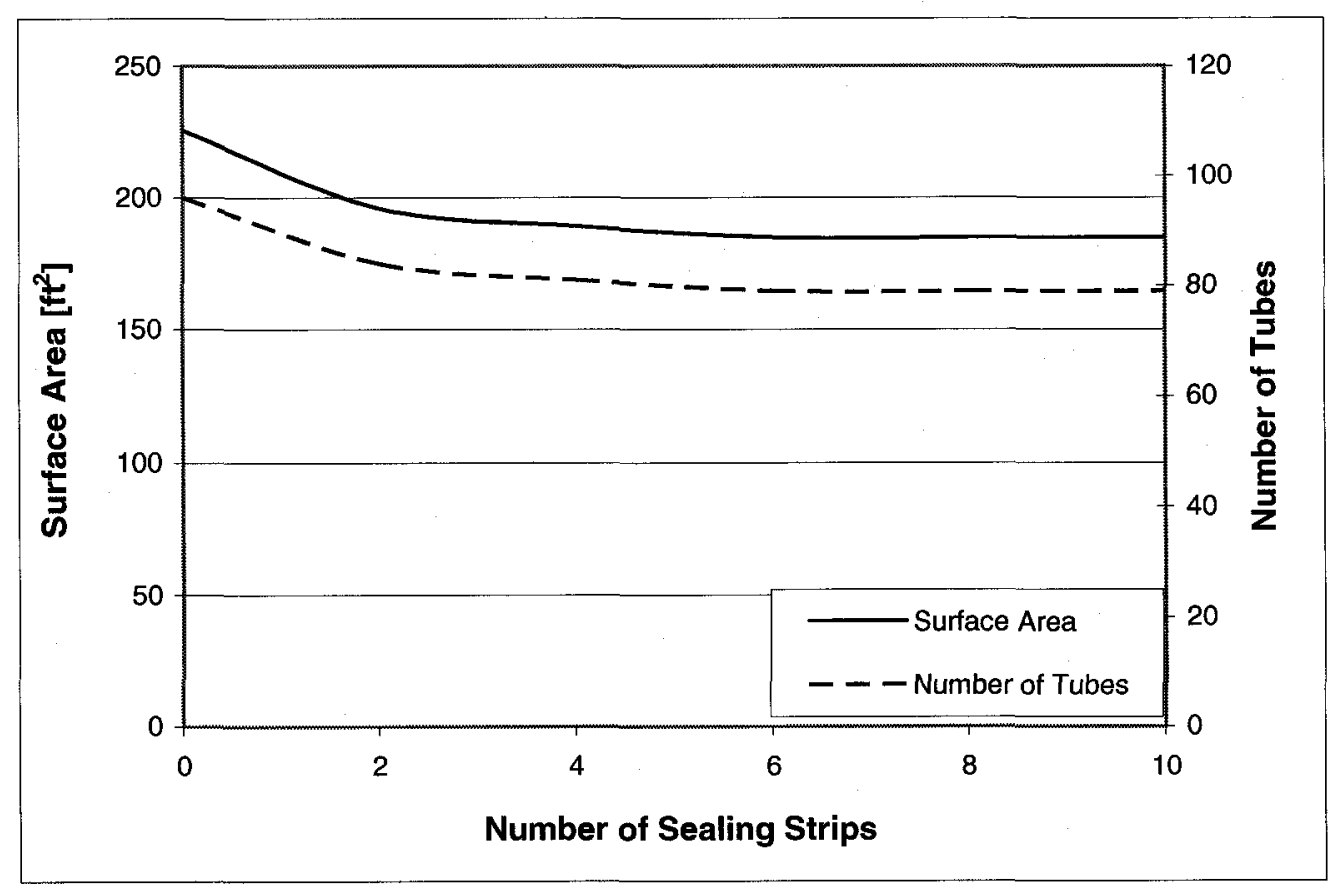

Figure 9.22: Surface Area and Tube Count Requirement as a Function of Number of Sealing Strips

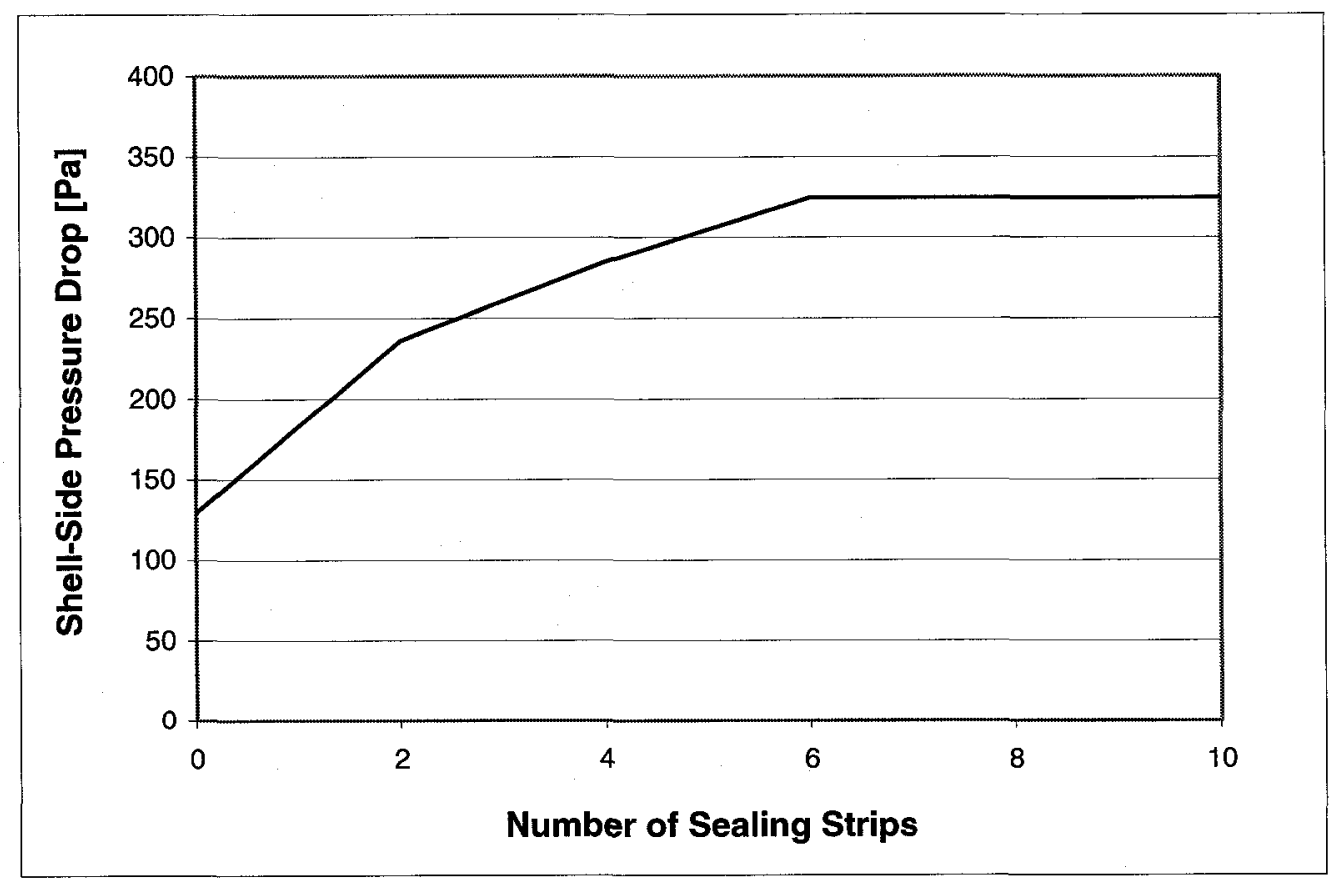

Figure 9.23: Predicted Pressure Drop as a Function of Number of Sealing Strips 


\subsubsection{Shell and Tube Heat Exchanger Geometry Considered for Application as a HSHE}

Tube-fin heat exchanger has been sized to meet the heat-transfer rate requirement, effectiveness, and pressure drop target of the HSHE. The heat exchanger has been sized to meet the 90 percent effectiveness target of the HSHE, and the pressure drop design target of 3 percent. Key dimensions determined from the thermal hydraulic analysis are summarized below.

\section{Outer Shell Geometry}

Number of Shells: $\quad 2$

Type of Shell: TEMA E

Tube-Side Flow Length: 6 feet

Shell Diameter: 14 inch

Inner Shell Geometry

Number of Baffles: $\quad 5$ to 12

Inner Baffle Spacing: $\quad 12$ to 24 inches

Central Baffle Spacing: $\quad 10$ to 20 inches

Outer Baffle Spacing: $\quad 12$ to 24 inches

Baffle Cut: 20\% Shell I.D.

Tube Geometry and Layout

Tube Type: Plain Tubes

Tube Length: $\quad 6$ feet

Tube Outer Diameter: $\quad 3 / 4$ inch

Tube Pitch: $\quad 1.00$ inch

Tube Layout: 45 degree

Number of Tubes: $\quad 81$ per Shell 


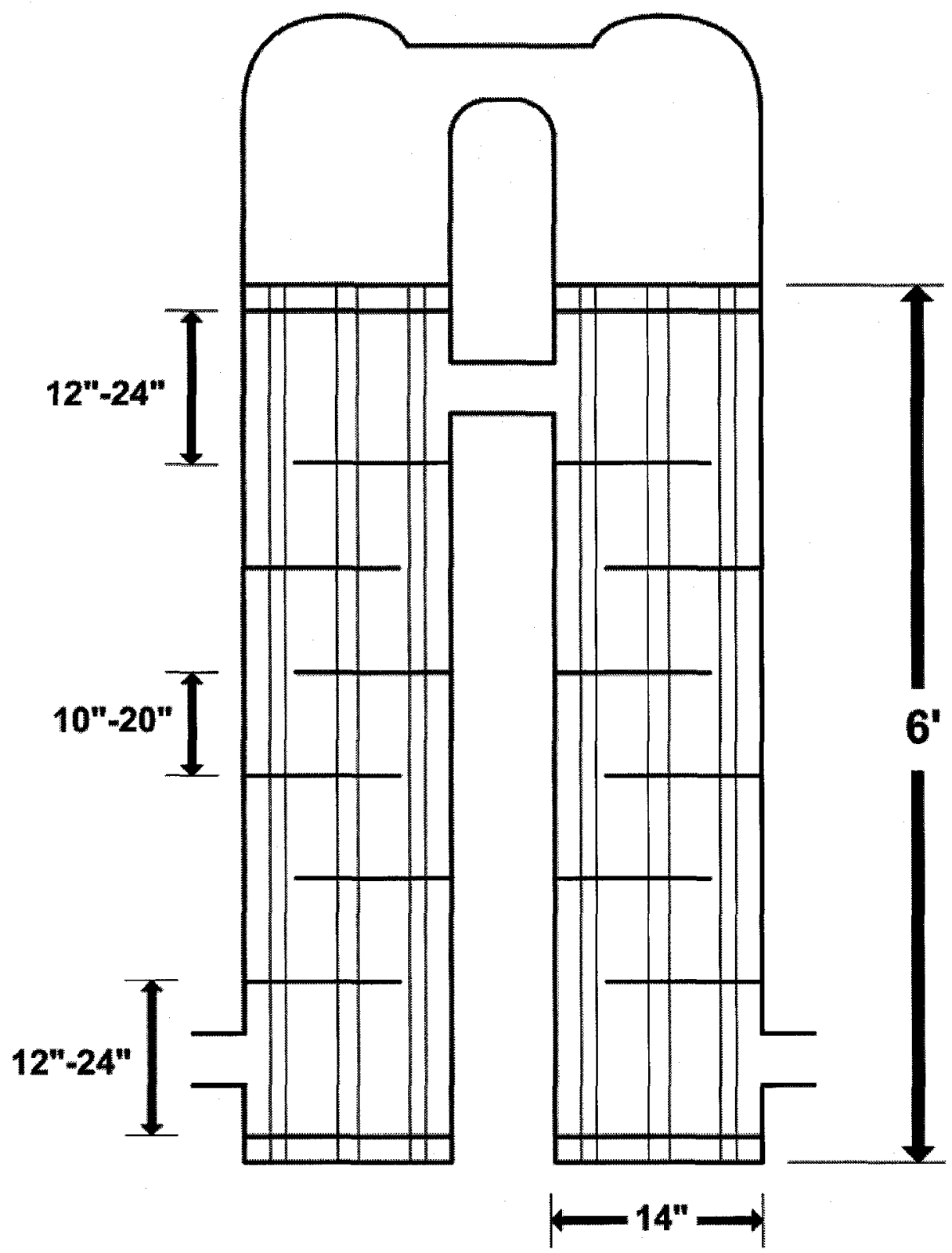

Figure 9.22: External Geometry of the Shell and Tube Heat Exchanger 


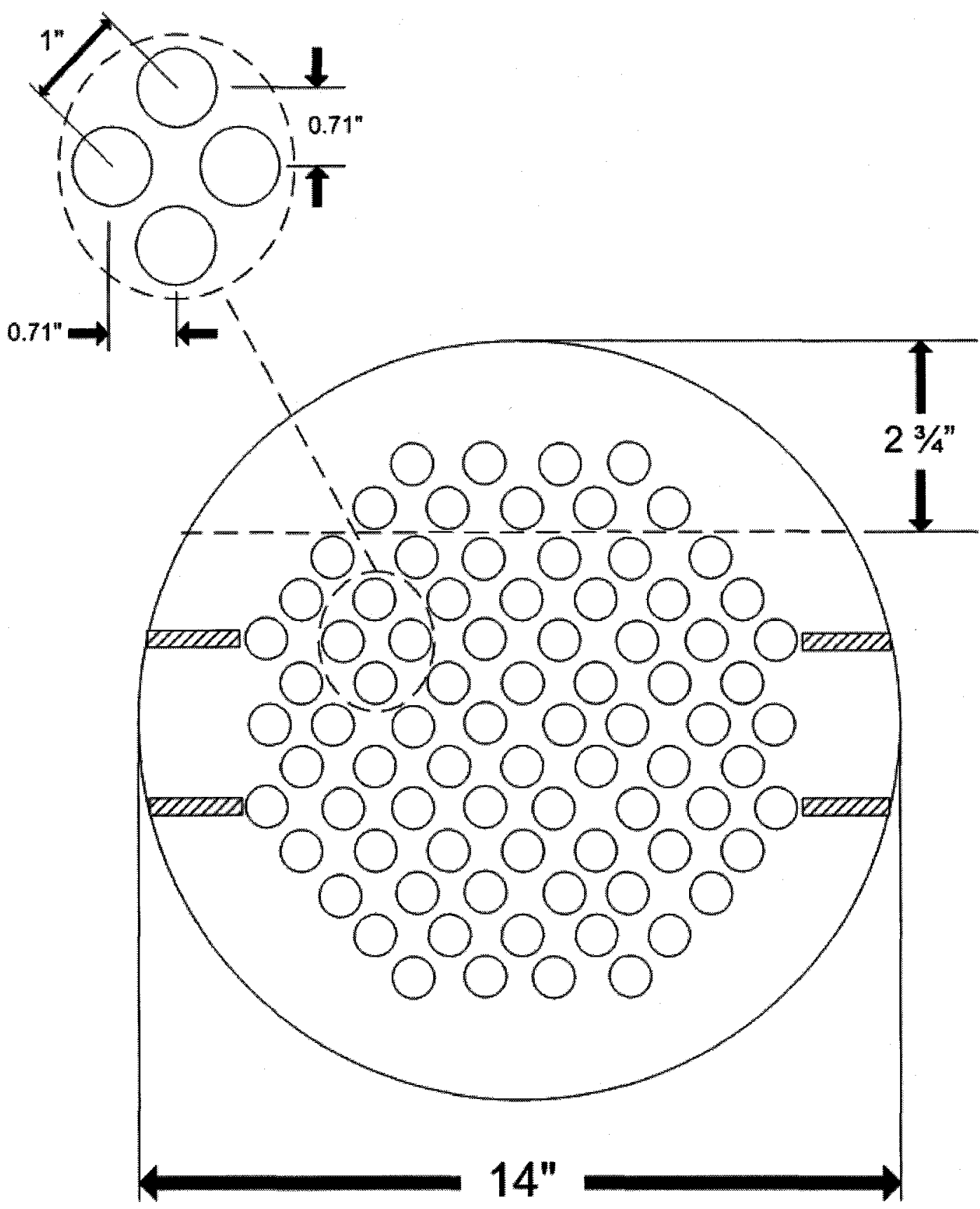

Figure 9.25: Tube Layout in the Shell and Tube Heat Exchanger 


\subsection{Comparative Analysis of the Tube-Fin Heat Exchanger and Shell- Tube Exchanger}

Heat exchanger type is selected based on cost, ease of manufacturing, and ease of integration to the $\mathrm{CBC}$ engine. The heat exchanger design characteristics that affect the above aspects are individually evaluated by a weighted qualitative analysis. A ranking is attached to a number of critical design characteristics that influence material and manufacturing costs, fabrication feasibility and integration compatibility. Each heat exchanger characteristic is analysed and an appropriate rank is allocated. The heat exchanger with highest point tally is selected for recuperator and a HSHE application.

\subsubsection{Heat-Transfer Surface Area Requirement (5)}

Heat-transfer surface area is designated a critical design aspect since this parameter governs the size of the heat exchanger and the associated material costs. The total fin and tubing surface area is compared for the two heat exchangers. Shell and tube heat exchanger has a tube surface area requirement of $190 \mathrm{ft}^{2}$. The tube-fin heat exchanger design requires a tube and fin surface area of $1290 \mathrm{ft}^{2}$, of which $80.2 \mathrm{ft}^{2}$ corresponds to the tubes. The point allocation is relative to the two heat exchanger types. Since the heat-transfer surface area is smaller, the shell and tube heat exchanger is allocated 4 points. In contrast, the tube-fin exchanger is allocated 1 point.

\subsubsection{Number of Tubes Required (5)}

The number of tubes is considered a critical design aspect since the manufacturing and installation costs directly correlate to the tube count. Cost is governed by the required machining time to drill associated holes in the tubesheets and baffles. Each of these holes must be made with fine tolerances. Each of the tubes is rolled into the tubesheet and welded. The number of tubes utilized will govern the time and cost required for the rolling and welding process. Therefore, minimizing the number of tubes is deemed beneficial. The tube-fin heat exchanger tube requirement is 96 tubes as 
compared to 162 for the shell and tube heat exchanger ( 81 per shell). The shell and tube heat exchanger is allocated 2 points. Tube-fin heat exchanger is allocated 4 point.

\subsubsection{Tube Length (5)}

The tube length affects the ability to incorporate a heat exchanger into a building envelope. A heat exchanger with long tubes would be difficult to install in a pre-existing mechanical room. Also, a heat exchanger with long tubes would be difficult to place vertically (with respect to the tube length), which will significantly reduce the overall footprint requirement. Both heat exchangers are designed with the same tube length of 6 feet. This tube length is considered practical for installation purposes. Both heat exchangers are rated 4 out of 5 .

\subsubsection{Proneness to Flow Induced Vibration (FIV) - Difficulty of Tube Support Implementation (4)}

Long tubes require support to prevent tube failure due to flow induced vibration (FIV). In a shell and tube heat exchanger, tube support is provided by baffles, which also guide the flow in crossflow orientation to the tubes. This inherent design feature, along with extensive availability of standards offered in literature (such as Reference 9.4), present an unlikely possibility of tube failure in a shell and tube heat exchanger. Therefore, the shell and tube heat exchanger is rated 3 out of 4 for this criterion.

In contrast, the shell-side flow velocity is very low (approximately $1.2 \mathrm{~m} / \mathrm{s}$ in comparison to $4.4 \mathrm{~m} / \mathrm{s}$ for the shell and tube heat exchanger). FIV may not be encountered at these low flow velocities. However, tube support will be required to prevent tube buckling. Installation of a support plate comparative to a baffle would present difficulties in integration, since the tubes may not be rolled into the support structure due to obstruction by the fins. Installation of such a support plate may only be possible by implementing a large number of short finned tubes. Implementation of short finned tubes would significantly increase the required tube welding time and cost. 
Alternative support structures that utilize rods are possible, however, this would also require increased manufacturing time and cost. The tube-fin heat exchanger is rated 2 out of 4 for this criterion.

\subsubsection{Transition Section Consideration (4)}

Heat exchanger design is modular, which facilitates integration with the CBC engine by implementation of transition sections. In a shell and tube heat exchanger, the shell-side inlet and outlet nozzles are relatively small and will require a small expansion duct. For tube side-flow, a transition section may be required between the tube inlet header and the burner. Geometry of this transition section will be burner dependant. A tube outlet duct that expels hot flue gasses will also be implemented. No difficulties are foreseen with the design and fabrication of transition sections for the shell and tube heat exchanger. The shell and tube exchanger is rated 3 (out of 4) for this criteria.

Large transitions sections are required for the tube-fin heat exchanger since the flow must be evenly distributed from a relatively small compressor outlet duct to a crosssectional size of 6 feet by 1.33 feet. Adequate flow distribution is required to ensure high heat-transfer rates and even temperature distribution throughout the tubes. These considerations will necessitate a lengthy transition section that will require high material and manufacturing costs. The tube fin exchanger is rated 0 (out of 4 ) for this criterion.

\subsubsection{Ability to Withstand Pressure - Relative Shell Size and Thickness \\ Requirement (3)}

The heat exchangers are considered pressure vessels since they must be designed to withstand a shell-side pressure of $384.8 \mathrm{kPa}$ (55.8 psia). Any unfired vessel that operates at an internal or external pressure above $103.3 \mathrm{kPa}(15 \mathrm{psig})$ and has an internal diameter, width, height, or cross-section above 6 inches must be designed according to ASME Boiler and Pressure Code, VIII, Division 1 [9.3]. Although the mechanical design of the heat exchanger is beyond the scope of this thesis, the required shell thickness of the 
two designs is considered since it will affect the overall heat exchanger cost. Therefore, the ability for the heat exchanger to withstand pressure criteria is placed.

The shell of the shell and tube heat exchanger is circular, which is an inherently stronger design, whereas the shell of the tube-fin exchanger is rectangular. Stress concentration will be present at the corners of the rectangular shell of the tube-fin heat exchanger design. The presence of stress concentrations will require a thorough stress analysis of the shell. Moreover, the quality welds that can withstand the stress concentrations will be very high. These welds will be subject to extensive testing, which will elongate the certification process and associated costs. The tube-fin exchanger is therefore rated 1 (out of 3 ) for the ability to withstand pressure. On the other hand, the shell and tube exchanger is rated 3 (out of 3 ) for the ability to withstand pressure.

\subsubsection{Fouling Consideration/Ease of Cleaning (4)}

Utilization of waste oils or biomass fuels requires heat exchanger selection that can accommodate a certain degree of fouling, and is designed to accommodate a cleaning method. Both heat exchanger designs have flue gas positioned on the tube side. Straight tubes of $3 / 4$ inch O.D. and 6 foot length are utilized which are compatible with mechanical cleaning methods. The only design difference is in the amount of tubes that will require periodical cleaning. The tube-fin heat exchanger is designed with 96 tubes, whereas the shell and tube heat exchanger is designed with 162 tubes. Also, the shell and tube heat exchanger has an additional flow reversal duct that is positioned between the two shells. Although this duct will be designed to be easily removable during service periods, it is an additional component that requires maintenance.

It is difficult to assess the fouling rate without service data under comparable conditions. The only indication of relative fouling rate stems from tube velocity as well as the tube Reynolds number. These variables indicate the level of turbulence of the flue gas, which has an influence on the particulate sedimentation rate. The level of turbulence 
governs the wall shear force that impacts the sedimentation rate of particulate fouling matter. The tube velocity in the tube-fin heat exchanger design is predicted to be 107 $\mathrm{m} / \mathrm{s}$, which corresponds to a Reynolds number of 11,000 . The tube velocity in the shell and tube exchanger is predicted to be $125 \mathrm{~m} / \mathrm{s}$, with a corresponding Reynolds number of 13,720. The tube-side Reynolds numbers are comparable, and therefore, the fouling rate is expected to be comparable. The shell and tube heat exchanger is rated 2 (out of 4) points due to the larger amount of tubes that requires cleaning, as well as additional cleaning of the flow reversal duct. The tube-fin exchanger is rated 4 (out of 4), since smaller number of tubes require cleaning.

\subsubsection{Heat Exchanger Fabrication Consideration (10)}

The fabrication aspects of each heat exchanger type are considered due to the significant time and cost requirement. Although the shell and tube heat exchanger design requires a higher number of tubes and has more components (such as baffles), this design is simpler to manufacture. The tubes are rolled into the baffles and are welded to the tubesheets. No welding is required between the tubes and the baffles or the baffles and the shell. The shell is rolled in two segments and welded together. The tubesheets may be either welded to the shell or bolted, depending whether the design allows for tube bundle withdrawal for maintenance. Rolling of the shell requires a specialized machine. The flow-reversal duct may be designed as a transverse duct welded to two bonnet shell ends.

In comparison, the tube-fin exchanger utilizes a rectangular shell, for which large metal plates may be used. No metal rolling capability is required for the shell; however, this is offset by the requirement for extensive number of long welds. Fabrication of finned tubes is typically performed by the tube manufacturer. A tube support structure may require a large number of welds, considering the number of tubes that require support. Although the overall design of the tube-fin heat exchanger is straightforward, fabrication will be labour intensive. 
Discussion with a machinist/welder yielded to strong favourability to fabricate the shell and tube heat exchanger. Typically, the shell and tube heat exchanger is regarded as simple to manufacturing, which is substantiated by the wide number of shell and tube heat exchangers in service. Therefore, the shell and tube heat exchanger is rated 7 (out of 10) and the tube-fin heat exchanger is rated 4 for fabrication.

\subsubsection{Ease of Integrating a Burner (4)}

A modular approach for burner integration to the Hot-Side Heat Exchanger will be employed. The burner will be positioned upstream of the tube-side flow. No difficulty is foreseen in integrating the burner to either design. Depending on the burner size, a transition duct may be required. For the shell and tube heat exchanger, the duct must be compatible with the 14 inch I.D shell. For the tube-fin heat exchanger, the duct must be compatible with the 1.33 foot by 1.33 foot cross-section. Since no difficulties in integration are foreseen, the score for this criterion is 4 (out of 4 ) for both heat exchangers.

\subsubsection{Pressure Drop (5)}

The pressure loss imparted by the heat exchanger is a critical design criterion due to the large effect on the power output and cycle efficiency. Pressure loss prediction of both heat exchangers has been performed. The shell-side pressure loss prediction for the shell and tube heat exchanger is $230 \mathrm{~Pa}$. In contrast, the predicted shell-side pressure drop for the tube fin heat exchanger is $10.5 \mathrm{kPa}$. The large difference in predicted pressure drop is due to the large variation in the predicted Reynolds number. The shellside Reynolds number of the shell and tube heat exchanger is predicted to be 27,000 , whereas the Reynolds number for the tube-fin heat exchanger is predicted to be 170 . The pressure drop prediction does not include inlet and outlet headers or the flow reversal duct. Both these predictions are within the 3 percent design goal. Based on the prediction, the shell and tube heat exchanger is rated 5, and the tube fin heat exchanger is rated 3 (out of 5). 


\subsubsection{Heat Exchanger Selection}

Point allocation of the above design criteria has been tallied in Table 9.3. The heat exchangers have been rated on a 50 point basis. The shell and tube heat exchanger is rated at 38 points. The tube-fin heat exchanger is rated at 23 points. Based on this qualitative analysis, the shell and tube heat exchanger is better suited for the $\mathrm{CBC}$ engine application. The shell and tube heat exchanger design is selected for the $\mathrm{CBC}$ engine application.

Table 9.3: Rating of Critical Heat Exchanger Design, Fabrication, and Performance Features

\begin{tabular}{|c|c|c|c|}
\hline Criterion & $\begin{array}{c}\text { Point } \\
\text { Allocation }\end{array}$ & $\begin{array}{c}\text { Shell and } \\
\text { Tube HX }\end{array}$ & $\begin{array}{c}\text { Tube Fin } \\
\text { HX }\end{array}$ \\
\hline Tube Surface Area Requirement & 5 & & \\
\hline Number of Tubes Required & 5 & 2 & 4 \\
\hline Tube Length & 5 & 4 & 4 \\
\hline Proneness to FIV & 4 & 3 & 2 \\
\hline Transition Section Consideration & 4 & 3 & 0 \\
\hline Ability to Withstand Pressure & 4 & 3 & 1 \\
\hline Fouling Consideration/Ease of & 4 & 3 & 1 \\
\hline Cleaning & & & 3 \\
\hline Fabrication Considerations & 10 & 7 & 4 \\
\hline Ease of Integrating a Burner & 4 & 4 & 3 \\
\hline Magnitude of Pressure Drop & 5 & 5 & $\mathbf{2 3}$ \\
\hline
\end{tabular}




\subsection{Conclusion}

The shell and tube heat exchanger and the tube-fin heat exchanger have been sized for HSHE application. Sizing was completed by performing a parametric analysis on heat exchanger geometry that will influence thermal-hydraulic performance. Each heat exchanger design was optimized to reduce the surface area and tube count, and to a lesser extent, optimized to reduce the pressure drop. A qualitative weighted analysis has been performed on each heat exchanger to select the most suitable design. The shell and tube heat exchanger was rated considerably higher than the tube-fin heat exchanger. The shell and tube heat exchanger is considered more suitable for HSHE application in a CBC engine. This design is selected for utilization as a HSHE. 


\section{CHAPTER 10}

\section{Conclusions and Future Work}

\subsection{Conclusions}

DG and renewable energy power generation technology has recently exhibited significant market growth. Although numerous technologies are offered for DG, there is no efficient and cost-effective DG technology that utilizes renewable energy, which may adequately supply electrical and thermal demand of a small business situated in an urban community. Application of a DG technology that utilizes renewable energy may benefit from both the growing DG energy market and the growing renewable energy market. The closed Brayton cycle engine is potentially suitable for both emerging and growing markets.

The CBC engine is a regenerative gas turbine engine that re-circulates the working fluid in a closed loop. A wide range of heat sources may be applied with a CBC engine, including fossil fuels (such as gas, oil, and coal), solar, nuclear, and biomass. Fossil fuels have been most commonly used for power generation installations and are 
burned in an indirectly-fired heat exchanger, where flue gasses and the working fluid are not mixed. Consequently, no corrosion or erosion in the turbomachinery is present resulting in the possibility of utilizing renewable fuels.

A preliminary market application area has been found for the $\mathrm{CBC}$ engine. There are more than 300 remote communities with a total population exceeding 200,000 people, which are not connected to an electrical grid or a piped natural gas network. Many of these communities utilize diesel engines for electrical power generation, which operate on isolated grids. A significant quantity of waste oil is generated by these diesel engines, which may be utilized in a CBC engine. Since remote communities are highly dependant on imported fuel, with a price strongly linked to transportation costs, utilization of waste oil would reduce the power generation costs imparted on these communities. Moreover, the only means of recycling waste oil is by shipping to Southerly regions. Due to the high cost of shipping, the waste oil is typically incinerated. There are more than 30 communities in the remote arctic region alone where incineration of waste oil is an environmental concern. It was proposed to develop a CBC engine for efficient waste oil incineration in these communities. Development of the waste oil $\mathrm{CBC}$ engine will reduce the capital cost of the technology to a level where a biomass CBC engine (for application in small businesses) may be competitive.

Development of a technology demonstration CBC engine for waste oil combustion has been initiated. The overall goal of the technology demonstrator engine is to develop an operational low-cost unit that does not necessarily generate power at high efficiencies. The invoked design strategy includes utilizing off-the shelf components to reduce design and manufacturing costs. The off-the-shelf components utilized include turbochargers and an alternator. The design-point power output level of $20 \mathrm{~kW}$ was selected due to availability of a low-cost alternator at this size range. Also, the power level of $20 \mathrm{~kW}$ was selected since it is considered the upper power limit of the competing Stirling engine and the lower design limit of the competing micro-gas turbine. The 
efficiency target was selected as 15 percent, due to turbocharger TIT and efficiency level limitation.

Design-point performance calculations have been performed to select the desired working fluid and $\mathrm{CBC}$ engine configuration, as well as determine component performance criteria and working gas conditions required to generate target power output and efficiency level. The working gasses considered for $\mathrm{CBC}$ engine application included air, carbon dioxide, or monatomic gasses such as helium, argon, xenon, or a mixture. Performance calculations have been conducted for the range of gasses. In an ideal case, where pressure losses are not present, the CBC engine performance is greater for gasses with a higher specific heat ratio. Also, it has been found that the optimum pressure ratio is lower for gasses with a high specific heat ratio. In the realistic case where pressure losses are present, it has been determined that the relative magnitude of pressure losses is higher when selecting a lower pressure ratio that corresponds to the optimum of the specific gas. As a result of the relatively higher pressure drop of monatomic gasses, air has been found to have the highest potential efficiency. Despite the potential size advantages offered by monatomic gasses (including gas mixtures), air has been selected as the working gas. This is decision is primarily based on CBC engine operations requirement in remote locations, where periodic recharging the working fluid would be costly.

The $\mathrm{CBC}$ arrangement that offers highest performance and a simple design is the regenerative free-turbine arrangement. This arrangement is selected over the regenerative single-shaft arrangement since simple means of alternator integration is offered. Free shaft space available on turbochargers is limited in length. By utilizing the free-turbine arrangement, the compressor positioned adjacent to the L.P. turbine may be discarded to provide sufficient shaft length for the alternator. The alternator can be attached to the L.P. turbine by the same means the discarded compressor has been attached. 
The effect of turbine inlet temperature (TIT) on CBC cycle performance has been analysed and the design-point TIT is selected. From discussion with turbocharger manufacturers, a TIT of $1050 \mathrm{~K}$ is the upper metallurgical limit. Operation at lower temperature will increase turbocharger life and reduce the hot-side heat exchanger surface area. The steady-state design-point TIT of $1025 \mathrm{~K}$ has been selected, which is the lowest TIT at which the efficiency target may be met.

The effect of the compressor inlet pressure on cycle performance has been analysed to ensure power generation of $20 \mathrm{~kW}$ is predicted. The performance study concluded that pressurization does not offer a significant performance improvement. However, pressurization will increase the difficulty of sealing the unit and necessitate thicker turbomachinery casing and heat exchanger shell. In the case of a technology demonstration engine, the possibility of testing at atmospheric conditions may reduce development costs. Furthermore, the low-temperature heat exchanger (waste heat recovery heat exchanger) would not require a design adherent to a pressure code. Since a large performance benefit is not expected, the compressor inlet will be operated at or near atmospheric pressure. The other control variable at the compressor inlet is the compressor inlet temperature (CIT). High compressor inlet temperature has an adverse effect on the cycle efficiency, and therefore, effort should be undertaken to significantly reduce the CIT. Control of the CIT will be maintained through control of liquid temperature in the cold-side heat exchanger inlet. For preliminary calculations, the coolant temperature and the $\mathrm{CIT}$ are chosen as $283 \mathrm{~K}\left(10^{\circ} \mathrm{C}\right)$, which is comparable to tap water temperature.

Turbomachinery has been matched to correspond to the $\mathrm{CBC}$ performance requirements. The turbomachinery has also been matched with respect to the speed parameter and the mass flow parameter. Selection was based on relative comparison of the highest possible efficiency. Performance maps for the turbochargers have been obtained, and the design-point compressor, H.P. turbine, and L.P. turbine isentropic 
efficiency has been determined as 77 percent, 70 percent, and 78 percent respectively. Based on this data, the cycle efficiency at the design point has been determined to be 15.1 percent. This design point efficiency target is reached with a recuperator effectiveness of 82 percent and a HSHE effectiveness of 90 percent. The selected design point compressor pressure ratio is 2.96 . This compressor pressure ratio corresponds to the maximum cycle efficiency.

Off-design performance calculations have been conducted in conjunction with turbocharger performance maps to ensure accurate performance prediction and stable operation at an adequate surge margin. An off-design control strategy has also been developed. The control strategy involves regulating the CIP from the design-point value of $119 \mathrm{kPa}$ to $70 \mathrm{kPa}$. Regulating the CIP prevents variation of the design-point TIT and variation of turbocharger design-point efficiency. In this manner, 50 percent of the design-point power can be reached with efficiency loss below 20 percent. This compares to an efficiency loss of 35 percent for half power operation with an open cycle engine. The power reduction strategy through variation of CIP is limited to the CIP of $70 \mathrm{kPa}$ or 47 percent design-point power. Further reduction in power is achieved by reducing the TIT.

The control strategy of varying the TIT with the power loading requirement is used in the power range of $0 \mathrm{~kW}$ to $9.4 \mathrm{~kW}$. Operation at a lower than design point TIT has a negative impact on the CBC part-load efficiency. The reduction in TIT is possible from $1025 \mathrm{~K}$ to $950 \mathrm{~K}$, at which point no net power is generated and the CBC engine is operating at idle speed. The part-load performance of the $\mathrm{CBC}$ engine has a flatter efficiency curve as compared to an $\mathrm{OBC}$ as a result of part-load operation at the designpoint TIT. However, the inherently lower pressure losses in an OBC engine result in power generation at higher efficiency levels. The design-point efficiency level of a hypothetical $\mathrm{OBC}$ engine with similar component performance values was predicted to be 18.4 percent as compared to 15.1 percent for the $\mathrm{CBC}$ engine. 
A tube-fin heat exchanger and a shell and tube heat exchanger have been sized for application as a HSHE in the CBC engine. Geometry of both heat exchangers has been outlined. The tube-fin heat exchanger thermal hydraulic design was performed according to experimental correlations for finned tubes in crossflow. The shell and tube heat exchanger design was performed by application of the Bell-Delaware method. A weighted quantitative analysis has been performed on both designs. The shell and tube heat exchanger was considered more suited for $\mathrm{CBC}$ engine application. This heat exchanger design utilizes two TEMA E shells of 14 inch I.D. that are attached by a flow reversal duct. 81 tubes of 6 foot length and 3/4 inch I.D. are utilized. These tubes are positioned at a centre-to-centre distance of 1 inch in a 45 degree arrangement. No difficulties in manufacturing or system integration are foreseen with the design. Moreover, the pressure drop requirement is predicted to be within 3 percent compressor delivery pressure (CDP).

Overall, the design of a technology demonstration CBC engine for waste oil combustion in remote Northern communities has been initiated. The preliminary design dictates that it is possible to develop a $\mathrm{CBC}$ engine by utilizing off-the-shelf components such as turbochargers. However, the application of turbochargers limits the design-point TIT, and therefore, the potential efficiency will be modest (predicted at 15 percent). The modest overall efficiency will limit the CBC engine application to areas with high energy cost and waste fuel disposal. 


\subsection{Future Work}

Several aspects require completion prior to fabrication and testing of the $\mathrm{CBC}$ engine. First, the mechanical design of the HSHE must be performed. This includes a performing a Flow Induced Vibration analysis and performing detailed stress analysis. The mechanical design should be performed according to TEMA Standards and the Pressure Vessel Code, Division VIII, Section 1. Heat exchanger materials must be selected.

The thermal hydraulic and mechanical design of the recuperator must be performed. The shell and tube heat exchanger will be used as the recuperator, and the thermal hydraulic theory presented in Chapter 8 may be applied. As described in Section 9.2, the size of the recuperator will be larger than the HSHE. Also, no fouling present in the recuperator and no cleaning requirement results in the ability to use smaller tubes. The mechanical design of the recuperator will be similar to the HSHE, although materials that are capable of withstanding lower temperatures may be applied.

The thermal hydraulic and mechanical design of the cold-side heat exchanger must be performed. The tube-fin heat exchanger will be utilized for this application. The design will vary from the one presented in Chapter 9 since a single header for the inlet and outlet will distribute the cooling fluid. The heat exchanger design will be multi-pass to simplify the header design.

Design or selection as well as integration of a burner must be performed. A natural gas burner will be utilized during initial testing and demonstration of $\mathrm{CBC}$ engine capability. It is possible to integrate an off-the-shelf natural gas burner for the technology demonstrator. An off-the-shelf burner for combustion of waste oils and biomass may also be found. 
An off-the-shelf alternator manufacturer that can manufacture a $20 \mathrm{~kW}$ alternator has been selected. The alternator will be fitted in a similar fashion as the disassembled compressor. Therefore, the alternator rotor dimensions must coincide with the turbocharger rotor dimensions. An alternator housing that is hermetically sealed must be designed. The cooling mechanism must be integrated into the alternator housing.

A control system must be developed for the $\mathrm{CBC}$ engine. The control system must be designed for hands-free operation since the engine is applied in remote communities. Also, the control system must include an emergency shut off to prevent over-speeding in case of loss of load. A starting mechanism must also be developed. It has been proposed to utilize compressed air stored in an auxiliary cylinder for starting.

The above components must be fabricated and integrated. A successful testing program must be completed prior to assembly and sales of the $\mathrm{CBC}$ engine. 


\section{References}

\section{Chapter 1}

[1.1] Bammert K., Twenty-Five Years of Operating Experience With the Coal-Fired, Closed-Cycle Gas Turbine Cogeneration Plant at Coburg, Transactions of ASME, Journal of Engineering Power, October 1983, Paper No. 83-GT-23.

[1.2] Keller C., Forty Years of Experience on Closed-Cycle Gas Turbines, Annals of Nuclear Energy, Vol. 5, 1978.

[1.3] Mullins P. Microturbines Packaged for Distributed Power Applications, Diesel Progress, North American Edition, Diesel and Gas Turbine Publications, November 2002 , pg. 46.

[1.4] Saravanamuttoo HIH., Rogers GFC., Cohen H., Gas Turbine Theory $5^{\text {th }}$ ed., Prentice Hall, Harlow, 2001.

\section{Chapter 2}

[2.1] Bradshaw, T. Clark II, W. The California Experience: From Deregulation Disaster to Flexible Power, UCCEE (UNEP Collaborating Centre on Energy and Environment), Meeting, Paris France, May 2002, www.uccee.org/SectorReform/CaliforniaExperience.pdf

[2.2] Reguly E. Ontario Liberals have got to act now on hydro, The Globe and Mail, December 2, 2003.

[2.3] Spears, J., Brennan, R., Cut Power Use, Ontario Warns, Toronto Star, July 4, 2002.

[2.4] Gralla, Joan, Blackout cost NYC 1 billion, Reuters, October 28, 2003, www.forbes.com/markets/newswire/2003/10/28/rtr1126494

[2.5] Dabrowski, W. Blackout to cost Ontario economy $\$ 550$ million, Financial Post, August 22, 2003.

[2.6] Rodgers, C. Small Gas Turbine Generator Set Starting, Proceedings of ASME Cogen-Turbo IGTI, Portland, Oregon, Vol. 9, 1994. 
[2.7] Galdo, J., Distributed Energy Resources-A National Perspective, Presented for Distributed Energy Resources: Policy Option for Virginia, Richmond, V.A., May 17, 2002.

[2.8] Tomashefsky, S., Marks M., Distributed Generation Strategic Plan, California Energy Commission, June 2002.

[2.9] Gauthier, J.E.D., Gas Turbine Theory Lecture Notes, Fall 2002.

[2.10] Martin, John R., Comparison of High-Efficiency Distributed Cogeneration and Large Combined Cycle Power Generation, Proceedings of ASME Turbo Expo June 1619, 2003, Atlanta, Georgia, USA, Paper No. GT2003-38109.

[2.11] Shewchuk, Stan, Gas Flaring: A Mounting Environmental Concern in Western Canada, Saskatchewan Business Magazine, June/July 2002.

[2.12] Distributed Energy Resources Guide: Markets, California Energy Commission, www.energy.ca.gov/distgen/markets/status.html, December 2003.

[2.13] Hedman, B., Darrow, K., Microturbine Market Review, Microturbine and Industrial Gas Turbine Peer Review Meeting, Nexus Energy Group, March 12, 2002, Fairfax, Virginia.

[2.14] Heintzman, A., Solomon, E., Fuelling the Future, House of Anansi Press Inc., Toronto, 2003.

[2.15] Medrano M., Brouwer J., Samuelson G.S., Carreras M., Dabdub D., Urban Air Quality of Distributed Generation, Proceedings of ASME Turbo Expo June 16-19, 2003, Atlanta, Georgia, USA, Paper No. GT2003-38309.

[2.16] McNeely, M., MHI Announces New KU3OB Diesel Engine, Diesel and Gas Turbine Worldwide, Diesel and Gas Turbine Publications, October 2002. [2.17] Distributed Energy Resources Guide: DER equipment, California Energy Commission, www.energy.ca.gov/distgen/equipment/equipment.html, December 2003. [2.18] Hedman B., Matching DG Technologies and Applications, Distributed Generation Conference, Denver, Colorado, August 9, 2001, www.eea-inc.com/dgchp_presentations/Matching_DG_Technologies.pdf. [2.19] Saravanamuttoo HIH., Rogers GFC., Cohen H., Gas Turbine Theory $5^{\text {th }}$ ed., Prentice Hall, Harlow, 2001. 
[2.20] Yamamoto T., Furuhata T., Arai N., Mori K., Design and Testing of the Organic Rankine Cycle, Energy, Elsevier Science, Volume 26, 2001, pg. 239-251.

[2.21] Hung, T.C, Shai T.Y., Wang S. K., A Review of Organic Cycles (ORCs) for the Recovery of Low-Grade Waste Heat,. Energy, Elsevier Science, Great Britain, Volume 22, No.7, 1997, pg. 661-667.

[2.22] Shah, R.P, Corman, J.C., Conceptual Design of Closed Brayton Cycle for Coal-

Fired Power Generation, Proceedings of IECEC, Washington, DC, 1977 (779024).

\section{Chapter 3}

[3.1] Bammert K., Rurik J., Griepentrog H., Highlights and Future Development of Closed-Cycle Gas Turbines, Transactions of ASME, Journal of Engineering Power, October 1974, Paper No. 74-GT-7.

[3.2] Bammert K., Groschup, G., Status Report on Closed-Cycle Power Plants in the Federal Republic of Germany, Transactions of ASME, Journal of Engineering Power, January 1977, Paper No. 76-GT-54.

[3.3] Bammert K., Twenty-Five Years of Operating Experience With the Coal-Fired, Closed-Cycle Gas Turbine Cogeneration Plant at Coburg, Transactions of ASME, Journal of Engineering Power, October 1983, Paper No. 83-GT-23.

[3.4] Deuster, G., Long-Time Operating Experience with Oberhausen Closed-Cycle Gas-Turbine Plant, Transactions of ASME, Proceedings of ASME Gas Turbine Conference, May 24-28, Brussels, Belgium, 1970, Paper No. 70-GT-73.

[3.5] Bammert K., Operating Experiences and Measurements on Turbo Sets of CCGTCogeneration Plants in Germany, Transactions of ASME, Journal of Engineering Power, January 1987, Paper No. 86-GT-101.

[3.6] Bammert K., Poesentrup H., The Behaviour of a Closed Cycle Gas Turbine with Time Dependent Operating Conditions, Transactions of ASME, Journal of Engineering Power, July 1980, Paper No. 79-GT/Isr-2.

[3.7] Bammert K., Nickel E., Design of Combustion Chambers of Heaters for Transmission of Primary Heat of Closed-Cycle Gas Turbines, Transactions of ASME, Journal of Engineering Power, June 1966, Paper No. 66-GT/CLC-1. 
[3.8] Keller C., Forty Years of Experience on Closed-Cycle Gas Turbines, Annals of Nuclear Energy, Vol. 5, 1978.

[3.9] Eckardt D., Rufli P., Advanced Gas Turbine Technology: ABB/BCC Historical

Firsts, Transactions of ASME, Journal of Engineering for Gas Turbines and Power, Vol. 124, July 2002, Paper No. 01-GT-395.

[3.10] Bammert K., Buende R., Comparison of Nuclear Power Plants with Closed-Cycle Helium Turbine and with Steam Turbine Cycle for Combined Power and Steam Generation, Transactions of ASME, Journal of Engineering Power, January 1973, Paper No. 72-GT-37.

[3.11] Bammert K., Boehm E., Buende R., Nuclear Power Plants with Closed-Cycle Helium Turbine for Industrial Energy Supply, Transactions of ASME, Journal of Engineering Power, January 1971, Paper No. 70-GT-93.

[3.12] McDonald C.F., The Closed-Cycle Turbine - Present and Future Prospectives for Fossil and Nuclear Heat Sources, Transactions of ASME, ASME Gas Turbine Conference, April 9-13, 1978, London, England, Paper No. 78-GT-102.

[3.13] McDonald C.F., Boland C.R., The Nuclear Closed-Cycle Gas Turbine (HTGRGT)-Dry Cooled Commercial Power Plant Studies, Transactions of ASME, Journal of Engineering Power, January 1981, Paper No. 80-GT-82.

[3.14] McDonald C.F., Smith, M.J., Turbomachinery Design Considerations for the Nuclear HTGR-GT Power Plant, Transactions of ASME, Journal of Engineering Power, January 1981, Paper No. 80-GT-80.

[3.15] Keller C., Schmidt D., Industrial Closed-Cycle Turbines for Conventional and Nuclear Fuel, Transactions of ASME, ASME Gas Turbine Conference, March 5-9, 1967, Houston, Texas, Paper No. 67-GT-10.

[3.16] Bammert K., Deuster G., Layout and Present Status of the Closed-Brayton Cycle Helium Turbine Plant Oberhausen, Transactions of ASME, ASME Gas Turbine Conference, March 30-April 4, 1974, Zurich, Switzerland, Paper No. 74-GT-132. [3.17] Luchter S., The Application of Closed-Cycle Gas Turbine System Technology to Mobile Nuclear Power Plants, Transactions of ASME, Journal of Engineering Power, March 1966, Paper No. 66-GT/CLC-3. 
[3.18] Janis J., Steely C., The Development and Operating Experience of the ML-1 Mobile Nuclear Power Plant, Transactions of ASME, Journal of Engineering Power, June 1966, Paper No. 66-GT-CLC-12.

[3.19] Baggenstoss W. G., Ashe T. L., Mission Design Drivers for Closed Brayton Cycle Space Power Conversion Configuration, Transactions of ASME, Journal for Gas Turbines and Power, October 1992, Paper No. 91-GT-139

[3.20] Klann, J. L., Wintucky, W. T., Status of the 2- To 15-kWe Brayton Power System and Potential Gains from Component Improvements, Proceedings of IECEC, August 1971, Boston, Massachusetts, Paper No. 719027.

[3.21] Dunn, J. H., Post Test Inspection of Three Brayton Rotating Units, Proceedings of IECEC, August 1971, Boston, Massachusetts, Paper No. 719030.

[3.22] Brown, W. J., Brayton-B Power System - A Progress Report, Proceedings of IECEC, September 22-26, 1969, Washington, DC, Paper No. 699078.

[3.23] Valerino A. S., Ream L. W., Performance of a Brayton-Cycle Power Conversion System Using a Helium-Xenon Gas Mixture, Proceedings of IECEC, August 1971, Boston, Massachusetts, Paper No. 719029.

[3.24] Gilbert, L. J., Curreri J. S., Cantoni D. A., Motor Starting Techniques for the 2To-15 kW Brayton Space Power System, Proceedings of IECEC, August 1971, Boston, Massachusetts, Paper No. 719032.

[3.25] Secunde R. R., Vrancik J. E., Spagnuolo A. C., Experimental Evaluation of the Electrical Subsystem of the 2-To-15 kW Brayton Power Conversion System, Proceedings of IECEC, August 1971, Boston, Massachusetts, Paper No. 719031.

[3.26] Brandes D. J., High-Temperature Nuclear Closed Brayton Cycle Power Conversion System for the Space Exploration Initiative., American Institute of Physics, CONF-910116, 1991.

[3.27] Shaltens R. K., Mason L. S., Early Results From Solar Dynamic Space Power System Testing, NASA Technical Memorandum 107252, July 1996.

[3.28] Tilliette, Z. P., Advances in Defining a Closed Brayton Conversion System for Future ARIANE 5 Space Nuclear Power Applications, Transactions of ASME, Journal of Engineering for Gas Turbines and Power, Vol. 109, January 1987, Paper No. 86-GT-15. 
[3.29] Tilliette, Z. P., Proust E., Carre F., A Four-Year Investigation of Brayton Cycle Systems for Future French Space Power Applications, Transactions of ASME, Journal of Engineering for Gas Turbines and Power, Vol. 110, October 1988, Paper No. 88-GT-157. [3.30] Johnson R. A., Determan W., Shirbacheh M., Low Power DIPS Design for NASA Missions, American Institute of Physics, Paper No. CONF-910116, 1991.

[3.31] Dobler F. X., Rackley R. A., Closed Gas Turbine Marine Power Systems, Proceedings of IECEC, August 18-22, 1975, Newark, Delaware, Paper No. 759160. [3.32] Fayrweather, D. J., Rackley R. A., Advanced Marine Closed Brayton Engines, Proceedings of IECEC, September 12-17, 1976, State Line, Nevada, Paper No. 769030. [3.33] Obara T., Yamamoto K., Development of an Autonomous Underwater Vehicle RI with a Closed-Cycle Diesel Engine, International Offshore and Polar Engineering Conference, April 10-15, 1994, Osaka, Japan.

[3.34] Thompson R. V., Development of a Depth Independent Closed-Cycle Diesel Engine, Offshore Technology Conference, May 4-7, 1981, Houston, Texas, Paper No. OTC 4031.

[3.35] Krey G., Utilization of the Cold by LNG Vaporization with Closed-Cycle Gas Turbine, Transactions of ASME, Journal of Engineering Power, April 1980, Paper No. 79-GT-84.

[3.36] Spillmann W., The Closed Cycle Gas Turbine for Nonconventional Applications, Transactions of ASME, Journal of Engineering Power, June 1966, Paper No. 66GT/CLC-8.

[3.37] Seery D., Sangiovanni J., Engineering Development of a Coal-Fired High Performance Power Generating System, Report to the U.S. Department of Energy, Report Number DE-AC22-95PC95144, United Technologies Research Center, www.netl.doe.gov/publications/proceedings/97/97ps/ps.pdf/PS1-5.pdf, March 9, 2004. [3.38] U.S. Department of Energy, Indirect-Fired Power Systems (IFPS), www.netl.doe.gov/publications/factsheets/program/prog032.pdf., March 10, 2004 [3.39] Ruby J., Robson F., Seery D., High Performance Power Systems (HIPPS)Opportunities and Options for the Coal-Fired Power Plant Market, www.netl.doe.gov/publications/proceedings/99/99korea/ruby.pdf, March 9, 2004. 
[3.40] Hurley J.P., Seery D.J., Robson F.L., Experience with an ODS High-Temperature Heat Exchanger in a Pilot-Scale HIPPS Plant, Materials at High Temperatures, Science Reviews, Vol. 20, No. 1, pg. 39-40, 2003.

[3.41] U.S. Department of Energy Homepage, Vision 21-The Ultimate Power Plant, www.fossil.energy.gov/programs/powersystems/vision21/index.html, Aug 3, 2004. [3.42] Saravanamuttoo HIH., Rogers GFC., Cohen H., Gas Turbine Theory $5^{\text {th }}$ ed., Prentice Hall, Harlow, 2001.

[3.43] Stahl, K., Neergaard M., IGCC Power Plant for Biomass Utilization, Varnamo, Sweden, Biomass and Bioenergy, Elsevier Science Ltd. Vol. 15, No. 3, pg. 205-211, 1988.

\section{Chapter 4}

[4.1] RETScreen Database - Canadian Remote Communities http://cedrl.mets.nrcan.gc.ca/e/412/retscreen_database_e.html, December 3, 2003.

[4.2] Heintzman, A., Solomon, E., Fueling the Future, House of Anansi Press Inc., Toronto, 2003.

[4.3] National Energy Foundation, Energy to Carbon Dioxide Converter, www.natenergy.org.uk/convert.htm, August 19, 2004.

\section{Chapter 5}

[5.1] Roberts S. K., Sjolander S. A., Semi-Closed Cycle $\mathrm{O}_{2} / \mathrm{CO}_{2}$ Combustion Gas Turbines: Influence of Fluid Properties on the Aerodynamic Performance of the Turbomachinery, Proceedings of ASME Turbo Expo, ASME Turbo Expo: Land, Sea, \& Air, Amsterdam, Netherlands, June 3-6, 2002.

[5.2] Moran M., Shapiro H., Fundamentals of Engineering Thermodynamics $4^{\text {th }}$ ed., John Willey \& Sons, New York, 2000.

[5.3] Turns S.R., An Introduction to Combustion: Concepts and Applications, McGraw-Hill, Boston, 2000. 
[5.4] Touloukian Y.S., Liley P.E., Saxena S.C., Thermophysical Properties of Matter, Volume 3 Thermal Conductivity, Nonmetallic Liquids and Gasses, IFI/Plenum, New York-Washington, 1970.

[5.5] Touloukian Y.S., Makita T., Thermophysical Properties of Matter, Volume 6 Specific Heat, Nonmetallic Liquids and Gasses, IFI/Plenum, New York-Washington, 1970.

[5.6] Touloukian Y.S., Makita T., Thermophysical Properties of Matter, Volume 11, Viscosity, IFI/Plenum, New York-Washington, 1970.

[5.7] Saravanamuttoo HIH., Rogers GFC., Cohen H., Gas Turbine Theory $5^{\text {th }}$ ed., Prentice Hall, Harlow, 2001.

\section{Chapter 6}

[6.1] Lee J.C., Campbell J. Jr., Wright D.E. Closed-Cycle Gas Turbine Working Fluids, Transactions of ASME, ASME Gas Turbine Conference and Products Show, March 1013, 1980, Paper No. 801007.

[6.2] McDonald C.F., Boland C.R., The Nuclear Closed-Cycle Gas Turbine (HTGRGT)-Dry Cooled Commercial Power Plant Studies, Transactions of ASME, Journal of Engineering Power, January 1981, Paper No. 80-GT-82.

[6.3] Roberts S. K., Sjolander S. A., Semi-Closed Cycle $\mathrm{O}_{2} / \mathrm{CO}_{2}$ Combustion Gas Turbines: Influence of Fluid Properties on the Aerodynamic Performance of the Turbomachinery, Proceedings of ASME Turbo Expo, ASME Turbo Expo: Land, Sea, \& Air, Amsterdam, Netherlands, June 3-6, 2002.

[6.4] Holman, J.P., Heat Transfer $6^{\text {th }}$ ed., McGraw-Hill, New York, New York, 1986.

[6.5] Osterle F., Teranasthiarphan K., A Thermodynamic Assessment of Carbon Dioxide as a Working Fluid in closed Gas Turbine Cycles, Proceedings of IECEC, August 18-22, 1975, Newark, Delaware, Paper No. 759163.

[6.6] Ulizar I., Pilidis P., A Semiclosed-Cycle Gas Turbine with Carbon-Dioxide-Argon as a Working Fluid, Transactions of ASME, Journal of Engineering for Gas Turbines and Power, Vol. 119, July 1997, Paper No. 96-GT-345. 
[6.7] Krey G., Utilization of the Cold by LNG Vaporization with Closed-Cycle Gas Turbine, Transactions of ASME, Journal of Engineering Power, April 1980, Paper No. 79-GT-84.

[6.8] Dobler F. X., Rackley R. A., Closed Gas Turbine Marine Power Systems, Proceedings of IECEC, August 18-22, 1975, Newark, Delaware, Paper No. 759160.

[6.9] Tomashefsky, S., Marks M., Distributed Generation Strategic Plan, California Energy Commission, June 2002.

[6.10] Saravanamuttoo HIH., Rogers GFC., Cohen H., Gas Turbine Theory $5^{\text {th }} e d$., Prentice Hall, Harlow, 2001.

[6.11] Garrett® Engine Boosting Systems homepage, www.egarrett.com/technology/tech_1050c.jsp, July 2003.

[6.12] BorgWarner Turbo Systems homepage, www.3k-warner.de/en/products/t_temp.asp, July 2003.

\section{Chapter 7}

[7.1] White F.M., Fluid Mechanics $2^{\text {nd }}$ ed., McGraw-Hill Inc., New York, 1986.

[7.2] Strub, R.A., Bonciani, L., Borer C.J., Casey M.V., Cole S.L., Cook B.B., Kotzur J., Simon H., and Strite M.A., Influence of the Reynolds Number on the Performance of Centrifugal Compressors, ASME Journal of Turbomachinery, Vol. 109, pg. 541-544, 1987.

[7.3] Wernet M.P., Bright M. M., Skoch G.J., An Investigation of Surge in a HighSpeed Centrifugal Compressor Using Digital PIV, Transactions of ASME, ASME Journal of Turbomachinery, Vol. 123, pg. 418-428, April 2001.

[7.4] Kuppan T., Heat Exchanger Design Handbook, Mercer Dekker, New York, New York, 2000.

[7.5] Peyton K.I., Fuel Field Manual, Sources and Solutions to Performance Problems, McGraw-Hill, New York, New York, 1998. 


\section{Chapter 8}

[8.1] Kuppan T., Heat Exchanger Design Handbook, Mercer Dekker, New York, New York, 2000.

[8.2] Gauthier, J.E.D., Gas Turbine Theory Lecture Notes, Fall 2002.

[8.3] Des Champs Technologies, Product Catalogue; www.deschamps.com, 2004.

[8.4] Kakaç, S., Liu, H., Heat Exchangers-Selection, Rating, and Thermal Design, CRC Press LLC, Boca Raton, Florida, 1998.

[8.5] Holman, J.P., Heat Transfer $6^{\text {th }}$ ed., McGraw-Hill, New York, New York, 1986.

[8.6] Standards of Tubular Exchanger Manufacturers Association $7^{\text {th }}$ ed., Tubular Exchangers Manufacturers Association, Inc., Tarrytown, New York, 1988.

[8.7] Palen J.W., Heat Exchanger Sourcebook, Hemisphere Publishing Corporation, New York, 1986.

[8.8] Phadke P.S., Determining Tube Counts for Shell-and-Tube-Exchangers, Chemical Engineering, pg. 65-68, September 3, 1984.

[8.9] Garrett-Price B.A., Smith S.A., Watts R., Knudsen J.G., Marner W.JU., Suitor J.W., Fouling of Heat Exchangers-Characteristics, Costs, Prevention, Control, and Removal, Noyes Publications, Park Ridge, New Jersey, 1985.

[8.10] Kays W. M., and London, A.L., Compact Heat Exchangers $3^{\text {rd }}$ ed., Krieger Publishing Company, Malabar, Florida, 1998.

[8.11] Fintube Technologies, Inc., homepage, www.fintubetech.com/escoa/, July 2004.

\section{Chapter 9}

[9.1] Profins Inc., www.highperfromancetube.com, September 2003.

[9.2] Unity Tube Inc., www.unitytube.com, September 2003.

[9.3] Kuppan T., Heat Exchanger Design Handbook, Mercer Dekker, New York, New York, 2000.

[9.4] Standards of Tubular Exchanger Manufacturers Association $7^{\text {th }}$ ed., Tubular Exchangers Manufacturers Association, Inc., Tarrytown, New York, 1988. 


\section{Appendix A}

\section{Detailed Calculations of Potential Energy Savings and Carbon Dioxide Emissions Savings}




\section{Potential Energy Savings}

\section{Waste Oil CBC Engine}

It has been depicted in the sales projection that 30 waste-oil fired $C B C$ engines would be sold to 30 communities. It has been estimated that there are 20 communities in Nunavut, Nunavik, and Northern Labrador that have sufficient population to implement a CBC engine. Another 10 communities in Northwest Territories and Yukon have sufficient population for a waste-oil fired engine.

The main sources of waste oil generated by communities is by power generation stations and transportation. The quantity of waste oil generated by the communities will vary according to each region due to differences in population. Larger power generation stations are expected in Yukon and Northwest Territories since these regions are more populated. Moreover, since Yukon and Northwest Territories have more roads, these regions have a greater quantity of vehicles. Therefore, it is expected that this region will generate more waste oil. As a result, separate estimate of waste oil availability are made for the two regions.

The amount of waste oil produced by a community in Nunavut from a power generation source is estimated as follows:

\section{Oil Changes Per Year For a Diesel Engine}

frequency $_{\text {oil_changes }}:=\frac{1}{1500 \mathrm{hr}} \quad$ Oil change is required every 1500 hours

frequency oil_changes $=5.8 \frac{1}{\mathrm{yr}}$

Mass of Waste Oil per Oil Change

Density of lubricating oil is between $850-950 \mathrm{~kg} / \mathrm{m}^{3}$.

$\rho_{\text {oil }}:=900 \cdot \frac{\mathrm{kg}}{\mathrm{m}^{3}}$

300 gallons of oil are required per oil change for an average sized diesel engine in a power generation station.

$$
\begin{aligned}
& \mathrm{m}_{\text {oil_change }}:=300 \cdot \mathrm{gal} \cdot\left(\rho_{\text {oil }}\right) \\
& \mathrm{m}_{\text {oil_change }}=1022.1 \mathrm{~kg}
\end{aligned}
$$

Amount of Oil Utilized by a Diesel Engine Per Year

$$
\begin{aligned}
& \mathrm{m}_{\text {oil }}:=\text { frequency }_{\text {oil_changes }} \cdot \mathrm{m}_{\text {oil_change }} \\
& \mathrm{m}_{\text {oil }}=5973 \frac{\mathrm{kg}}{\mathrm{yr}}
\end{aligned}
$$


Typical Calorific Value is Between $42 \mathrm{MJ}$ to $45 \mathrm{MJ}$

Calorific $:=42 \cdot 10^{6} \frac{\mathrm{J}}{\mathrm{kg}}$

Amount of Energy from Waste Oil Generated by a Community per Year

$\mathrm{GJ}:=10^{9} \mathrm{~J}$

$\mathrm{E}_{\text {Power_Gen }}:=\mathrm{m}_{\mathrm{oil}} \cdot$ Calorific

$\mathrm{E}_{\text {Power_Gen }}=250.9 \frac{\mathrm{GJ}}{\mathrm{yr}}$

It is foreseen that a production $\mathrm{CBC}$ engine will have an overall thermal to electrical conversion efficiency of 25 percent.

$\eta_{\mathrm{CBC}}:=25 \%$

It is also estimated that 85 percent of waste heat may be recovered for space heating.

$\varepsilon_{\text {waste_heat }}:=85 \%$

$\mathrm{E}_{\text {displaced_Power_Gen }}:=\mathrm{E}_{\text {Power_Gen }} \cdot \eta_{\mathrm{CBC}}+\mathrm{E}_{\text {Power_Gen }} \cdot\left(1-\eta_{\mathrm{CBC}}\right) \varepsilon_{\text {waste_heat }}$

$\mathrm{E}_{\text {displaced_Power_Gen }}=222.6 \frac{\mathrm{GJ}}{\mathrm{yr}}$

This is the energy saved from utilizing waste oil for combined heat and power application instead of direct incineration as is current practice. The value is presented per engine per year, or per community per year, since it is expected that one engine per community would be implemented.

The amount of waste oil produced by a community in Nunavut from motor vehicles is estimated as follows:

A motor vehicle count in Nunavut has been obtained from The Department of Community Government and Transportation, Motor Vehicle Division. The number of registered cars in Nunavut is counted to be 3543 , the number of registered trucks is 563 . There are currently 1134 ATVs registered in Nunavut, however, it has been specified that this is low since ATVs are not required to be registered as long as they are not used on public roads. The number of ATVs is probably closer to 3000 , with an estimated $75 \%$ (or 2250 ) of ATVs being 4 stroke. Moreover, there are 47 motorcycles, where it is estimated that about $65 \%$, or 30 , are 4 stroke. It is expected that each type of vehicle requires an oil change 4 times a year. It is assumed that Motorcycles and ATVs require $2 \mathrm{~L}$ of oil, cars require $4.5 \mathrm{~L}$ of oil, and trucks require $8 \mathrm{~L}$ of oil per oil change. It is expected that a portion of the oil is burned off, and ATVs will generate 1.5L of waste oil, cars $4 \mathrm{~L}$ of waste oil, and trucks $7 \mathrm{~L}$ of waste oil. 
The amount of waste oil generated by the vehicles is estimated below:

ATVs and Motorcycles

$\mathrm{m}_{\text {atv }}:=2280 \cdot \frac{4}{\mathrm{yr}} \cdot 1.5 \mathrm{~L} \cdot \rho_{\mathrm{oil}} \quad \mathrm{m}_{\mathrm{atv}}=1.2 \times 10^{4} \frac{\mathrm{kg}}{\mathrm{yr}}$

Cars

$\mathrm{m}_{\text {cars }}:=3543 \cdot \frac{4}{\mathrm{yr}} \cdot 4 \mathrm{~L} \cdot \rho_{\text {oil }} \quad \mathrm{m}_{\text {cars }}=5.1 \times 10^{4} \frac{\mathrm{kg}}{\mathrm{yr}}$

Trucks

$\mathrm{m}_{\text {trucks }}:=563 \cdot \frac{4}{\mathrm{yr}} \cdot 7 \mathrm{~L} \cdot \rho_{\text {oil }} \quad \mathrm{m}_{\text {trucks }}=1.4 \times 10^{4} \frac{\mathrm{kg}}{\mathrm{yr}}$

The total waste oil produced by vehicles is:

$\mathrm{m}_{\text {vehicle }}:=\mathrm{m}_{\mathrm{atv}}+\mathrm{m}_{\text {cars }}+\mathrm{m}_{\text {trucks }} \quad \mathrm{m}_{\text {vehicle }}=7.8 \times 10^{4} \frac{\mathrm{kg}}{\mathrm{yr}}$

It should be noted that this estimate is conservative since waste oil generated by inboard boats and airports have not been included.

It is expected that the $C B C$ engine would be implemented into communities with a population of over 900 people; there are 11 communities with sufficient population in Nunavut and the total population of these communities is 19230 . The amount of waste oil generated from vehicles calculated above includes smaller communities where a CBC engine would not be implemented. The waste oil generated is expressed (below) per larger community by taking a fraction of population living in larger communities by the total number of people residing in Nunavut and dividing it by the number of large communities.

$\mathrm{m}_{\text {community }}:=\frac{\mathrm{m}_{\text {vehicle }} \cdot \frac{19230}{26745}}{11}$

$\mathrm{m}_{\text {community }}=5067 \frac{\mathrm{kg}}{\mathrm{yr}}$

The potential energy savings due to utilizing the waste oil generated by vehicles is calculated belon This value is per community per year.

$\mathrm{E}_{\text {vehicle }}:=\mathrm{m}_{\text {community }} \cdot$ Calorific

$\mathrm{E}_{\text {vehicle }}=212.8 \frac{\mathrm{GJ}}{\mathrm{yr}}$

$\mathrm{E}_{\text {displaced_Vehicle }}:=\mathrm{E}_{\mathrm{vehicle}} \cdot \eta_{\mathrm{CBC}}+\mathrm{E}_{\mathrm{vehicle}} \cdot\left(1-\eta_{\mathrm{CBC}}\right) \varepsilon_{\text {waste_heat }}$

$\mathrm{E}_{\text {displaced_Vehicle }}=188.9 \frac{\mathrm{GJ}}{\mathrm{yr}}$ 
The total energy savings due utilization of waste oil from power generation and transportation is estimated as:

$$
\begin{aligned}
& \mathrm{E}_{\mathrm{TOT} \_ \text {Nunavut }}:=\mathrm{E}_{\text {displaced_Power_Gen }}+\mathrm{E}_{\text {displaced_Vehicle }} \\
& \mathrm{E}_{\mathrm{TOT} \text { _Nunavut }}=411.5 \frac{\mathrm{GJ}}{\mathrm{yr}}
\end{aligned}
$$

This value may be used for 11 units (or communities) to be implemented in Nunavut. It is expected that a similar amount of waste oil would be produced by communities in Nunavik. There are 5 communities with sufficient population (of over 900 people) in Nunavik. Moreover, at least 4 communities in Northern Labrador region would have sufficient population, for a total of 20 communities.

Therefore, for the initial $20 \mathrm{CBC}$ units, the amount of energy savings is $410 \mathrm{GJ}$ (two significant figures).

The remaining waste oil units could be implemented in Northwest Territories and Yukon. There are seven communities in GNWT with sufficient population, and three in Yukon. It is expected that the amount of vehicles would be greater due to a greater number of highways available. Registered vehicle data was available from the Government of Northwest Territories Bureau of Statistics Division. The amount of waste oil generated in GNWT is estimated as before.

$$
\begin{aligned}
& \mathrm{m}_{\text {motorcycles_GNWT }}:=427 \cdot 65 \% \cdot \frac{4}{\mathrm{yr}} \cdot 1.5 \mathrm{~L} \cdot \rho_{\text {oil }} \\
& \mathrm{m}_{\text {cars_GNWT }}:=24236 \cdot \frac{4}{\mathrm{yr}} \cdot 4 \mathrm{~L} \cdot \rho_{\text {oil }} \\
& \mathrm{m}_{\text {Trucks_GNWT }}:=3121 \cdot \frac{4}{\mathrm{yr}} \cdot 7 \mathrm{~L} \cdot \rho_{\mathrm{oil}} \\
& \mathrm{m}_{\text {vehicle_GNWT }}:=\mathrm{m}_{\text {motorcycles_GNWT }}+\mathrm{m}_{\text {cars_GNWT }}+\mathrm{m}_{\text {Trucks_GNWT }} \\
& \mathrm{m}_{\text {vehicle_GNWT }}=4.3 \times 10^{5} \frac{\mathrm{kg}}{\mathrm{yr}}
\end{aligned}
$$

Similarly, the amount of waste oil is expressed on a larger community bases. The population of GNWT is 37,360 , with 28,775 people living in the 7 communities with sufficiently large population.

$$
\begin{aligned}
\mathrm{m}_{\mathrm{GNWT}} & :=\frac{\mathrm{m}_{\text {vehicle_GNWT }} \cdot \frac{28775}{37360}}{7} \\
\mathrm{~m}_{\mathrm{GNWT}} & =4.7 \times 10^{4} \frac{\mathrm{kg}}{\mathrm{yr}}
\end{aligned}
$$


The energy savings potential due to utilizing waste oil produced by vehicles is:

$\mathrm{E}_{\mathrm{GNWT}}:=\mathrm{m}_{\mathrm{GNWT}} \cdot$ Calorific

$\mathrm{E}_{\mathrm{GNWT}}=1983 \frac{\mathrm{GJ}}{\mathrm{yr}}$

$\mathrm{E}_{\text {displaced_Vehicle_GNWT }}:=\mathrm{E}_{\mathrm{GNWT}} \cdot \eta_{\mathrm{CBC}}+\mathrm{E}_{\mathrm{GNWT}} \cdot\left(1-\eta_{\mathrm{CBC}}\right) \varepsilon_{\text {waste_heat }}$

$\mathrm{E}_{\text {displaced_Vehicle_GNWT }}=1760 \frac{\mathrm{GJ}}{\mathrm{yr}}$

The energy savings due to power generation is adjusted for population variation in Northwest Territories:

$E_{\text {displaced_Power_Gen_GNWT }}:=E_{\text {displaced_Power_Gen }} \cdot \frac{28775}{19230}$

$\mathrm{E}_{\text {displaced_Power_Gen_GNWT }}=333.1 \frac{\mathrm{GJ}}{\mathrm{yr}}$

Total energy savings, due to power generation and transportation in Northwest Territories is calculated below. It is expected that communities in Yukon would have similar potential energy savings.

$\mathrm{E}_{\text {Tot_GNWT }}:=\mathrm{E}_{\text {displaced_Power_Gen_GNWT }}+\mathrm{E}_{\text {displaced_Vehicle_GNWT }}$

$\mathrm{E}_{\text {Tot_GNWT }}=2093 \frac{\mathrm{GJ}}{\mathrm{yr}}$

Therefore, for the later $10 \mathrm{CBC}$ waste oil units, the amount of energy savings is $2090 \mathrm{GJ}$ (three significant figures). This estimate should be considered conservative since airport operations, boat operations, and mining operations are not included in the quantity of waste oil estimate.

\section{Biomass CBC Engine}

The Biomass CBC engine is expected to generate $25 \mathrm{~kW}$. The potential energy conversion efficiency of $40 \%$ is foreseen through CBC engine development.

$\mathrm{kJ}:=1000 \mathrm{~J}$

$\mathrm{P}_{\mathrm{CBC}}:=25 \mathrm{~kW}$

$\eta_{\text {CBC_Bio }}:=40 \%$

Amount of energy necessitated to obtain $25 \mathrm{~kW}$ of power is calculated below and expressed on a yearly basis.

$$
\mathrm{E}_{\mathrm{CBC}}:=\frac{\mathrm{P}_{\mathrm{CBC}}}{\eta_{\text {CBC_Bio }}} \quad \mathrm{E}_{\mathrm{CBC}}=1972 \frac{\mathrm{GJ}}{\mathrm{yr}}
$$


The power generated may be expressed is terms of electrical energy:

$\mathrm{E}_{\mathrm{CBC} \_ \text {electical }}:=\mathrm{E}_{\mathrm{CBC}} \cdot \eta_{\mathrm{CBC} \_ \text {Bio }}$

$\mathrm{E}_{\text {CBC_electical }}=789 \frac{\mathrm{GJ}}{\mathrm{yr}}$

The waste heat generated by the $\mathrm{CBC}$ is $60 \%$ of the heat input. It is estimated that $85 \%$ of the waste heat may be recovered.

$\mathrm{E}_{\text {waste_heat_Biomass }}:=\mathrm{E}_{\mathrm{CBC}} \cdot\left(1-\eta_{\mathrm{CBC} \_ \text {Bio }}\right) \cdot \varepsilon_{\text {waste_heat }}$

$\mathrm{E}_{\text {waste_heat_Biomass }}=1006 \frac{\mathrm{GJ}}{\mathrm{yr}}$

Total Energy Savings for Biomass CBC Engine per Year

$\mathrm{E}_{\mathrm{CBC} \_ \text {Biomass }}:=\mathrm{E}_{\mathrm{CBC} \_ \text {electical }}+\mathrm{E}_{\text {waste_heat_Biomass }}$

$\mathrm{E}_{\mathrm{CBC} \_ \text {Biomass }}=1795 \frac{\mathrm{GJ}}{\mathrm{yr}}$

These values are utilized along with the implementation schedule, as depicted in Chapter 4.1.3, Table 4.2.

A - 7 


\section{Carbon Dioxide Emissions Savings Calculations}

\section{Waste Oil Units}

The carbon dioxide emission savings from utilizing waste oil that would otherwise be incinerated is a sum of the emissions savings due to power generation and space heating.

The conversion factor for $\mathrm{CO}_{2}$ production from a power generation source is [4.3]:

$$
\begin{aligned}
& \mathrm{CF}_{\mathrm{GRID}}:=0.43 \frac{\mathrm{kg}}{\mathrm{kW} \cdot \mathrm{hr}} \\
& \mathrm{CO}_{2} \text { _Nunavut_Grid }:=25 \mathrm{~kW} \cdot \mathrm{CF}_{\mathrm{GRID}} \\
& \mathrm{CO}_{2} \text { _Nunavut_Grid }=104 \frac{\mathrm{ton}}{\mathrm{yr}}
\end{aligned}
$$

The conversion factor for $\mathrm{CO}_{2}$ production from space heating burning diesel is [4.3]:

$$
\mathrm{CF}_{\text {Diesel }}:=74 \frac{\mathrm{kg}}{\mathrm{GJ}}
$$

Utilizing this waste heat for space heating instead of supplemental burning of heating fuel in a furnace has the potential to save carbon dioxide emissions of:

$$
\begin{aligned}
& \mathrm{CO}_{2} \text { Nunavut_Heat }:=\mathrm{E}_{\text {TOT_Nunavut }}\left(1-\eta_{\mathrm{CBC}}\right) \cdot \boldsymbol{\varepsilon}_{\text {waste_heat }} \cdot \mathrm{CF}_{\text {Diesel }} \\
& \mathrm{CO}_{2} \text { Nunavut_Heat }=21 \frac{\mathrm{ton}}{\mathrm{yr}}
\end{aligned}
$$

Total emission savings for the initial 20 units

$$
\begin{aligned}
& \mathrm{CO}_{2} \text { _emission_savings_Nunavut }:=\mathrm{CO}_{2} \text { NNunavut_Grid }+\mathrm{CO}_{2} \_ \text {Nunavut_Heat } \\
& \mathrm{CO}_{2} \text { emission_savings_Nunavut }=125 \frac{\text { ton }}{\mathrm{yr}}
\end{aligned}
$$

Similar evaluation is conducted for the emission savings for the later 10 units, to be implemented in GNWT and Yukon.

The same $25 \mathrm{~kW}$ is generated in GNWT and Yukon, and therefore, Carbon Dioxide emissions savings due to utilizing waste oil is:

$$
\begin{aligned}
& \mathrm{CO}_{2} \text { GNWT_Grid }:=\mathrm{CO}_{2} \text { Nunavut_Grid } \\
& \mathrm{CO}_{2} \text { GNWT_Grid }=104 \frac{\text { ton }}{\mathrm{yr}}
\end{aligned}
$$


Carbon Dioxide emissions savings due to space heating with waste oil is:

$\mathrm{CO}_{2}$ GNWT_Heat $:=\mathrm{E}_{\text {Tot_GNWT }} \cdot\left(1-\eta_{\mathrm{CBC}}\right) \cdot \varepsilon_{\text {waste_heat }} \cdot \mathrm{CF}_{\text {Diesel }}$

$\mathrm{CO}_{2}$ GNWT_Heat $_{-}=109 \frac{\mathrm{ton}}{\mathrm{yr}}$

Total emissions savings from combined heat and power is:

$\mathrm{CO}_{2}$ emission_savings_GNWT $:=\mathrm{CO}_{2}$ _GNWT_Grid $+\mathrm{CO}_{2}$ GNWT_Heat

$\mathrm{CO}_{2}$ _emission_savings_GNWT $=213 \frac{\text { ton }}{\mathrm{yr}}$

\section{Biomass CBC Units}

Power generation from an alternative energy source has an emissions savings of:

$\mathrm{CO}_{2}$ BBiomass_Grid $:=25 \mathrm{~kW} \cdot \mathrm{CF}_{\mathrm{GRID}}$

$\mathrm{CO}_{2}$ Biomass_Grid $=104 \frac{\text { ton }}{\mathrm{yr}}$

Space Heating by an alternative energy source has a savings of

$\mathrm{CO}_{2}$ BBiomass_Heat $:=\mathrm{E}_{\text {waste_heat_Biomass }} \cdot \mathrm{CF}_{\text {Diesel }}$

$\mathrm{CO}_{2} \_$Biomass_Heat $=82 \frac{\text { ton }}{\mathrm{yr}}$

Additionally, power generation from an alternative energy source

$\mathrm{CO}_{2}$ _Emission_savings_biomass $:=\mathrm{CO}_{2}$ _Biomass_Heat $+\mathrm{CO}_{2}$ _Biomass_Grid

$\mathrm{CO}_{2}$ _Emission_savings_biomass $=186 \frac{\text { ton }}{\mathrm{yr}}$ 
Appendix B

\section{Properties of Gasses}


Table B.1: Properties of Selected Gasses

\begin{tabular}{|c|c|c|c|c|c|}
\hline Gas & $\begin{array}{c}\text { Molecular } \\
\text { Weight } \\
{[\mathbf{k g} / \mathbf{k m o l}]}\end{array}$ & $\begin{array}{c}\text { Specific } \\
\text { Heat, Cp } \\
{[\mathbf{k J} / \mathbf{k g} \text { K] }]}\end{array}$ & $\begin{array}{c}\text { Specific } \\
\text { Heat } \\
\text { Ratio } \\
\Gamma\end{array}$ & $\begin{array}{c}\text { Thermal } \\
\text { Conductivity, } \\
\mathbf{k} \\
{[\mathbf{W} / \mathbf{m} * \mathbf{K}]}\end{array}$ & $\begin{array}{c}\text { Prandtl } \\
\text { Number, } \\
\mathbf{N u}\end{array}$ \\
\hline Air & 28.97 & 1.004 & 1.40 & 0.0261 & 0.707 \\
\hline Argon & 39.94 & 0.520 & 1.667 & 0.0177 & 0.643 \\
\hline $\begin{array}{c}\text { Carbon } \\
\text { Dioxide }\end{array}$ & 44.01 & 0.849 & 1.285 & 0.0166 & 0.770 \\
\hline Helium & 4.003 & 5.200 & 1.667 & 0.149 & 0.710 \\
\hline Nitrogen & 28.01 & 1.042 & 1.40 & 0.0259 & 0.713 \\
\hline Xenon & 131.30 & 0.158 & 1.667 & 0.00562 & 0.63 \\
\hline
\end{tabular}

All values are at quoted for $298 \mathrm{~K}$

Table B.2: Coefficients for Variation of Specific Heat and Enthalpy for Air [5.2]

\begin{tabular}{|c|c|c|}
\hline Coefficients for Air & \multicolumn{2}{|c|}{ Temperature Range } \\
\hline & $\mathbf{2 0 0 K - 8 0 0 K}$ & $\mathbf{8 0 0 K - 2 2 0 0 K}$ \\
\hline $\mathbf{a}_{\mathbf{0}}$ & $0.24336328 \mathrm{E} 00$ & $0.19075549 \mathrm{E} 00$ \\
\hline $\mathbf{a}_{1}$ & $-0.32921648 \mathrm{E}-04$ & $0.12752498 \mathrm{E}-03$ \\
\hline $\mathbf{a}_{2}$ & $0.47395140 \mathrm{E}-07$ & $-0.54651988 \mathrm{E}-07$ \\
\hline $\mathbf{a}_{3}$ & $0.10126885 \mathrm{E}-09$ & $0.89378182 \mathrm{E}-11$ \\
\hline $\mathbf{a}_{4}$ & $-0.89883655 \mathrm{E}-13$ & $0.00000000 \mathrm{E} 00$ \\
\hline $\mathbf{C H}$ & $-0.40567100 \mathrm{E} 00$ & $0.11317630 \mathrm{E} 02$ \\
\hline
\end{tabular}

B-2 
Table B.3: Coefficients for Variation of Specific Heat and Enthalpy for Carbon Dioxide [5.2]

\begin{tabular}{|c|c|c|}
\hline $\begin{array}{c}\text { Coefficients for } \\
\mathbf{C 0}_{\mathbf{2}}\end{array}$ & \multicolumn{2}{|c|}{ Temperature Range } \\
\hline & $\mathbf{1 0 0 K - 1 0 0 0 K}$ & $\mathbf{1 0 0 0 K - 5 0 0 0 K}$ \\
\hline $\mathbf{a}_{\mathbf{0}}$ & $0.02275724 \mathrm{E} 02$ & $0.04453623 \mathrm{E} 02$ \\
\hline $\mathbf{a}_{\mathbf{1}}$ & $0.09922072 \mathrm{E}-01$ & $0.03140168 \mathrm{E}-01$ \\
\hline $\mathbf{a}_{\mathbf{2}}$ & $-0.10409113 \mathrm{E}-04$ & $-0.12784105 \mathrm{E}-05$ \\
\hline $\mathbf{a}_{3}$ & $0.06866686 \mathrm{E}-07$ & $0.02393996 \mathrm{E}-08$ \\
\hline $\mathbf{a}_{4}$ & $-0.02117280 \mathrm{E}-10$ & $-0.16690333 \mathrm{E}-13$ \\
\hline $\mathbf{C H}$ & $-0.04837314 \mathrm{E} 06$ & $-0.04896696 \mathrm{E} 06$ \\
\hline
\end{tabular}

Table B.4: Coefficients for Variation of Specific Heat and Enthalpy for Nitrogen Gas [5.2]

\begin{tabular}{|c|c|c|}
\hline $\begin{array}{c}\text { Coefficient for } \\
\mathbf{N}_{\mathbf{2}}\end{array}$ & \multicolumn{2}{|c|}{ Temperature Range } \\
\hline & $\mathbf{1 0 0 K - 1 0 0 0 K}$ & $\mathbf{1 0 0 0 K - 5 0 0 0 K}$ \\
\hline $\mathbf{a}_{\mathbf{0}}$ & $0.03298677 \mathrm{E} 02$ & $0.02926640 \mathrm{E} 02$ \\
\hline $\mathbf{a}_{1}$ & $0.14082404 \mathrm{E}-02$ & $0.14879768 \mathrm{E}-02$ \\
\hline $\mathbf{a}_{\mathbf{2}}$ & $-0.03963222 \mathrm{E}-04$ & $-0.05684760 \mathrm{E}-05$ \\
\hline $\mathbf{a}_{3}$ & $0.05641515 \mathrm{E}-07$ & $0.10097038 \mathrm{E}-09$ \\
\hline $\mathbf{a}_{4}$ & $-0.02444854 \mathrm{E}-10$ & $-0.06753351 \mathrm{E}-13$ \\
\hline $\mathbf{C H}$ & $-0.10208999 \mathrm{E} 04$ & $-0.09227977 \mathrm{E} 04$ \\
\hline
\end{tabular}

B-3 


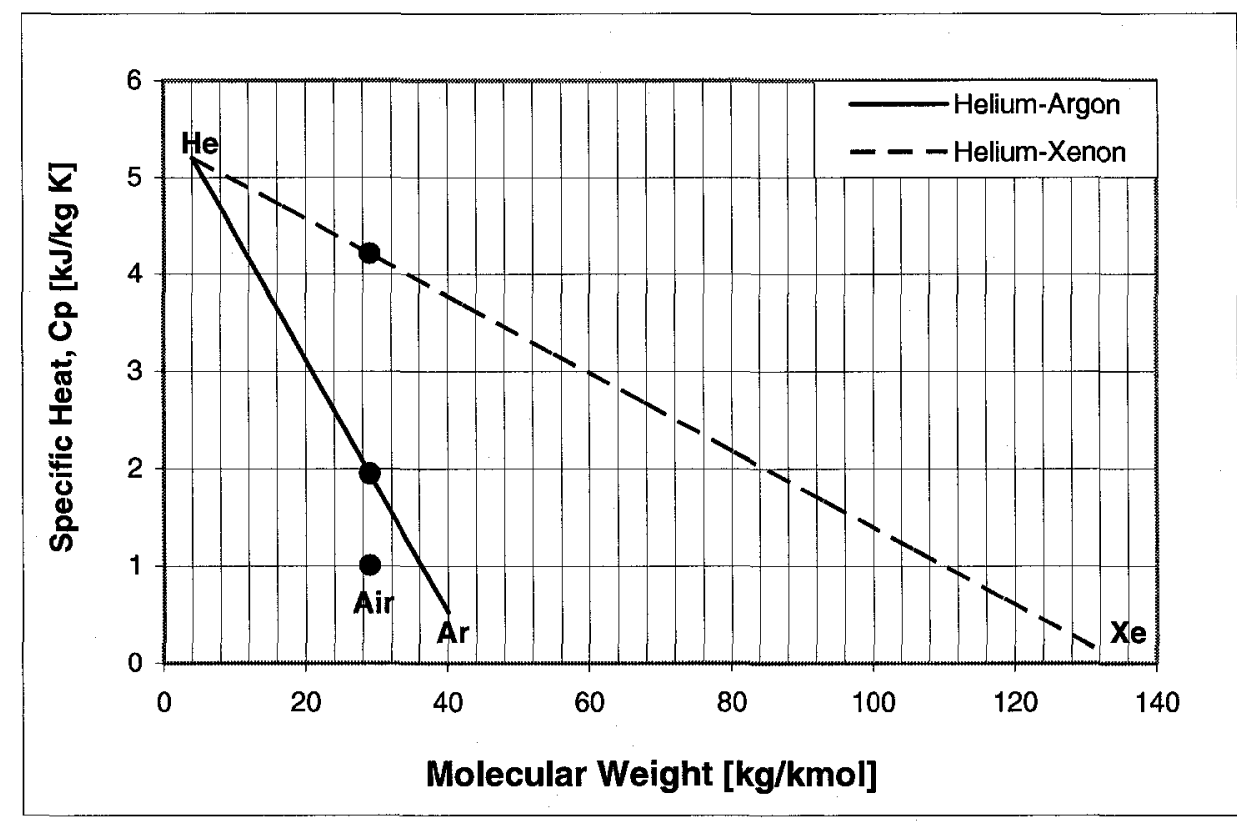

Figure B.1: Specific Heat of Helium-Argon and Helium Xenon Mixtures [5.5]

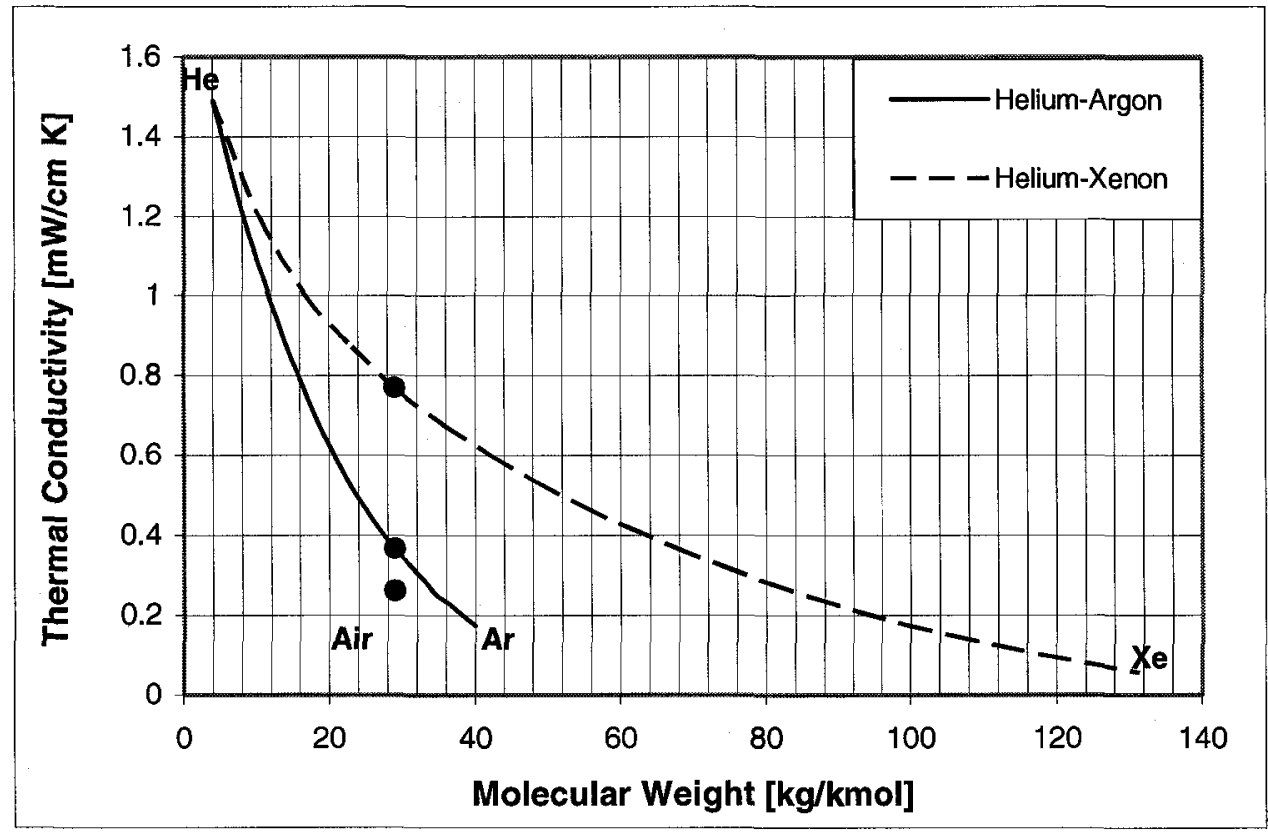

Figure B.2: Thermal Conductivity of Helium-Argon and Helium Xenon Mixtures [5.4]

B-4 


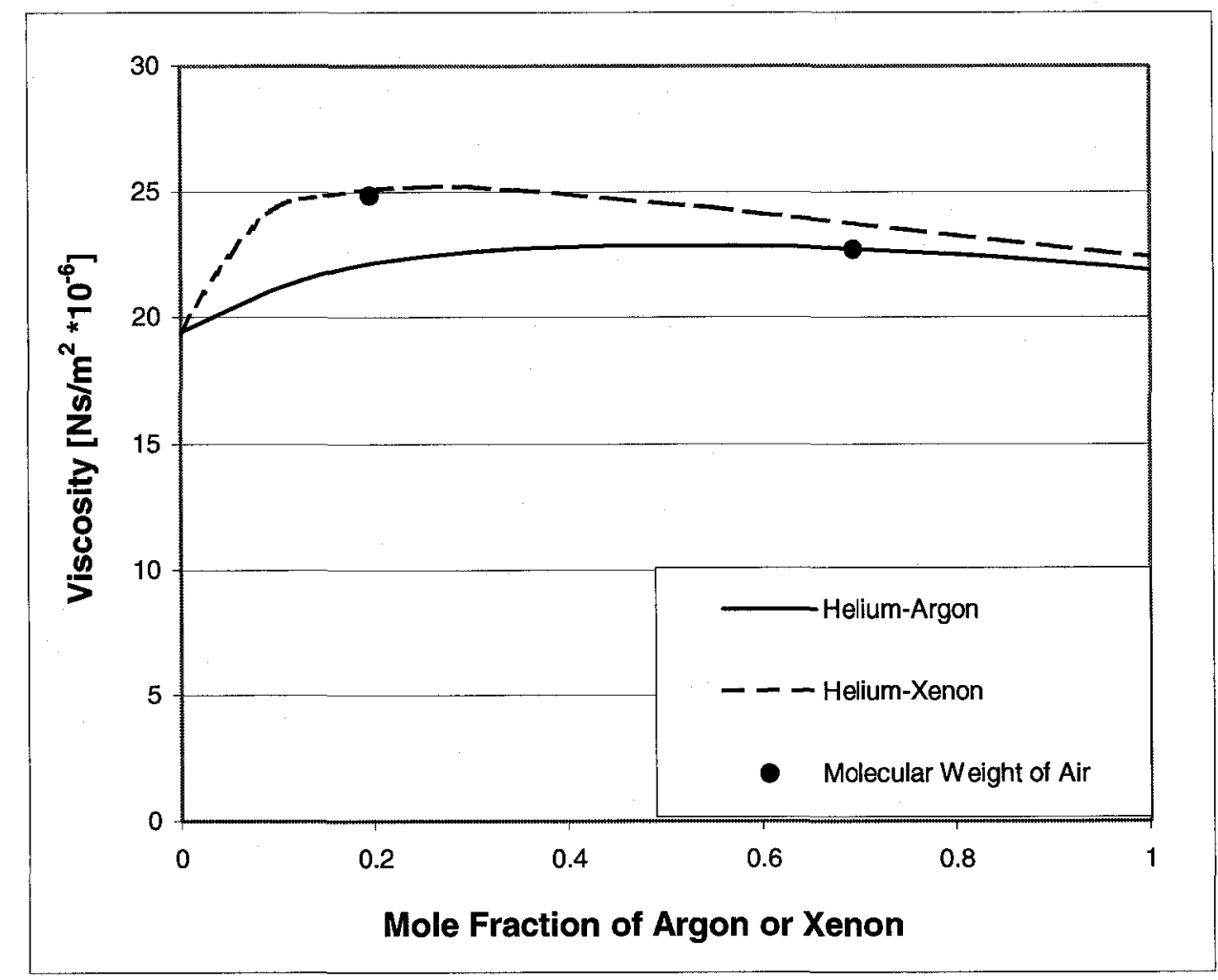

Figure B.3: Viscosity of Helium-Argon and Helium-Xenon Mixtures [5.6]

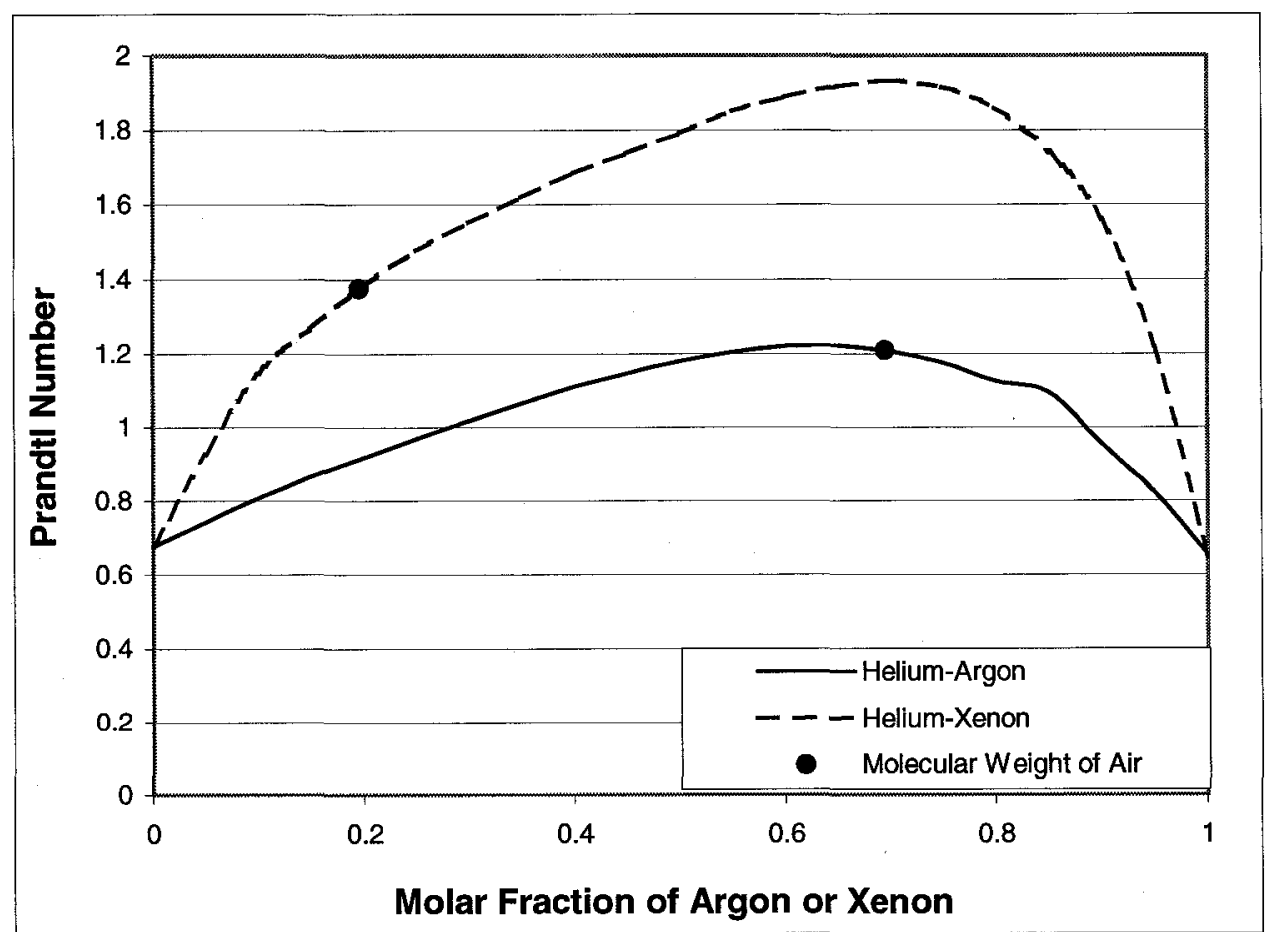

Figure B.4: Prandtl Number of Helium-Argon and Helium-Xenon Mixtures [5.4-5.6]

B-5 


\section{Appendix C}

\section{Turbocharger Performance Maps}




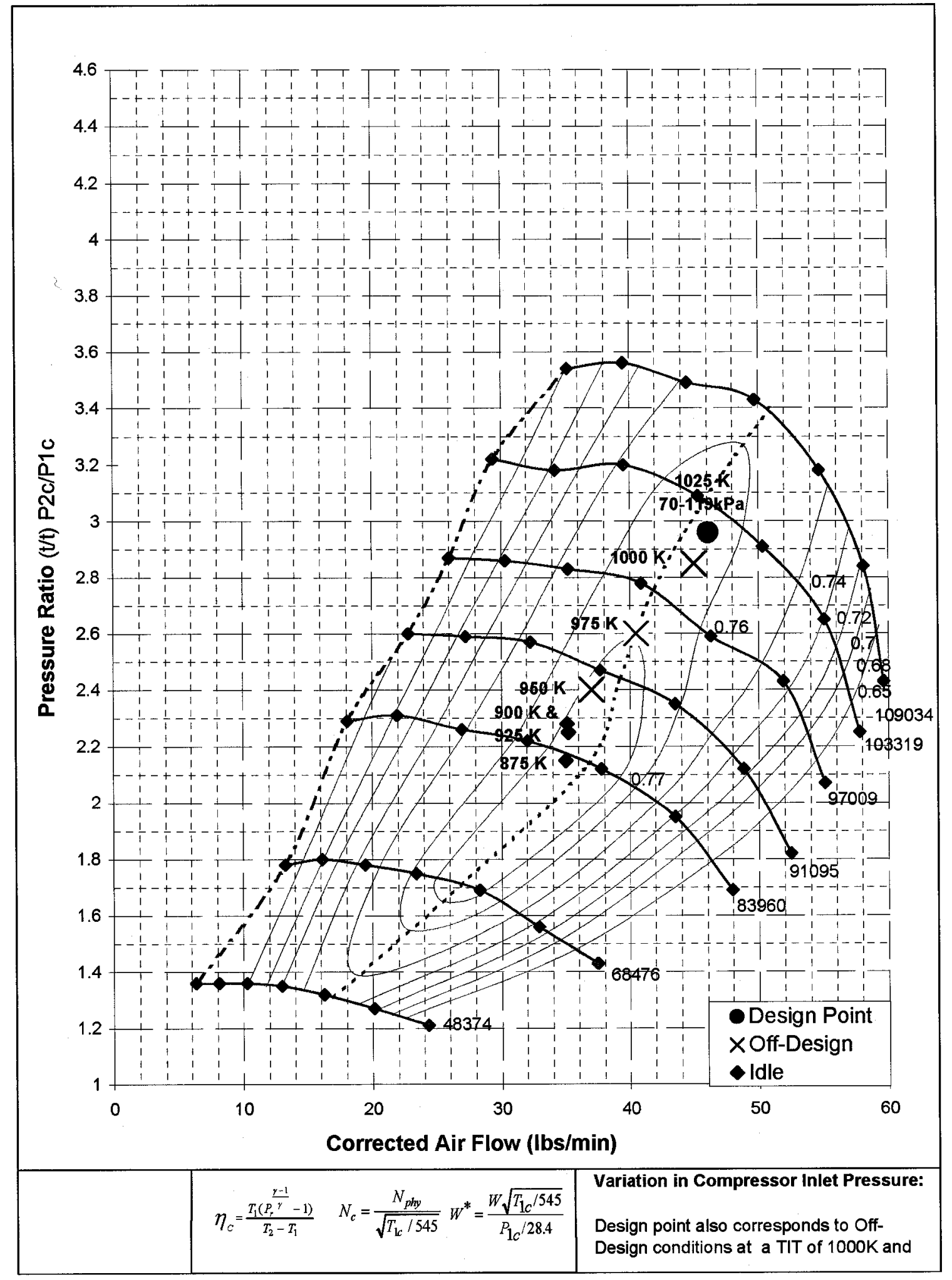

Figure C.1: Compressor Performance Map with Selected CBC Design and Off-Design Points 


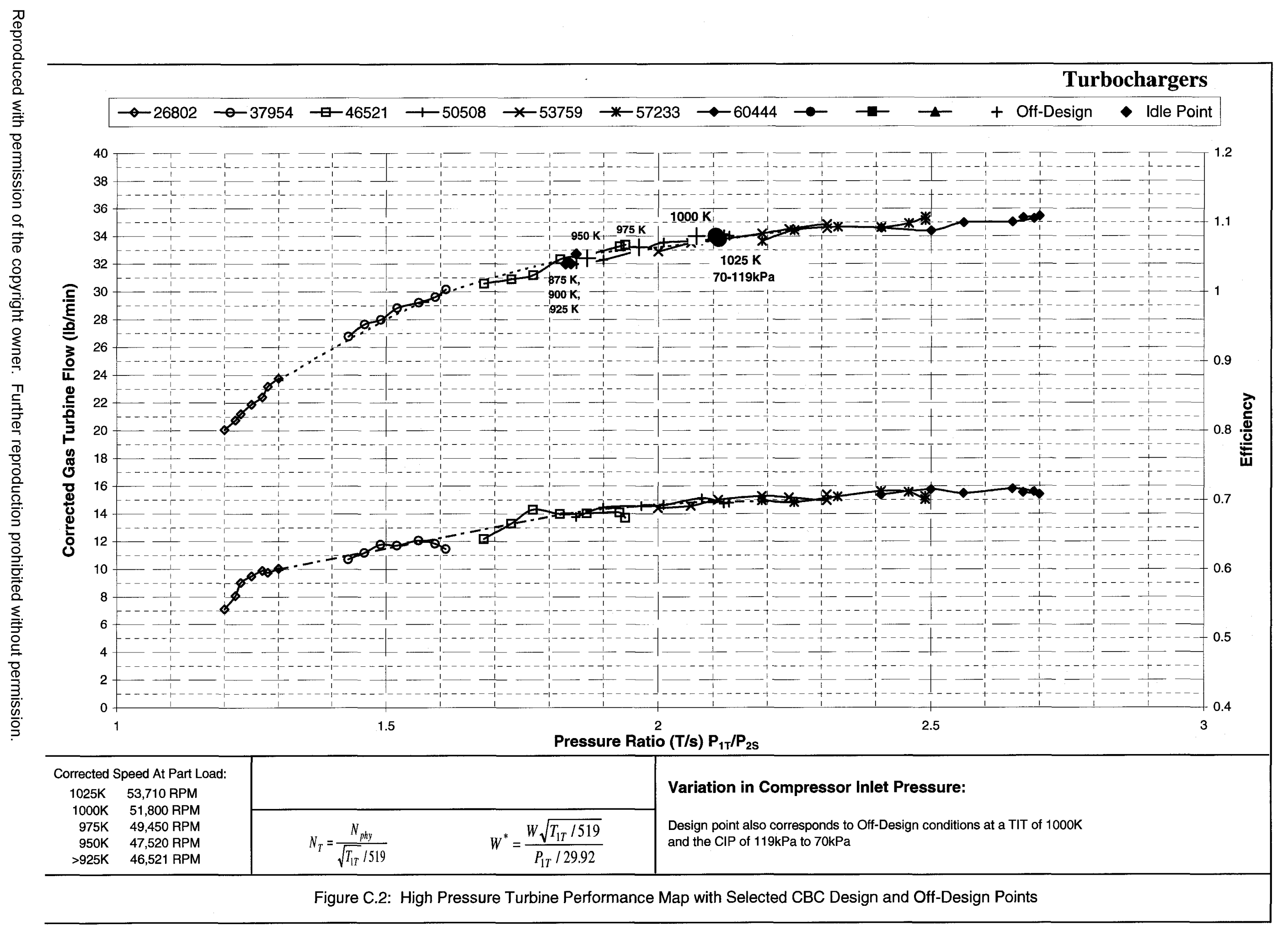




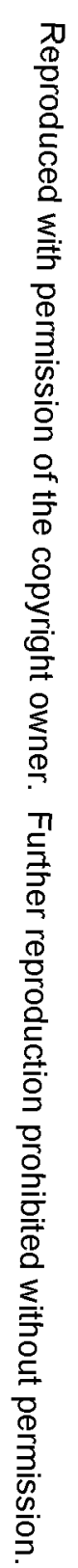

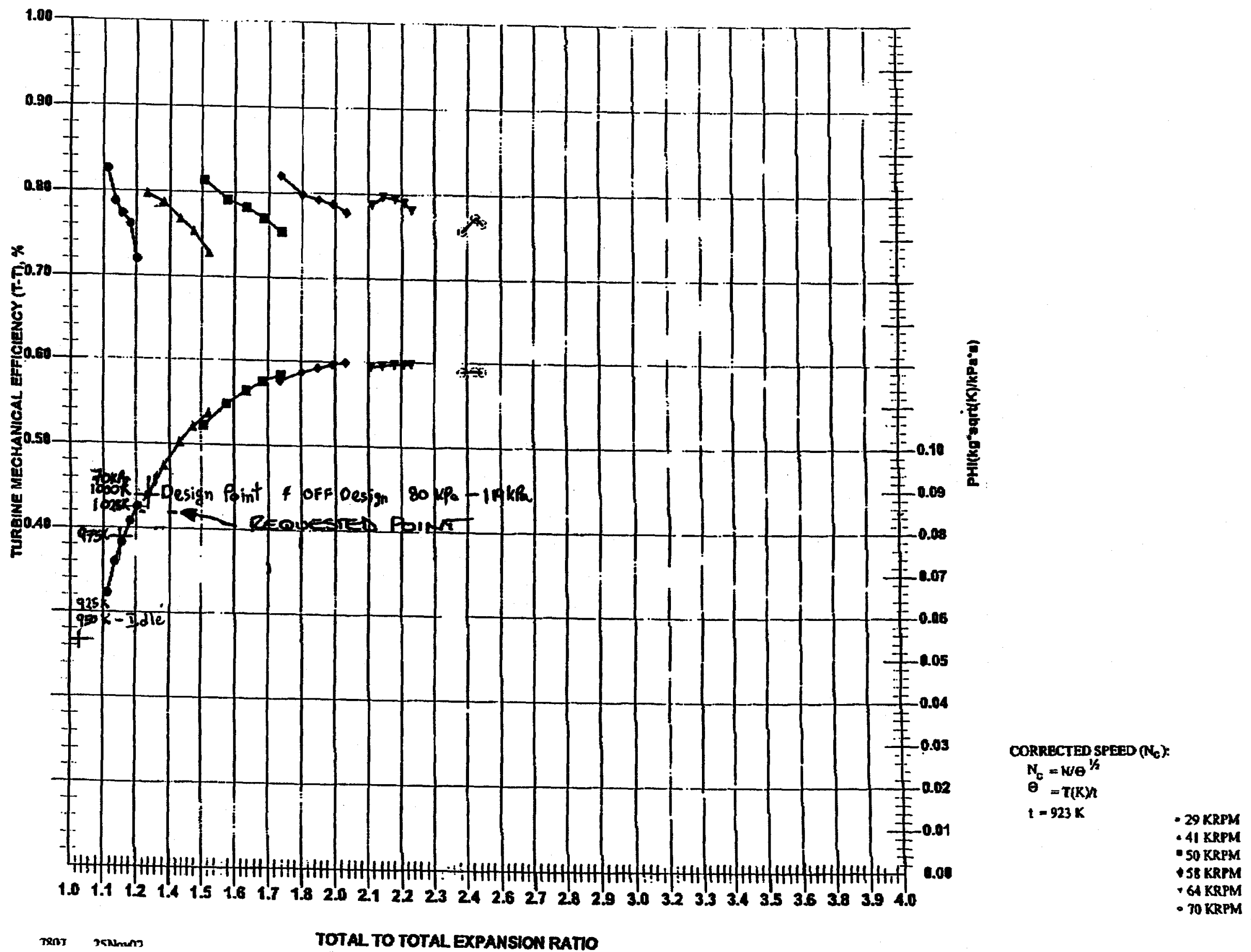

Figure C.3: Low Pressure Turbine Performance Map with Selected CBC Design and Off-Design Points 


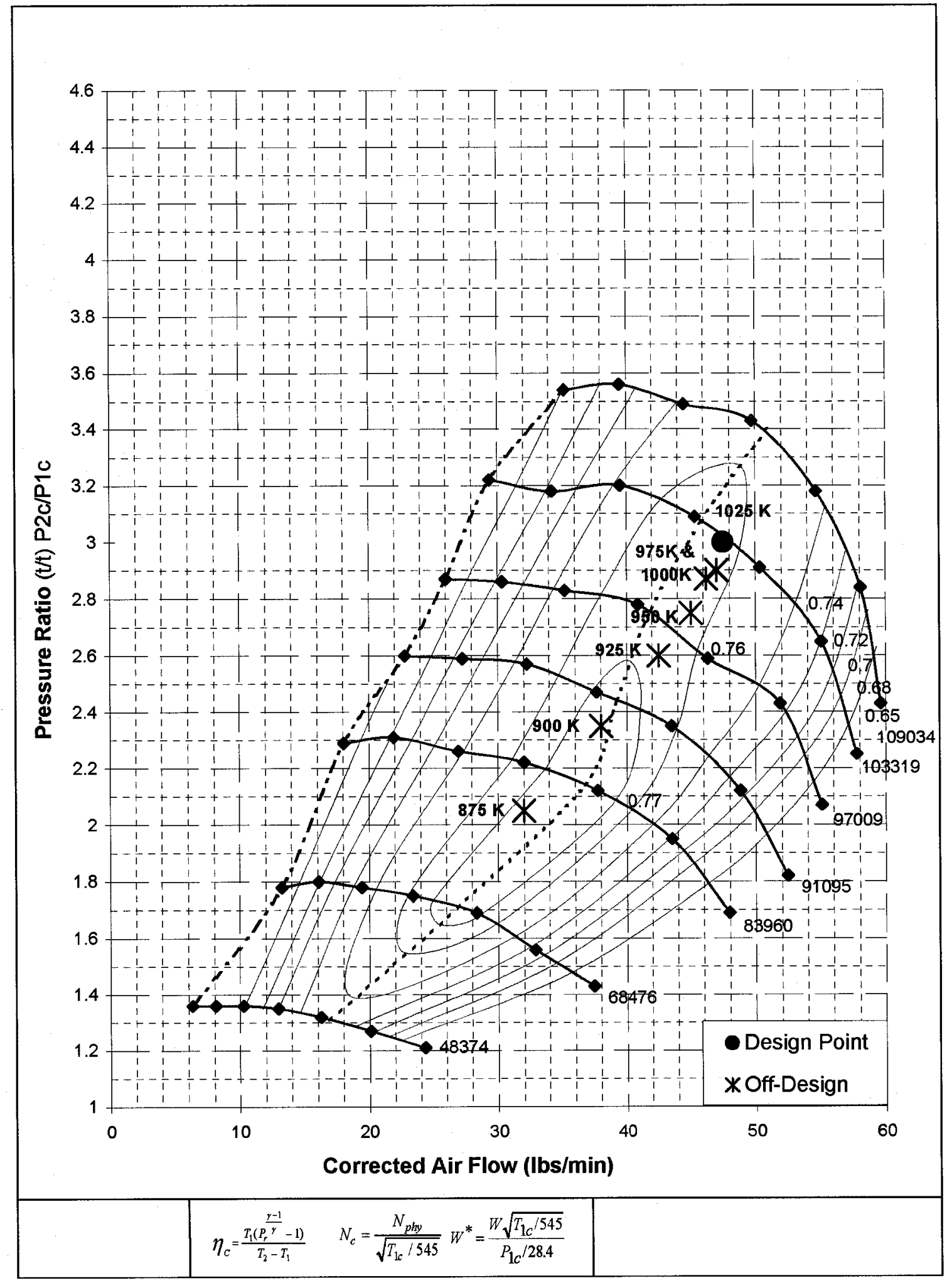

Figure C.4: Compressor Performance Map Depicting Design and Off-Design Points of the Hypothetical OBC Engine 


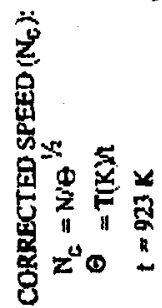

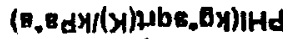

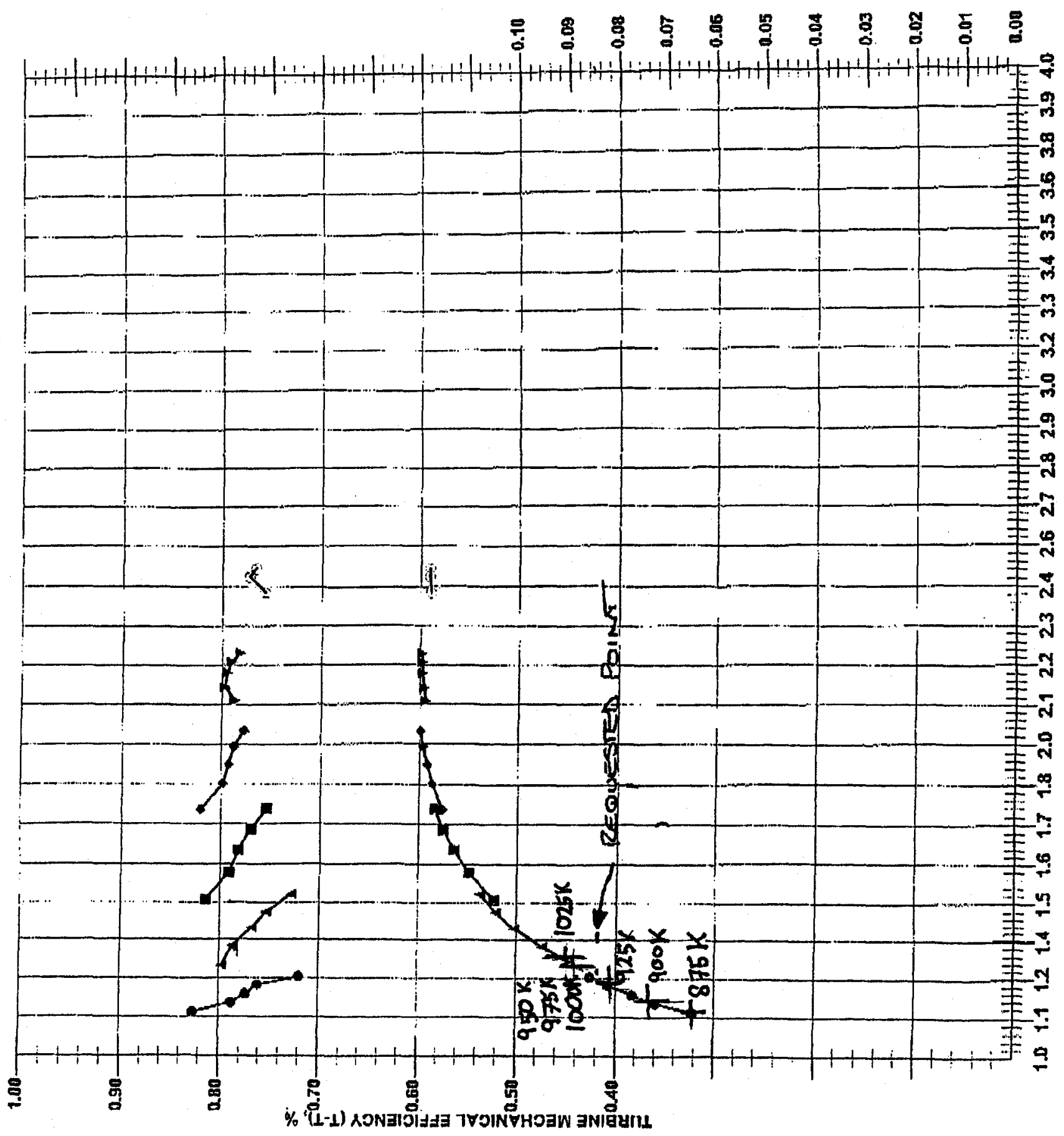




\section{Appendix D}

\section{Heat Transfer Correlations}


Table D.1: Heat Transfer Correlations for Bare Tubes in Staggered and Inline Arrangement for Tube Banks of 10 Rows or More Tube Rows [8.5]

\begin{tabular}{|c|c|c|c|c|c|c|c|c|}
\hline & \multicolumn{8}{|c|}{ Non-Dimensional Transversal Pitch $\left(\mathrm{P}_{\mathrm{n}} / \mathrm{d}_{\mathrm{o}}\right)$} \\
\hline \multirow{2}{*}{$\frac{P_{t}}{d_{o}}$} & \multicolumn{2}{|c|}{1.25} & \multicolumn{2}{|c|}{1.5} & \multicolumn{2}{|c|}{2} & \multicolumn{2}{|c|}{3} \\
\hline & $\bar{C}$ & $\mathrm{n}$ & $\bar{C}$ & $\mathrm{n}$ & $\mathrm{C}$ & $\mathrm{N}$ & $\bar{C}$ & $\mathrm{~N}$ \\
\hline \multicolumn{9}{|c|}{ Inline Arrangement } \\
\hline 1.25 & 0.386 & 0.592 & 0.305 & 0.608 & 0.111 & 0.704 & 0.0703 & 0.752 \\
\hline 1.5 & 0.407 & 0.586 & 0.278 & 0.620 & 0.112 & 0.702 & 0.0753 & 0.744 \\
\hline 2.0 & 0.464 & 0.570 & 0.332 & 0.602 & 0.254 & 0.632 & 0.220 & 0.648 \\
\hline 3.0 & 0.322 & 0.601 & 0.396 & 0.584 & 0.415 & 0.581 & $\begin{array}{l}0.317 \\
\end{array}$ & 0.608 \\
\hline \multicolumn{9}{|c|}{ Staggered Arrangement } \\
\hline 0.6 & --- & $-\cdots$ & $-\ldots$ & --- & --- & --- & 0.236 & 0.636 \\
\hline 0.9 & --- & --- & --- & --- & 0.495 & 0.571 & 0.445 & 0.581 \\
\hline 1.0 & --- & --- & 0.552 & 0.558 & --- & --- & --- & --- \\
\hline 1.125 & --- & --- & $\ldots$ & -- & 0.531 & 0.565 & 0.575 & 0.560 \\
\hline 1.25 & 0.575 & 0.556 & 0.561 & 0.554 & 0.576 & 0.556 & 0.579 & 0.562 \\
\hline 1.5 & 0.501 & 0.568 & 0.511 & 0.562 & 0.502 & 0.568 & 0.542 & 0.568 \\
\hline 2.0 & 0.448 & 0.572 & 0.462 & 0.568 & 0.535 & 0.556 & 0.498 & 0.570 \\
\hline 3.0 & 0.344 & 0.592 & 0.395 & 0.580 & 0.488 & 0.562 & 0.467 & 0.574 \\
\hline
\end{tabular}

*The constant, $\mathrm{C}$, and the exponent, $\mathrm{n}$, are applied in Equation 8.24.

Table D.2: Ratio of Heat Transfer Coefficient, $h_{0}$, for Tube Banks of less than 10 Rows of Tubes to Tube Banks of More than 10 Rows of Tubes for Bare Tubes in Staggered and Inline Arrangement [8.5]

\begin{tabular}{|c|c|c|c|c|c|c|c|c|c|c|}
\hline $\begin{array}{c}\text { Number of } \\
\text { Tube Rows, N }\end{array}$ & 1 & 2 & 3 & 4 & 5 & 6 & 7 & 8 & 9 & 10 \\
\hline $\begin{array}{c}\text { Inline } \\
\text { Arrangement }\end{array}$ & 0.64 & 0.80 & 0.87 & 0.90 & 0.92 & 0.94 & 0.96 & 0.98 & 0.99 & 1.0 \\
\hline $\begin{array}{c}\text { Staggered } \\
\text { Arrangement }\end{array}$ & 0.68 & 0.75 & 0.83 & 0.89 & 0.92 & 0.95 & 0.97 & 0.98 & 099 & 1.0 \\
\hline
\end{tabular}

*The coefficient is multiplied by the results of Equation 8.24 
Table D.3: Correlation Coefficients for the Coulburn Factor, $\mathbf{j}$, Used to Calculate the Ideal Heat Transfer Coefficient [8.3]

\begin{tabular}{|c|c|c|c|c|c|}
\hline \multirow{2}{*}{$\begin{array}{c}\text { Layout } \\
\text { Angle } \\
\boldsymbol{\Theta}_{\mathbf{t p}}\end{array}$} & \multirow{2}{*}{$\begin{array}{c}\text { Reynolds } \\
\text { Number } \\
\mathbf{R e}_{\mathrm{s}}\end{array}$} & \multicolumn{4}{|c|}{ Correlation Coefficients } \\
\hline & & $\mathbf{a}_{1}$ & $\mathbf{a}_{2}$ & $\mathbf{a}_{3}$ & $\mathbf{a}_{4}$ \\
\hline \multirow{5}{*}{$30^{\circ}$} & $10^{4}-10^{5}$ & 0.321 & -0.388 & 1.450 & 0.519 \\
\hline & $10^{3}-10^{4}$ & 0.321 & -0.388 & & \\
\hline & $10^{2}-10^{3}$ & 0.593 & -0.477 & & \\
\hline & $10-10^{2}$ & 1.360 & -0.657 & & \\
\hline & $<10$ & 1.400 & -0.667 & & \\
\hline \multirow{5}{*}{$45^{\circ}$} & $10^{4}-10^{5}$ & 0.370 & -0.396 & 1.930 & 0.500 \\
\hline & $10^{3}-10^{4}$ & 0.370 & -0.396 & & \\
\hline & $10^{2}-10^{3}$ & 0.730 & -0.500 & & \\
\hline & $10-10^{2}$ & 0.498 & -0.656 & & \\
\hline & $<10$ & 1.550 & -0.667 & & \\
\hline \multirow{5}{*}{$90^{\circ}$} & $10^{4}-10^{5}$ & 0.370 & -0.395 & 1.187 & 0.370 \\
\hline & $10^{3}-10^{4}$ & 0.107 & -0.266 & & \\
\hline & $10^{2}-10^{3}$ & 0.408 & -0.460 & & \\
\hline & $10-10^{2}$ & 0.900 & -0.631 & & \\
\hline & $<10$ & 0.970 & -0.667 & & \\
\hline
\end{tabular}

*The coefficients are used with Equation $8.72 \& 8.73$ 
Table D.4: Correlation Coefficients for the Friction Factor, $\mathbf{f}_{\mathrm{s}}$, Used to Calculate the Ideal Crossflow Pressure Drop [8.4]

\begin{tabular}{|c|c|c|c|c|c|}
\hline \multirow{2}{*}{$\begin{array}{c}\text { Layout } \\
\text { Angle } \\
\Theta_{\text {tp }}\end{array}$} & \multirow{2}{*}{$\begin{array}{c}\text { Reynolds } \\
\text { Number } \\
\mathbf{R e}_{\mathrm{s}}\end{array}$} & \multicolumn{4}{|c|}{ Correlation Coefficients } \\
\hline & & $\mathbf{b}_{1}$ & $\mathbf{b}_{2}$ & $\mathbf{b}_{3}$ & $\mathbf{b}_{4}$ \\
\hline \multirow{5}{*}{$30^{\circ}$} & $10^{4}-10^{5}$ & 0.372 & -0.123 & 7.00 & 0.500 \\
\hline & $10^{3}-10^{4}$ & 0.486 & -0.152 & & \\
\hline & $10^{2}-10^{3}$ & 4.570 & -0.476 & & \\
\hline & $10-10^{2}$ & 45.100 & -0.973 & & \\
\hline & $<10$ & 48.000 & -1.000 & & \\
\hline \multirow{5}{*}{$45^{\circ}$} & $10^{4}-10^{5}$ & 0.303 & -0.126 & 6.59 & 0.520 \\
\hline & $10^{3}-10^{4}$ & 0.333 & -0.136 & & \\
\hline & $10^{2}-10^{3}$ & 3.500 & -0.476 & & \\
\hline & $10-10^{2}$ & 26.200 & -0.913 & & \\
\hline & $<10$ & 32.000 & -1.000 & & \\
\hline \multirow{5}{*}{$90^{\circ}$} & $10^{4}-10^{5}$ & 0.391 & -0.148 & 6.30 & 0.378 \\
\hline & $10^{3}-10^{4}$ & 0.0815 & +0.022 & & \\
\hline & $10^{2}-10^{3}$ & 6.0900 & -0.602 & & \\
\hline & $10-10^{2}$ & 32.1000 & -0.963 & & \\
\hline & $<10$ & 35.000 & -1.000 & & \\
\hline
\end{tabular}

*The coefficients are used with Equation $8.80 \& 8.81$ 


\section{Appendix E}

\section{Gas Stream Fouling Factor}


Table E.1: Gas Stream Fouling Factors [8.8] [8.9]

\begin{tabular}{|c|c|c|}
\hline Gas Stream & $\begin{array}{c}\text { Weierman } \\
\text { Fouling Factors } \\
\mathrm{hr}^{*} \mathrm{ft}^{2} * \circ \mathrm{F} / \mathrm{Btu}\end{array}$ & $\begin{array}{c}\text { TEMA Standards } \\
\text { Fouling Factors } \\
\mathrm{hr}^{* \mathrm{ft}^{2} * \mathrm{o} / \mathrm{Btu}}\end{array}$ \\
\hline Natural Gas & $0.0005-0.003$ & 0.005 \\
\hline Propane & $0.001-0.003$ & ---- \\
\hline Butane & $0.001-0.003$ & ---- \\
\hline No.2 Oil & $0.002-0.004$ & $\begin{array}{l}---- \\
---\end{array}$ \\
\hline No.6 Oil & $0.003-0.007$ & ----- \\
\hline Crude Oil & $0.004-0.015$ & - \\
\hline Residual Oil & $0.005-0.02$ & ----- \\
\hline Coal & $0.005-0.05$ & ----- \\
\hline Gas Turbine & 0.0015 & ----- \\
\hline Diesel Engine & 0.003 & 0.010 \\
\hline
\end{tabular}

*All fouling factors presented in literature are expressed in Imperial Units 